RODRIGO DE FREITAS BUENO

NITRIFICAÇÃO E DESNITRIFICAÇÃO SIMULTÂNEA EM REATOR COM BIOMASSA EM SUSPENSÃO E FLUXO CONTÍNUO DE ESGOTO

SÃO PAULO

JULHO DE 2011 


\title{
NITRIFICAÇÃO E DESNITRIFICAÇÃO SIMULTÂNEA EM REATOR COM BIOMASSA EM SUSPENSÃO E FLUXO CONTÍNUO DE ESGOTO
}

\author{
Dissertação apresentada ao Programa de \\ Pós-Graduação em Saúde Pública da \\ Faculdade de Saúde Pública da \\ Universidade de São Paulo, em \\ cumprimento às exigências para \\ obtenção do título de Mestre em Saúde \\ Pública.
}

Área de Concentração: Saúde Ambiental

Linha de Pesquisa: Engenharia Ambiental e Tecnologias de Saneamento

Orientador:

Professor Associado Roque Passos Piveli

SÃO PAULO

JULHO DE 2011 


\section{NITRIFICAÇÃO E DESNITRIFICAÇÃO SIMULTÂNEA EM REATOR COM BIOMASSA EM SUSPENSÃO E FLUXO CONTÍNUO DE ESGOTO}

Dissertação aprovada em: 27/07/2011.

Comissão examinadora:

Professor Associado Roque Passos Piveli Orientador - EP/USP

Professor Titular Adrianus C. Van Haandel

Examinador externo - UFCG

Professor Titular Pedro Alem Sobrinho

Examinador interno - EP/USP 
É expressamente proibida a comercialização deste documento, tanto na sua forma impressa como eletrônica. Sua reprodução total ou parcial é permitida exclusivamente para fins acadêmicos e científicos, desde que na reprodução figure a identificação do autor, título, instituição e ano da tese/dissertação. 


\section{AGRADECIMENTOS}

Esta dissertação é um produto sinérgico aos estudos realizados por grandes pesquisadores e profissionais envolvidos na área de tratamento de esgotos. Sou grato a muitos pensadores pela inspiração e pela sabedoria, e pelas raízes e fontes de sua sabedoria.

Também agradeço a Deus e a minha família pelo apoio e força em todos os momentos difíceis.

Pelo desenvolvimento e pela produção desta dissertação sou imensamente grato a:

Professor Roque Passos Piveli, pela orientação desta dissertação, pela amizade, dedicação e paciência e, em especial por ser um profissional admirável.

Professor Pedro Alem Sobrinho, pelas orientações e conselhos que engrandeceram de forma expressiva nossos conhecimentos, contribuindo grandemente na realização deste trabalho.

Professor Adrianus C. Van Haandel, que gentilmente nos cedeu o respirômetro e pelos conselhos e orientações, contribuindo grandemente na continuidade deste trabalho.

Aos amigos do laboratório, em especial, Fábio Campos e Laerte pela amizade e pelo auxílio na realização das análises laboratoriais, na operação do sistema experimental e na troca de conhecimentos.

Aos bolsistas e grandes amigos, mestrandos e doutorandos do departamento de Engenharia Hidráulica e Ambiental da Escola Politécnica da Universidade de São Paulo, em especial, Carolina Yabroudi e Humberto Ruggeri, pela amizade e por suas múltiplas e excelentes sugestões.

Ao CNPq / CAPES pela disponibilização da bolsa de mestrado e, a Faculdade de Saúde Pública da Universidade de São Paulo.

E a todos que de alguma forma contribuíram para que essa dissertação pudesse ser concluída com êxito. 


\section{RESUMO}

BUENO, R. F. Nitrificação e desnitrificação simultânea em reator com biomassa em suspensão e fluxo contínuo de esgoto. 2011. 115p. Dissertação [Mestrado] - Faculdade de Saúde Pública da Universidade de São Paulo, São Paulo, 2011.

Recentemente foi desenvolvido na Europa o processo conhecido por Nitrificação e Desnitrificação Simultânea (NDS), em que o lodo ativado opera com tempo de retenção de sólidos suficientemente altos para que a nitrificação ocorra mesmo com baixa concentração de oxigênio dissolvido nos tanques de aeração, situação em que é possível a manutenção de condições anóxicas no interior dos flocos e a ocorrência da desnitrificação. Em países de clima tropical, muitas estações de tratamento de esgoto foram construídas ou estão sendo projetadas para operarem sob as condições da variante do processo de lodo ativado conhecida por aeração prolongada, reconhecidamente eficiente na remoção de matéria orgânica e na nitrificação do esgoto. Tais estações podem ser adaptadas para estas novas condições, de forma a se obter o benefício técnico da desnitrificação e o ganho econômico relativo à redução no consumo de energia elétrica para aeração. Este estudo avaliou as condições de remoção de nitrogênio via NDS em um sistema de lodo ativado com aeração prolongada alimentada em fluxo contínuo com diferentes idades do lodo 40, 30 e 20 dias, tratando esgoto sanitário. O processo de tratamento permaneceu estável durante todo o período de observação. Os resultados experimentais demonstram que é possível manter baixas concentrações de OD no tanque de aeração em uma faixa relativamente estreita $\left(0,3-0,8 \mathrm{mg} \cdot \mathrm{L}^{-1}\right)$, e, consequentemente desenvolver os processos de nitrificação e desnitrificação sob as mesmas condições (NDS) com alta eficiência e estabilidade. A remoção de DQO e DBO foi acima de 90\%. Os valores de crescimento específico máximo $\left(\mu_{\mathrm{m} 20}\right)$ das bactérias autotróficas nitritantes e nitratantes, resultaram muito próximos aos descritos na literatura, sendo para a idade do lodo de 20 dias os valores de $0,68 \mathrm{~d}^{-1}$ para as bactérias nitritantes e de $0,62 \mathrm{~d}^{-1}$ para as bactérias nitratantes. Os valores das taxas de utilização máxima de amônia foram maiores do que as obtidas com o nitrito e, pode-se observar que o acúmulo de nitrato devido à diminuição da amônia foi mais rápido do que o com nitrito. Desse modo, conclui-se que a nitrificação foi governada pelas bactérias autotróficas nitritantes. A taxa de utilização de nitrato foi maior tendo como substrato material rapidamente biodegradável. Confirmando que a disponibilidade de carbono tem papel fundamental nas taxas de desnitrificação no processo de NDS.

Palavras-chave: Nitrificação e desnitrificação simultânea (NDS); lodo ativado; aeração prolongada; baixa concentração de oxigênio; respirometria. 


\begin{abstract}
BUENO, R. F. Simultaneous nitrification and denitrification in reactor with biomass in suspension and continuous flow of sewage. 2011. 115p. Dissertação [Mestrado] - Faculdade de Saúde Pública da Universidade de São Paulo, São Paulo, 2011.

It was developed in Europe the process known as Simultaneous Nitrification and Denitrification (SND) in activated sludge that operates with a SRT, high enough for nitrification to occur, even with low concentration of dissolved oxygen in the aeration tanks. Such situation in the tanks is possible to maintain anoxic conditions inside the flocs and to have the occurrence of denitrification. In countries with tropical climate, many sewage treatment plants have been built or are being designed to operate under the conditions of the variant of the activated sludge process known as extended aeration, admittedly effective in removing organic matter and nitrification of the sewage. Such plants may be adapted to these new conditions in order to obtain the technical benefit of denitrification and economic gain on the reduction in energy consumption for aeration. This study aimed at assessing the conditions of nitrogen removal by SND in a system of extended aeration activated sludge in a continuous flow, with different SRT of 40, 30 and 20 days, treating sewage. The process of treatment remained stable throughout the observation period. The experimental results show that it is possible to maintain low DO concentrations in the aeration tank in a relatively narrow range $\left(0.3\right.$ to $\left.0.8 \mathrm{mg} \cdot \mathrm{L}^{-1}\right)$, and hence develop the processes of nitrification and denitrification under the same conditions (NDS) with high efficiency and stability. The BOD and COD removal was above 90\%. The values of maximum specific growth $\left(\mu_{\mathrm{m} 20}\right)$ of bacteria autotrophic nitrites and nitrates, are the result very similar to those described in the literature, for the sludge age of 20 days the values of $0.68 \mathrm{~d}^{-1}$ for nitrites bacterium and $0,62 \mathrm{~d}^{-1}$ for nitrates bacterium. The values of the maximum utilization rates of ammonia were higher than those obtained with the nitrite and can be observed that the accumulation of nitrate of ammonia due to the decrease was faster than with nitrite. This way, it was concluded that nitrification was ruled by autotrophic nitrites. The utilization rate of nitrate was higher as substrate material readily biodegradable. Confirming that the availability of carbon performs a fundamental role in the denitrification rates in the process of SND.
\end{abstract}

Keywords: Simultaneous nitrification and denitrification (SND); activated sludge; extended aeration; low oxygen concentration; respirometry. 


\section{SUMÁRIO}

CAPÍTULO 1

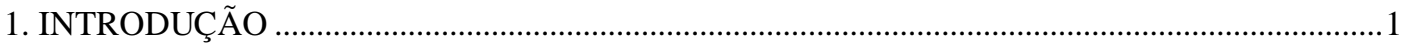

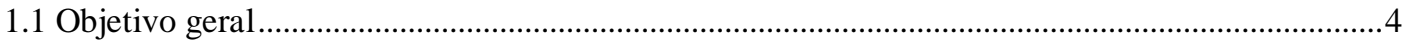

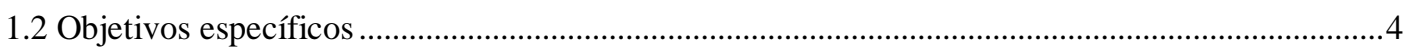

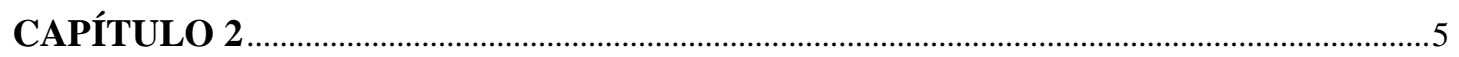

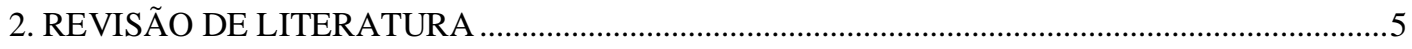

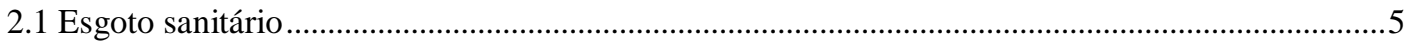

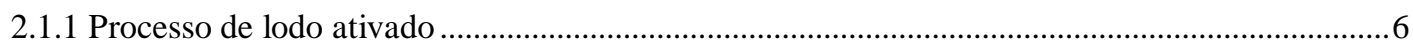

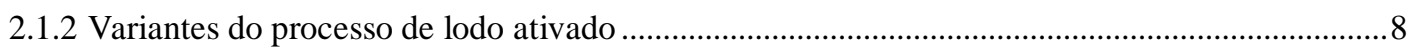

2.2 Cinética do processo de remoção de material orgânico .................................................................12

2.2.1 Balanço de Massa de Material Orgânico...................................................................................... 12

2.2.2 Fatores cinéticos da utilização de material orgânico ...............................................................13

2.3 Remoção de nitrogênio no processo de lodo ativado .................................................................... 15

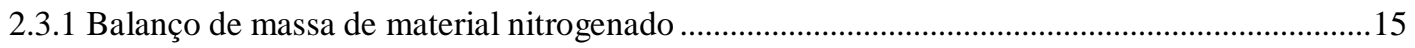

2.3.2 Forma e reações de material nitrogenado..............................................................................15

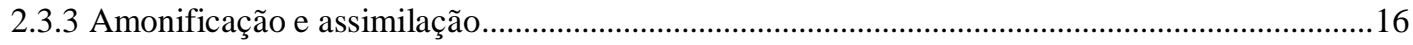

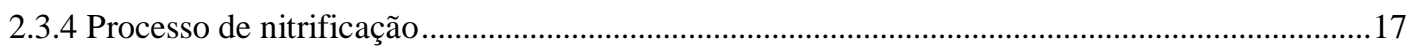

2.3.5 Fatores intervenientes no processo da nitrificação ....................................................................... 18

2.3.6 Cinética da nitrificação no sistema de lodo ativado ................................................................20

2.4 Processo de desnitrificação ....................................................................................................24

2.4.1 Condições necessárias para desnitrificação ...............................................................................22

2.4.2 Estequiometria das reações do material nitrogenado ...............................................................22

2.5 Variação da alcalinidade no processo de amonificação, nitrificação e desnitrificação.................28

2.6 Principais processos de remoção de nitrogênio com biomassa em suspensão ..............................31

2.7 Processos mais recentes de remoção de nitrogênio com biomassa em suspensão .........................35

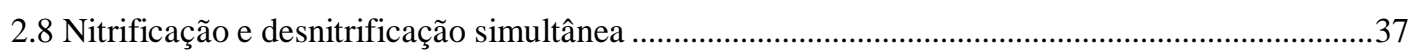

2.8.1 Remoção de nitrogênio em reator único de nitrificação e desnitrificação ..................................37

2.8.2 Condições necessárias para nitrificação e desnitrificação simultânea ........................................37

2.8.3 Sistemas de remoção biológica de nitrogênio pelo processo de NDS.......................................43

2.8.3.1 Valo de oxidação com baixa concentração de OD e monitoramento Sym-Bio ${ }^{\mathrm{TM}}{ }_{\text {....................44 }}$

2.8.3.2 Sistema de lodo ativado com diferentes concentrações de OD do tipo Orbal $^{\mathrm{TM}}$....................45

2.8.3.3 Sistema de lodo ativado por aeração prolongada de fluxo contínuo .......................................46

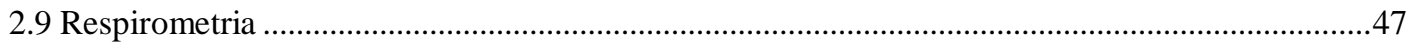




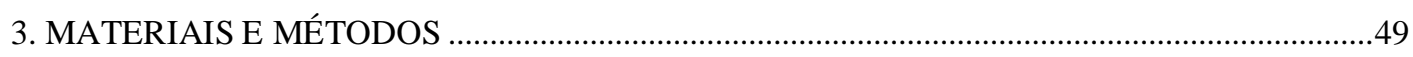

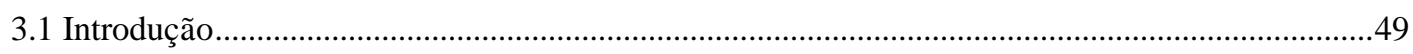

3.1.1 Sistema de lodo ativado com aeração prolongada .................................................................49

3.2 Controle de oxigênio dissolvido .........................................................................................51

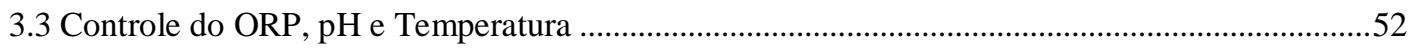

3.4 Características do esgoto sanitário .........................................................................................53

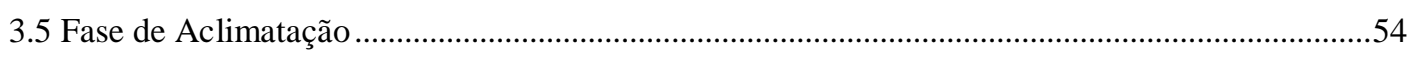

3.6 Condições de operação e ensaios laboratoriais ……………………………………………….....5

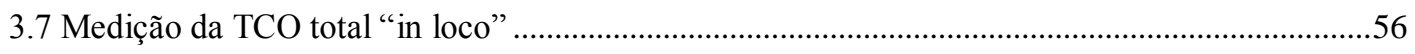

3.8 Balanços de massa do material orgânico e nitrogenado ....................................................................56

3.9 Uso da Respirometria para determinação das constantes cinéticas da nitrificação .........................57

3.9.1 Investigação experimental da atividade bacteriana autotrófica ...................................................59

3.9.2. Estimativa das constantes de crescimento específico $\left(\mu_{m}\right)$, constante de meia saturação de Monod $\left(\mathrm{K}_{\mathrm{n}}\right)$ e da taxa máxima de nitritação e nitratação $\left(\mathrm{r}_{\mathrm{n} \text { max }}\right)$......................................................62

3.9.3 Frações biodegradáveis de matéria orgânica do esgoto sanitário ..................................................64

3.9.4 Investigação experimental da atividade bacteriana heterotrófica e determinação da cinética da

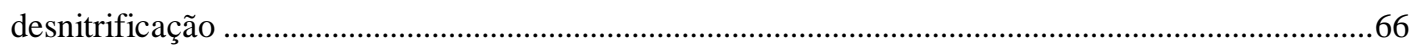

CAPÍTULO 4

4. APRESENTAÇÃO DOS RESULTADOS E DISCUSSÕES …………………………………......68

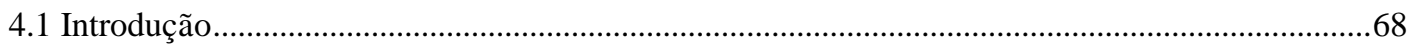

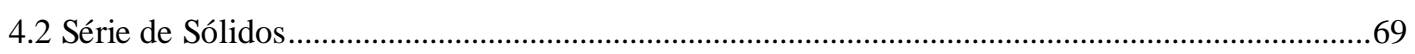

4.2.1 Esgoto sanitário afluente e efluente final após tratamento...........................................................69

4.2.2 Licor misto do sistema de lodo ativado ...................................................................................71

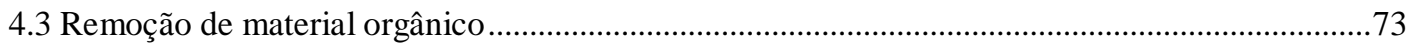

4.3.1 Resultados da TCO “in loco" e TCOc correspondente à oxidação de material orgânico ...........73

4.3.2 Resultados do balanço de massa do material orgânico .................................................................74

4.4 Resultados da DQO e DBO no afluente e efluente do sistema de lodo ativado ..............................75

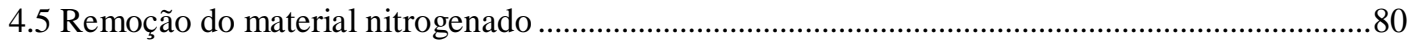

4.5.1 Resultados do balanço de massa do material nitrogenado ........................................................ 80

4.5.2 Resultados de nitrogênio amoniacal e orgânico no afluente e efluente do sistema de lodo

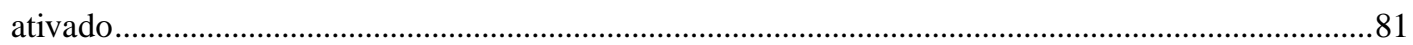

4.5.3 Resultados de nitrito e nitrato no afluente e efluente do sistema de lodo ativado .......................83

4.6 Variação da alcalinidade devido a amonificação, nitrificação e desnitrificação .............................85

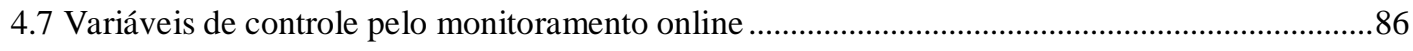

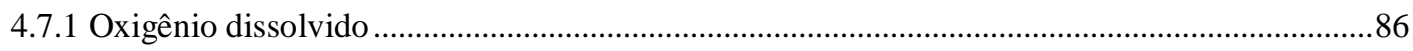

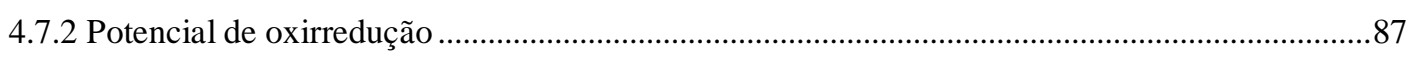

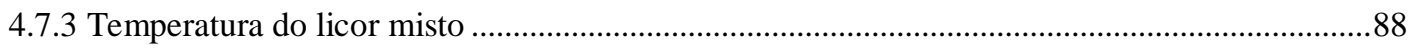




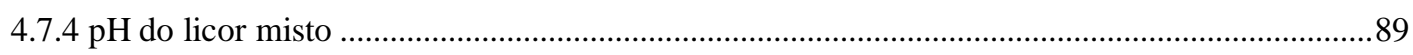

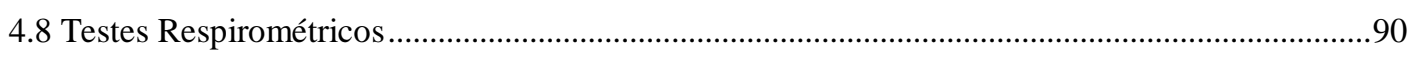

4.8.1 Resultados das frações de matéria orgânica no esgoto sanitário afluente ..................................90

4.8.2 Fatores cinéticos de utilização de material orgânico ...............................................................92

4.9 Constantes cinéticas das bactérias autotróficas nitritantes e nitratantes.......................................93

4.9.1 Verificação do balanço de massa para validação do teste respirométrico .................................93

4.9.2 Resultados da taxa de consumo de oxigênio devido ao consumo de amônia e nitrito por meio

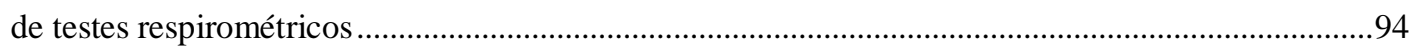

4.9.3 Determinação da constante de crescimento específico $\left(\mu_{\mathrm{m}}\right)$..............................................95

4.9.4 Constante de meia saturação de amônia e nitrito $\left(\mathrm{K}_{\mathrm{n}}\right)$............................................................97

4.9.5 Taxa máxima de utilização de amônia e nitrito $\left(\mathrm{r}_{\text {n.máx }}\right)$................................................................97

4.10 Determinação das constantes cinéticas da desnitrificação e comparação da taxa de oxidação de material orgânico tendo como oxidante o oxigênio dissolvido e o nitrato ........................................100

4.10.1 Comparação da capacidade de nitrificação e desnitrificação .................................................103

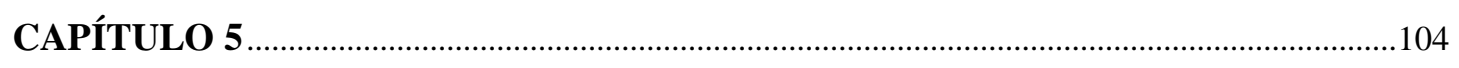

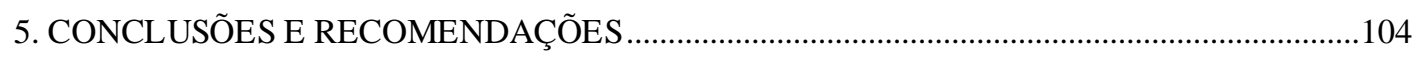

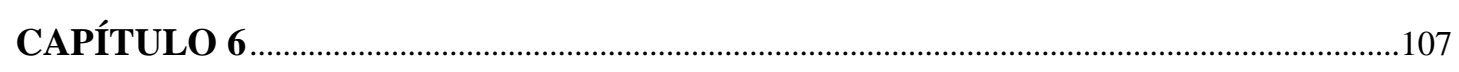

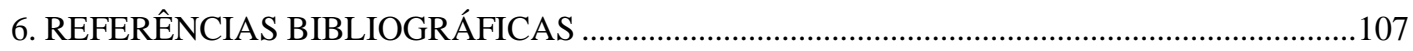

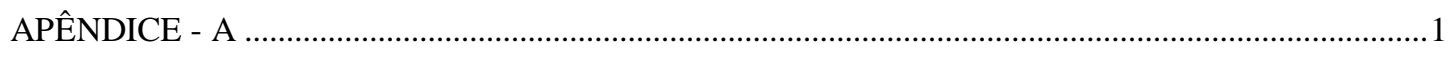

Valores pontuais das determinações da série de sólidos .................................................................... 1

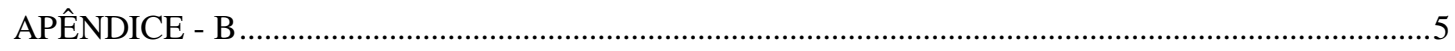

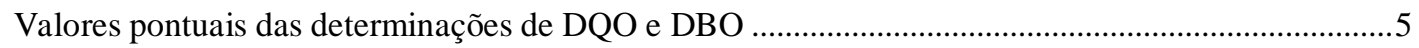

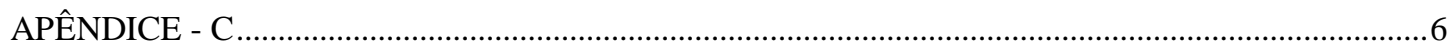

Valores pontuais das determinações de nitrogênio ......................................................................... 6

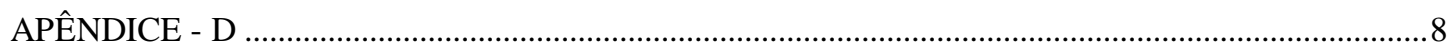

Valores pontuais das determinações de alcalinidade .....................................................................

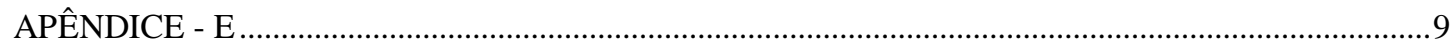

Valores das médias diárias do monitoramento online do lodo .....................................................9 


\section{LISTA DE FIGURAS}

\section{Capítulo 2}

Figura 2: Divisão geral do material orgânico de esgoto sanitário (em termos de DQO).

Figura 2.1: Esquema das unidades da etapa biológica do sistema de lodo ativado

Figura 2.2: Representação esquemática das formas e das possíveis reações do material nitrogenado no sistema de lodo ativado.

Figura 2.3: Variação do número de oxidação de nitrogênio nos processos de nitrificação e desnitrificação ...

Figura 2.4: representação da variação da concentração de OD num floco em função da distância do centro para concentração subcrítica, crítica e supercrítica

Figura 2.5: Variação teórica versus variação experimental da alcalinidade para diferentes sistemas de lodo ativado

Figura 2.6: Representação esquemática de um sistema de lodo ativado com pré-desnitrificação.......32

Figura 2.7: Representação esquemática de um sistema de lodo ativado com pós-desnitrificação.....33

Figura 2.8: Representação esquemática de um sistema de lodo ativado pelo processo Bardenpho de 3 estágios .....

Figura 2.9: Representação esquemática de um sistema de lodo ativado pelo processo UCT com 5 reatores sequenciais.

Figura 2.10: Esquema dos transportes e transformações que podem ocorrer em um floco em meio com baixa concentração de oxigênio dissolvido

Figura 2.11: Relação entre concentração de oxigênio dissolvido e idade do lodo para obtenção de

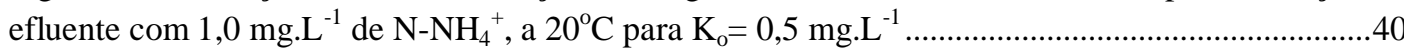

Figura 2.12: Efeito da concentração de OD na velocidade de desnitrificação.

Figura 2.13: Representação esquemática de um sistema de lodo ativado de remoção de nitrogênio, modificado para operar com baixa concentração de OD promovendo o processo de NDS ..44

Figura 2.14: Sistema de lodo ativado tipo Orbal $^{\mathrm{TM}}$ de remoção de nitrogênio, modificado para operar com baixa concentração de OD promovendo o processo de NDS .46

Figura 2.15: Tela principal do software 4.0 do respirômetro e seus principais componentes . .48

\section{Capítulo 3}

Figura 3.1: Corte esquemático do sistema de lodo ativado com sensores de medição online .49

Figura 3.2: Visão geral do tanque de aeração com misturadores e sensores de controle online.........50

Figura 3.3: Visão geral do decantador com raspador automatizado.....

Figura 3.4: Representação do sistema de controle de oxigênio (1) medidor/controlador, (2) data logger, (3) válvula solenóide e (4) sensor de OD............................................................................52

Figura 3.5: Controladores online, (1) medidor de ORP, (2) pH e (3) temperatura............................53

Figura 3.6: Visão geral dos equipamentos de controle/monitoramento online ...................................53

Figura 3.7: Sistema de lodo ativado com aeração prolongada de fluxo contínuo................................54 
Figura 3.8: Respirômetro modelo Beluga S32c, do tipo aberto e semi-contínuo, desenvolvido no Departamento de Engenharia Elétrica da UFCG - Universidade Federal de Campina Grande..........58

Figura 3.9: Respirograma experimental com medições de OD na faixa de $\left(0,3-0,8 \mathrm{mg} . \mathrm{L}^{-1}\right)$ e TCO

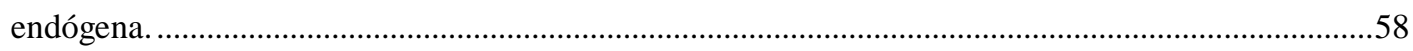

Figura 3.10: Cromatógrafo de íons Dionex com amostrador automático para análise de ânions e cátions

Figura 3.11: Respirograma genérico da adição de um substrato solúvel a uma batelada de lodo ativado.

Figura 3.12: Exemplo de um respirograma experimental com adição de amônia como substrato em uma batelada de lodo ativado 61

Figura 3.13: Respirograma experimental da determinação das frações do material orgânico.

\section{Capítulo 4}

Figura 4.1: Concentrações de sólidos suspensos totais e voláteis no afluente (entrada) e efluente final (saída) durante as Fases I, II e III do estudo

Figura 4.2: Diagrama Box-Whiskers: Análises médias da DQO e DBO total e solúvel do afluente e efluente nas Fases I, II e III.

Figura 4.2.1: Série temporal com médias móveis de 4 termos: Análise da DQO e DBO total e solúvel do afluente e efluente nas Fases I, II e III.

Figura 4.2.2: Diagrama Box-Whiskers: Eficiência na remoção da DQO e DBO total e solúvel nas Fases I, II e III. . .78

Figura 4.2.3: Série temporal com médias móveis de 4 termos: Eficiência na remoção de DQO e DBO total e solúvel nas Fases I, II e III. 79

Figura 4.3: Diagrama Box-Whiskers: Análises médias da NTK, N-orgânico e $\mathrm{NH}_{3}{ }^{-}$do afluente e efluente nas Fases I, II e III.

Figura 4.3.1: Série temporal com médias móveis de 4 termos: Análise do NTK, N-orgânico e $\mathrm{NH}_{3}{ }^{-}$ do afluente e efluente nas Fases I, II e III.

Figura 4.4: Série temporal com médias móveis de 4 termos: Concentração de $\mathrm{NO}_{3}^{-}$no efluente final após tratamento nas Fases I, II e III.

Figura 4.5: Comparação entre a variação da alcalinidade teórica causada pelo efeito estequiométrico combinado de amonificação, nitrificação e desnitrificação com o valor experimental observado no sistema de lodo ativado.

Figura 4.6: Série temporal com médias móveis de 4 termos: Monitoramento online da concentração de OD no licor misto durante as Fases I, II e III.

Figura 4.6.1: Série temporal com médias móveis de 4 termos: Monitoramento online do potencial de oxirredução no licor misto durante as Fases I, II e III.

Figura 4.6.2: Série temporal com médias móveis de 4 termos: Monitoramento online de temperatura no licor misto durante as Fases I, II e III.

Figura 4.6.3: Série temporal com médias móveis de 4 termos: Monitoramento online de pH no licor misto durante as Fases I, II e III. 
Figura 4.7: Fluxograma geral referente às frações de material orgânico, determinadas a partir de testes respirométricos com o esgoto sanitário proveniente do CRUSP e restaurante central da USP.

Figura 4.8: Exemplo de um respirograma experimental de uma batelada de lodo ativado com substrato de cloreto de amônio obtido durante a Fase III do estudo.

Figura 4.9: Diminuição na concentração de amônia e acúmulo de nitrato durante os testes respirométricos na Fase III.

Figura 4.9.1: Diminuição na concentração de nitrito e acúmulo de nitrato durante os testes respirométricos na Fase III.

Figura 4.10: Diminuição na concentração de nitrato em função do tempo com diferentes substratos e adição de $10 \mathrm{mgN} . \mathrm{L}^{-1}$ de nitrato de potássio na Fase III do estudo. 101

Figura 4.11: Taxa de consumo de oxigênio em ambiente aeróbio e taxa equivalente de consumo de oxigênio em ambiente com baixa concentração de oxigênio e nitrato 


\section{LISTA DE TABELAS}

\section{Capítulo 2}

Tabela 2: Valores de referência das frações de material orgânico em esgoto municipal bruto ............6

Tabela 2.1: Classificação do sistema de lodo ativado em função da idade do lodo ............................. 9

Tabela 2.2: Principais características dos sistemas de lodos ativados utilizados para o tratamento de

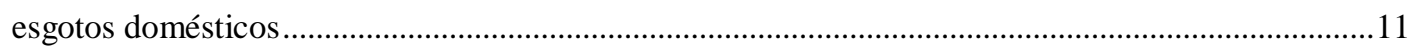

Tabela 2.3: Valores de referência das constantes cinéticas de utilização de material orgânico ..........15

Tabela 2.4: Valores de referência das constantes de decaimento de Nitrossomonas $\left(\mathrm{b}_{\mathrm{n}}\right)$..................22

Tabela 2.5: Valores das constantes de meia saturação de amônia para as Nitrossomonas $\left(\mathrm{K}_{\mathrm{n}}\right)$..........23

Tabela 2.6: Valores das constantes de crescimento específico máximo de Nitrossomonas $\left(\mu_{\mathrm{m}}\right)$.......23

Tabela 2.7: Taxa de desnitrificação por miligrama de sólidos suspensos voláteis por dia, em sistemas de lodo ativado com pré-desnitrificação e pós-desnitrificação ..............................................33

Tabela 2.8: Coeficientes cinéticos típicos do processo de nitrificação................................................42

\section{Capítulo 3}

Tabela 3.1: Características do esgoto sanitário afluente durante as Fases I, II e III do estudo...........54

Tabela 3.2: Resumo das condições de operação das Fases I, II e III. ..................................................55

Tabela 3.3: Programa de monitoramento do sistema piloto durante as Fases I, II e III. .....................55

Tabela 3.4: Equações utilizadas para determinação do balanço de massa do material orgânico.........56

Tabela 3.5: Equações utilizadas para determinação do balanço de massa do material nitrogenado ..57

Tabela 3.6: Substratos para os testes respirométricos com bactérias autotróficas nitrificantes ...........59

\section{Capítulo 4}

Tabela 4.1: Sólidos totais e suas frações no esgoto sanitário afluente

Tabela 4.1.2: Sólidos em suspensão e suas frações no esgoto sanitário afluente 69

Tabela 4.1.3: Sólidos totais e suas frações no efluente final .70

Tabela 4.1.4: Sólidos em suspensão e suas frações no efluente final ..................................................70

Tabela 4.2.1: Relação entre as variáveis de IVL, TRS e A/M ...........................................................71

Tabela 4.2.2: Sólidos totais e suas frações no licor misto .......................................................................72

Tabela 4.2.3: Concentrações de sólidos em suspensão e suas frações no licor misto .........................72

Tabela 4.2.4: Sólidos totais e suas frações no retorno de lodo...........................................................72

Tabela 4.2.5: Sólidos em suspensão e suas frações no retorno de lodo .............................................73

Tabela 4.3: Taxa de consumo de oxigênio "in loco" no licor misto durante as Fases I, II e III ..........73

Tabela 4.3.1: Balanço de massa de material orgânico no sistema de lodo ativado, referente às idades de lodo de 40, 30 e 20 dias. 
Tabela 4.4.1: Concentrações médias de DQO e DBO no esgoto sanitário afluente

Tabela 4.4.2: Concentrações médias de DQO e DBO no efluente final.

Tabela 4.5: Balanço de massa de material nitrogenado no sistema de lodo ativado, referente às idades de lodo de 40, 30 e 20 dias.

Tabela 4.5.1: Concentrações médias de NTK, N-orgânico e $\mathrm{NH}_{3}{ }^{-}$no afluente nas Fases I, II e III...81

Tabela 4.5.2: Concentrações médias de NTK, N-orgânico e $\mathrm{NH}_{3}{ }^{-}$no efluente nas Fases I, II e III ...81

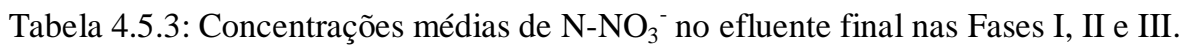

Tabela 4.6: Variação da alcalinidade teórica causada pelo efeito estequiométrico devido à amonificação, nitrificação e desnitrificação durante as Fases I, II e III do estudo

Tabela 4.6.1: Valores médios de alcalinidade no afluente e efluente e a variação obtida experimentalmente devido à amonificação, nitrificação e desnitrificação nas Fases I, II e III. ..........85

Tabela 4.7: Valores médios das concentrações de OD no licor misto nas Fases I, II e III. ................87

Tabela 4.7.1: Valores médios do potencial de oxirredução no licor misto nas Fases I, II e III. ..........88

Tabela 4.7.2: Valores médios de temperatura no licor misto durante as Fases I, II e III. ...................89

Tabela 4.7.3: Valores médios de pH no licor misto durante as Fases I, II e III. ................................90

Tabela 4.8: Valores médios das frações de matéria orgânica biodegradável presente no esgoto sanitário obtido através de testes respirométricos.

Tabela 4.8.1: Valores médios das frações de matéria orgânica biodegradável presente no esgoto sanitário obtido através de testes respirométricos.

Tabela 4.8.2: Valores médios das constantes cinéticas de utilização de material orgânico ................93

Tabela 4.9: Valores médios da TCO devido ao consumo de amônia pelas bactérias nitritantes ........95

Tabela 4.9.1: Valores médios da TCO devido ao consumo de nitrito pelas bactérias nitratantes ......95

Tabela 4.9.2: Valores médios das constantes de crescimento específico máximo das bactérias envolvidas na nitrificação $\left(\mu_{\mathrm{m}}\right)$.

Tabela 4.9.3: Valores médios das constantes de meia saturação de amônia na equação de Monod para o crescimento das bactérias envolvidas na nitrificação $\left(K_{n}\right)$

Tabela 4.9.4.: Valores médios das taxas máximas de utilização de amônia e nitrito ..........................98

Tabela 4.10: Valores médios das constantes de desnitrificação $\left(\mathrm{K}_{\mathrm{d}}\right)$

Tabela 4.10.1: Taxa de consumo de oxigênio utilizando substrato solúvel, particulado e esgoto sanitário e taxa equivalente de consumo de oxigênio utilizando como substrato o nitrato. .102

Tabela 4.10.2: Constantes cinéticas referentes à TCO, por miligrama de sólidos ativos por dia, com substratos solúvel, particulado e Fase endógena.

Tabela 4.10.3: Valores médios da capacidade de desnitrificação e nitrificação observada no sistema de lodo ativado. 


\section{LISTA DE ABREVIATURAS, SIGLAS E SÍMBOLOS}

$\mu_{\mathrm{m}}$ : Taxa específica de crescimento $\left(\mathrm{d}^{-1}\right)$

$\mu_{\text {máx }}$ Taxa específica máxima de crescimento $\left(\mathrm{d}^{-1}\right)$

$\mu_{\mathrm{mT}}$ : Taxa de crescimento máximo das bactérias a uma temperatura $\mathrm{T}\left(\mathrm{d}^{-1}\right)$

a: Recirculação de licor misto

ANAMMOX: Anaerobic Ammonium Oxidation

AT: Amplitude total

$\mathrm{b}_{\mathrm{h}}$ : Decaimento de bactérias heterotróficas $\left(\mathrm{d}^{-1}\right)$

$\mathrm{b}_{\mathrm{n}}$ : Constante de decaimento para as bactérias autotróficas nitrificantes $\left(\mathrm{d}^{-1}\right)$

$\mathrm{B}_{\mathrm{n}}$ : Balanço de massa de material nitrogenado

$\mathrm{B}_{\mathrm{o}}$ : Balanço de massa de material orgânico

Cr: Massa de lodo ativo presente no sistema por unidade de DQO

CRUSP: Conjunto residencial da Universidade de São Paulo

CTH: Centro Tecnológico de Hidráulica - Escola Politécnica da Universidade de São Paulo

CV: Coeficiente de variação

DBO: Demanda Bioquímica de Oxigênio (mg. $\left.\mathrm{L}^{-1}\right)$

$\mathrm{D}_{\mathrm{ec}}$ : Decantador

$\mathrm{D}_{\mathrm{p}}$ : Capacidade de desnitrificação com material orgânico particulado $\left(\mathrm{mgN} \cdot \mathrm{d}^{-1}\right)$

DP: Desvio Padrão

DQO: Demanda Química de Oxigênio (mg.L $\mathrm{L}^{-1}$ )

$\mathrm{D}_{\mathrm{s}}$ : Capacidade de desnitrificação com material orgânico solúvel $\left(\mathrm{mgN} \cdot \mathrm{d}^{-1}\right)$

$\mathrm{D}_{\mathrm{t}}$ : Capacidade de desnitrificação total de um sistema de lodo ativado

$\mathrm{dX}_{\mathrm{n}} / \mathrm{dtc}$ : Taxa de crescimento das bactérias nitrificantes (mgSSV.L $\mathrm{L}^{-1} \cdot \mathrm{d}^{-1}$ )

$\mathrm{dX}_{\mathrm{n}} / \mathrm{dtd}$ : Taxa de decaimento das bactérias nitrificantes $\left(\mathrm{mgSSV} . \mathrm{L}^{-1} \cdot \mathrm{d}^{-1}\right)$

$\mathrm{dX}_{\mathrm{n}} / \mathrm{dte}$ : Taxa de descarga de lodo de excesso $\left(\mathrm{mgSSV} . \mathrm{L}^{-1} \cdot \mathrm{d}^{-1}\right)$

Efluente: Esgoto efluente após tratamento no sistema de lodo ativado

ETE: Estação de tratamento de esgoto

f aeróbia: Fração aeróbia dos sistemas de lodo ativado operados

f: Fração de lodo orgânico decaído como resíduo endógeno

$\mathrm{f}_{\mathrm{b}}$ : Fração biodegradável de esgoto

$\mathrm{f}_{\mathrm{bp}}$ : Fração biodegradável particulada de esgoto

$\mathrm{f}_{\mathrm{bs}}$ : Fração biodegradável solúvel de esgoto

$\mathrm{f}_{\mathrm{cv}}$ : Produção de massa bacteriana $\left(\mathrm{gSSV}^{-1} \cdot \mathrm{gDQO}^{-1}\right)$

$\mathrm{f}_{\mathrm{n}}$ : Fração de nitrogênio total Kjeldahl em lodo volátil

$\mathrm{f}_{\text {up }}$ : Fração de DQO não biodegradável particulada

$\mathrm{f}_{\mathrm{us}}$ : Fração de DQO não biodegradável solúvel 
IVL: Índice volumétrico de lodo

$\mathrm{K}_{\mathrm{d}}$ : Constante de desnitrificação

$\mathrm{K}_{\mathrm{la}}$ : Constante de transferência de oxigênio

$\mathrm{K}_{\mathrm{n}}$ : Constante de meia saturação bactérias autotróficas (mgN.L $\mathrm{L}^{-1}$ )

$\mathrm{K}_{\mathrm{o}}$ : Constante de meia saturação de oxigênio (mg.L-1)

$\mathrm{K}_{\mathrm{H}}$ : Constante de meia saturação bactérias heterotróficas (mgN.L ${ }^{-1}$ )

$\mathrm{K}_{\mathrm{S}}$ : Constante de meia saturação de substrato $\left(\mathrm{mgS} . \mathrm{L}^{-1}\right)$

MMA: Ministério do Meio Ambiente

MNae: Fluxo de nitrogênio amoniacal efluente $\left(\mathrm{mgN} \cdot \mathrm{d}^{-1}\right)$

$\mathrm{MN}_{\mathrm{C}}$ : Fluxo da concentração de amônia nitrificada $\left(\mathrm{gN} \cdot \mathrm{d}^{-1}\right)$

$\mathrm{MN}_{\mathrm{d}}$ : Fluxo de nitrogênio utilizado na desnitrificação $\left(\mathrm{mgN} \cdot \mathrm{d}^{-1}\right)$

$\mathrm{MN}_{\mathrm{l}}$ : Fluxo de nitrogênio total Kjeldahl no lodo $\left(\mathrm{mgN} \cdot \mathrm{d}^{-1}\right)$

$\mathrm{MN}_{\mathrm{na}}$ : Fluxo de nitrato afluente $\left(\mathrm{mgN} \cdot \mathrm{d}^{-1}\right)$

$\mathrm{MN}_{\mathrm{oe}}$ : Fluxo de nitrogênio orgânico efluente $\left(\mathrm{mgN} \cdot \mathrm{d}^{-1}\right)$

$\mathrm{MN}_{\mathrm{ta}}$ : Fluxo de nitrogênio total Kjeldahl afluente $\left(\mathrm{mgN} \cdot \mathrm{d}^{-1}\right)$

$\mathrm{MN}_{\mathrm{te}}$ : Fluxo de nitrogênio total Kjeldahl efluente $\left(\mathrm{mgN} . \mathrm{d}^{-1}\right)$

MO: Matéria orgânica

$\mathrm{M}_{\mathrm{oc}}$ : Consumo de oxigênio para oxidação de material orgânico $\left(\mathrm{mgO}^{\mathrm{d}} \mathrm{d}^{-1}\right)$

$\mathrm{M}_{\text {oeq }}$ : Oxigênio equivalente recuperado através da desnitrificação $\left(\mathrm{mgO}^{-1} \mathrm{~d}^{-1}\right)$

$\mathrm{M}_{\mathrm{on}}$ : Consumo de oxigênio para nitrificação $\left(\mathrm{mgO} . \mathrm{d}^{-1}\right)$

$\mathrm{M}_{\mathrm{ot}}$ : Consumo total de oxigênio no reator aeróbio (mgO.d $\left.\mathrm{d}^{-1}\right)$

$\mathrm{mS}_{\mathrm{o}}$ : Fração de DQO afluente oxidada no sistema (mgDQO. $\left.\mathrm{d}^{-1}\right)$

$\mathrm{MS}_{\mathrm{ta}}$ : Fluxo de DQO afluente (mgDQO.d $\mathrm{d}^{-1}$ )

$\mathrm{mS}_{\mathrm{te}}$ : Fração de DQO detectada no efluente (mgDQO.d $\left.\mathrm{d}^{-1}\right)$

$\mathrm{mS}_{\mathrm{XV}}$ : Fração de DQO afluente descarregada no lodo de excesso (mgDQO.d $\mathrm{d}^{-1}$ )

$\mathrm{MX}_{\mathrm{t}}$ : Massa de lodo colocado no cilindro para teste de sedimentabilidade

$\mathrm{mX}_{\mathrm{v}}$ : Produção de lodo $\left(\mathrm{mgSSV}^{-1} \cdot \mathrm{mgDQO}^{-1}\right)$

N: Nitrogênio

$\mathrm{N}_{\mathrm{a}}$ : Concentração de amônia $\left(\mathrm{mgN} \cdot \mathrm{L}^{-1}\right)$

$\mathrm{N}_{\mathrm{aa}}$ : Concentração de nitrogênio amoniacal afluente $\left(\mathrm{mgN} \cdot \mathrm{L}^{-1}\right)$

$\mathrm{N}_{\mathrm{ae}}$ : Concentração de nitrogênio amoniacal efluente $\left(\mathrm{mgN} \cdot \mathrm{L}^{-1}\right)$

$\mathrm{N}_{\mathrm{C}}$ : Concentração de amônia nitrificada $\left(\mathrm{mgN} . \mathrm{L}^{-1}\right)$

$\mathrm{N}_{\mathrm{D}}$ : Não detectado pelo método padrão utilizado

NDS: Nitrificação e desnitrificação simultânea

$\mathrm{NH}_{3}$ : Gás amoníaco $\left(\mathrm{mgN} . \mathrm{L}^{-1}\right)$

$\mathrm{NH}_{4}^{+}$: Íon amônio $\left(\mathrm{mgN} . \mathrm{L}^{-1}\right)$

$\mathrm{N}_{1}$ : Concentração de NTK para a produção de lodo de excesso $\left(\mathrm{mgN} . \mathrm{L}^{-1}\right)$ 
$\mathrm{N}_{\text {na }}$ : Concentração de nitrogênio nitrato afluente $\left.\left(\mathrm{mgN} \cdot \mathrm{L}^{-1}\right)\right)$

$\mathrm{N}_{\text {ne: }}$ : Concentração de nitrato no efluente $\left(\mathrm{mgN} . \mathrm{L}^{-1}\right)$

$\mathrm{N}-\mathrm{NO}_{2}{ }_{2}^{-}$: Nitrito $\left(\mathrm{mgN} . \mathrm{L}^{-1}\right)$

$\mathrm{N}-\mathrm{NO}_{3}{ }_{3}^{-}$: Nitrato $\left(\mathrm{mgN} . \mathrm{L}^{-1}\right)$

$\mathrm{N}_{\mathrm{o}}$ : Material nitrogenado inicial referente a recirculações (mgN.L ${ }^{-1}$ )

$\mathrm{N}_{\mathrm{oa}}$ : Concentração de nitrogênio orgânico afluente $\left(\mathrm{mgN} . \mathrm{L}^{-1}\right)$

$\mathrm{N}_{\mathrm{oe}}$ : Concentração de nitrogênio orgânico efluente $\left(\mathrm{mgN} . \mathrm{L}^{-1}\right)$

N-Orgânico: Nitrogênio Orgânico $\left(m g N . L^{-1}\right)$

$\mathrm{N}_{\mathrm{ta}}$ : Concentração de NTK afluente $\left(\mathrm{mgN} . \mathrm{L}^{-1}\right)$

$\mathrm{N}_{\mathrm{te}}$ : Concentração de NTK efluente $\left(\mathrm{mgN} \cdot \mathrm{L}^{-1}\right)$

NTK: Concentração de nitrogênio total Kjeldahl (mgN.L $\left.\mathrm{L}^{-1}\right)$

OD: Concentração de oxigênio dissolvido (mg. $\left.\mathrm{L}^{-1}\right)$

OD ${ }_{\text {máx: }}$ Valor de oxigênio dissolvido de referência superior $\left(\mathrm{mg} . \mathrm{L}^{-1}\right)$

$\mathrm{OD}_{\text {min }}$ : Valor de oxigênio dissolvido de referência inferior (mg. $\left.\mathrm{L}^{-1}\right)$

OLAND: Oxygen Limited Autotrophic Nitrification Denitrification

pH: Potencial hidrogeniônico

PROSAB: Programa de Saneamento Básico

q: Volume de licor misto a ser descartado $\left({\mathrm{L} . \mathrm{d}^{-1}}^{-1}\right)$

$\mathrm{Q}_{\mathrm{a}}$ : Vazão afluente $\left({\left.\mathrm{L} \cdot \mathrm{d}^{-1}\right)}^{-1}\right.$

$\mathrm{Q}_{\mathrm{e}}$ : Vazão efluente $\left({\left.\mathrm{L} . \mathrm{d}^{-1}\right)}^{-1}\right.$

$\mathrm{Q}_{\mathrm{ra}}$ : Vazão de recirculação "a" $\left({\left.\mathrm{L} . \mathrm{d}^{-1}\right)}^{-1}\right.$

r: Taxa de recirculação de licor misto

RBS: Reator em bateladas seqüenciais

$\mathrm{r}_{\mathrm{d}}$ : Taxa de desnitrificação

$\mathrm{r}_{\mathrm{dp}}$ : Taxa de desnitrificação para material lentamente biodegradável

$\mathrm{r}_{\mathrm{ds}}$ : Taxa de desnitrificação para material rapidamente biodegradável

$\mathrm{R}_{\mathrm{h}}$ : Tempo de permanência do líquido $\left(\mathrm{d}^{-1}\right)$

$\mathrm{r}_{\text {máx }}$ : Taxa de utilização máxima material carbonáceo (mgDQO.mgX $\mathrm{x}_{\mathrm{a}}^{-1} \cdot \mathrm{d}^{-1}$ )

$r_{\text {n.máx: }}$ Taxa de utilização máxima de amônia, nitrito ou nitrato

$\mathrm{R}_{\mathrm{s}}$ : Idade de lodo $\left(\mathrm{d}^{-1}\right)$

$\mathrm{R}_{\mathrm{sm}}$ : Idade de lodo mínima para que ocorra nitrificação

$\mathrm{r}_{\mathrm{us}}$ : Taxa de utilização de material rapidamente biodegradável

S: Concentração de substrato (mg. $\left.\mathrm{L}^{-1}\right)$

S32c: Software do respirômetro Beluga

$\mathrm{S}_{\mathrm{ba}}$ : DQO biodegradável afluente (mg.L $\mathrm{L}^{-1}$ )

$\mathrm{S}_{\mathrm{bpa}}$ : DQO biodegradável particulada afluente $\left(\mathrm{mg} \cdot \mathrm{L}^{-1}\right)$

$\mathrm{S}_{\mathrm{bsa}}$ : DQO biodegradável solúvel afluente $\left(\mathrm{mg} \cdot \mathrm{L}^{-1}\right)$ 
SHARON: Single-reactor High-activity Ammonium Removal Over Nitrite

SS: Sólidos suspensos $\left(\mathrm{mg} . \mathrm{L}^{-1}\right)$

SSF: Sólidos suspensos fixos (mg.L $\left.\mathrm{L}^{-1}\right)$

SST: Sólidos suspensos totais $\left(\mathrm{mg} . \mathrm{L}^{-1}\right)$

SSV: Sólidos suspensos voláteis $\left(\mathrm{mg} . \mathrm{L}^{-1}\right)$

$\mathrm{S}_{\mathrm{ta}}$ : DQO afluente $\left(\mathrm{mg} \cdot \mathrm{L}^{-1}\right)$

$\mathrm{S}_{\mathrm{te}}$ : DQO efluente (mg.L $\left.\mathrm{L}^{-1}\right)$

$\mathrm{S}_{\text {ua: }}$ DQO não biodegradável afluente $\left(\mathrm{mg} . \mathrm{L}^{-1}\right)$

$\mathrm{S}_{\text {upa }}$ : DQO não biodegradável particulada afluente $\left(\mathrm{mg} . \mathrm{L}^{-1}\right)$

$\mathrm{S}_{\text {usa }}$ : DQO não biodegradável solúvel afluente $\left(\mathrm{mg} . \mathrm{L}^{-1}\right)$

T: Temperatura $\left({ }^{\circ} \mathrm{C}\right)$

TCO "in loco": Taxa de consumo de oxigênio real do sistema $\left(\mathrm{mgO}_{2} \cdot \mathrm{L}^{-1} \cdot \mathrm{h}^{-1}\right)$

TCO: Taxa de consumo de oxigênio $\left(\mathrm{mgO}_{2} \cdot \mathrm{L}^{-1} \cdot \mathrm{h}^{-1}\right)$

$\mathrm{TCO}_{\text {end }}$ : Taxa de Consumo de Oxigênio endógena $\left(\mathrm{mgO}_{2} \cdot \mathrm{L}^{-1} \cdot \mathrm{h}^{-1}\right)$

$\mathrm{TCO}_{\text {eq }}$ : Taxa de consumo de oxigênio equivalente $\left(\mathrm{mgO}_{2} \cdot \mathrm{L}^{-1} \cdot \mathrm{h}^{-1}\right)$

$\mathrm{TCO}_{\text {exo }}$ : Taxa de consumo de oxigênio exógena $\left(\mathrm{mgO}_{2} \cdot \mathrm{L}^{-1} \cdot \mathrm{h}^{-1}\right)$

$\mathrm{TCO}_{\text {exo.máx: }}$ Taxa de consumo de oxigênio exógena máxima $\left(\mathrm{mgO}_{2} \cdot \mathrm{L}^{-1} \cdot \mathrm{h}^{-1}\right)$

$\mathrm{TCO}_{\mathrm{n}}$ : TCO total devido à nitrificação $\left(\mathrm{mgO}_{2} \cdot \mathrm{L}^{-1} \cdot \mathrm{h}^{-1}\right)$

$\mathrm{TCO}_{\text {n.máxima }}$ TCO total devido à nitrificação máxima $\left(\mathrm{mgO}_{2} \cdot \mathrm{L}^{-1} \cdot \mathrm{h}^{-1}\right)$

$\mathrm{TCO}_{\text {total: }}$ Taxa de consumo de oxigênio total $\left(\mathrm{mgO}_{2} \cdot \mathrm{L}^{-1} \cdot \mathrm{h}^{-1}\right)$

TDH: Tempo de detenção hidráulica (h)

UCT: University of Cape Town

USP: Universidade de São Paulo

$\mathrm{V}_{\mathrm{r}}$ : Volume do reator $\left(\mathrm{L}^{-1}\right)$

$\mathrm{V}_{\mathrm{T}}$ : Volume total $\left(\mathrm{L}^{-1}\right)$

$\mathrm{V}_{\mathrm{U}}:$ Volume útil $\left(\mathrm{L}^{-1}\right)$

$\mathrm{X}$ : Concentração ativa das bactérias $\left(\mathrm{mgX} . \mathrm{L}^{-1}\right)$

$\mathrm{X}_{\mathrm{a}}$ : Concentração ativa das bactérias heterotróficas $\left(\mathrm{mgX}_{\mathrm{a}} \cdot \mathrm{L}^{-1}\right)$

$\mathrm{X}_{\mathrm{e}}$ : Concentração de resíduo endógeno (mg.L $\left.\mathrm{L}^{-1}\right)$

$\mathrm{X}_{\mathrm{F}}$ : Concentração de sólidos fixos $\left(\mathrm{mg} \cdot \mathrm{L}^{-1}\right)$

$\mathrm{X}_{\mathrm{i}}$ : Concentração de resíduo inerte (mg. $\mathrm{L}^{-1}$ )

$\mathrm{X}_{\mathrm{n}}$ : Concentração ativa de bactérias nitrificantes $\left(\mathrm{mgX}_{\mathrm{n}} \cdot \mathrm{L}^{-1}\right)$

$\mathrm{X}_{\mathrm{t}}$ : Concentração de lodo (gSTS.L $\mathrm{L}^{-1}$ )

$\mathrm{X}_{\mathrm{V}}$ : Concentração de sólidos voláteis $\left(\mathrm{mg} . \mathrm{L}^{-1}\right)$

$\mathrm{Y}_{\mathrm{n}}$ : Coeficiente de rendimento das bactérias autotróficas $\left(\mathrm{mgN} \cdot \mathrm{L}^{-1} \cdot \mathrm{d}^{-1}\right)$

$\theta$ : Coeficiente de dependência da temperatura - Arrehnius 


\section{CAPÍTULO 1}

\section{INTRODUÇÃO}

Os sistemas de lodo ativado se distinguem de outros sistemas de tratamento biológico de esgotos por oferecerem a possibilidade de se remover de águas residuárias, os nutrientes nitrogênio e fósforo com requisitos mínimos de área. Para dispor das vantagens desses sistemas, quanto à remoção de nutrientes, podem-se variar suas configurações e, dessa maneira, elevar o seu potencial de tratamento. Grande parte do lodo em sistemas de lodo ativado se compõe de bactérias heterotróficas facultativas, isto é, bactérias que usam o material orgânico como fonte de energia, utilizando oxigênio como aceptor final de elétrons. Todavia, quando em situações onde o oxigênio não está presente, essas bactérias são capazes de utilizar a energia contida no material orgânico, através da fermentação, ou utilizar outro oxidante como aceptor final de elétrons, por exemplo, nitrato ou nitrito. Quando nitrato ou nitrito são utilizados pelas bactérias heterotróficas facultativas como oxidante da matéria orgânica, ocorre a remoção de nitrogênio como gás $\left(\mathrm{N}_{2}\right)$ num processo denominado de desnitrificação (SANTOS, 2009).

O processo de desnitrificação contribui para mitigar o problema de eutrofização nos corpos d'água receptores. Esse processo se deve, principalmente, a atuação de bactérias quimiorganotróficas, e fototróficas e de alguns fungos (SCHMIDT et al., 2003). De forma geral, a desnitrificação é precedida pela nitrificação que é um processo realizado comumente por organismos autotróficos nitrificantes. Em regiões de clima tropical, a nitrificação, mesmo que não tenha sido prevista em projeto, quase sempre acontece. Por esse motivo, a desnitrificação deve estar inserida no projeto original de dimensionamento para que problemas operacionais graves não ocorram, como por exemplo, a flotação do lodo no decantador secundário devido à liberação de nitrogênio gasoso (VAN HAANDEL e MARAIS, 1999).

A presente Revisão do Plano Diretor de Esgotos da Região Metropolitana de São Paulo tem sido norteada pelo cenário atual em que o padrão de emissão de $20 \mathrm{mg} \cdot \mathrm{L}^{-1}$ para a concentração de nitrogênio amoniacal, constante na Resolução 357/2005 do CONAMA (BRASIL, 2005) foi temporariamente suspenso para esgoto sanitário pela Resolução 397/2008 do CONAMA. Porém, prevendo-se a possibilidade futura de revogação da suspensão, bem como o interesse em melhorar a qualidade da água do Rio Tietê a jusante da RMSP, pode-se recomendar a avaliação da necessidade não apenas da nitrificação do esgoto, como também a redução biológica do nitrato. Entende-se que, nos dias atuais, as alternativas de pré-desnitrificação e de pósdesnitirifação, processos que podem ser associados aos sistemas de lodo ativado, são satisfatoriamente conhecidos. Embora possa ser futuramente implantado nas ETEs da RMSP, o arranjo com pré-desnitrificação tem por principal aspecto desfavorável a necessidade de grandes 
vazões de recirculação de lodo da zona aerada para a zona anóxica, dependendo da concentração de nitrato a ser obtida no efluente final, acarretando elevação significativa dos custos operacionais em função do consumo de energia elétrica por estas elevatórias adicionais. A pós-desnitrificação, por sua vez, exige a adição artificial de carbono orgânico para esse processo heterotrófico em que os microrganismos usam nitrato como aceptor de elétrons.

Os sistemas de lodo ativado que trabalham sob o regime de bateladas sequenciais são bastante propícios para a obtenção da desnitrificação, bastando à manutenção de etapas anóxicas nos ciclos operacionais, ainda trazendo a vantagem de levarem ao consumo de matéria orgânica biodegradável sem introdução de oxigênio. Porém, adaptar sistemas de fluxo contínuo existentes na RMSP para a operação em bateladas sequenciais é praticamente impossível. Restam como alternativas a serem avaliadas, contemplando apenas biomassa em suspensão, o processo de nitrificação e desnitrificação simultâneas (NDS), atualmente em uso em ETEs em outros países.

Conforme será visto, este processo só pode ser conseguido quando se mantêm idades do lodo elevadas e baixas concentrações de OD. Muitas ETEs de pequeno e médio porte poderão ser adaptadas para NDS de forma a se obter o benefício técnico da desnitrificação e o ganho econômico relativo à redução no consumo de energia elétrica para aeração, merecendo maior aprofundamento sobre o conhecimento teórico deste processo. Negativamente pode ser citada a necessidade de um controle mais rigoroso do sistema de aeração.

Para projetar ou aprimorar racionalmente um sistema de lodo ativado com remoção de nutrientes via NDS é preciso que se saiba a estequiometria e a cinética das populações bacterianas que se desenvolvem em tais sistemas. Essa cinética pode ser afetada por diversos fatores ambientais e operacionais aos quais as bactérias estão submetidas, sendo estes: temperatura, concentração disponível de oxigênio dissolvido (OD), pH e, também, a configuração de projeto. Modelos matemáticos são amplamente utilizados para descrever a cinética de processos biológicos que ocorrem em sistemas de lodo ativado e auxiliam, de forma eficaz, na determinação de relações estequiométricas.

As constantes cinéticas da nitrificação são críticas na compreensão do modo de funcionamento do sistema de tratamento de esgoto, além de definirem parâmetros importantes para esses como: a idade de lodo mínima e máxima que pode ser aplicada, o volume dos reatores visando a NDS máxima, concentração mínima e máxima de OD que pode ser aplicada e capacidade de NDS. As bactérias responsáveis pela remoção de nitrogênio são capazes de produzir enzimas que catalisam as reações de oxidação das formas nitrogenadas, onde ensaios de laboratório podem ser realizados para avaliar a taxa dessas reações avaliando-se as mudanças na concentração dos substratos ou produtos envolvidos (amônia, nitrito, nitrato, oxigênio dissolvido, etc.). Dentre 
varias técnicas que podem ser utilizadas, a respirometria (determinação da taxa de consumo de oxigênio) destaca-se devido à velocidade na resposta dos dados e a flexibilidade de aplicação, podendo estabelecer não só a taxa das reações, como também mensurar a influência no metabolismo bacteriano de fatores ambientais como temperatura, oxigênio dissolvido (OD) e potencial hidrogeniônico $(\mathrm{pH})$ como podemos observar em vários estudos realizados tendo a respirometria como ferramenta (CATUNDA, 1996; VAN HAANDEL e MARAIS, 1999; BORZANI et al., 2001; FERREIRA, 2002; ANDREOTTOLA, et al, 2005;). A partir dessas considerações definiu-se uma investigação experimental em escala piloto, que teve como principal objetivo avaliar as condições de remoção de nitrogênio por NDS em um sistema de lodo ativado com aeração prolongada em fluxo contínuo. 


\subsection{Objetivo geral}

Definiu-se uma investigação experimental em escala piloto, que teve como principal objetivo avaliar as condições de remoção de nitrogênio, por meio do processo conhecido como nitrificação e desnitrificação simultânea (NDS) em um sistema de lodo ativado com aeração prolongada em fluxo contínuo, com diferentes idades do lodo, tratando esgoto sanitário, a fim de contribuir para identificar as condições necessárias para o desenvolvimento de um processo estável e eficiente em países com clima tropical.

\subsection{Objetivos específicos}

Como objetivos específicos apresentam-se:

(1) Montar e operar, sob condições controladas de OD na faixa de $0,3-0,8 \mathrm{mg} \cdot \mathrm{L}^{-1}$, um sistema de lodo ativado com aeração prolongada, alimentado em fluxo contínuo, tratando esgoto sanitário, desenvolvendo o processo de NDS;

(2) Avaliar o desempenho do sistema nas diferentes idades de lodo quanto à sedimentabilidade do lodo, quanto à remoção de matéria orgânica e de nutrientes, notadamente o nitrogênio, por meio de análises físicas e químicas;

(3) Utilizar o modelo simplificado da teoria de lodo ativado, descrito por VAN HAANDEL e MARAIS (1999) para a determinação da cinética das bactérias nitrificantes, desnitrificantes e demais heterotróficas;

(4) Determinar por meio da respirometria as principais constantes cinéticas envolvidas no processo de nitrificação sendo: As constantes de crescimento específico máximo das bactérias nitritantes e nitratantes $\left(\mu_{m}\right)$, de meia saturação de $\operatorname{Monod}\left(K_{n}\right)$ e a taxa de utilização máxima de substrato específico $\left(r_{n . m a ́ x}\right)$ e, a capacidade de nitrificação $\left(\mathrm{N}_{\mathrm{C}}\right)$ do sistema;

(5) Determinar por meio da respirometria e testes analíticos, as principais constantes cinéticas da desnitrificação. Comparar a taxa de oxidação de material orgânico (rapidamente e lentamente biodegradável e com o próprio esgoto sanitário) tendo como oxidante o oxigênio dissolvido e o nitrato e, avaliar a capacidade de desnitrificação $\left(\mathrm{D}_{\mathrm{C}}\right)$ do sistema. 


\section{CAPÍTULO 2}

\section{REVISÃO DE LITERATURA}

\subsection{Esgoto sanitário}

Esgoto sanitário pode ser considerado como aquele que provém principalmente de residências, estabelecimentos comercias, instituições ou quaisquer edificações que disponham de instalações de banheiros, lavanderias e cozinhas, sejam elas urbanas ou rurais. Compõe-se essencialmente da água de banho, excretas, sabão, detergentes e águas de lavagens. As urinas e fezes, além de outros compostos que podem ocorrer nos esgotos sanitários, constituem $0,1 \%$ das impurezas, sendo o restante $(99,9 \%)$ essencialmente água. Nas fezes estão cerca de $25 \%$ da matéria orgânica e na urina 2,5\% (VON SPERLING, 2005; JORDÃO E PESSOA, 2005; FUNASA, 2006). A concentração e composição do material orgânico dependem da origem do esgoto. Cerca de $70 \%$ dos sólidos no esgoto são de origem orgânica. Quando se tem a finalidade de modelar, por exemplo, o sistema de lodo ativado, é necessário dividir o material orgânico afluente em frações diferentes. VAN HAANDEL e MARAIS (1999) utilizam a DQO (Demanda Química de Oxigênio) como parâmetro representativo da matéria orgânica visto que é possível relacionar estequiometricamente e de forma direta a DQO com o material orgânico. De acordo com esses autores, o material orgânico em termos de DQO pode ser biodegradável e não biodegradável. A Figura 2 apresenta um esquema das frações do material orgânico em um sistema de lodo ativado. Esclarece-se que a terminologia utilizada nesta seção é a apresentada por VAN HAANDEL E MARAIS (1999) no desenvolvimento do modelo cinético utilizado como referência nesta pesquisa.

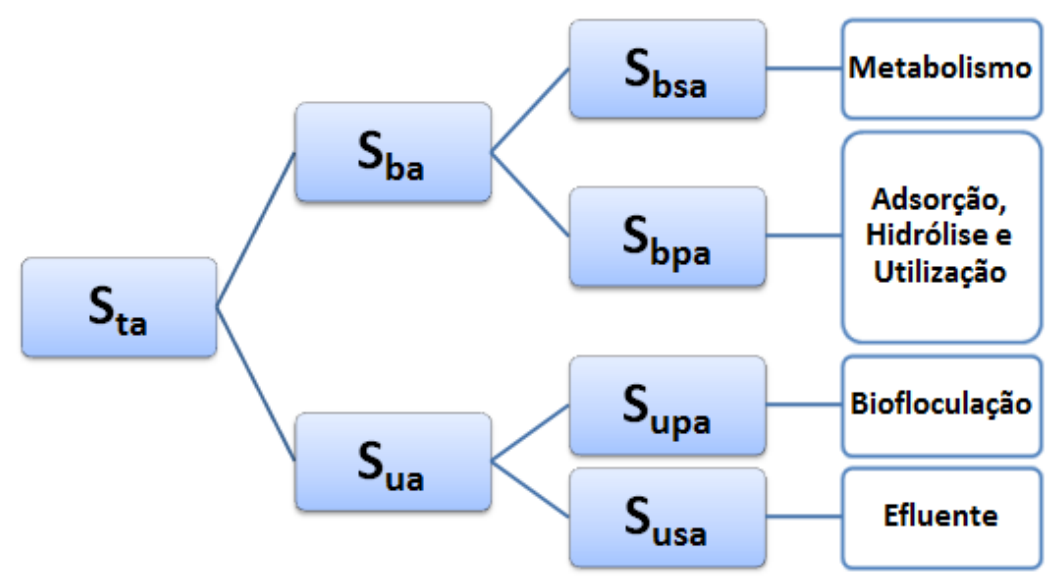

Figura 2: Divisão geral do material orgânico de esgoto sanitário (em termos de DQO). Fonte: adaptado de (VAN HAANDEL E MARAIS, 1999) 
A massa bacteriana, através de seu metabolismo, pode agir sobre o material orgânico afluente $\left(\mathrm{S}_{\mathrm{ta}}\right)$, porém essas ações bioquímicas não afetam o material não biodegradável ( $\left.\mathrm{S}_{\mathrm{ua}}\right)$. Para uma descrição mais refinada do sistema de lodo ativado, ambos, o material biodegradável $\left(\mathrm{S}_{\mathrm{ba}}\right)$ e não biodegradável $\left(S_{\text {ua }}\right)$, são divididos em frações sendo estas: solúvel $\left(S_{\text {bsa }}\right.$ e $\left.S_{\text {usa }}\right)$ e particulada $\left(S_{\text {bpa }}\right.$ e $S_{\text {upa }}$ ). A subdivisão leva em consideração o tamanho físico do material orgânico (VAN HAANDEL e VAN DER LUBBE, 2007).

Com a representação das frações do material orgânico em forma de DQO é possível apresentar as frações de material orgânico (biodegradável e não biodegradável) conforme a Tabela 2, onde se observam os valores típicos das frações de material orgânico em esgoto municipal bruto, encontrados em pesquisas com diferentes águas residuárias.

Tabela 2: Valores de referência das frações de material orgânico em esgoto municipal bruto

\begin{tabular}{cccccccc}
\hline \multicolumn{8}{c}{ Frações de matéria orgânica biodegradável e não biodegradável } \\
\hline Esgoto Municipal & $\mathbf{f}_{\mathbf{b}}$ & $\mathbf{f}_{\mathbf{b s}}$ & $\mathbf{f}_{\mathbf{b p}}$ & $\mathbf{f}_{\mathbf{u}}$ & $\mathbf{f}_{\mathbf{u s}}$ & $\mathbf{f}_{\mathbf{u p}}$ & Referência \\
\hline Campina Grande & 0,80 & 0,27 & 0,53 & 0,20 & 0,15 & 0,05 & SILVA FILHO, 2003 \\
\hline Campina Grande & 0,88 & 0,25 & 0,63 & 0,12 & 0,07 & 0,05 & COURA DIAS et al, 1982 \\
\hline $\begin{array}{c}\text { Cidade do Cabo } \\
\text { (África do Sul) }\end{array}$ & 0,75 & 0,25 & 0,58 & 0,21 & 0,09 & 0,12 & MARAIS E EKAMA, 1976 \\
\hline $\begin{array}{c}\text { Burlington } \\
\text { (Canadá) }\end{array}$ & 0,63 & - & - & 0,37 & 0,12 & 0,25 & SUTTON et al, 1979 \\
\hline
\end{tabular}

Fonte: adaptado de (VAN HAANDEL e MARAIS, 1999).

\subsubsection{Processo de lodo ativado}

O processo de lodo ativado são sistemas biológicos amplamente utilizados para o tratamento de despejos domésticos e industriais, em nível mundial, devido, principalmente à qualidade do efluente e os baixos requisitos por área, além da possibilidade de se variar alguns processos. No entanto, o sistema de lodo ativado inclui um índice de mecanização superior ao de outros sistemas de tratamento, implicando em uma operação mais sofisticada e em maiores consumos de energia elétrica (VON SPERLING, 2002). A Figura 2.1 mostra as unidades que são partes integrantes da etapa biológica do sistema de lodo ativado: 


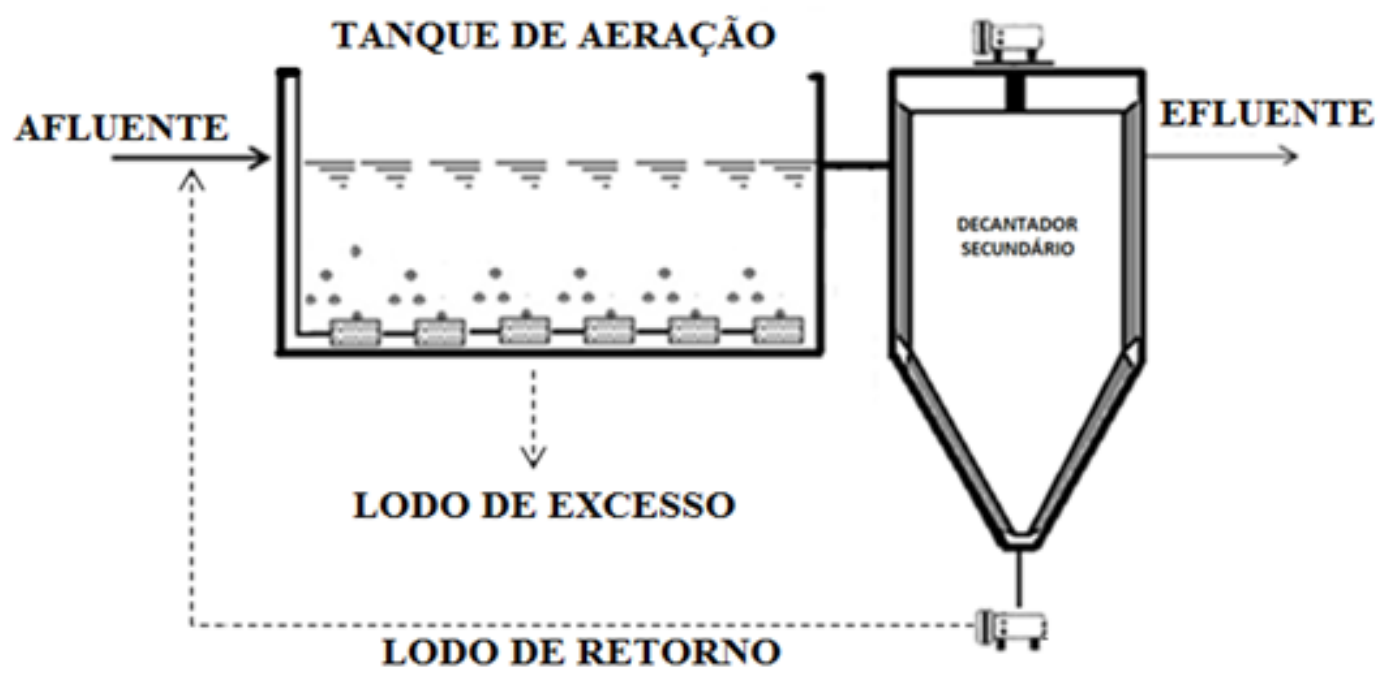

Figura 2.1: Esquema das unidades da etapa biológica do sistema de lodo ativado Fonte: Adaptado de (VON SPERLING, 2002)

No tanque de aeração (reator) ocorrem as reações bioquímicas de remoção de matéria orgânica e, em determinadas condições, da matéria nitrogenada. A matéria orgânica é em parte convertida em biomassa bacteriana (lodo) e em parte mineralizada para $\mathrm{CO}_{2}$ e $\mathrm{H}_{2} \mathrm{O}$. Devido às boas características de sedimentabilidade do lodo, a biomassa bacteriana pode ser separada do efluente tratado por simples sedimentação no decantador secundário, permitindo que o efluente final saia clarificado (METCALF e EDDY,1991). Os sólidos sedimentados no fundo do decantador secundário são recirculados para o tanque de aeração, aumentando a concentração de biomassa ativa do mesmo, o que é responsável pela elevada eficiência do sistema. Em um sistema de lodo ativado convencional os sólidos são recirculados do fundo da unidade de decantação, por meio de bombeamento, para a unidade de aeração. No sistema de lodo ativado, o tempo de detenção do líquido é bem baixo, da ordem de horas, implicando em que o volume do tanque de aeração seja bem reduzido.

No entanto, devido à recirculação dos sólidos, estes permanecem no sistema por um tempo superior ao do líquido. O tempo de retenção dos sólidos é denominado idade do lodo, ou seja, a idade de lodo representa o tempo médio que uma partícula de lodo permanece no sistema, e pode ser determinada pela razão: massa de lodo no reator pela massa de lodo descarregada diariamente (grosseiramente dividindo-se a quantidade de lodo (seco) contida no tanque de aeração pela quantidade diária de lodo (seco) retirada do sistema como lodo em excesso). É o parâmetro fundamental para o dimensionamento e operação de sistemas de lodo ativado (VAN HAANDEL e MARAIS, 1999). Ainda, no tanque de aeração, devido à entrada contínua de alimento, na forma de DBO dos esgotos, os microrganismos crescem e se reproduzem continuamente. Para manter o sistema em equilíbrio, é necessário que se retire 
aproximadamente a mesma quantidade de biomassa que é aumentada por reprodução. Este é, portanto o lodo biológico excedente, que pode ser extraído diretamente do tanque de aeração ou da linha de recirculação.

\subsubsection{Variantes do processo de lodo ativado}

Desde sua concepção por LOCKETT e ADERN em 1914 apud (METCALF e EDDY, 1991), desenvolveram-se vários sistemas que usam lodo ativado em suspensão para efetuar a remoção de material orgânico e nutriente de águas residuárias, que deram lugar às seguintes variantes (VON SPERLING, 2002; JORDÃO e PESSOA, 2005):

- Divisão quanto à idade do lodo

-Lodo ativado convencional -Aeração prolongada

- Divisão quanto ao fluxo

-Fluxo contínuo

-Fluxo intermitente (batelada)

- Divisão quanto ao regime hidráulico do reator biológico

-Processo de mistura completa

-Processo tubular, pistonado ou "Plug Flow"

- Divisão quanto ao afluente à etapa biológica do sistema de lodo ativado

-Esgoto bruto

-Efluente de decantador primário

-Efluente de reator anaeróbio

-Efluente de outro processo de tratamento de esgotos

\subsubsection{Divisão quanto ao regime hidráulico do reator biológico}

Quanto ao regime hidráulico do reator biológico, existe o sistema de mistura completa no qual o reator tem as dimensões largura e comprimento igual, e o sistema pistonado, no qual o comprimento do tanque de aeração é bem maior que a largura. $\mathrm{O}$ reator de mistura completa que é o nosso caso, tem as vantagens de promover uma distribuição homogênea de oxigênio, possibilitando um melhor controle na concentração de OD no licor misto, promovendo um ambiente mais estável para ocorrência da NDS. O sistema de mistura completa apresenta uma boa capacidade de absorver cargas tóxicas instantâneas e amenizar variações de cargas orgânicas, pois essas se diluem rápida e uniformemente no conteúdo do tanque de aeração. No 
sistema pistonado a carga orgânica é consumida ao longo do comprimento do mesmo, necessitando gradualmente menos oxigênio dissolvido. A redução gradual de consumo de oxigênio dissolvido pode ser atendida aplicando-se uma aeração maior no ponto de entrada do esgoto e diminuindo-a ao longo do tanque de aeração, (Processo de Aeração Escalonada ou Aeração Decrescente) (VAN HAANDEL e MARAIS, 1999; VON SPERLING, 2002).

\subsubsection{Divisão quanto à idade do lodo}

Os sistemas de lodo ativado podem ser classificados, em função da idade do lodo, em uma das seguintes principais categorias, conforme Tabela 2.1:

Tabela 2.1: Classificação do sistema de lodo ativado em função da idade do lodo

\begin{tabular}{cccc}
\hline Idade do lodo & $\begin{array}{c}\text { Carga de DBO aplicada por } \\
\text { unidade de volume }\end{array}$ & $\begin{array}{c}\text { Faixa de idade } \\
\text { do lodo }\end{array}$ & Denominação usual \\
\hline Reduzidíssima & Altíssima taxa & Inferior a 3 dias & Aeração modificada \\
\hline Reduzida & Alta taxa & 4 a 10 dias & $\begin{array}{c}\text { Lodo ativado } \\
\text { convencional }\end{array}$ \\
\hline Intermediária & Intermediária & 11 a 17 dias & - \\
\hline Elevada & Baixa taxa & 18 a 30 dias & Aeração prolongada \\
\hline Fonte: Adaptada de (VON SPERLING, 2002) & &
\end{tabular}

\subsubsection{Reatores de altíssima taxa (fluxo contínuo)}

Reatores de altíssimas taxas ou de alta capacidade distinguem-se dos demais por operarem com idade do lodo de 2 a 3 dias e tempo de detenção hidráulica de 1 a 2 horas (VAN HAANDEL e MARAIS, 1999; JORDÃO E PESSOA, 2005). Nesses reatores há pouca respiração endógena sendo exercida, visto que existe uma grande disponibilidade de alimento, baixo TDH e pouca massa bacteriana, o que leva a uma grande produção de lodo não estabilizado. Esse lodo em excesso pode exigir grandes unidades de tratamento para estabilizá-lo. 


\subsubsection{Reatores de alta taxa (fluxo contínuo)}

Reatores de alta taxa denominados de lodo ativado convencional, operam com idade do lodo de 4 a 10 dias e o TDH no tanque de aeração é da ordem de 6 a 8 horas. Para se economizar energia para aeração e reduzir o volume do reator biológico, parte da matéria orgânica (em suspensão, sedimentável) dos esgotos é retirada antes do tanque de aeração através de um decantador primário. Assim, os sistemas de lodo ativado convencional tem como parte integrante o tratamento primário. Com esta idade do lodo, a biomassa retirada do sistema no lodo de excedente requer ainda uma etapa de estabilização no tratamento do lodo, por conter ainda um elevado teor de matéria orgânica armazenada nas suas células (VON SPERLING, 2002).

\subsubsection{Reatores de baixa taxa (fluxo contínuo)}

Reatores de baixa taxa denominados de lodo ativado por aeração prolongada, que é o nosso caso, opera com uma idade de lodo elevada entre 18 a 30 dias e com tempo de TDH em torno de 16 a 24 horas. Recomenda-se esse tipo de processo para que se tenha a promoção satisfatória da nitrificação, visto que as bactérias nitrificantes são de crescimento lento em comparação com as bactérias heterotróficas que oxidam a matéria orgânica. Quando o sistema recebe a mesma carga de DBO de esgoto bruto que o sistema convencional, haverá menor disponibilidade de alimento para as bactérias, ou seja, a relação alimento/microrganismos (A/M) é menor que no processo convencional e a quantidade de biomassa (KgSSVTA) maior. O volume do tanque de aeração é também mais elevado. Portanto, há menos matéria orgânica por unidade de biomassa no tanque de aeração. Em decorrência as bactérias, para sobreviver, passam a utilizar de forma mais intensa nos seus processos metabólicos a própria matéria orgânica biodegradável componente das suas células (VON SPERLING, 2002). Esta matéria orgânica celular é convertida em gás carbônico e água através da respiração. Isto corresponde a uma estabilização da biomassa, ocorrendo no próprio tanque de aeração. No entanto para a estabilização do lodo no tanque de aeração há um consumo adicional de oxigênio (respiração endógena) que é significativo e pode ser maior que o consumo para metabolizar o material orgânico afluente (respiração exógena). Deste modo, os sistemas de aeração prolongada usualmente não possuem decantadores primários, para evitar a necessidade de se estabilizar o lodo primário. Com isto, obtém-se uma grande simplificação no fluxograma do processo, sendo o sistema composto de basicamente de tanque de aeração e decantador secundário, conforme apresentado anteriormente na Figura 2.1. A consequência desta simplificação do sistema é o gasto elevado com energia para aeração 
quando comparado com outros sistemas, já que o lodo é estabilizado aerobiamente no tanque de aeração. Estudos realizados por ALEM SOBRINHO e KATO (1999), ALEM SOBRINHO (2001), ALEM SOBRINHO e JORDÃO (2001) comparam o gasto com energia elétrica na aeração para os principais sistemas de lodo ativado e suas principais características no tratamento de esgotos domésticos, como se observa na Tabela 2.2. Como veremos posteriormente, uma das maneiras de se reduzir o gasto com energia elétrica em um sistema de aeração prolongada, sem reduzir a eficiência dos processos, é adaptando o sistema para operar em condições controladas com baixas concentrações de oxigênio dissolvido, desenvolvendo o processo de nitrificação e desnitrificação simultânea, tema desse estudo. Que além da economia com o gasto de energia elétrica na aeração nos traz o beneficio da desnitrificação no sistema.

Tabela 2.2: Principais características dos sistemas de lodos ativados utilizados para o tratamento de esgotos domésticos

\begin{tabular}{|c|c|c|c|c|}
\hline \multirow[b]{2}{*}{ Item geral } & \multirow[b]{2}{*}{ Item específico } & \multicolumn{3}{|c|}{ Modalidade } \\
\hline & & Convencional & $\begin{array}{c}\text { Aeração } \\
\text { prolongada }\end{array}$ & $\begin{array}{c}\text { UASB-lodos } \\
\text { ativados }\end{array}$ \\
\hline Idade do lodo & Idade do lodo $\left(\mathrm{d}^{-1}\right)$ & 4-10 & $18-30$ & $6-10$ \\
\hline Relação A/M & $\begin{array}{c}\text { Relação A/M } \\
\left(\text { kgDBO.KgSSVTA.d }{ }^{-1}\right)\end{array}$ & 0,25 a 0,50 & 0,07 a 0,15 & 0,25 a 0,40 \\
\hline \multirow{7}{*}{$\begin{array}{l}\text { Eficiência de } \\
\text { remoção }\end{array}$} & $\mathrm{DBO}(\%)$ & $85-95$ & 93-98 & $85-95$ \\
\hline & DQO $(\%)$ & $85-90$ & $90-95$ & $83-90$ \\
\hline & Sólidos em suspensão (\%) & $85-95$ & $85-95$ & $85-95$ \\
\hline & Amônia (\%) & $85-95$ & $90-95$ & $75-90$ \\
\hline & ${ }^{(1)}$ Nitrogênio (\%) & $25-30$ & $15-25$ & $15-25$ \\
\hline & ${ }^{(1)}$ Fósforo (\%) & $25-30$ & $10-20$ & $10-20$ \\
\hline & Coliformes (\%) & $60-90$ & $70-95$ & $70-95$ \\
\hline \multirow{2}{*}{ Massa de lodo } & $\begin{array}{c}\text { A ser tratado } \\
\left(\mathrm{L}^{-1} \text { lodo.hab.ano }\right)\end{array}$ & $60-80$ & $40-45$ & $20-30$ \\
\hline & $\begin{array}{c}\text { A ser disposto } \\
\left(\mathrm{L}^{-1} \text { lodo.hab.ano }\right)\end{array}$ & $30-45$ & $40-45$ & $20-30$ \\
\hline \multirow{2}{*}{$\begin{array}{l}\text { (2) Volume de } \\
\text { lodo }\end{array}$} & $\begin{array}{c}\text { A ser tratado } \\
\left(\mathrm{g}^{-1} \text { ST.hab.dia }\right)\end{array}$ & $3,5-8,0$ & $3,5-5,5$ & $0,5-1,0$ \\
\hline & $\begin{array}{l}\text { A ser disposto } \\
\left(\mathrm{g}^{-1} \text { ST.hab.dia) }\right.\end{array}$ & $0,10-0,25$ & $0,10-0,25$ & $0,05-0,15$ \\
\hline \multirow[b]{2}{*}{${ }^{(3)}$ Energia } & Potência instalada (w.hab) & $2,5-4,5$ & $3,5-5,5$ & $1,8-3,5$ \\
\hline & $\begin{array}{c}\text { Consumo energético } \\
\text { (kwh.hab.ano) }\end{array}$ & $18-26$ & $20-35$ & $14-20$ \\
\hline
\end{tabular}

Fonte: Adaptada parcialmente de ALEM SOBRINHO e KATO (1999), ALEM SOBRINHO (2001), ALEM SOBRINHO e JORDÃO (2001).

Notas:

${ }^{(1)}$ : Pode-se alcançar eficiências maiores na remoção de N (especialmente no lodo ativado convencional e na aeração prolongada) e de $\mathrm{P}$ (especialmente no lodo ativado convencional) através de etapas específicas (desnitrificação e desfosfatação). A modalidade UASB - lodo ativado não é eficiente na remoção biológica de $\mathrm{N}$ e P; 
(2): O volume de lodo é função da concentração de sólidos totais (ST), a qual depende dos processos utilizados no tratamento da Fase líquida e da Fase sólida. A faixa superior do volume per capita de lodo a ser disposto está associada ao desaguamento por centrífuga e filtro de correia (menores concentrações de ST no lodo desidratado), ao passo que a faixa inferior está associada a leitos de secagem ou filtros-prensa (maiores concentrações de ST);

${ }^{(3)}$ : A potência instalada deve ser suficiente para suprir a demanda de $\mathrm{O}_{2}$ em cargas de pico. $\mathrm{O}$ consumo energético pressupõe certo controle do fornecimento do $\mathrm{O}_{2}$, reduzindo-o em momentos de menor demanda.

\subsection{Cinética do processo de remoção de material orgânico}

Esclarece-se que a terminologia e o modelo cinético utilizado nesta pesquisa para a determinação da cinética do processo de remoção de material orgânico e do material nitrogenado é o modelo simplificado da teoria de lodo ativado, descrito por VAN HAANDEL e MARAIS (1999).

\subsubsection{Balanço de massa de material orgânico}

Em um sistema de lodo ativado, uma fração da massa de material orgânico afluente ( $\left.\mathrm{mS}_{\mathrm{ta}}\right)$ não é removida da Fase líquida e deixa o sistema junto com o efluente $\left(\mathrm{mS}_{\mathrm{te}}\right)$; outra é transformada em lodo orgânico e deixa o sistema como lodo de excesso $\left(\mathrm{mS}_{\mathrm{xv}}\right)$; e a fração restante é oxidada para produtos inorgânicos gasosos $\left(\mathrm{mS}_{\mathrm{o}}\right)$. As frações de material orgânico que deixam o sistema na forma de lodo, oxidada e no efluente, em termos de DQO, permitem fazer o balanço de massa do material orgânico $\left(\mathrm{B}_{\mathrm{o}}\right)$ (Equação 2). De acordo com VAN HAANDEL E MARAIS (1999), quando o balanço fecha, ou seja, quando $B_{o}=1$ o sistema é dito operar sob condições de carga orgânica constante e que os erros analíticos normalmente cometidos não são significativos.

$\mathrm{B}_{\mathrm{o}}=\left(\mathrm{MS}_{\mathrm{te}}+\mathrm{MS}_{\mathrm{xv}}+\mathrm{MS}_{\mathrm{o}}\right) / \mathrm{MS}_{\mathrm{ta}}=1$

Sendo:

$\mathrm{MS}_{\mathrm{ta}}$ : fluxo de DQO afluente (mgDQO. $\left.\mathrm{d}^{-1}\right)$

$\mathrm{MS}_{\mathrm{te}}$ : fluxo de DQO efluente (mgDQO. $\left.\mathrm{d}^{-1}\right)$

$\mathrm{MS}_{\mathrm{xv}}$ : fluxo de DQO que sai no lodo de excesso (mgDQO.d $\mathrm{d}^{-1}$ )

$\mathrm{MS}_{\mathrm{o}}$ : fluxo de DQO oxidada (mgDQO.d $\mathrm{d}^{-1}$ ) 


\subsubsection{Fatores cinéticos da utilização de material orgânico}

O principal fator a ser considerado, quando se pretende determinar a cinética da utilização do material orgânico, é a taxa de utilização deste material. Essa taxa corresponde à velocidade com que os processos oxidativos e de síntese ocorrem em sistemas de lodo ativado. A taxa de crescimento das bactérias heterotróficas é proporcional à taxa de utilização de substrato. A concentração do substrato influencia a taxa de utilização desse substrato. Assim, o crescimento bacteriano ocorre em função da disponibilidade de material orgânico. Quando há pouca disponibilidade de substrato, a taxa de crescimento é proporcionalmente reduzida e quando não se tem limitação de substrato essa taxa de crescimento é máxima (VAN HAANDEL e MARAIS, 1999). A Equação 2.1 expressa a relação entre a taxa específica máxima de crescimento e a disponibilidade desse substrato.

$\mu_{\mathrm{m}}=\mu_{\text {máx }} *\left[S /\left(\mathrm{S}+\mathrm{K}_{\mathrm{s}}\right)\right]$

Sendo:

$\mu_{\mathrm{m}}$ : taxa específica de crescimento $\left(\mathrm{d}^{-1}\right)$;

$\mu_{\text {máx: }}$ taxa específica máxima de crescimento $\left(\mathrm{d}^{-1}\right)$;

$\mathrm{K}_{\mathrm{s}}$ : constante de meia saturação;

S: concentração de substrato $\left(\mathrm{mg} \cdot \mathrm{L}^{-1}\right)$.

Quando a quantidade de substrato é máxima, de modo que não limita o metabolismo bacteriano, $\mathrm{S}>\mathrm{K}_{\mathrm{s}}$, pode-se considerar que $\mu_{\mathrm{m}}$ é igual ao valor de $\mu_{\text {máx }}$, sendo $\mu_{\text {máx }}$ determinado conforme a Equação (2.2) (VAN HAANDEL e MARAIS, 1999).

$\mu_{\text {máx }}=\left(\mathrm{Y} * \mathrm{r}_{\text {máx }}\right) / \mathrm{X}_{\mathrm{a}}$

(Equação 2.2)

Sendo:

$\mathrm{X}_{\mathrm{a}}$ : concentração das bactérias heterotróficas $\left(\mathrm{mg} \cdot \mathrm{L}^{-1}\right)$;

Y: coeficiente de rendimento das bactérias heterotróficas $\left(0,45 \mathrm{mgX}_{\mathrm{a}}{ }^{*} \mathrm{mgDQO}{ }^{-1}\right)$ (VAN HAANDEL e MARAIS, 1999);

$\mathrm{r}_{\text {máx: }}$ taxa de utilização máxima do material carbonáceo $\left(\mathrm{mgDQO} \mathrm{mgX}_{\mathrm{a}}{ }^{-1} \cdot \mathrm{d}^{-1}\right)$, determinada, por exemplo, através de testes respirométricos.

A Equação 2.3 apresenta uma forma simples de determinar a taxa máxima de utilização do material carbonáceo.

$\mathrm{r}_{\text {máx }}=3 * \mathrm{TCO}_{\text {exo }} / \mathrm{X}_{\mathrm{a}}$

(Equação 2.3)

Sendo:

$\mathrm{r}_{\text {máx }}$ : taxa de utilização máxima do material carbonáceo $\left(\operatorname{mgDQO} * m g X \mathrm{a}^{-1} * \mathrm{~d}^{-1}\right)$;

$\mathrm{TCO}_{\text {exo }}$ : taxa de consumo de oxigênio exógena (a DQO oxidada é equivalente a $\mathrm{TCO}_{\text {exo }} * 3$, visto que $1 / 3$ do material biodegradável adicionado é oxidado. 
observando as Equações 2.2 e 2.3, percebe-se que, tendo-se determinado a $\mathrm{TCO}_{\text {exo }}$ (através dos testes respirométricos), para se calcular $r_{\text {máx }}$ (Equação 2.3) e $\mu_{\text {máx }}$ (Equação 2.2) é necessária a determinação da concentração de lodo ativo $X_{a}$ (Equação 2.4). É importante destacar que nem todo material volátil é biomassa ativa. O valor desse parâmetro pode ser estabelecido por dois critérios independentes segundo MARAIS e EKAMA, (1976):

(1) a teoria de lodo ativado mostra que a concentração de lodo ativo se expressa como:

$\mathrm{X}_{\mathrm{a}}=\mathrm{Y} * \mathrm{R}_{\mathrm{h}} * \mathrm{~S}_{\mathrm{ta}} /\left(1+\mathrm{b}_{\mathrm{h}} * \mathrm{R}_{\mathrm{s}}\right) * \mathrm{R}_{\mathrm{h}}$

Sendo:

$\mathrm{R}_{\mathrm{h}}$ : tempo de permanência do líquido $\left(\mathrm{d}^{-1}\right)$;

$\mathrm{S}_{\mathrm{ta}}$ : DQO do afluente $\left(\mathrm{mg} . \mathrm{L}^{-1}\right)$;

$\mathrm{b}_{\mathrm{h}}$ : constante de decaimento de lodo ativo $\left(\mathrm{d}^{-1}\right)$;

$\mathrm{R}_{\mathrm{s}}$ : idade de lodo $\left(\mathrm{d}^{-1}\right)$;

(2) a partir da TCO endógena, determinada na ausência de material extracelular, também se pode determinar o valor de $X_{a}$ :

A Equação 2.5 apresenta mais uma maneira de cálculo utilizado para determinar a concentração das bactérias heterotróficas ativas no sistema. Para melhor estimativa de $\mathrm{X}_{\mathrm{a}}$, usa-se a média dos resultados obtidos pelos dois métodos.

$\mathrm{X}_{\mathrm{a}}=\mathrm{TCO}_{\mathrm{end}} /\left[\mathrm{f}_{\mathrm{cv}} *(1-\mathrm{f}) * \mathrm{~b}_{\mathrm{h}}\right]$

Sendo:

$\mathrm{b}_{\mathrm{h}}$ : constante de decaimento para as bactérias heterotróficas $\left(0,24 * 1,04^{(\mathrm{t}-20)}\right.$, onde $\mathrm{t}$ é a temperatura de operação) (VAN HAANDEL e MARAIS, 1999);

$\mathrm{X}_{\mathrm{a}}$ : concentração das bactérias heterotróficas $\left(\mathrm{mgSSV}^{-1} \cdot \mathrm{L}^{-1}\right)$;

$\mathrm{TCO}_{\text {end }}$ : taxa de consumo de oxigênio endógena $\left(\mathrm{mgO}_{2} \cdot \mathrm{L}^{-1} \cdot \mathrm{h}^{-1}\right)$;

$\mathrm{f}_{\text {cv }}$ : fator de conversão de DQO para material ativo heterotrófico $\left(1,5 \mathrm{mgDQO} \cdot \mathrm{mgSSV}^{-1}\right)(\mathrm{VAN}$ HAANDEL e MARAIS, 1999);

f: fração não biodegradável após total decaimento do lodo $=0,2$ (resíduo endógeno).

Na Tabela 2.3 se observam os valores típicos das constantes de crescimento específico máximo das bactérias heterotróficas $\left(\mu_{\mathrm{m}}\right)$, as taxas de utilização de material orgânico das bactérias heterotróficas $\left(r_{\text {máx }}\right)$ e as constantes de meia saturação de Monod. 
Tabela 2.3: Valores de referência das constantes cinéticas de utilização de material orgânico

\begin{tabular}{ccl}
\hline & \multicolumn{2}{c}{ Fatores cinéticos de utilização de material orgânico } \\
\hline Constante & \multicolumn{1}{c}{ Valores } & \multicolumn{1}{c}{ Referências } \\
\hline \multirow{3}{*}{$\boldsymbol{\mu}_{\mathbf{m}}\left(\mathbf{d}^{-\mathbf{1}}\right)$} & 3,7 & LAWRENCE et al., (1970) apud BAILEY E OLLIS, (1977). \\
\cline { 2 - 3 } & $2,4-7,2$ & HORAN (1990). \\
\cline { 2 - 3 } & $1,5-5,0$ & METCALF e EDDY (2003) \\
\hline $\mathbf{r}_{\text {máx }}$ & 20 & DOLD et al., (1980) apud VAN HAANDEL (2006). \\
$\left(\mathbf{m g D Q O . L ^ { - 1 } )}\right.$ & $5,0-40,0$ & METCALF e EDDY (2003) \\
\hline $\mathbf{K}_{\mathbf{s}}$ & 5 & DOLD et al., (1980) apud VAN HAANDEL (2006). \\
\cline { 2 - 3 }$\left(\mathbf{m g D Q O . L ^ { - 1 } )}\right.$ & $1,0-5,0$ & METCALF E EDDY (2003) \\
\hline
\end{tabular}

Fonte: adaptado de (VAN HAANDEL e MARAIS, 1999; METCALF e EDDY, 2003).

\subsection{Remoção de nitrogênio no processo de lodo ativado}

\subsubsection{Balanço de Massa de Material Nitrogenado}

$\mathrm{O}$ balanço de massa do material nitrogenado $\left(\mathrm{B}_{\mathrm{n}}\right)$ permite avaliar os procedimentos analíticos utilizados para determinar as diversas formas de nitrogênio, e assegurar a quantificação das frações de nitrogênio presentes em sistemas de lodo ativado. Segundo VAN HAANDEL e MARAIS (1999), as frações nitrogenadas deixam o sistema de lodo ativado sob três formas: como material sólido no lodo de excesso, como material dissolvido no efluente ou como nitrogênio gasoso para a atmosfera. A Equação 2.6 apresenta o cálculo típico do balanço de massa nitrogenado.

$\mathrm{B}_{\mathrm{n}}=\left(\mathrm{MN}_{\mathrm{l}}+\mathrm{MN}_{\mathrm{te}}+\mathrm{MN}_{\mathrm{d}}\right) / \mathrm{MN}_{\mathrm{ta}}$

(Equação 2.6)

Sendo:

$\mathrm{B}_{\mathrm{n}}$ : balanço de massa de material nitrogenado $\left(\mathrm{mgN} \cdot \mathrm{d}^{-1}\right)$

$\mathrm{MN}_{\mathrm{l}}$ : fluxo de nitrogênio descarregado no lodo de excesso $\left(\mathrm{mgN} \cdot \mathrm{d}^{-1}\right)$

$\mathrm{MN}_{\mathrm{te}}$ : fluxo de nitrogênio descarregado no efluente $\left(\mathrm{mgN} \cdot \mathrm{d}^{-1}\right)$

$\mathrm{MN}_{\mathrm{d}}$ : fluxo de nitrogênio utilizado na desnitrificação $\left(\mathrm{mgN} \cdot \mathrm{d}^{-1}\right)$

$\mathrm{MN}_{\mathrm{ta}}$ : fluxo de nitrogênio afluente $\left(\mathrm{mgN} \cdot \mathrm{d}^{-1}\right)$

\subsubsection{Forma e reações de material nitrogenado}

O material nitrogenado em águas residuárias se compõe principalmente de nitrogênio amoniacal (gasoso, $\mathrm{NH}_{3}^{-}$, e salino, $\mathrm{NH}_{4}^{+}$) e nitrogênio orgânico (uréia, aminoácidos e outras substâncias orgânicas como o grupo amino). Ocasionalmente ocorrem traços de formas oxidadas do 
nitrogênio, nitrito $\left(\mathrm{NO}_{2}^{-}\right)$e nitrato $\left(\mathrm{NO}_{3}^{-}\right)$, a Figura 2.2 mostra de forma esquemática as frações e possíveis reações do material nitrogenado no sistema de lodo ativado. No caso do material nitrogenado, o parâmetro adequado para quantifica-lo é bem definido: deve-se determinar a concentração do nitrogênio nas suas diferentes formas. Na prática usam-se testes titulométricos, espectrofotométricos, eletrodos específicos ou cromatografia iônica para determinar as concentrações de amônia, nitrito e nitrato. O nitrogênio orgânico pode ser determinado após a sua conversão química para amônia (digestão). A soma da concentração de nitrogênio orgânico e amoniacal é chamada de NKT - nitrogênio total kjeldahl (VAN HAANDEL e MARAIS, 1999).

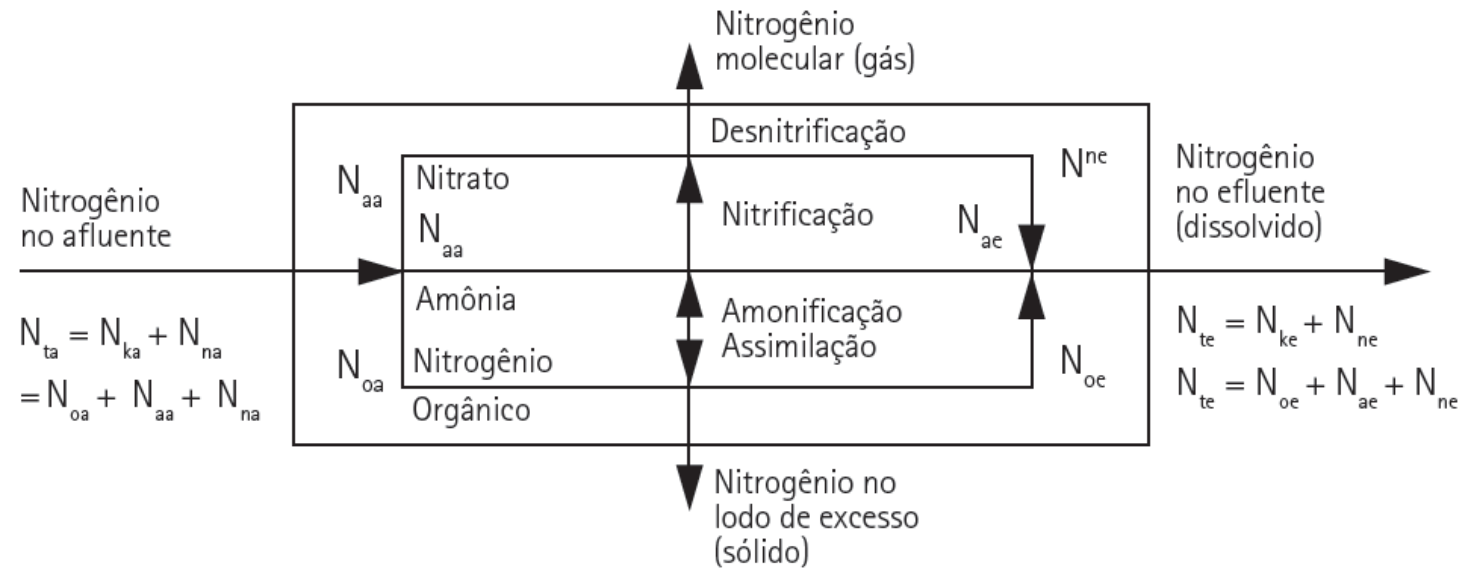

Figura 2.2: Representação esquemática das formas e das possíveis reações do material nitrogenado no sistema de lodo ativado. Fonte: (VAN HAANDEL e MARAIS 1999).

\subsubsection{Amonificação e assimilação}

Dependendo do processo de tratamento de esgotos, podem ocorrer várias reações que mudam a forma do material nitrogenado: amonificação (ou, o inverso: assimilação de amônia); nitrificação e desnitrificação (Figura 2.2). Na reação de amonificação, o nitrogênio orgânico é convertido em nitrogênio amoniacal. Na assimilação, o processo inverso ocorre (a amônia é incorporada à biomassa, estando presente, portanto, na forma de nitrogênio orgânico). Levandose em consideração que o nitrogênio amoniacal, a um pH perto do valor neutro, terá, predominantemente, a forma salina ionizada $\left(\mathrm{NH}_{4}^{+}\right)$, pode-se escrever: 


$$
\mathrm{R}-\mathrm{NH}_{2}+\underset{\text { Assimilação }}{\stackrel{\text { Amonificação }}{\stackrel{\mathrm{H}_{2} \mathrm{O}+\mathrm{H}^{+} \leftarrow \rightarrow \mathrm{R}-\mathrm{OH}}{\rightleftarrows}}}+\mathrm{NH}_{4}^{+}
$$

(Equação 2.7)

\subsubsection{Processo de nitrificação}

A nitrificação é a oxidação biológica da amônia, tendo como produto final o nitrato. A reação requer a mediação de bactérias especificas e se realiza em dois passos sequencias. No primeiro passo, a amônia é oxidada para nitrito (nitritação) através da ação bioquímica das bactérias como as do gênero Nitrossomonas. No seguinte passo, a oxidação de nitrito para nitrato (nitratação) é mediada por bactérias como as do gênero Nitrobacter. Ambos os gêneros Nitrossomonas e Nitrobacter somente desenvolvem atividade bioquímica na presença de oxigênio dissolvido (OD), isto é, são aeróbios obrigatórios. Ambos os passos podem ser escritos como:

$\mathrm{NH}_{4}^{+}+3 / 2 \mathrm{O}_{2} \rightarrow \mathrm{NO}_{2}^{-}+\mathrm{H}_{2} \mathrm{O}+2 \mathrm{H}^{+}$

$\mathrm{NO}_{2}^{-}+1 / 2 \mathrm{O}_{2} \rightarrow \mathrm{NO}_{3}^{-}+$

(Equação 2.8)

$\mathrm{NH}_{4}^{+}+2 \mathrm{O}_{2} \rightarrow \mathrm{NO}_{3}^{-}+\mathrm{H}_{2} \mathrm{O}+2 \mathrm{H}^{+}$

Em temperaturas baixas $\left(<20^{\circ} \mathrm{C}\right)$, a nitratação é muito mais rápida que a nitritação, de modo que se pode considerar que a nitratação é imediata e a acumulação de nitrito sempre será muito pequena em sistemas sob condições estacionárias. Em contraste, em temperaturas elevadas (> $25^{\circ} \mathrm{C}$ ) a nitritação é mais rápida que a nitratação, e por esta razão pode haver acumulação de nitrito quando se cria condições adequadas (VAN HAANDEL e MARAIS 1999). A Figura 2.3 mostra a demanda de oxigênio na nitrificação (nitritação e nitratação) e a demanda de material orgânico na desnitrificação.
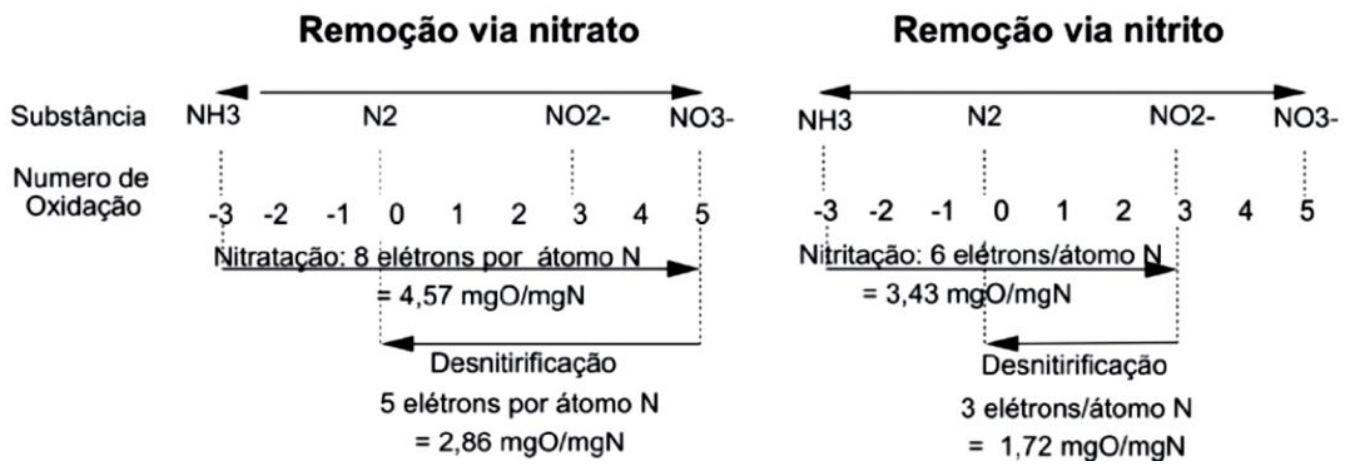

Figura 2.3: Variação do número de oxidação de nitrogênio nos processos de nitrificação e desnitrificação. Fonte: (VAN HAANDEL e MARAIS 1999). 


\subsubsection{Fatores intervenientes no processo da nitrificação}

As bactérias nitrificantes são bastante sensíveis a fatores ambientais e operacionais que podem influenciar diretamente em seu metabolismo de forma a interferir na taxa de crescimento e, como consequência, a taxa de oxidação da amônia. Como exemplo desses fatores tem-se a temperatura, o pH, a concentração de oxigênio dissolvido e à presença de substâncias tóxicas ou inibidoras, que exercem influência direta sobre o crescimento das bactérias, conforme já comprovado por vários pesquisadores (DOWNING et al., 1964; BARNES e BLISS, 1983 apud VON SPERLING, 2002; VAN HAANDEL e MARAIS, 1999; SEDLAK, 1991 apud METCALF e EDDY, 2003).

\subsubsection{Efeito da temperatura}

A temperatura é um fator de grande influência sobre a taxa de crescimento máxima dos organismos nitrificantes $\left(\mu_{\text {máx }}\right)$. Segundo DOWNING (1978), o efeito da temperatura pode ser descrito por:

$\mu_{\operatorname{máx}(\mathrm{T})}=\mu_{\operatorname{máx}\left(20^{\circ} \mathrm{C}\right)} \cdot \theta^{(\mathrm{T}-20)}$

onde:

$\mu_{\operatorname{máx}(\mathrm{T})}$ : taxa de crescimento máxima a uma temperatura $\mathrm{T}\left(\mathrm{d}^{-1}\right)$

$\theta$ : coeficiente de temperatura

T: temperatura $\left({ }^{\circ} \mathrm{C}\right)$

O coeficiente de temperatura $\theta$ é reportado numa faixa de 1,08 a 1,13 , sendo que o valor de 1,10, suportado por um grande número de dados, afigura-se como razoável (BARNES e BLISS, 1983 apud VON SPERLING, 2002 e VAN HAANDEL \& MARAIS, 1999). Segundo VON SPERLING (2002) para cada acréscimo de aproximadamente $7^{\circ} \mathrm{C}$ na temperatura, a taxa de crescimento dobra e, inversamente, cada queda de $7^{\circ} \mathrm{C}$ implica na redução da taxa de crescimento à metade. Os coeficientes de saturação $K_{N}$ e $K_{O}$ aumentam também com o acréscimo da temperatura, embora não haja consistência nos dados disponíveis na literatura. Estudos realizados por ARCEIVALA, 1981 e BARNES e BLISS, 1983 apud VON SPERLING, 2002, relatam a ocorrência da nitrificação numa faixa de 5 a $50^{\circ} \mathrm{C}$, mas a temperatura ótima encontra-se na ordem de 25 a $36^{\circ} \mathrm{C}$. 


\subsubsection{Efeito do $\mathrm{pH}$}

Segundo DOWNING (1978), o pH do licor misto tem importante efeito sobre a taxa de nitrificação, apresentando o seu ótimo e aproximadamente constante na faixa de $\mathrm{pH}$ de 7,2 a 8,0. Abaixo de 7,2, $\mu_{\text {máx }}$ decresce com o pH segundo a seguinte relação:

$\mu_{\text {máx }(\mathrm{pH})}=\mu_{\text {máx }}[1-0,83(7,2-\mathrm{pH})]$

onde:

$\mu_{\text {máx }(\mathrm{pH})}$ : taxa de crescimento máxima das bactérias nitrificantes para um dado $\mathrm{pH}\left(\mathrm{d}^{-1}\right)$

$\mu_{\text {máx }}$ t taxa de crescimento máxima das bactérias nitrificantes no $\mathrm{pH}$ de $7,2\left(\mathrm{~d}^{-1}\right)$

Segundo estudos (EPA,1993), a equação 2.10 tem a faixa de validade do $\mathrm{pH}$ de 6,0 a 7,2. Para a estabilidade do desempenho, é desejável manter-se o pH na faixa de 6,5 a 8,0. É importante saber que a própria nitrificação é responsável pelo decréscimo de $\mathrm{pH}$, gerando como produto final $\mathrm{H}^{+}$. O decréscimo do $\mathrm{pH}$ é função da capacidade tampão do meio ou, em outras palavras da sua alcalinidade. Segundo VAN HAANDEL e MARAIS (1999) para concentrações de alcalinidade total acima de $35 \mathrm{ppmCaCO}_{3}$ o $\mathrm{pH}$ não varia consideravelmente. No entanto, para alcalinidades abaixo dessa concentração há variações do $\mathrm{pH}$ com a alcalinidade, podendo acarretar prejuízos à estação de tratamento de esgoto (ETE) caso esse $\mathrm{pH}$ atinja valores extremos (muito ácido ou muito alcalino) danificando a massa biológica responsável pelo tratamento. As relações estequiométricas de alcalinidade envolvidas no processo de nitrificação são apresentadas na seção 2.5 .

\subsubsection{Efeito da Concentração de Oxigênio Dissolvido}

O oxigênio dissolvido no tanque de aeração é um pré-requisito indispensável para ocorrência da nitrificação e tem sido objeto de várias pesquisas e estudos ao longo dos anos. Afigura-se que a concentração de OD critica, a qual a nitrificação não se processa, encontra-se em torno de 0,2 mg.L - $^{-1}$ (BARNES e BLISS, 1983 apud VON SPERLING, 2002). Segundo DOWNING (1978) a concentração de OD crítica é em torno de $0,5 \mathrm{mg} \cdot \mathrm{L}^{-1}$, já a e recomendação da EPA, (1993), é que a concentração de OD mínimo seja de $2,0 \mathrm{mg} . \mathrm{L}^{-1}$, de forma a evitar problemas com os picos de amônia afluente. No entanto, pesquisas recentes com diferentes arranjos nos sistemas de lodo ativado, confirmam que é possível obter eficiências elevadas na nitrificação, com baixas concentrações de OD, normalmente na faixa de $0,3-0,8 \mathrm{mg} \cdot \mathrm{L}^{-1}$, que é o caso desta pesquisa. Isso 
é possível, devido a um maior conhecimento do controle de ar injetado nos tanques de aeração, bem como o desenvolvimento da tecnologia de sensores (TRIVEDI e HEINEN, 2000 apud METCALF \& EDDY, 2003; ZENG et al, 2003; WANG, B. et al., 2005; YING-CHIH CHIU et $a l$, 2006; PENG ZHANG e ZHOU QI, 2007; DAVID THAURÉ et al, 2008. SEUNG H. BAEK e KRISHNA R. PAGILLA, 2008; WANG JIANLONG et al, 2008; X. CHEN et al, 2010). O efeito da concentração de OD sobre a taxa de crescimento pode ser representado também pela cinética de Monod, da seguinte forma:

$\mu=\mu_{\text {máx }} *\left[\mathrm{OD} / \mathrm{K}_{\mathrm{O}}+\mathrm{OD}\right]$

onde:

OD: oxigênio dissolvido no tanque de aeração $\left(\mathrm{mg} . \mathrm{L}^{-1}\right)$

$\mathrm{K}_{\mathrm{O}}$ : coeficiente de saturação para o oxigênio $\left(\mathrm{mg} \cdot \mathrm{L}^{-1}\right)$

\subsubsection{Cinética da nitrificação no sistema de lodo ativado}

A nitrificação se desenvolve em dois passos sequenciais, mas geralmente se considera somente o primeiro passo (oxidação de amônia para nitrito), que tem maior importância para a cinética do processo. Quando à população de nitrificadores está bem estabelecida, o segundo passo, a oxidação de nitrito para nitrato, desenvolve-se tão rapidamente, que, para efeitos práticos, pode ser considerada instantânea. DOWNING et al (1964) foram os primeiros a mostrar que o crescimento de Nitrossomonas na oxidação de amônia para nitrito pode ser descrito adequadamente com auxilio da equação de Monod:

$\left(\mathrm{dX}_{\mathrm{n}} / \mathrm{d}_{\mathrm{t}}\right)=\left(\mathrm{dX} \mathrm{X}_{\mathrm{n}} / \mathrm{dt}\right)_{\mathrm{c}}+\left(\mathrm{dX} \mathrm{X}_{\mathrm{n}} / \mathrm{dt}\right)_{\mathrm{d}}$

Com: $\left(\mathrm{dX}_{\mathrm{n}} / \mathrm{dt}\right)_{\mathrm{c}}=\mu \mathrm{X}_{\mathrm{n}}=\mu_{\mathrm{m}} \mathrm{X}_{\mathrm{n}} \cdot \mathrm{N}_{\mathrm{a}} /\left(\mathrm{N}_{\mathrm{a}}+\mathrm{K}_{\mathrm{n}}\right) \quad$ e $\quad\left(\mathrm{dX}_{\mathrm{n}} / \mathrm{dt}\right)_{\mathrm{d}}=-\mathrm{b}_{\mathrm{n}} \mathrm{X}_{\mathrm{n}}$

Onde:

$\mathrm{X}_{\mathrm{n}}$ : concentração de Nitrossomonas (mgSVS.L $\left.\mathrm{L}^{-1}\right)$

$(\mathrm{dX} / \mathrm{nt})$ : taxa de variação da concentração de Nitrossomonas $\left(\operatorname{mgSVS} . \mathrm{L}^{-1} . \mathrm{d}^{-1}\right) /$ taxa de crescimento líquido

$(\mathrm{dX} / \mathrm{nt})_{\mathrm{c}}$ : taxa de crescimento de Nitrossomonas $\left(\mathrm{mgSVS} . \mathrm{L}^{-1} \cdot \mathrm{d}^{-1}\right) /$ taxa de crescimento bruto

$\left(\mathrm{dX}_{\mathrm{n}} / \mathrm{dt}\right)_{\mathrm{d}}$ : taxa de decaimento de Nitrossomonas $\left(\mathrm{mgSVS} . \mathrm{L}^{-1} \cdot \mathrm{d}^{-1}\right)$

$\mu$ : taxa específica de crescimento de Nitrossomonas $\left(\mathrm{d}^{-1}\right)$

$\mu_{\mathrm{m}}$ : taxa específica máxima de crescimento de Nitrossomonas $\left(\mathrm{d}^{-1}\right)$

$\mathrm{b}_{\mathrm{n}}$ : constante de decaimento de Nitrossomonas $\left(\mathrm{d}^{-1}\right)$

$\mathrm{k}_{\mathrm{n}}$ : constante de meia saturação de $\operatorname{Monod}\left(\mathrm{mgN} \cdot \mathrm{L}^{-1}\right)$ 
Na equação de MONOD, a constante $\mu$ representa o crescimento bruto dos microrganismos por unidade de tempo. Assim, um valor $\mu=0,6 \mathrm{~d}^{-1}$ significa que a massa de microrganismos sintetizada tem uma taxa de $60 \%$ ao dia. Como a taxa de crescimento é exponencial, quando não há limitação de substrato, o crescimento em um dia seria $\mathrm{N}_{1} / \mathrm{N}_{0}=\exp \left(0,6^{*} 1\right)=1,81$, ou seja, a massa pode aumentar em um dia até um fator 1,81 ou $81 \%$. A equação 6.13 mostra que o valor de $\mu$ depende da concentração do substrato $\left(\mathrm{N}_{\mathrm{a}}\right)$, sendo que para uma concentração alta (saturação) se atinge o valor $\mu_{\mathrm{m}}$. A constante $\mathrm{K}_{\mathrm{n}}$ é igual à concentração do substrato quando $\mu=$ $1 / 2 \mu_{\mathrm{m}}$ e por esta razão é chamada de constante de meia saturação. Para calcular a concentração residual de amônia em um sistema de lodo ativado completamente misturado e operado sob condições estacionárias, usa-se a equação básica de DOWNING et al (1964). Nessas condições, não há variação de massa de Nitrossomonas: a taxa de crescimento líquida (que é igual a taxa de crescimento bruto menos a taxa de decaimento de Nitrossomonas) é igual à taxa de descarga de lodo de excesso (supõe-se que o lodo seja retirado continuamente do reator biológico). Portanto:

$\left(\left(\mathrm{dX}_{\mathrm{n}} / \mathrm{d}_{\mathrm{t}}\right)=0=\left(\mathrm{dX} \mathrm{X}_{\mathrm{n}} / \mathrm{dt}\right)_{\mathrm{c}}+\left(\mathrm{dX} \mathrm{X}_{\mathrm{n}} / \mathrm{dt}\right)_{\mathrm{d}}+\left(\mathrm{dX} \mathrm{X}_{\mathrm{n}} / \mathrm{dt}\right)_{\mathrm{e}}\right.$

(Equação 2.13)

A taxa de variação da concentração de Nitrossomonas devido à descarga de lodo $\left(\mathrm{dX}_{\mathrm{n}} / \mathrm{dt}\right)_{\mathrm{e}}$, pode ser expressa como:

$\left(\mathrm{d} \mathrm{X}_{\mathrm{n}} / \mathrm{dt}\right)_{\mathrm{e}}=-\mathrm{X}_{\mathrm{n}} / \mathrm{R}_{\mathrm{s}}$

Usando-se as Equações 2.12 e 2.14 na Equação 2.13, tem-se:

$\left(\mathrm{d} X_{\mathrm{n}} / \mathrm{dt}\right)=0=\mu_{\mathrm{m}} \mathrm{X}_{\mathrm{n}} \mathrm{N}_{\mathrm{a}} /\left(\mathrm{N}_{\mathrm{a}}+\mathrm{K}_{\mathrm{n}}\right)-\mathrm{b}_{\mathrm{n}} \mathrm{X}_{\mathrm{n}}-\mathrm{X}_{\mathrm{n}} / \mathrm{R}_{\mathrm{s}}=\mu_{\mathrm{m}} \cdot \mathrm{N}_{\mathrm{a}} /\left(\mathrm{N}_{\mathrm{a}}+\mathrm{K}_{\mathrm{n}}\right)-\mathrm{b}_{\mathrm{n}}-1 / \mathrm{R}_{\mathrm{s}}$

(Equação 2.15)

Ou, rearranjando:

$N_{a}=K_{n}\left(b_{n}+1 / R_{s}\right) /\left[\mu_{m}-\left(b_{n}+1 / R_{s}\right)\right]$

(Equação 2.16)

A Equação 2.16 dá o valor da concentração de amônia no licor misto, em um sistema de lodo ativado completamente misturado, e, portanto, também no efluente. Essa concentração residual, que é indicativa para a eficiência da nitrificação, depende das três constantes cinéticas $\mu_{\mathrm{m}}, \mathrm{K}_{\mathrm{n}} \mathrm{e}$ $b_{n}$ e de uma variável do processo: a idade de lodo $R_{s}$. É notável que a concentração residual não dependa da sua concentração inicial. Naturalmente, a concentração residual de amônia nunca pode ser superior à concentração no afluente de amônia disponível para nitrificação. Esta condição define uma idade de lodo mínima expressa como:

$\mathrm{N}_{\mathrm{a}}<<\mathrm{N}_{\mathrm{p}}=\mathrm{K}_{\mathrm{n}}\left(\mathrm{b}_{\mathrm{n}}+1 / \mathrm{R}_{\mathrm{sn}}\right) /\left(\mu_{\mathrm{m}}-\mathrm{b}_{\mathrm{n}}-1 / \mathrm{R}_{\mathrm{sn}}\right)$

(Equação 2.17)

ou

$\mathrm{R}_{\mathrm{sn}}=\left(1+\mathrm{K}_{\mathrm{n}} / \mathrm{N}_{\mathrm{p}}\right) /\left[\mu_{\mathrm{m}}-\mathrm{b}_{\mathrm{n}}\left(1+\mathrm{K}_{\mathrm{n}} / \mathrm{N}_{\mathrm{p}}\right)\right]$ 
Onde:

Np: concentração de amônia disponível para nitrificação (mg. $\left.\mathrm{L}^{-1}\right)$.

Para águas residuárias municipais a concentração de amônia disponível para nitrificação é sempre muito maior que $K_{n}$. Nesse caso, a razão $K n / N_{p}$ é $<<1$ e a (Equação 2.17) se simplifica para:

$\mathrm{R}_{\mathrm{sn}}=1 /\left(\mu_{\mathrm{m}}-\mathrm{b}_{\mathrm{n}}\right)$

(Equação 2.18)

A Equação 2.18 expressa que, até uma idade de lodo $R_{s n}=1 /\left(\mu_{m}-b_{n}\right)$, a nitrificação não se desenvolve porque a taxa de retirada de Nitrossomonas é maior que a taxa máxima de crescimento líquido. Para idades de lodo superiores à mínima $\mathrm{R}_{\mathrm{sn}}$ a nitrificação desenvolver-se-á e a sua eficiência dependerá da idade de lodo e dos valores das constantes $K_{n}, \mu_{m}$ e $b_{n}$.

Após o trabalho pioneiro de DOWNING, vários pesquisadores realizaram investigações experimentais para determinar as constantes cinéticas de nitrificação no sistema de lodo ativado. VAN HAANDEL E MARAIS (1999), analisando a influência de diferentes valores das constantes de nitrificação sobre a eficiência de oxidação de amônia em sistemas de lodo ativado, concluíram três aspectos: O primeiro é que a faixa de variação das constantes de decaimento e de meia saturação $\left(0<b_{n}<0,1 d^{-1}\right.$ e $\left.0<K_{n}<2 \mathrm{mg} \cdot \mathrm{L}^{-1}\right)$ tem, relativamente, pouca importância sobre a nitrificação. Para efeitos práticos podem ser considerados $b_{n}=0,04(1,123)^{(t-20)}$ e $K_{n}=$ $1,0(1,123)^{(t-20)}$. Na Tabela 2.4 e 2.5 se observam os valores típicos das constantes de decaimento $\left(b_{n}\right)$ e das constantes de meia saturação de amônia na equação de Monod para o crescimento de Nitrossomonas $\left(\mathrm{K}_{\mathrm{n}}\right)$.

Tabela 2.4: Valores de referência das constantes de decaimento de Nitrossomonas $\left(\mathrm{b}_{\mathrm{n}}\right)$

\begin{tabular}{cccc}
\hline \multicolumn{4}{c}{ Constante de decaimento de Nitrossomonas $\left(\mathbf{b}_{\mathbf{n}}\right)$} \\
\hline $\mathbf{b}_{\mathbf{n T}}\left(\mathbf{d}^{\mathbf{- 1}}\right)$ & $\mathbf{T}\left({ }^{\mathbf{0}} \mathbf{C}\right)$ & $\mathbf{b}_{\mathbf{n 2 0}}\left(\mathbf{d}^{-\mathbf{1}}\right)$ & Referência \\
\hline 0,0 & 20 & 0,0 & DOWNING et al, (1964) \\
\hline 0,0 & 15 & 0,0 & DOWNING et al, (1964) \\
\hline 0,0 & 10 & 0,0 & GUJER (1979) \\
\hline 0,04 & 20 & 0,04 & EKAMA \& MARAIS (1976) \\
\hline 0,12 & 29 & 0,09 & LIJKELMA (1973) \\
\hline 0,12 & 23 & 0,11 & PODUSKA \& ANDREWS (1974) \\
\hline- & 20 & $0,05-0,15$ & METCALF E EDDY (2003)
\end{tabular}

Fonte: adaptado de (VAN HAANDEL e MARAIS, 1999) e (METCALF E EDDY, 2003). 
Tabela 2.5: Valores das constantes de meia saturação de amônia para as Nitrossomonas $\left(\mathrm{K}_{\mathrm{n}}\right)$

Constante de meia saturação de amônia para o crescimento de Nitrossomonas $\left(K_{n}\right)$

\begin{tabular}{cccc}
\hline $\mathbf{K}_{\mathbf{n T}}\left(\mathbf{d}^{\mathbf{1}}\right)$ & $\left.\mathbf{T} \mathbf{~}^{\mathbf{0}} \mathbf{C}\right)$ & $\mathbf{K}_{\mathbf{n 2 0}}\left(\mathbf{d}^{\mathbf{- 1}}\right)$ & Referência \\
\hline 0,0 & 23 & 0,04 & PODUSKA \& ANDREWS (1974) \\
\hline 0,2 & 15 & 0,1 & DOWNING et al, (1964) \\
\hline 0,2 & 20 & 0,2 & DOWNING et al, (1964) \\
\hline 0,2 & 10 & 0,6 & GUJER (1979) \\
\hline 0,5 & 14 & 1,0 & EKAMA \& MARAIS (1976) \\
\hline 1,0 & 20 & 1,0 & EKAMA \& MARAIS (1976) \\
\hline 1,0 & 20 & 1,0 & LIJKELMA (1973) \\
\hline- & - & $0,5-1,0$ & METCALF E EDDY (2003)
\end{tabular}

Fonte: adaptado de (VAN HAANDEL e MARAIS, 1999) e (METCALF E EDDY, 2003).

Em segundo lugar, em contraste, a influência do valor da constante de crescimento máximo de nitrificantes $\mu_{\mathrm{m}}$ sobre a idade de lodo mínima de nitrificação é muito grande e idealmente deve ser determinada antes que se faça o projeto do sistema de tratamento. Geralmente, porém, não se dispõe da água residuária quando se faz o sistema de tratamento e, neste caso, pode se adotar como valor estimado $\mu_{\mathrm{m} 20}=0,4 \mathrm{~d}^{-1}$. Por fim, tendo em vista que a idade mínima de lodo depende, principalmente, do valor de $\mu_{\mathrm{m}}$, torna-se necessário analisar por que razões há uma variação tão grande nos valores dessa constante. Os valores que influenciam o valor $\mu_{\mathrm{m}}$ podem ser divididos em duas categorias: fatores relacionados com a origem ou a natureza da água residuária e fatores que se referem às condições operacionais prevalecentes no sistema de tratamento. Referente às condições operacionais do sistema de lodo ativado, pode-se distinguir os seguintes fatores que influenciam o valor de $\mu_{\mathrm{m}}$ : temperatura; concentração de oxigênio dissolvido; pH do licor misto; nitrificação em sistemas com zonas não aeradas. Na Tabela 2.6, podem-se observar os valores típicos das constantes de crescimento específico máximo de Nitrossomonas $\left(\mu_{\mathrm{m}}\right)$.

Tabela 2.6: Valores das constantes de crescimento específico máximo de Nitrossomonas $\left(\mu_{\mathrm{m}}\right)$.

\begin{tabular}{cccc}
\hline \multicolumn{4}{c}{ Constantes de crescimento específico máximo de Nitrossomonas $\left(\boldsymbol{\mu}_{\mathbf{m}}\right)$} \\
\hline $\boldsymbol{\mu}_{\mathbf{m T}}\left(\mathbf{d}^{-1}\right)$ & $\mathbf{T}\left({ }^{\mathbf{C}} \mathbf{C}\right)$ & $\boldsymbol{\mu}_{\mathbf{m} \mathbf{2 0}}\left(\mathbf{d}^{-1}\right)$ & Referências \\
\hline 0,33 & 15 & 0,66 & BARNARD $(1991)$ \\
\hline 0,47 & 15 & 0,45 & KAYSER (1991) \\
\hline 0,45 & 15 & 0,73 & ECKENFELDER (1992) \\
\hline 0,53 & 25 & 0,26 & SUTTON et al, $(1979)$ \\
\hline $0,40-0,50$ & 14 & $0,80-1,00$ & GUJER (1977) \\
\hline $0,33-0,65$ & 20 & $0,33-0,65$ & EKAMA \& MARAIS (1976) \\
\hline $1,08-1,44$ & 23 & $0,75-1,02$ & PODUSKA \& ANDREWS (1974) \\
\hline 0,57 & 16 & 0,76 & GUJER \& JENKINS (1975) \\
\hline $0,34-0,40$ & 12 & $0,86-1,01$ & GUJER \& JENKINS (1975) \\
\hline 0,50 & 20 & 0,50 & LAWRENCE \& BROWN $(1973)$ \\
\hline 0,94 & 29 & 0,33 & LIJKELMA (1973) \\
\hline 0,33 & 20 & 0,33 & DOWNING et al, $(1964)$ \\
\hline- & - & $0,20-0,90$ & METCALF E EDDY (2003)
\end{tabular}

Fonte: adaptado de (VAN HAANDEL e MARAIS, 1999; METCALF e EDDY, 2003). 


\subsection{Processo de desnitrificação}

A desnitrificação é a redução biológica de nitrato para nitrogênio molecular, tendo-se material orgânico como redutor. Admitindo-se uma fórmula geral estrutural $\mathrm{C}_{\mathrm{X}} \mathrm{H}_{\mathrm{Y}} \mathrm{O}_{\mathrm{Z}}$ para material orgânico, então as reações de redução e de oxidação podem ser escritas como:

Oxidação:

(Equação 2.19)

$\mathrm{C}_{\mathrm{X}} \mathrm{H}_{\mathrm{Y}} \mathrm{O}_{\mathrm{Z}}+(2 \mathrm{x}-\mathrm{z}) \mathrm{H}_{2} \mathrm{O} \rightarrow \mathrm{xCO}_{2}+(4 \mathrm{x}+\mathrm{y}-2 \mathrm{z}) \mathrm{H}^{+}+(4 \mathrm{x}+\mathrm{y}-2 \mathrm{z}) \mathrm{e}$

Ou:

$1 /(4 x+y-2 z) \mathrm{C}_{\mathrm{X}} \mathrm{H}_{\mathrm{Y}} \mathrm{O}_{\mathrm{Z}}+(2 \mathrm{x}-\mathrm{z}) /(4 \mathrm{x}+\mathrm{y}-2 \mathrm{z}) \mathrm{H}_{2} \mathrm{O} \rightarrow 1 /(4 \mathrm{x}+\mathrm{y}-2 \mathrm{z}) \mathrm{CO}_{2}+\mathrm{H}^{+}+\mathrm{e}$

Redução no caso de nitrato:

(Equação 2.20)

$\mathrm{e}+6 / 5 \mathrm{H}^{+}+1 / 5 \mathrm{NO}_{3}^{-} \rightarrow 1 / 10 \mathrm{~N}_{2}+1 / 5 \mathrm{H}_{2} \mathrm{O}$

Redox:

$1 /(4 \mathrm{x}+\mathrm{y}-2 \mathrm{z}) \mathrm{C}_{\mathrm{X}} \mathrm{H}_{\mathrm{Y}} \mathrm{O}_{\mathrm{Z}}+1 / 5 \mathrm{H}^{+}+1 / 5 \mathrm{NO}_{3}^{-}$

$\rightarrow \mathrm{x} /(4 \mathrm{x}+\mathrm{y}-2 \mathrm{z}) \mathrm{CO}_{2}+1 / 10 \mathrm{~N}_{2}+1 / 5^{*}(2 \mathrm{x}+3 \mathrm{y}-\mathrm{z}) /(4 \mathrm{x}+\mathrm{y}-2 \mathrm{z}) \mathrm{H}_{2} \mathrm{O}$

$\mathrm{Ou}:$

$\mathrm{C}_{\mathrm{X}} \mathrm{H}_{\mathrm{Y}} \mathrm{O}_{\mathrm{Z}}+(4 \mathrm{x}+\mathrm{y}-2 \mathrm{z}) / 5 \mathrm{H}^{+}+(4 \mathrm{x}+\mathrm{y}-2 \mathrm{z}) / 5 \mathrm{NO}_{3}^{-}$

$\rightarrow \mathrm{x} \mathrm{CO}+1 / 5(2 \mathrm{x}+3 \mathrm{y}-2 \mathrm{z}) \mathrm{H}_{2} \mathrm{O}+1 / 10(4 \mathrm{x}+\mathrm{y}-2 \mathrm{z}) \mathrm{N}_{2}$

Redução no caso de nitrito:

(Equação 2.21)

Nitrito: e $+4 / 3 \mathrm{H}^{+}+1 / 3 \mathrm{NO}_{2}^{-} \rightarrow 1 / 6 \mathrm{~N}_{2}+2 / 3 \mathrm{H}_{2} \mathrm{O}$

Redox:

$1 / 3 \mathrm{H}^{+}+1 / 3 \mathrm{NO}_{2}^{-}+1 /(4 \mathrm{x}+\mathrm{y}-2 \mathrm{z}) \mathrm{C}_{\mathrm{X}} \mathrm{H}_{\mathrm{Y}} \mathrm{O}_{\mathrm{Z}}+(2 \mathrm{x}-\mathrm{z}) /(4 \mathrm{x}+\mathrm{y}-2 \mathrm{z}) \mathrm{H}_{2} \mathrm{O}$

$\rightarrow \mathrm{x} /(4 \mathrm{x}+\mathrm{y}-2 \mathrm{z}) \mathrm{CO}_{2}+1 / 6 \mathrm{~N}_{2}+2 / 3 \mathrm{H}_{2} \mathrm{O}$

Tanto as Equações 2.20 e 2.21 como a Figura 2.3 mostram claramente que, em principio, há uma grande vantagem em usar a nitritação em vez da nitratação como caminho para remoção de nitrogênio - no caso de nitritação a demanda de oxigênio é $25 \%$ menor que no caso de nitratação. Por outro lado, na desnitrificação, a demanda de material orgânico no caso de redução de nitrito é somente $3 / 5$ ou $60 \%$ da demanda no caso da redução de nitrato. Estudos realizados por VAN HAANDEL, et al., 2009 In: PROSAB - Livro 2, Capítulo 6, evidenciaram experimentalmente que a taxa de utilização de nitrito é muito menor que a taxa de utilização de nitrato - o que reduz sensivelmente a vantagem de se produzir nitrito. Outro problema é que somente é possível parar a nitrificação em nitrito quando as condições são favoráveis: temperaturas acima de $25^{\circ} \mathrm{C}$ a $30^{\circ} \mathrm{C}$. Por esta razão, em sistemas convencionais, normalmente, tem-se a nitrificação para nitrato como primeiro passo na remoção de nitrogênio. 
Numericamente, no caso de esgoto sanitário, a concentração do NKT no afluente geralmente é de 40 a $60 \mathrm{mgN} \cdot \mathrm{L}^{-1}$, ou seja, uma fração na faixa de 0,08 a 0,12 da DQO afluente. Desta concentração total, em torno de 75 por cento é nitrogênio amoniacal e 25 por cento é nitrogênio orgânico. Nos processos de tratamento biológico dos esgotos, o nitrogênio orgânico é rapidamente, e quase quantitativamente, convertido em nitrogênio amoniacal (amonificação). Se a nitrificação ocorre, e se houver capacidade de oxigenação suficiente, então também o processo de oxidação da amônia é quase completo, deixando uma baixa concentração de nitrogênio amoniacal. Se depois da nitrificação o processo de desnitrificação se desenvolve eficientemente, o teor de nitrogênio dissolvido no efluente final será baixo, menos que $5 \mathrm{mg} / \mathrm{L}$, sendo possível observar uma eficiência de remoção de 90 a 95 por cento do nitrogênio no efluente, por exemplo, no caso do processo de lodos ativados. A eficiência da desnitrificação depende acentuadamente da disponibilidade de material orgânico para redução de nitrato (ou nitrito) e da temperatura (que influi na velocidade do processo). Quando a disponibilidade de material orgânico no afluente é insuficiente, existe a possibilidade de se adicionar um composto de baixo custo e degradação rápida como, por exemplo, metanol ou etanol (VAN HAANDEL, et al., 2009 In: PROSAB - Livro 2, Capítulo 6).

\subsubsection{Condições necessárias para desnitrificação}

As condições necessárias para que o processo de desnitrificação se desenvolva no sistema de lodo ativado podem ser resumidas como se segue: presença de uma massa bacteriana facultativa; presença de nitrato e ausência de OD no licor misto; condições ambientais adequadas para o crescimento de microrganismos; presença de um doador de elétrons (redutor de nitrato).

\subsubsection{Massa bacteriana facultativa}

Uma bactéria é denominada de facultativa quando pode usar tanto OD como nitrato para oxidar o material orgânico. A maioria das bactérias que se desenvolvem no sistema de lodo ativado é facultativa. Estabeleceu-se experimentalmente que um lodo gerado sob condições aeróbias, quando sujeito a um ambiente anóxico na presença de material orgânico, demonstrará imediatamente a capacidade de usar nitrato como oxidante e continuará a desnitrificação sem variação mensurável da reatividade do lodo - enquanto a condição anóxica persiste. Conclui-se que não há necessidade do lodo se adaptar para o uso do nitrato. 


\subsubsection{Presença de nitrato e ausência de OD}

A presença de OD em um licor misto inibe o desenvolvimento da desnitrificação. Um problema na quantificação da influência da concentração de OD sobre a desnitrificação é que se desenvolvem gradientes de concentração nos flocos. A concentração de OD no microambiente em volta de uma bactéria em um floco de lodo pode ser muito diferente daquela no seio da Fase líquida (Figura 2.4). Efetivamente, tem sido observada a remoção eficiente de nitrato em reatores aerados de lodo ativado (PASVEER, 1965 e MATSCHE,1971 apud (VAN HAANDEL, et al., 2009 In: PROSAB - Livro 2, Capítulo 6), que serão abordados na revisão sobre nitrificação e desnitrificação simultâneas (NDS) tema desse estudo.

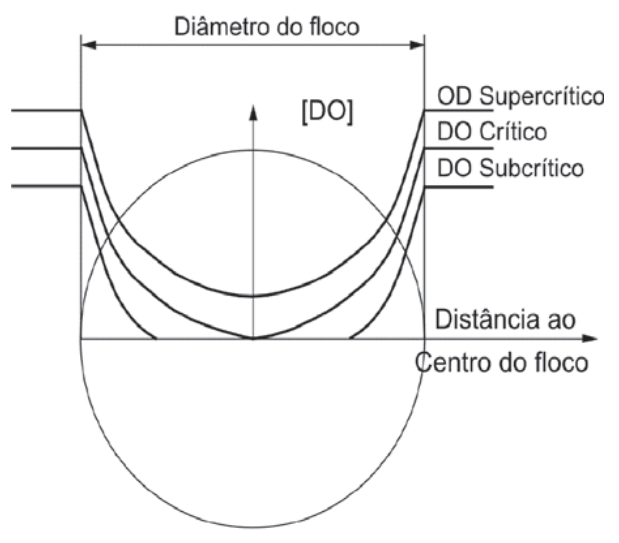

Figura 2.4: representação da variação da concentração de OD num floco em função da distância do centro para concentração subcrítica, crítica e supercrítica. Fonte: (VAN HAANDEL e MARAIS 1999).

\subsubsection{Condições ambientais adequadas para os microrganismos}

Entre as condições mais importantes estão a temperatura e o pH do licor misto. A taxa de desnitrificação aumenta com a temperatura até um valor ótimo de $40^{\circ} \mathrm{C}$. A influência do $\mathrm{pH}$ sobre a desnitrificação tem sido observada por vários autores. A dependência da desnitrificação do pH é muito menos acentuada que a da nitrificação, de modo que, quando há condições de pH favoráveis para nitrificação, a desnitrificação também se desenvolverá bem. Entre as condições ambientais adequadas tem-se, ainda, a necessidade de não se ter limitação por substâncias tóxicas. Não há muita informação sobre influência de materiais tóxicos para desnitrificação além da inibição já mencionada de OD e íons de hidrogênio (pH). Em geral, observa-se que as bactérias nitrificantes são mais sensíveis à presença de materiais tóxicos do que as bactérias atuantes na desnitrificação. Logo, quando a nitrificação se desenvolve, a desnitrificação também é possível (VAN HAANDEL, et al., 2009 In: PROSAB - Livro 2, Capítulo 6). 


\subsubsection{Presença de um doador de elétrons}

A presença de um doador de elétrons é essencial para redução de nitrato. $\mathrm{O}$ doador de elétrons na desnitrificação é o material orgânico biodegradável. De acordo com a natureza do material orgânico, podem-se definir diferentes classes de sistema de desnitrificação; dois que serão mais propriamente considerados. Os primeiros são os sistemas com uma fonte externa de material orgânico. Nestes sistemas, o material orgânico é adicionado após a nitrificação. Entre os materiais usados na prática estão o metanol, o etanol, a acetona e o ácido acético. Os segundos são os sistemas que possuem uma fonte interna de material orgânico. Neste caso, o material orgânico do afluente é usado para redução de nitrato. Como material orgânico pode-se utilizar aquele do afluente ou então a massa bacteriana (respiração endógena) (VAN HAANDEL, et al., 2009 In: PROSAB - Livro 2, Capítulo 6).

\subsubsection{Estequiometria das reações do material nitrogenado}

\subsubsection{Consumo de oxigênio}

Quanto ao consumo de oxigênio para o material nitrogenado, interessam somente os processos de nitrificação e desnitrificação. A Figura 2.4 mostra esquematicamente a transferência de elétrons nos processos de nitrificação e desnitrificação. Observa-se que, na nitrificação, o número de oxidação do nitrogênio na amônia (-3) aumenta para (+5) no nitrato através da transferência de 8 elétrons por átomo de nitrogênio, que são aceitos pelo oxigênio, sendo preciso quatro átomos (duas moléculas) de oxigênio para isso (no oxigênio o número de oxidação muda de 0 para -2 na reação). Portanto, na nitrificação de 1 mol de $\mathrm{N}$ amoniacal, o consumo de oxigênio é de 64/14 = 4,57 mgO.mg N $\mathrm{m}^{-1}$ (VAN HAANDEL e MARAIS, 1999).

No processo de desnitrificação, o oxidante nitrato (número de oxidação $=+5$ ) é reduzido para nitrogênio molecular (número de oxidação $=0$ ), havendo, portanto, transferência de 5 elétrons por átomo N. Nota-se que, dos 8 elétrons liberados pelo nitrogênio amoniacal na sua oxidação para nitrato, somente 5 são recuperados quando o nitrato é reduzido para nitrogênio molecular. Desse modo, em termos de equivalentes oxidimétricos, o nitrato na desnitrificação tem uma capacidade de oxidação igual a uma fração $5 / 8$ de oxigênio necessário na nitrificação. Em outras palavras, uma fração de $5 / 8=0,625$ do consumo de oxigênio na nitrificação $\left(4,57 \mathrm{mgO} \mathrm{mg} \mathrm{N}^{-1}\right)$ pode ser recuperada como "oxigênio equivalente" no processo de desnitrificação. Isto é: $0,625 * 4,57=2,86 \mathrm{mgO} \cdot \mathrm{mg} \mathrm{N}^{-1}$. Conclui-se que, para a remoção de nitrogênio, há um consumo líquido de 4,57-2,86 = 1,71 mgO.mg N $\mathrm{m}^{-1}$ (VAN HAANDEL e MARAIS, 1999). 


\subsection{Variação da alcalinidade no processo de amonificação, nitrificação e desnitrificação}

O efeito da amonificação, nitrificação e desnitrificação sobre a alcalinidade pode ser deduzido por simples relações estequiométricas, usando-se as equações de reação dos três processos (Equações 2.22a, 2.22b e 2.22c) (VAN HAANDEL, et al., 2009 In: PROSAB - Livro 2, Capítulo 6). Observa-se que, nas três reações, há envolvimento de íons de hidrogênio: na amonificação há consumo de $1 \mathrm{~mol}$ de $\mathrm{H}^{+}$por mol de amônia produzido; na nitrificação há produção de 2 moles de $\mathrm{H}^{+}$por mol de nitrato formado, e na desnitrificação há consumo de 1 mol de $\mathrm{H}^{+}$por mol de nitrato reduzido. Sabendo-se que a produção de $1 \mathrm{~mol} \mathrm{de} \mathrm{H}^{+}$(acidez mineral) equivale ao consumo de 1 mol de alcalinidade (ou 50g $\mathrm{CaCO}_{3}$ ), tem-se, nos três processos as situações que serão consideradas a seguir: No processo de amonificação, há uma produção de alcalinidade de $50 \mathrm{~g}$ por mol amônia $(14 \mathrm{~g} \mathrm{~N})$ amonificado. No processo de nitrificação, há um consumo de alcalinidade de $2 \times 50=100 \mathrm{~g} \mathrm{CaCO}_{3}$ por mol $\mathrm{N}(14 \mathrm{~g})$. Finalmente, no processo de desnitrificação, produz-se $50 \mathrm{~g} \mathrm{CaCO}_{3}$ por mol N. As variações da alcalinidade podem ser expressas como:

(Equação 2.22)

$(\Delta \mathrm{alc} / \Delta \mathrm{N})_{\mathrm{am}}=50 / 14=3,57 \mathrm{mg} \mathrm{CaCO} 3 \cdot \mathrm{mgN}^{-1}$
$(\Delta \mathrm{alc} / \Delta \mathrm{N})_{\mathrm{n}}=-100 / 14=-7,14 \mathrm{mg} \mathrm{CaCO} 3 \cdot \mathrm{mgN}^{-1}$
$(\Delta \mathrm{alc} / \Delta \mathrm{N})_{\mathrm{d}}=50 / 14=3,57 \mathrm{mg} \mathrm{CaCO} \cdot \mathrm{mgN}^{-1}$

Onde:

$(\Delta \mathrm{alc} / \Delta \mathrm{N})$ : variação da alcalinidade por mg $\mathrm{N}$.

am: amonificação

n: nitrificação

d: desnitrificação

No caso de esgoto municipal, o efeito da amonificação sobre a alcalinidade é geralmente pequeno, como mostra a seguinte análise. A concentração de nitrogênio amonificado no sistema de lodo ativado é dada pela diferença entre o nitrogênio orgânico afluente e a soma de nitrogênio orgânico no efluente e no lodo de excesso, ou seja:

$\mathrm{N}_{\mathrm{am}}=\mathrm{N}_{\mathrm{oa}}-\left(\mathrm{N}_{\mathrm{oe}}+\mathrm{N}_{\mathrm{l}}\right)$

(Equação 2.23)

Onde:

$\Delta \mathrm{N}_{\mathrm{am}}$ : concentração de nitrogênio amonificado no sistema de lodo ativado ( $\left.\mathrm{mgN} . \mathrm{L}^{-1}\right)$

$\mathrm{N}_{\mathrm{oa}}$ : concentração de nitrogênio orgânico afluente $\left(\mathrm{mgN} \cdot \mathrm{L}^{-1}\right)$

$\mathrm{N}_{\mathrm{oe}}$ : concentração de nitrogênio orgânico efluente $\left(\mathrm{mgN} \cdot \mathrm{L}^{-1}\right)$

$\mathrm{N}_{\mathrm{l}}$ : concentração de nitrogênio orgânico no lodo de excesso (mgN.L $\left.\mathrm{L}^{-1}\right)$ 
Normalmente para esgoto sanitário, a concentração do nitrogênio orgânico no efluente é muito pequena (em torno de 1 a $2 \mathrm{mgN} \cdot \mathrm{L}^{-1}$ ), enquanto os valores das concentrações $\mathrm{N}_{\text {oa }}$ e $\mathrm{N}_{1}$ são aproximadamente igual a 25 por cento do NTK do afluente. Desse modo, a variação da concentração de nitrogênio orgânico é muito pequena e, consequentemente, a variação da alcalinidade devido à amonificação também será pequena. A variação da alcalinidade devido à amonificação é dada por:

$\Delta \mathrm{alc}_{\mathrm{am}}=3,57 \Delta \mathrm{N}_{\mathrm{am}}=3,57\left(\mathrm{~N}_{\mathrm{oa}}-\mathrm{N}_{\mathrm{oe}}-\mathrm{N}_{\mathrm{l}}\right)$

Onde o valor de $\Delta \mathrm{alc}_{\mathrm{am}}$ pode ser positivo ou negativo

A variação da alcalinidade em um sistema de tratamento de esgoto, devido à nitrificação, é calculada a partir da concentração de amônia nitrificada. Esta concentração é igual à diferença entre a concentração do NKT afluente $\left(\mathrm{N}_{\mathrm{ka}}\right)$ e a soma das concentrações do NKT efluente $\left(\mathrm{N}_{\mathrm{ke}}\right)$ e aquela necessária para a produção de lodo $\left(\mathrm{N}_{1}\right)$.

$\mathrm{N}_{\mathrm{c}}=\mathrm{N}_{\mathrm{ka}}-\mathrm{N}_{\mathrm{ke}}-\mathrm{N}_{1}$

(Equação 2.25)

Onde:

$\mathrm{N}_{\mathrm{c}}$ : concentração de amônia afluente nitrificada no sistema $\left(\mathrm{mgN} \cdot \mathrm{L}^{-1}\right)$

O efeito da nitrificação sobre a alcalinidade pode ser expressa como:

$\Delta \mathrm{alc}_{\mathrm{n}}=-7,14 \mathrm{~N}_{\mathrm{c}}=-7,14\left(\mathrm{~N}_{\mathrm{ka}}-\mathrm{N}_{\mathrm{ke}}-\mathrm{N}_{\mathrm{l}}\right)$

(Equação 2.26)

Devido a desnitrificação, a variação da alcalinidade depende da concentração do nitrato removido do sistema. Essa concentração é dada por:

$\Delta \mathrm{N}_{\mathrm{d}}=\mathrm{N}_{\mathrm{na}}+\mathrm{N}_{\mathrm{c}}-\mathrm{N}_{\mathrm{ne}}$

(Equação 2.27)

Portanto, a variação da alcalinidade ocasionada pela desnitrificação pode ser expressa como:

$\Delta \mathrm{alc}_{\mathrm{d}}=3,57 \Delta \mathrm{N}_{\mathrm{d}}=3,57\left(\mathrm{~N}_{\mathrm{na}}+\mathrm{N}_{\mathrm{ka}}-\mathrm{N}_{\mathrm{ke}}-\mathrm{N}_{1}-\mathrm{N}_{\mathrm{ne}}\right)$

(Equação 2.28)

A variação total da alcalinidade do sistema de lodo ativado devido às reações de nitrogênio será igual à soma dos efeitos da amonificação, nitrificação e desnitrificação.

(Equação 2.29)

$\Delta \mathrm{alc}_{\mathrm{t}}=\Delta \mathrm{alc}_{\mathrm{am}}+\Delta \mathrm{alc}_{\mathrm{n}}+\Delta \mathrm{alc}_{\mathrm{d}}=3,57\left(\mathrm{~N}_{\mathrm{oa}}-\mathrm{N}_{\mathrm{oe}}-\mathrm{N}_{\mathrm{l}}\right)-7,14\left(\mathrm{~N}_{\mathrm{ka}}-\mathrm{N}_{\mathrm{ke}}-\mathrm{N}_{\mathrm{l}}\right)+3,57\left(\mathrm{~N}_{\mathrm{na}}+\mathrm{N}_{\mathrm{ka}}-\mathrm{N}_{\mathrm{ke}}-\mathrm{N}_{\mathrm{l}}-\mathrm{N}_{\mathrm{ne}}\right)$ 
Lembrando que a concentração do NTK (Nk) é a soma da concentração de nitrogênio orgânico (No) e amoniacal (Na), a Equação 2.28 se simplifica para:

$\Delta \mathrm{alc}_{\mathrm{t}}=-3,57\left(\mathrm{~N}_{\mathrm{aa}}-\mathrm{N}_{\mathrm{na}}-\mathrm{N}_{\mathrm{ae}}+\mathrm{N}_{\mathrm{ne}}\right)=3,57\left(\Delta \mathrm{N}_{\mathrm{a}}-\Delta \mathrm{N}_{\mathrm{n}}\right)$

(Equação 2.30)

$\mathrm{Na}$ prática, a alcalinidade natural das águas residuárias poderá ter um valor inferior aquele necessário para manter um $\mathrm{pH}$ estável no reator onde ocorre a nitrificação. Isto é particularmente provável quando o sistema é inteiramente aeróbio, ou seja, quando a nitrificação se desenvolve, sem que a desnitrificação ocorra. Nesse caso, torna-se necessário aumentar a alcalinidade da água residuárias - o que geralmente é feito através de adição de cal. Sem adição de alcalinidade, o comportamento do sistema de lodo ativado será instável: haverá períodos de nitrificação eficiente e, consequentemente, redução da alcalinidade e do pH até que ele atinja um valor que não permite o desenvolvimento da nitrificação. Quando a nitrificação é inibida, automaticamente, a alcalinidade e o pH aumentarão pela introdução do afluente até que se criem novamente condições favoráveis para a nitrificação. Inicia-se, então, um novo ciclo. Se a desnitrificação é incluída no sistema de tratamento, então a diminuição da alcalinidade será menor e muitas vezes não haverá necessidade de adição de cal. Isto ocorre porque, no processo de desnitrificação, há produção de alcalinidade (VAN HAANDEL, et al., 2009 In: PROSAB Livro 2, Capítulo 6).

$\Delta \operatorname{alc}_{\mathrm{t}}=3,57\left(\mathrm{~N}_{\mathrm{aa}}-\mathrm{N}_{\mathrm{na}}-\mathrm{N}_{\mathrm{ae}}+\mathrm{N}_{\mathrm{ne}}\right)=3,57\left(\Delta \mathrm{N}_{\mathrm{a}}-\Delta \mathrm{N}_{\mathrm{n}}\right)$

Onde:

$\Delta \mathrm{N}_{\mathrm{a}}$ : variação da concentração de amônia no sistema $\Delta \mathrm{N}_{\mathrm{n}}$ : variação da concentração de nitrato no sistema

Na Equação 2.31, os parâmetros à direita podem ser determinados experimentalmente usando-se testes padronizados. Logo, é possível calcular teoricamente qual a variação da alcalinidade causada pelo efeito estequiométrico combinado de amonificação, nitrificação e desnitrificação. Este valor é, então, posteriormente comparado com a variação observada da alcalinidade. $\mathrm{Na}$ Figura 2.5 se observam resultados de variação teórica e experimental da alcalinidade, mostrando que há uma boa correlação entre teoria e experimento. 


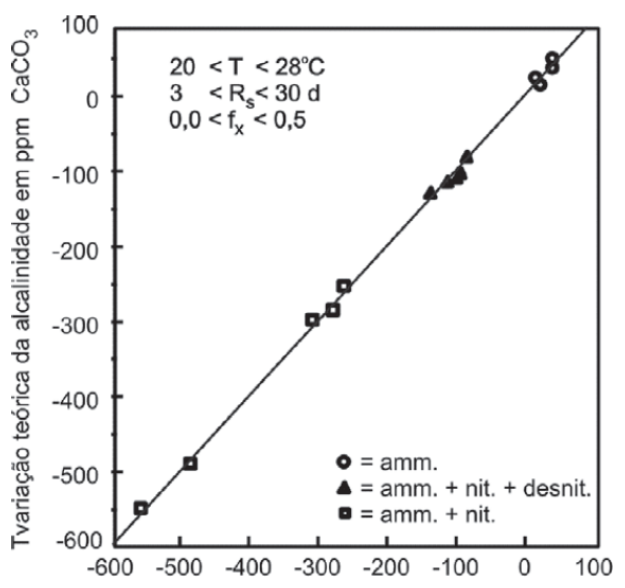

Figura 2.5: Variação teórica versus variação experimental da alcalinidade para diferentes sistemas de lodo ativado. Fonte: (VAN HAANDEL e MARAIS 1999).

\subsection{Principais processos de remoção de nitrogênio com biomassa em suspensão}

\subsubsection{Sistema de lodo ativado com pré-desnitrificação}

Tendo em vista a necessidade não apenas da nitrificação do esgoto, como também a redução biológica do nitrato. Entende-se que, nos dias atuais, as alternativas de pré-desnitrificação e de pós-desnitrificação, processos que podem ser associados aos sistemas de lodos ativados, são satisfatoriamente conhecidos. O reator possui uma zona anóxica seguida pela zona aeróbia. A nitrificação ocorre na zona aeróbia, conduzindo a formação de nitratos. Os nitratos são direcionados a zona anóxica por meio da recirculação interna, como se observa na Figura 2.6. Embora possa ser futuramente implantado nas ETEs em operação, o arranjo com prédesnitrificação tem por principal aspecto desfavorável a necessidade de grandes vazões de recirculação de lodo da zona aerada para a zona anóxica (100 a 400\%) da vazão afluente, dependendo da concentração de nitrato a ser obtida no efluente final, acarretando elevação significativa dos custos operacionais em função do consumo de energia elétrica por estas elevatórias adicionais (VON SPERLING, 2002; METCALF \& EDDY, 2003). 


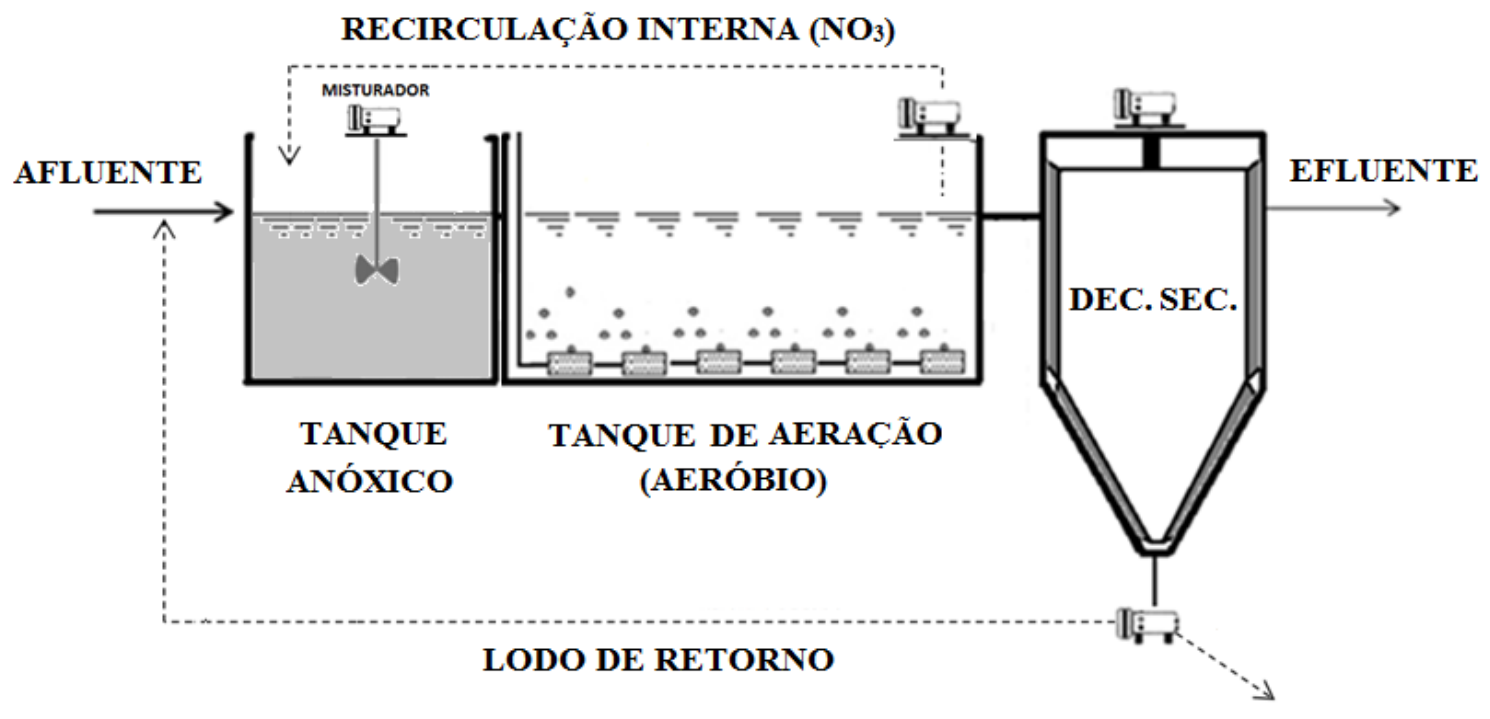

LODO DE EXCESSO

Figura 2.6: Representação esquemática de um sistema de lodo ativado com pré-desnitrificação. Fonte: Adaptado de (VON SPERLING, 2002; METCALF \& EDDY, 2003)

\subsubsection{Sistema de lodo ativado com pós-desnitrificação}

Como se observa na Figura 2.7, o sistema é composto por um reator com uma zona aeróbia seguida por uma zona anóxica e, opcionalmente, uma zona aeróbia final. A remoção de carbono e a produção de nitratos ocorrem na zona aeróbia. Os nitratos formados entram na zona anóxica, onde são reduzidos a nitrogênio gasoso. Desta forma, não há necessidade de recirculações internas como no sistema de pré-desnitrificação. A desvantagem é que a desnitrificação ocorre em condições endógenas, já que a maior parte do carbono orgânico é removido na zona aeróbia. Em decorrência a taxa de desnitrificação é mais lenta $\left(0,015\right.$ a $\left.0,045 \mathrm{mgNO}_{3}-\mathrm{N} \cdot \mathrm{mgSSV} \mathrm{d}^{-1}\right)$ (VON SPERLING, 2002) conforme se observa na Tabela 2.7 os valores típicos das taxas de desnitrificação por miligrama de sólidos ativos por dia, obtidas em sistemas de lodo ativado com pré-desnitrificação e pós-desnitrificação tendo como substrato esgoto bruto.

Uma possibilidade para se aumentar a taxa de desnitrificação na zona anóxica é adição artificial de carbono orgânico ou de se direcionar parte do esgoto bruto diretamente à zona anóxica. No entanto, o uso do esgoto pode acarretar problemas na zona anóxica, devido à introdução de amônia não nitrificada, deteriorando a qualidade do efluente final. Em relação à adição artificial de carbono orgânico, há uma elevação significativa dos custos operacionais no sistema. A zona aerada final (opcional) é operada com baixo TDH (em torno de 30 minutos). As principais finalidades são o desprendimento das bolhas de nitrogênio gasoso e a adição de oxigênio dissolvido antes da sedimentação (VON SPERLING, 2002; METCALF \& EDDY, 2003). 


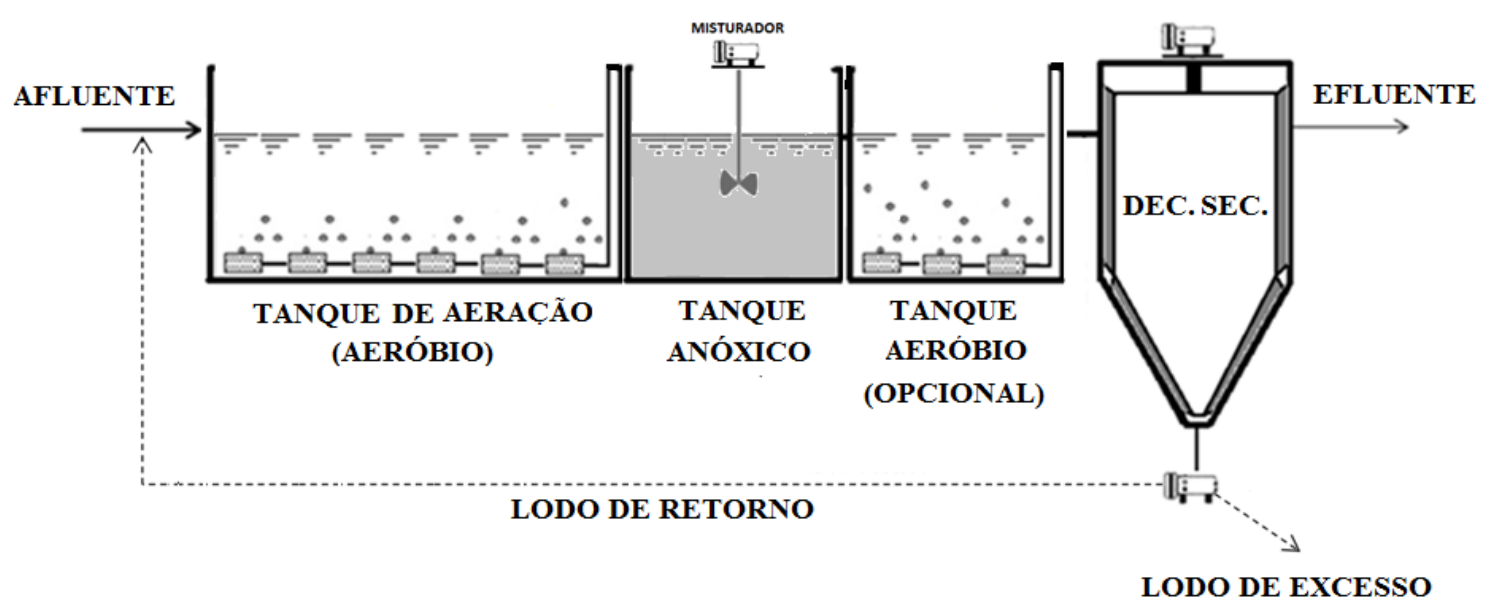

Figura 2.7: Representação esquemática de um sistema de lodo ativado com pós-desnitrificação. Fonte: Adaptado de (VON SPERLING, 2002; METCALF \& EDDY, 2003)

Tabela 2.7: Taxa de desnitrificação por miligrama de sólidos suspensos voláteis por dia, em sistemas de lodo ativado com pré-desnitrificação e pós-desnitrificação

\begin{tabular}{clc}
\hline \multicolumn{2}{c}{ Taxa de desnitrificação específica } \\
\hline Tipo & \multicolumn{1}{c}{ Posição da zona anóxica } & $\begin{array}{c}\text { Taxa de desnitrificação } \\
\left(\mathbf{m g N O}_{\mathbf{3}} \text {-N.mgSSV.d }^{\mathbf{1}}\right)\end{array}$ \\
\hline Esgoto bruto & $\begin{array}{l}\text { Zona anóxica a montante da zona } \\
\text { aerada (Pré-D) }\end{array}$ & $0,03-0,11$ \\
\hline $\begin{array}{c}\text { Metabolismo } \\
\text { endógeno }\end{array}$ & $\begin{array}{l}\text { Zona anóxica a jusante da zona } \\
\text { aerada (Pós-D) }\end{array}$ & $0,015-0,045$ \\
\hline
\end{tabular}

Fonte: apud SPERLING, 1997 (ECKENFELDER \& ARGAMAN, 1978; ARCEIVALA, 1981; METCALF E EDDY, 1991 e EPA, 1993).

\subsubsection{Sistema de lodo ativado Bardenpho}

O processo Bardenpho de 3 estágios corresponde a uma combinação dos dois arranjos (Prédesnitrificação e Pós-desnitrificação), além da zona de re-aeração final (opcional), como se observa na Figura 2.8. A eficiência de remoção de nitrogênio é bastante elevada, da ordem de $90 \%$ ou mais, já que os nitratos não removidos na primeira zona anóxica podem ser removidos na segunda zona anóxica. No entanto o TRS na zona aerada deve ser suficiente para ocorrência da nitrificação. A desvantagem desse sistema é a necessidade de reatores com volume total maior. Existem variantes desse sistema como o Bardenpho modificado de 3 estágios com o primeiro reator anaeróbio seguido de um anóxico e um aeróbio, e o Bardenpho modificado de 5 estágios (anaeróbio-anóxico-aeróbio-anóxico-aeróbio) que podem agregar a remoção biológica 
de fósforo na zona anaeróbia do sistema. No entanto, há uma tendência de formação de lodo filamentoso e a desnitrificação pode ser incompleta devido à falta de matéria orgânica (VON SPERLING, 2002 e VAN HAANDEL e MARAIS, 1999).

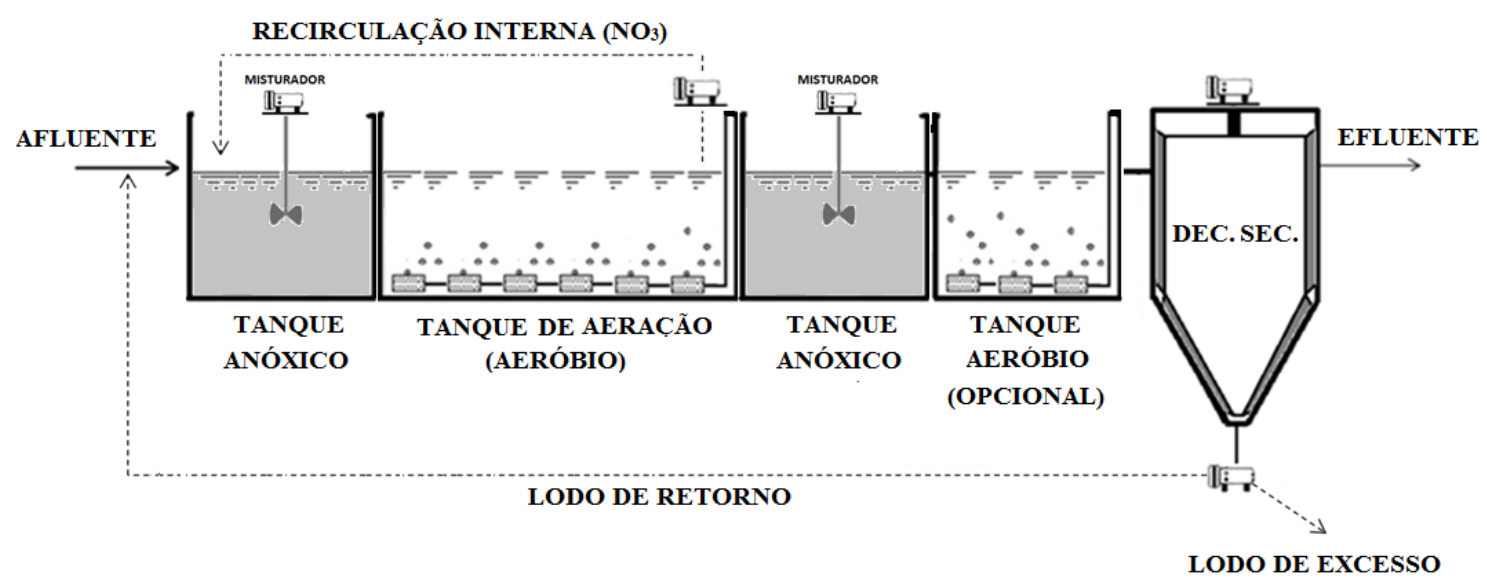

Figura 2.8: Representação esquemática de um sistema de lodo ativado pelo processo Bardenpho de 3 estágios. Fonte: Adaptado de (VON SPERLING, 2002; VAN HAANDEL e MARAIS, 1999)

\subsubsection{Sistema de lodo ativado UCT (University of Cape Town)}

Na Figura 2.9 apresenta-se o sistema UCT que é um sistema de lodo ativado composto de 4 reatores sendo o primeiro anaeróbio, o segundo e o quarto anóxicos e o terceiro aeróbio, podendo ou não apresentar um quinto reator, sendo este aeróbio. Após a série de reatores há um decantador secundário. O sistema UCT, proposto por RABINOWITZ e MARAIS (1980) apud (VAN HAANDEL e MARAIS, 1999), foi desenvolvido para que, simultaneamente, houvesse a remoção dos macronutrientes nitrogênio e fósforo. Para a remoção de fósforo nesse sistema, assim como para o sistema Bardenpho há necessidade da presença de uma zona anaeróbia e de material rapidamente biodegradável. No sistema UCT se evita a introdução de nitrato na zona anaeróbia (como ocorre no sistema Bardenpho modificado com 3 e/ou 5 reatores), introduzindose lodo da zona anóxica para a zona anaeróbia, recirculação " $r$ ". Na zona anóxica a concentração de nitrato é mantida baixa através do controle da taxa de recirculação "a" (Figura 2.9), de tal maneira que o nitrato disponível para desnitrificação na zona anóxica se iguala à capacidade de desnitrificação nesta. O sistema UCT modificado foi desenvolvido para assegurar que não haja introdução de nitrato, mesmo quando a concentração de nitrato e da taxa de desnitrificação varia com o tempo. A zona anóxica do pré-desnitrificante está dividida em duas, descarregando-se o lodo de retorno do decantador na primeira parte e na segunda parte o lodo proveniente do reator aeróbio. Nessas condições, a remoção de nitrato na primeira parte será 
completa, havendo total proteção da zona anaeróbia, favorecendo assim a remoção de fósforo. Porém, ao configurar as zonas anóxicas dessa maneira, o efluente pode apresentar maiores concentrações de nitrato, visto que não existe uma zona anóxica para pós-desnitrificação e pode acarretar problemas como flotação do lodo no decantador secundário.

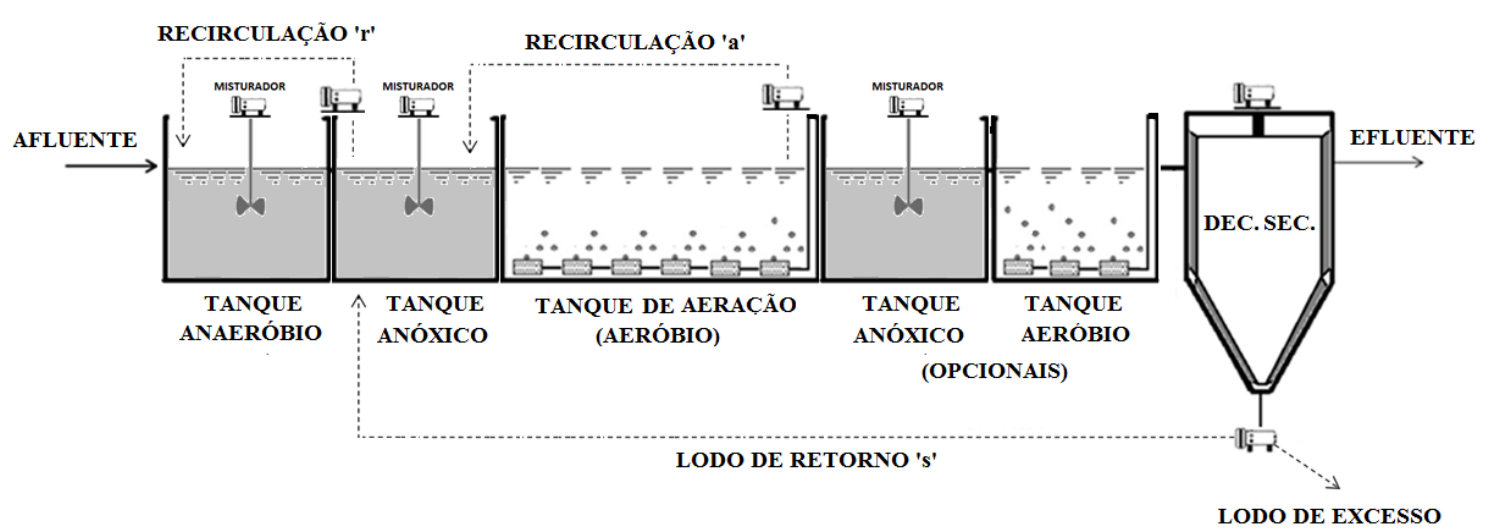

Figura 2.9: Representação esquemática de um sistema de lodo ativado pelo processo UCT com 5 reatores sequenciais (anaeróbio-anóxico-aeróbio-anóxico-aeróbio). Fonte: Adaptado de (VAN HAANDEL e MARAIS, 1999)

\subsection{Processos mais recentes de remoção de nitrogênio com biomassa em suspensão}

Estudos mais recentes têm mostrado que, que a remoção biológica de nitrogênio pode acontecer de outras formas além da via comum: nitrificação e desnitrificação completas. Os novos processos consistem em rotas alternativas de remoção biológica de nitrogênio em águas residuárias. Um exemplo interessante é o processo SHARON (Single Reactor for High Activity Ammonium Removal Over Nitrite) em que se estabelece um curto-circuito nos processos de nitrificação e desnitrificação. Um grupo de investigadores da Universidade Técnica de Delft na Holanda desenvolveu esse processo que é capaz de nitrificar parcialmente águas residuais e produzir quantidades consideráveis de nitrito (HELLINGA et al., 1998).

A nitrificação é interrompida numa etapa intermediária, em que a oxidação da amônia cessa na forma de nitrito para numa próxima etapa, sem aeração, haver conversão de nitrito a nitrogênio gasoso, economizando, dessa forma, energia e doadores de elétrons. A oxidação para nitrito só requer 3/4 da demanda de oxigênio necessário para a oxidação para nitrato como também a desnitrificação do nitrito requer apenas 3/5 do material orgânico necessário para a remoção do nitrato (SCHMIDT et al., 2003). 
O sistema SHARON é operado sob curtos tempos de detenção hidráulica, altas temperaturas $\left(30^{\circ} \mathrm{C}\right.$ a $\left.35^{\circ} \mathrm{C}\right)$, elevadas vazões específicas de alimentação (alta concentração de amônia no efluente) e sem recirculação (VAN VELDHUIZEN et al., 1997; e JETTEN et al., 2000).

Outros processos em estudos são: ANAMMOX (Anaerobic Ammonium Oxidation) que é realizado por microrganismos autotróficos e dispensa adição de fonte externa de carbono (JETTEN et al., 1999 apud VAN HAANDEL, et al., 2009 In: PROSAB - Livro 2, Capítulo 6). Esse processo também já é operado em escala real e combina parte do nitrogênio, na forma de nitrito, com o nitrogênio amoniacal excedente e transforma a amônia a nitrogênio gasoso sob condições anaeróbias, reduzindo significativamente o consumo de oxigênio e DQO na Fase de desnitrificação (MULDER et al., 1995).

O processo ANAMMOX geralmente requer um passo anterior de nitrificação parcial, que converte em nitrito parte do amônio presente no afluente. $\mathrm{O}$ nitrito pode ser produzido pelo processo SHARON à montante do tanque ANAMMOX, convertendo cerca de 50\% do amônio afluente em nitrito (VILLAVERDE, 2001). CANON (Completely Autotrophic Nitrogen removal Over Nitrito), processo alternativo ao processo Sharon-Anammox economicamente vantajoso, uma vez que permite a remoção de amônio em um único reator, apesar de apresentar eficiência de remoção de nitrogênio inferior (SCHMIDT et al., 2003). Esse sistema exige, no entanto, um rigoroso controle da concentração de oxigênio, para garantir a nitrificação parcial e evitar o envenenamento da biomassa Anammox por nitrito, devido a excesso de oxigênio (NIELSEN et al., 2005).

No processo OLAND (Oxygen Limited Autotrophic Nitrification Denitrification), o oxigênio é fornecido em quantidade estequiométrica para que a nitrificação proceda apenas até nitrito e, subseqüentemente, devido à escassez de aceptores de elétrons, o nitrito formado seja consumido para oxidar o restante do amônio (VERSTRAETE e PHILIPS, 1998).O processo OLAND, quando comparado ao processo de nitrificação e desnitrificação convencional, permite uma economia de 62,5\% de oxigênio (energia) e $100 \%$ de agente redutor (fonte de carbono orgânico). Além de que, a oxidação direta de amônio a nitrogênio gasoso pode ser alcançada em uma única Fase (VERSTRAETE e PHILIPS, 1998).

O processo conhecido como nitrificação e desnitrificação simultânea - NDS, tema desse estudo, é baseado na remoção de nitrogênio em sistemas de reator único, ou seja, a nitrificação e a desnitrificação podem ocorrer simultaneamente em um único reator sob condições iguais, com TRS suficientemente altos e concentrações de OD baixas, conforme demonstrado na revisão a seguir. 


\subsection{Nitrificação e desnitrificação simultâneas}

\subsubsection{Remoção de nitrogênio em reator único de nitrificação e desnitrificação}

Segundo os autores VAN HAANDEL, et al., 2009:221 In: PROSAB - Livro 2, Capítulo 6. A remoção de nitrogênio em sistemas de reator único tem sido proposta desde o início da tecnologia de sistemas de lodo unitário (PASVEER, 1969; MATSCHÉ, 1970), mas, recentemente, tem-se visto vários artigos propondo de novo este método. Nos primeiros dias de remoção biológica de nitrogênio, normalmente usava-se aeradores de superfície que eram muito populares na época. Neste caso, a estratificação de OD em reatores aeróbios pode ser muito grande, o que facilitava o desenvolvimento de regiões anóxicas no licor misto (onde a desnitrificação ocorre). Isto é mais provável na medida em que o reator é mais profundo, criando, desta forma, uma distância maior entre os pontos de OD mínimo e máximo (perto dos aeradores). Como a demanda de oxigênio é variável e geralmente se aplica uma aeração estática, a concentração de OD variará com o tempo e estas zonas anóxicas terão volume variável. Por esta razão, a magnitude da desnitrificação é irregular: quando a carga é baixa, a demanda de oxigênio será pequena, a concentração de OD alta e a desnitrificação limitada. Em momentos de maior carga, a desnitrificação se desenvolverá mais, mas poderá haver nitrificação incompleta devido à falta de oxigênio dissolvido.

No entanto, nos últimos anos, tem-se observado um grande interesse pela remoção de nitrogênio em reator unitário pelo processo de nitrificação e desnitrificação simultânea, devido ao uso de aeração por ar difuso (que é introduzido no fundo do reator), neste caso haverá menos estratificação e, mediante ao uso de um sistema automatizado de controle da concentração de OD que pode ser ajustado para atender as variações de carga. A remoção biológica de nitrogênio nessas condições pode ser obtida com ótimo desempenho e estabilidade, como pode ser observada nesse estudo.

\subsubsection{Condições necessárias para nitrificação e desnitrificação simultânea}

Nitrificação e desnitrificação simultâneas (NDS) implicam que os dois processos ocorrem no mesmo reator sob condições de operação idêntica. Segundo VON HUYSSTEEN, apud TCHOBANOGLOUS et al. (2004), uma quantidade significativa de nitrogênio pode ser removida em um sistema de lodos ativados de estágio único sem que haja uma região específica em condições anóxicas. Esta observação foi feita em lodos ativados com mistura completa com aeradores superficiais e valos de oxidação, sistemas com tempo de retenção hidráulica e de residência celular elevado, nas quais os processos de nitrificação e desnitrificação podem 
ocorrer simultaneamente, havendo regiões de baixa concentração de oxigênio dissolvido no lodo do tanque de aeração, seu consumo torna o ambiente favorável para o surgimento de reações anóxicas. O oxigênio dissolvido e o substrato solúvel presentes na parte exterior do floco difundem-se na zona aeróbia e, dependendo da concentração de oxigênio dissolvido, de amônia e de DQO biodegradável, o oxigênio dissolvido poderá ser consumido rapidamente no interior do floco de forma que se torna indisponível na camada interna. O nitrato produzido na zona aeróbia pode difundir-se em direção à camada interna conjuntamente com o substrato, ocorrendo a desnitrificação, conforme a ilustração da Figura 2.10.

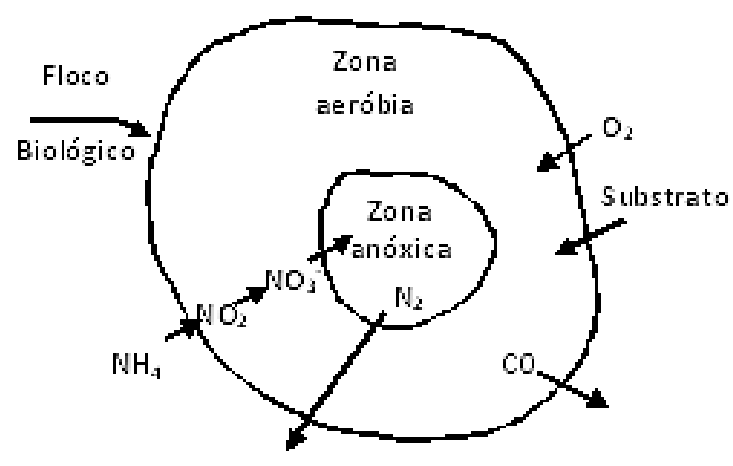

Figura 2.10: Esquema dos transportes e transformações que podem ocorrer em um floco em meio com baixa concentração de oxigênio dissolvido. Fonte: Adaptado de (METCALF \& EDDY, 2003).

Considerando-se que pode ocorrer desnitrificação aeróbia, muitos autores (ROBERTSON e KUENEN, 1984 e 1994; RITTMANN e LANGELAND, 1985; POTH M, et al., 1985; HELMER C, et al. 1998; VAN LOOSDRECHT e JETTEN, 1998; YOO K., 1999; POCHANA e KELLER, 1999; VILLABERDE, et al., 2000; ZHANG P., et al., 2001; SATOH et al, 2003), realizaram experimentos com nitrificação e desnitrificação simultâneas em reatores aeróbios e levantaram as seguintes hipóteses sobre o processo de NDS:

(a) de natureza física ("teoria de microambiente"): os gradientes de concentração de OD dentro dos flocos ou biofilmes microbianos (de diâmetro de 100 a $150 \mu \mathrm{m}$ ) formam populações diferenciadas ao longo do biofilme devido às limitações difusionais: as nitrificantes ocupam zonas de altas concentrações de OD e as desnitrificantes localizam-se em regiões de concentrações mais baixas;

(b) de natureza biológica: existência de bactérias desnitrificantes aeróbias e nitrificantes heterotróficas. Supõe-se que os microrganismos responsáveis pela desnitrificação são capazes de reduzir nitrogênio por determinado tempo, mesmo quando a concentração de oxigênio dissolvido começa a aumentar, considerando que a biomassa esteja submetida a baixas concentrações de OD.

(c) de controle operacional e ambiental: 
- O Controle automatizado da concentração de OD em baixas concentrações, é um fator "chave" para o desenvolvimento e estabilidade do processo NDS;

- Elevado tempo de retenção de sólidos (TRS);

- Matéria orgânica disponível;

- Temperatura que favoreçam a nitrificação

Os estudos realizados por POCHANA e KELLER (1999) mostraram que a adição de matéria orgânica prontamente biodegradável resulta em aumento da velocidade de desnitrificação. STENSTRON e SONG, apud RUSTEN, 1994, observaram que a velocidade de nitrificação não depende apenas da concentração de oxigênio dissolvido no lodo, mas também da quantidade de DBO presente. Quanto maior a DBO solúvel, a velocidade de utilização do oxigênio é maior, reduzindo a velocidade de nitrificação e a disponibilidade de oxigênio dissolvido na parte mais interna do floco. As velocidades de nitrificação e desnitrificação devem ocorrer em níveis semelhantes para que esses processos ocorram simultaneamente. A velocidade de nitrificação é reduzida pela baixa concentração de oxigênio dissolvido, enquanto que a velocidade de desnitrificação é reduzida pela baixa concentração de substrato solúvel na parte mais interna do floco. Apenas os sistemas com tempos de detenção elevados como os processos com aeração prolongada são capazes de acomodar simultaneamente a nitrificação e a desnitrificação. Os sistemas com pré-desnitrificação são desfavorecidos pela necessidade de razões elevadas de recirculação interna de lodo, isto é, recirculação de lodo da zona aerada para a câmara anóxica, dependendo da concentração desejada de nitrato no efluente. Os sistemas com pósdesnitrificação são dificultados pela necessidade de introdução de fonte externa de carbono para permitir a desnitrificação. $O$ balanço de alcalinidade é essencial para o equilíbrio e avaliação dos fenômenos que ocorrem nesses processos, sendo que há consumo de alcalinidade na nitrificação e reposição de apenas parte da alcalinidade consumida - aproximadamente a metade - na desnitrificação. Foram observados níveis elevados de nitrificação e desnitrificação em valos de oxidação operando com concentração de oxigênio dissolvido na faixa de 0,1 a $0,4 \mathrm{mg} \cdot \mathrm{L}^{-1} \mathrm{e}$ com idades do lodo elevadas (RITTMAN E LANGELAND, 1985, apud TCHOBANOGLOUS, 2004). A baixa concentração de oxigênio dissolvido resulta em velocidade de nitrificação mais baixa e os flocos de lodos ativados serão mantidos apenas parcialmente aeróbios. As velocidades de nitrificação e desnitrificação são dependentes da cinética da reação, tamanho, estrutura e densidade do floco, carga de DQO rapidamente biodegradável e concentração de oxigênio dissolvido no lodo. O modelo de Monod pode ser adaptado para estimar o efeito da baixa concentração de oxigênio dissolvido nas velocidades de nitrificação e desnitrificação e no desempenho do sistema. O efeito da concentração de oxigênio dissolvido sobre a idade do lodo $\mathrm{R}_{\mathrm{s}}$ para obtenção de concentração de $\mathrm{N}-\mathrm{NH}_{4}{ }^{+}$no efluente de $1,0 \mathrm{mg} \cdot \mathrm{L}^{-1}$ é mostrado na Figura 2.11 . 


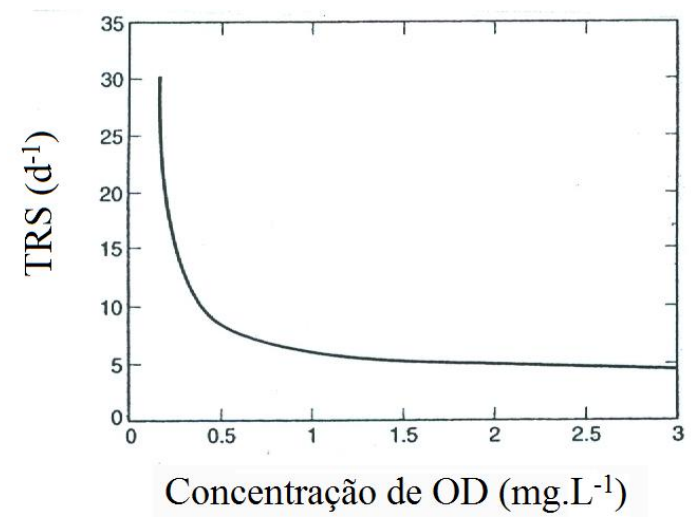

Figura 2.11: Relação entre concentração de oxigênio dissolvido e idade do lodo para obtenção de efluente com $1,0 \mathrm{mg} \cdot \mathrm{L}^{-1}$ de N-NH${ }_{4}{ }^{+}$, a $20^{\circ} \mathrm{C}$ para $\mathrm{K}_{0}=0,5 \mathrm{mg} \cdot \mathrm{L}^{-1}$. Fonte: Adaptado de (METCALF \& EDDY, 2003).

Com base na equação 2.32 a velocidade de nitrificação à concentração de oxigênio dissolvido de $0,2 \mathrm{mg} . \mathrm{L}^{-1}$ corresponde a $24 \%$ da velocidade à concentração de oxigênio dissolvido de 2,0 mg. $L^{-1}$, exigindo idades do lodo de 19,9 e 4,7 dias, respectivamente. A velocidade de desnitrificação pode ser relacionada com a velocidade de utilização do substrato conforme a equação X. Na Tabela 2.8 são apresentados os coeficientes cinéticos utilizados na construção da Figura 2.12.

$r_{s u}=-\left(\frac{k X S}{K_{S}+S}\right)\left(\frac{N O_{3}}{K_{S, N O_{3}}+N O_{3}}\right)\left(\frac{K_{O}^{\prime}}{K_{O}^{\prime}+O D}\right) \eta$

Sendo:

$\mathrm{r}_{\mathrm{su}}$ : velocidade de utilização do substrato;

k: velocidade máxima de utilização do substrato;

$\mathrm{X}$ : Concentração de biomassa;

$\mathrm{K}_{\mathrm{d}}$ : Constante de meia velocidade;

$\mathrm{K}_{\mathrm{S}, \mathrm{NO} 3}$ : Constante de meia velocidade para reação limitada por $\mathrm{NO}_{3}$;

$\mathrm{K}^{\prime}{ }_{\mathrm{O}}$ : Coeficiente de inibição por oxigênio;

$\eta$ : Relação entre a taxa de utilização do substrato com $\mathrm{NO}_{3}{ }^{-}$x OD como aceptor de elétrons

A velocidade de utilização de nitrato pode ser relacionada com a velocidade de utilização do substrato conforme a equação acima, seguindo procedimento em que primeiro é relacionada com a velocidade de utilização de oxigênio, dada por:

Oxigênio Consumido $=\mathrm{DQO}_{\mathrm{b} \text {,removida }}-\mathrm{DQO}_{\text {lodo descartado }}$

$\mathrm{r}_{\mathrm{O}}=\mathrm{Q}\left(\mathrm{S}_{0}-\mathrm{S}\right)-1,48 \mathrm{P}_{\mathrm{X}, \text { bio }}\left(\mathrm{r}_{\mathrm{O}}\right.$ em $\mathrm{kg} / \mathrm{d}$ e $\mathrm{P}_{\mathrm{X}}$ em $\left.\mathrm{kgSSV} / \mathrm{d}\right)$

(Equação 2.33) 
Dividindo-se por V (volume do reator):

$r_{\mathrm{O}}=-\mathrm{r}_{\mathrm{su}}-1,48 \mathrm{r}_{\mathrm{g}}$

Onde:

$\mathrm{r}_{\mathrm{O}}$ : velocidade de utilização de oxigênio, $\mathrm{g} / \mathrm{m}^{3}$.d;

$\mathrm{r}_{\mathrm{su}}$ : velocidade de utilização de substrato, $\mathrm{g} / \mathrm{m}^{3}$.d;

$\mathrm{r}_{\mathrm{g}}$ : velocidade de crescimento líquido de biomassa, $\mathrm{g} / \mathrm{m}^{3} . \mathrm{d}$

Mas $r_{g}=-r_{s u}-k_{d} X$

$r_{O}=-(1-1,48 Y) r_{s u}+1,42 k_{d} X$

(Equação 2.34)

Semi-reações por mol de e $\mathrm{e}^{-}$transferidos:

$0,25 \mathrm{O}_{2}+\mathrm{H}^{+}+\mathrm{e}^{-} \rightarrow 0,25 \mathrm{H}_{2} \mathrm{O}$

$0,20 \mathrm{NO}_{3}+1,2 \mathrm{H}^{+}+\mathrm{e}^{-} \rightarrow 0,1 \mathrm{~N}_{2}+0,6 \mathrm{H}_{2} \mathrm{O}$

$0,33 \mathrm{NO}_{3}+1,33 \mathrm{H}^{+}+\mathrm{e}^{-} \rightarrow 0,67 \mathrm{~N}_{2}+0,17 \mathrm{H}_{2} \mathrm{O}$

$0,25 \times 32 \mathrm{~g} \mathrm{O}_{2} \rightarrow 0,20 \times 14$ (em equivalentes de $\mathrm{N}$ )

Portanto: $8 \mathrm{~g} \mathrm{O}_{2} \rightarrow 2,8 \mathrm{~g} \mathrm{~N}$

E, portanto: $\mathrm{O}_{2} / \mathrm{NO}_{3}(\mathrm{em} \mathrm{N})=8 / 2,8=2,86$

Usando 2,86 equiv $\mathrm{O}_{2} / \mathrm{g} \mathrm{N}-\mathrm{NO}_{3}$, tem-se:

$\mathrm{r}_{\mathrm{NO} 3}=\mathrm{r}_{\mathrm{O}} / 2,86$

$\mathrm{r}_{\mathrm{NO} 3}$ : velocidade de redução de $\mathrm{N}-\mathrm{NO}_{3}, \mathrm{em} \mathrm{g} / \mathrm{m}^{3} . \mathrm{d}$

$r_{\mathrm{NO}_{3}}=-\left(\frac{1-1,48 Y}{2,86}\right) \cdot r_{s u}+\left(\frac{1,48}{2,86}\right) k_{d} \cdot X \cdot \eta$

(Equação 2.35)

$r_{N O_{3}}=-\left(\frac{1-1,48 Y}{2,86}\right)\left(\frac{k X S}{K_{S}+S}\right)\left(\frac{N O_{3}}{K_{S, N O_{3}}+N O_{3}}\right)\left(\frac{K_{O}^{\prime}}{K_{O}^{\prime}+O D}\right)+\left(\frac{1,48}{2,86}\right) k_{d} \cdot X \cdot \eta$ (Equação 2.36)

A velocidade de redução de nitrato pode ser expressa em função das concentrações de $\mathrm{DQO}_{\mathrm{rb}}$, $\mathrm{N}-\mathrm{NO}_{3}, \mathrm{OD}$ e biomassa. O coeficiente de inibição $\mathrm{k}_{0}{ }_{0}$ é de difícil determinação, dependendo do tamanho e estrutura do floco. Na Figura 2.12, o efeito da concentração de OD na velocidade de desnitrificação é lançado em gráfico para valores de $\mathrm{k}_{0}{ }_{0}$ (coeficiente de inibição) de $0,02 \mathrm{mg} . \mathrm{L}^{-1}$ e $0,20 \mathrm{mg} \cdot \mathrm{L}^{-1}$. 
Tabela 2.8: Coeficientes cinéticos típicos do processo de nitrificação

\begin{tabular}{|c|c|c|c|}
\hline Coeficiente & Unidade & Faixa & Valor Típico \\
\hline$\mu_{\mathrm{nm}}$ & $\mathrm{gSSV}^{-1} \cdot \mathrm{gSSV}^{-1} \cdot \mathrm{d}^{-1}$ & $0,20-0,90$ & 0,75 \\
\hline $\mathrm{K}_{\mathrm{N}}$ & $\mathrm{gN} \mathrm{NH}_{4}{ }^{+} \cdot \mathrm{m}^{3}$ & $0,5-1,0$ & 0,74 \\
\hline$Y_{n}$ & $\mathrm{gSSV}^{-1} \cdot \mathrm{gN}^{-\mathrm{NH}_{4}}{ }^{+}$ & $0,10-0,15$ & 0,12 \\
\hline $\mathrm{k}_{\mathrm{dn}}$ & $\mathrm{gSSV}^{-1} \cdot \mathrm{gSSV}^{-1} \cdot \mathrm{d}^{-1}$ & $0,05-0,15$ & 0,18 \\
\hline $\mathrm{K}_{\mathrm{o}}$ & g. $\mathrm{m}^{3}$ & $0,40-0,60$ & 0,50 \\
\hline \multicolumn{4}{|c|}{ Valores de $\theta$ (Coeficiente para correção devida à Temperatura) } \\
\hline$\mu_{\mathrm{nm}}$ & - & $1,06-1,123$ & 1,07 \\
\hline $\mathrm{K}_{\mathrm{N}}$ & - & $1,03-1,123$ & 1,053 \\
\hline$k_{\mathrm{dn}}$ & - & $1,03-1,08$ & 1,04 \\
\hline
\end{tabular}

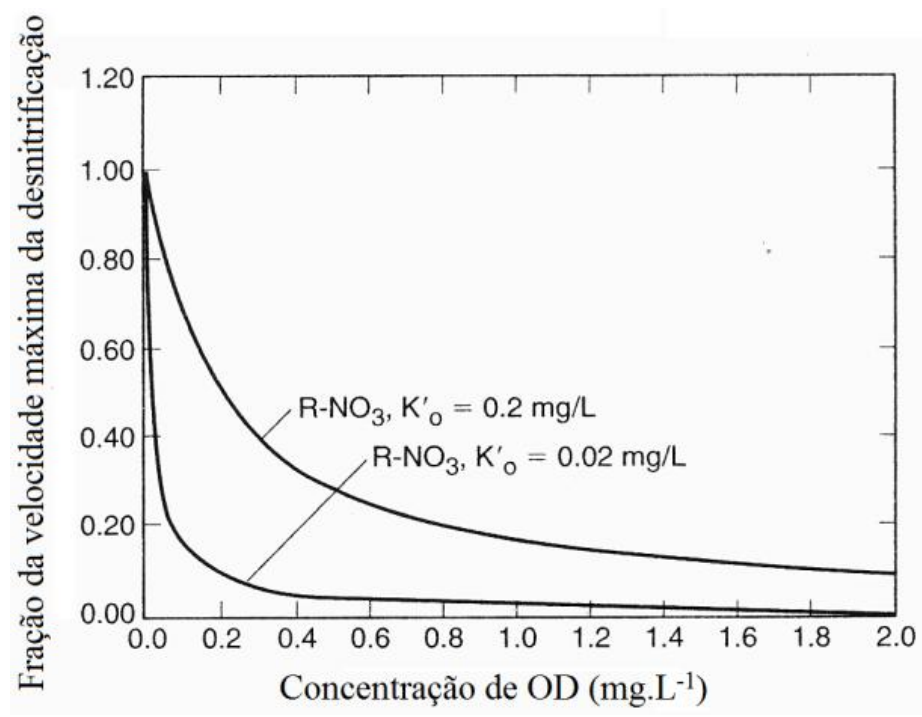

Figura 2.12: Efeito da concentração de OD na velocidade de desnitrificação. Fonte: Adaptado de (METCALF \& EDDY, 2003).

Observa-se que, para concentração de OD de $0,20 \mathrm{mg} \cdot \mathrm{L}^{-1}$, a velocidade de desnitrificação pode ser $10 \%$ ou $50 \%$ da máxima. Em uma concentração de OD ao redor de $0,5 \mathrm{mg} . \mathrm{L}^{-1}$ a velocidade de nitrificação se iguala à velocidade de desnitrificação. HOLMAN e WAREHAM (2005) contestam a ideia de que a concentração ideal de OD seja de $0,5 \mathrm{mg} . \mathrm{L}^{-1}$ para ocorrência de NDS. Estudos realizados por PENG ZHANG e ZHOU QI (2007) relatam que a taxa de nitrificação teve eficiência de $93 \%$ sob uma concentração de OD entre $0,3-0,8 \mathrm{mg} \cdot \mathrm{L}^{-1}$, sem afetar o desenvolvimento da NDS. No entanto, concentrações maiores que $1,0 \mathrm{mg} \cdot \mathrm{L}^{-1}$ inibem a desnitrificação aeróbia. Os autores relataram que com a cultura de bactérias NDS estabelecida no reator, as desnitrificantes aeróbias podem continuar a reduzir nitrogênio em ambiente aeróbio por tempo limitado, desde que as concentrações de OD não excedam 1,0 mg. $\mathrm{L}^{-1}$. Para sistemas com idade do lodo elevada (tempo de retenção hidráulica entre 18 e 30 horas), o tempo é suficiente para obtenção de eficiência elevada na redução de $\mathrm{NO}_{3}$, mesmo ocorrendo inibição devido à presença de OD em baixas concentrações. Conclusivamente, pode ser afirmado que um 
sistema de lodos ativados com aeração prolongada de fluxo contínuo pode ser adaptado para garantir também a desnitrificação do esgoto, implantando-se um sistema controlador da introdução de oxigênio dissolvido. A demanda deve ser suprida sem que ocorra ou deficit ou superavit excessivo, ou seja, mantendo-se a concentração de OD na faixa de 0,3 a $0,8 \mathrm{mg} . \mathrm{L}^{-1}$, apesar da variação da carga orgânica afluente.

\subsubsection{Sistemas de remoção biológica de nitrogênio pelo processo de NDS}

Muitos estudos de remoção biológica de nitrogênio sob condições aeróbias com baixa concentração de oxigênio dissolvido foram realizados desenvolvendo o processo de NDS (COLLOVOGNARELLI e BERTANZA, 1999; HELMER e KUNST, 1998; TURK e MAVINIC, 1989). Segundo os autores COLLOVOGNARELLI e BERTANZA (1999) uma das vantagens do uso da NDS é a remoção da DQO e de nitrogênio na eficiência de processos tradicionais, com menor consumo de energia elétrica na aeração (cerca de 30-40\% a menos), em comparação com um processo de pré-desnitrificação convencional. Outra vantagem é a produção de alcalinidade devido a desnitrificação conjunta e a produção de um efluente com baixa concentração de nitrogênio $\left(<3,0 \mathrm{mgN} . \mathrm{L}^{-1}\right)$ como obtidas em sistemas do tipo Orbal ${ }^{\mathrm{TM}} \mathrm{e}$ Sym-Bio $^{\text {TM }}$ (METCALF \& EDDY, 2003). Ainda, o processo elimina a necessidade de tanques para desnitrificação convencionais e, consequentemente, simplifica o projeto, economizando espaço e tempo. No entanto, uma limitação é a necessidade de um sistema de controle de aeração rigoroso e operação especializada, outra limitação é o tamanho dos tanques que necessitam de grandes volumes. Essas vantagens e limitações se aplicam a maioria dos sistemas que desenvolvem o processo de NDS (KELLER et al, 1997; SEN e DENTEL, 1998; HONG ZHAO et al, 1998; YOO et al ., 1999; ZHAO et al, 1999; METCALF \& EDDY, 2003). O processo de NDS foi aplicado a uma ampla gama de processos de tratamento biológico de águas residuais, tais como:

- Sistemas de biofilme aeróbio (HELMER e KUNST, 1998);

- Sistemas de Membranas (Y. J. CHANG e S.K. TSENG, 1999; WANG, B. et al., 2005; SEUNG H. BAEK e KRISHNA R. PAGILLA, 2008);

- Sistema de remoção biológica de fósforo reforçada (ZENG et al, 2003);

- Sistemas de reatores de leito fluidizado (SEN e DENTEL, 1998; BENT HALLINGSORENSEN e SOREN NORS NIELSEN, 1996);

- Sistemas de reator em bateladas sequenciais - SBR (MUINCH et al, 1996; ZENG et al, 2003; RAYMOND J. ZENG et al, 2003; YING-CHIH CHIU et al, 2006; WANG JIANLONG et al, 2008);

- Sistemas de valos de oxidação (VON HUYSSTEEN, apud TCHOBANOGLOUS et al., 2004; X. CHEN et al, 2010; TRIVEDI e HEINEN, 2000 apud METCALF \& EDDY, 2003);

- Sistemas de fluxo misto de lodos ativados (PENG ZHANG e ZHOU QI, 2007; DAVID THAURÉ et al, 2008). 
Dentre os sistemas citados anteriormente e de interesse nesta pesquisa destacam-se os seguintes processos:

\subsubsection{Valo de oxidação com baixa concentração de OD e monitoramento Sym- Bio $^{\text {TM }}$}

Estudos em valos de oxidação realizados por TRIVEDI e HEINEN (2000) apud METCALF \& EDDY (2003), mostram que é possível obter uma concentração de $\mathrm{NO}_{3}-\mathrm{N}$ e $\mathrm{NH}_{4}-\mathrm{N}$, menores que 3,0 mgN.L $\mathrm{L}^{-1}$ e 1,0 mgN.L $\mathrm{L}^{-1}$ no efluente final pelo processo de NDS. Para manter a concentração de OD abaixo de $0,5 \mathrm{mg} \cdot \mathrm{L}^{-1}$, o sistema de aeração pode ser controlado manualmente ou por um sistema automatizado. No estudo foram utilizados aeradores ao longo do canal do valo de oxidação como se observa na Figura 2.13, formando zonas anóxicas e aeróbias ao decorrer do sistema, permitindo um melhor controle do oxigênio. Além desse controle, os pesquisadores monitoraram as mudanças de NADH (enzima nicotinamida adenina dinucleotídeos) produzida pelas bactérias envolvidas na NDS no lodo ativado, através de uma sonda de medição, conhecido como processo de Sym-Bio ${ }^{\mathrm{TM}}$.

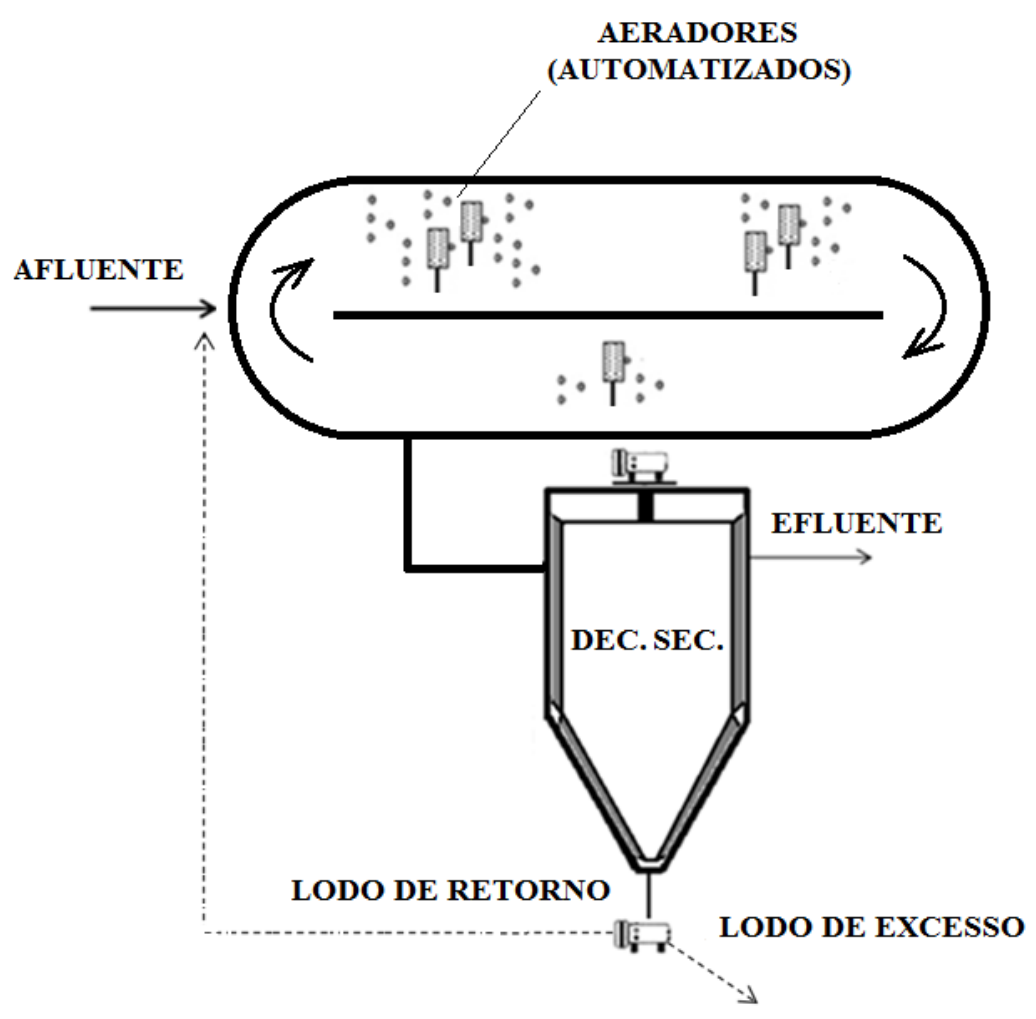

Figura 2.13: Representação esquemática de um sistema de lodo ativado de remoção de nitrogênio, modificado para operar com baixa concentração de OD promovendo o processo de NDS. Fonte: Adaptado de (METCALF \& EDDY, 2003) 


\subsubsection{Sistema de lodo ativado com diferentes concentrações de OD do tipo Orbal $^{\mathrm{TM}}$}

Outro arranjo do sistema de lodo ativado para remoção de nitrogênio pelo processo de NDS, é o sistema Orbal $^{\mathrm{TM}}$ (METCALF \& EDDY, 2003), onde o sistema é operado em canais em série, com diferentes concentrações de OD, conforme se observa na Figura 2.14. Sendo o primeiro canal operado com OD praticamente zero $\left(<0,3 \mathrm{mg} \cdot \mathrm{L}^{-1}\right)$, o segundo canal de 0,5 a 1,5 mg. $\mathrm{L}^{-1}$, e o terceiro canal com alta concentração de OD na faixa de 2,0 a 3,0 mg. $\mathrm{L}^{-1}$.

O primeiro canal recebe o esgoto afluente e o lodo de retorno (geralmente cerca de $50 \%$ do volume total). Os volumes do segundo e terceiro canal, são cerca de 1/3 e 1/6 do volume total, respectivamente. O reciclo de licor misto interno, para os canais externos permite a desnitrificação de nitratos resultantes da nitrificação nos canais internos.

Variações do processo podem operar com ou sem reciclo interno do terceiro para o primeiro canal. O sistema opera com um TRS de 10 a 30 dias, com uma concentração de SSV no licor misto na faixa de 2,0 a 4,0 g.L $\mathrm{L}^{-1}$. O TDH de operação total, normalmente fica entre 10 a 20 horas, sendo de 6 a 10 horas na zona anóxica e de 3 a 6 horas na zona aeróbia.

A vantagem desse sistema é a possível economia com o gasto de energia elétrica para aeração, a produção de alcalinidade devido a desnitrificação conjunta, a produção de um efluente com baixa concentração de nitrogênio $\left(<3,0 \mathrm{mgN} . \mathrm{L}^{-1}\right)$, facilidade da incorporação e construção dos sistemas. No entanto como limitações, é necessário um sistema de controle rigoroso e operação especializada, outra desvantagem é o tamanho dos tanques que necessitam de grandes volumes. Essas vantagens e limitações se aplicam ao sistema do tipo $\mathrm{Sym}_{-} \mathrm{Bio}^{\mathrm{TM}}$ e aos principais processos de NDS. 


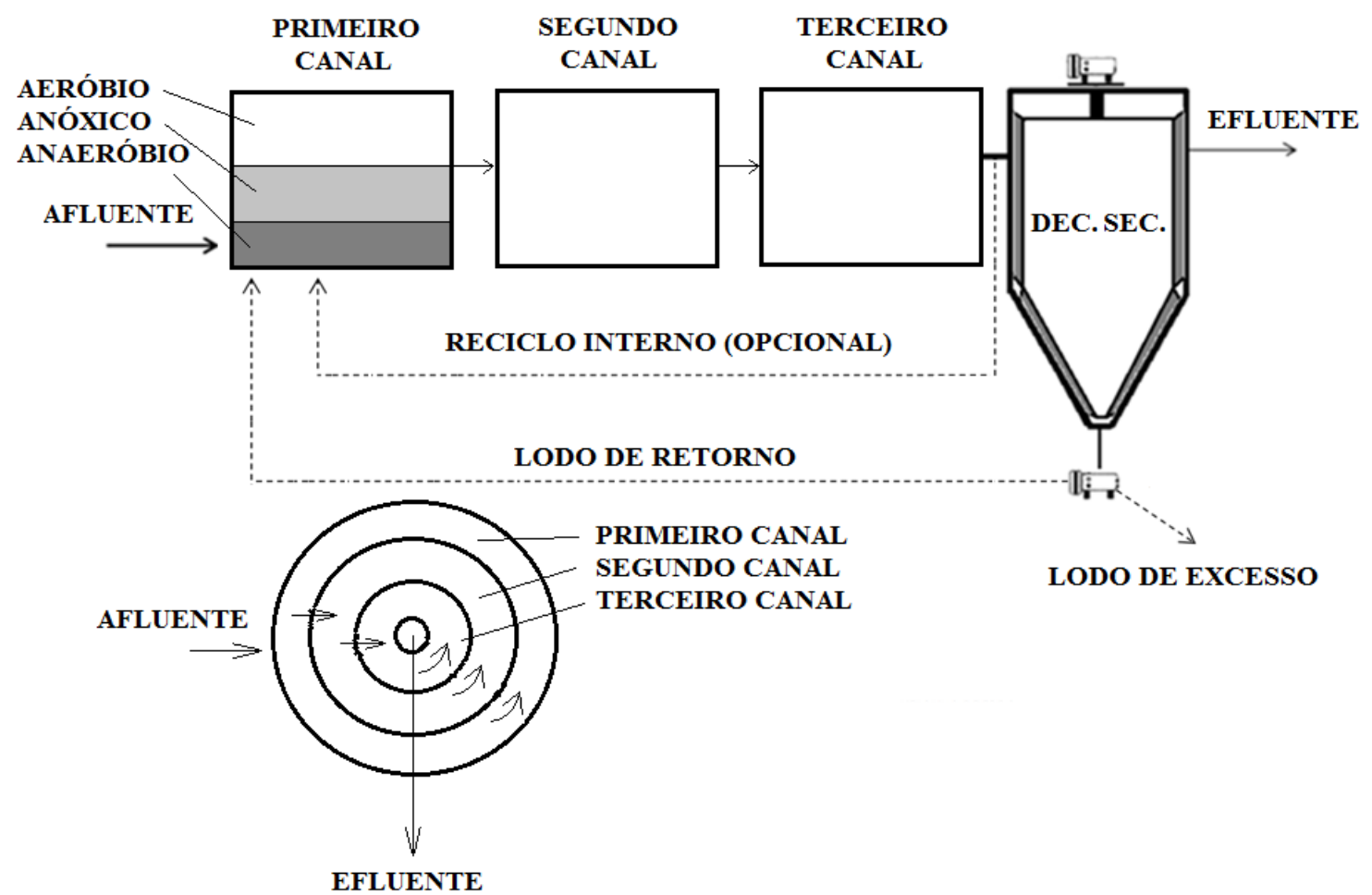

Figura 2.14: Representação esquemática de um sistema de lodo ativado tipo Orbal $^{\mathrm{TM}}$ de remoção de nitrogênio, modificado para operar com baixa concentração de OD promovendo o processo de NDS. Fonte: Adaptado de (METCALF \& EDDY, 2003)

\subsubsection{Sistema de lodo ativado por aeração prolongada de fluxo contínuo}

Os autores PENG ZHANG e ZHOU QI, 2007 realizaram pesquisas em um sistema piloto de lodo ativado por aeração prolongada alimentado em fluxo contínuo com esgoto sintético. $\mathrm{O}$ arranjo do sistema foi semelhante ao da Figura 2.1 apresentada na seção 2.1 desse Capítulo, com a exceção de um misturador no tanque de aeração. Os autores operaram o sistema com TRS elevados, na faixa de 60, 45 e 30 dias com razões de A/M de 0,05-0,30gDQO.gSSVLM.d ${ }^{-1}$. A concentração de OD no tanque de aeração foi mantida na faixa de $0,3-0,8 \mathrm{mg} \cdot \mathrm{L}^{-1}$. O estudo mostra a ocorrência do processo de NDS em todas as condições. Porém, na condição onde o TRS de 45 dias com razão de A/M de 0,1gDQO.gSSVLM.d ${ }^{-1}$ e uma relação $\mathrm{C} / \mathrm{N}$ de 10 , o sistema apresentou uma melhor eficiência, chegando a 93\% na nitrificação, e acima de $60 \%$ na remoção de nitrogênio total. Estudos com baixa concentração de OD $(0,5 \mathrm{mg} . \mathrm{L}-1)$ conduzidos por THAURÉ et al. (2008) em uma ETE localizada próxima de Toulouse com capacidade de $1000 \mathrm{~m}^{3} / \mathrm{d}(11,6 \mathrm{~L} / \mathrm{s})$, obteve uma redução significativa de energia elétrica na aeração, na ordem de 10 a 50\%. A ETE foi operada com TRS de 30 a 40 dias, com razão A/M de 0,03 a 0,05 kgDQO.kgSSVLM.d ${ }^{-1}$ e concentração de SSV no licor misto de 3 a 4 g.L $L^{-1}$. Os autores ainda relatam que não foi observado o aparecimento de bactérias filamentosas no licor misto e a 
ocorrência do processo de NDS durante o controle de OD em baixas concentrações. Com base na revisão apresentada, nota-se, que é possível obter o processo de NDS com eficiência elevada em um arranjo praticamente simples, que é o caso do sistema escolhido nesta pesquisa.

\subsection{Respirometria}

A Respirometria é uma ferramenta que, em geral, possibilita a medição da taxa de consumo de oxigênio (TCO) exercida pelos microrganismos aeróbios. Essa medição é realizada através de determinações contínuas ou semi-contínuas do consumo de oxigênio, quando o respirômetro utilizado é aberto.

Os respirômetros abertos caracterizam-se pela exposição do meio de reação ao ambiente atmosférico, considerando a reoxigenação através de aeradores em sua estrutura de funcionamento. Quando o respirômetro é aberto, pode ser do tipo contínuo (aeração constante) ou semi-contínuo (intervalos de aeração e não aeração).

Uma comparação entre os respirômetros abertos feita por FERREIRA, (2002) apud SILVA FILHO, (2009) indica que o método semi-contínuo ainda é apresentado como o mais preciso, e mais utilizado para desenvolvimento de estudos em sistemas de lodo ativado.

Para a investigação experimental dessa dissertação, foi utilizado o respirômetro modelo Beluga S32c, do tipo aberto e semi-contínuo, desenvolvido no Departamento de Engenharia Elétrica da UFCG - Universidade Federal de Campina Grande (CATUNDA et al., 1996).

Para a determinação da TCO, o respirômetro Beluga realiza a medição direta da concentração de oxigênio dissolvido, além da temperatura quando usando um eletrodo do tipo YSI5718 ou equivalente. A Figura 2.15 mostra o layout de um respirograma obtido por meio do software S4.021C em uma batelada do lodo excedente do sistema de tratamento, desse estudo. Nota-se no primeiro quadro as medições de OD na faixa de $\left(0,3-0,8 \mathrm{mg} \cdot \mathrm{L}^{-1}\right)$ e no quadro abaixo as medições da TCO exógena. 


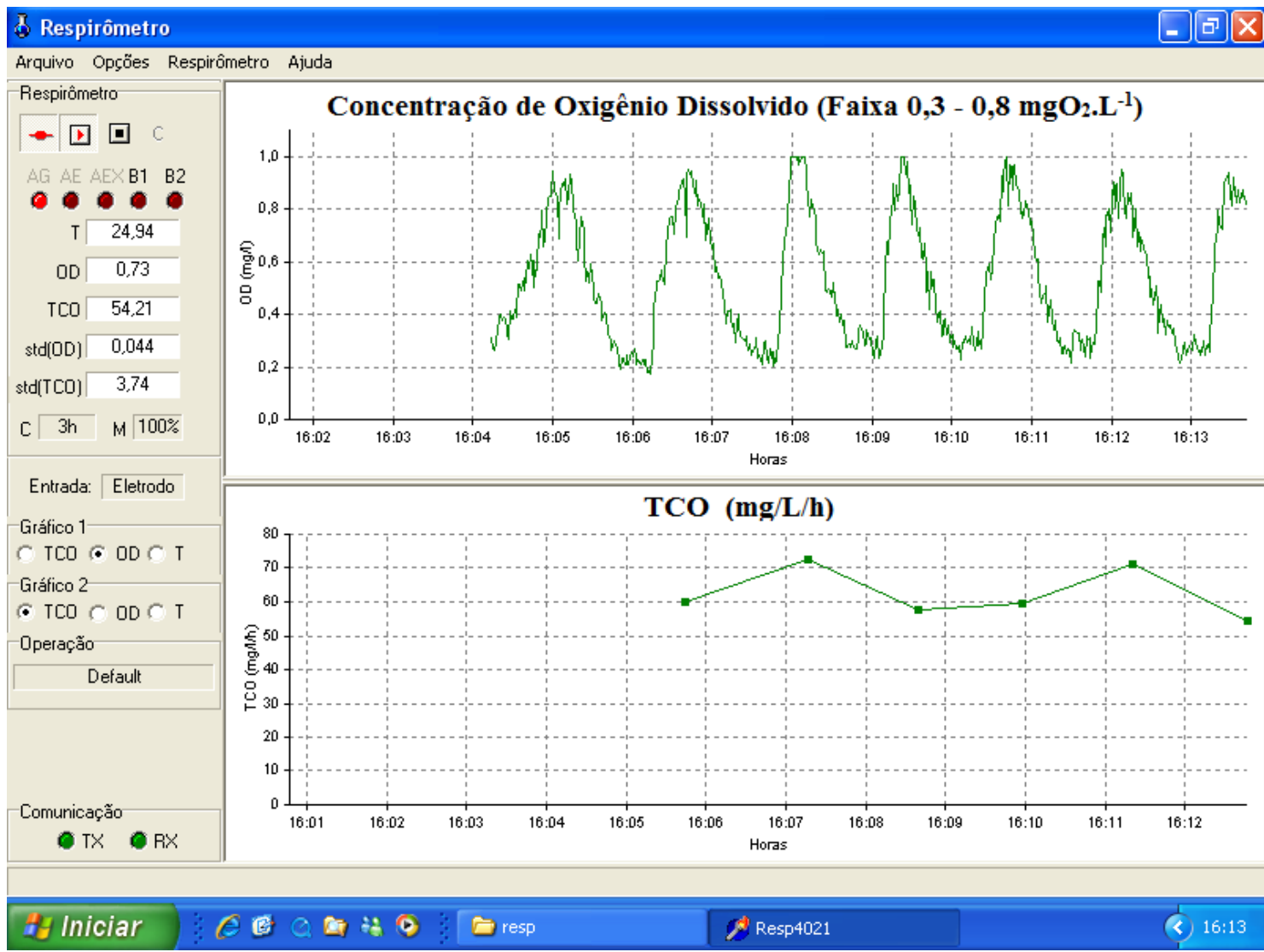

Figura 2.15: Tela principal do software 4.0 do respirômetro e seus principais componentes 


\section{MATERIAIS E MÉTODOS}

\subsection{Introdução}

\subsubsection{Sistema de lodo ativado com aeração prolongada}

Uma planta em escala piloto, alimentada com esgoto sanitário com fluxo constante sob condições de lodo ativado por aeração prolongada foi instalado no Centro Tecnológico de Hidráulica - Escola Politécnica da Universidade de São Paulo (USP) - São Paulo - Brasil. A Figura 3.1 mostra o arranjo experimental utilizado neste estudo. A aeração é feita por ar difuso para garantir o suprimento de oxigênio. Para evitar a sedimentação, misturadores foram instalados no tanque de aeração. Uma válvula solenóide controlada por um medidor de oxigênio dissolvido (OD) foi utilizado para manter a concentração de OD na faixa de $0,3-0,8 \mathrm{mg} \cdot \mathrm{L}^{-1}$. O volume útil do tanque de aeração é 183L. A concentração de $\mathrm{OD}, \mathrm{pH}$, temperatura e potencial de oxidação-redução (ORP), foram medidos e monitorados durante todo o estudo online, por meio de sensores instalados no tanque de aeração. Os dados foram registrados em um computador, por um data logger. $\mathrm{O}$ reator foi mantido em temperatura ambiente e o $\mathrm{pH}$ do lodo foi controlado na faixa de 6,5 a 7,5 .

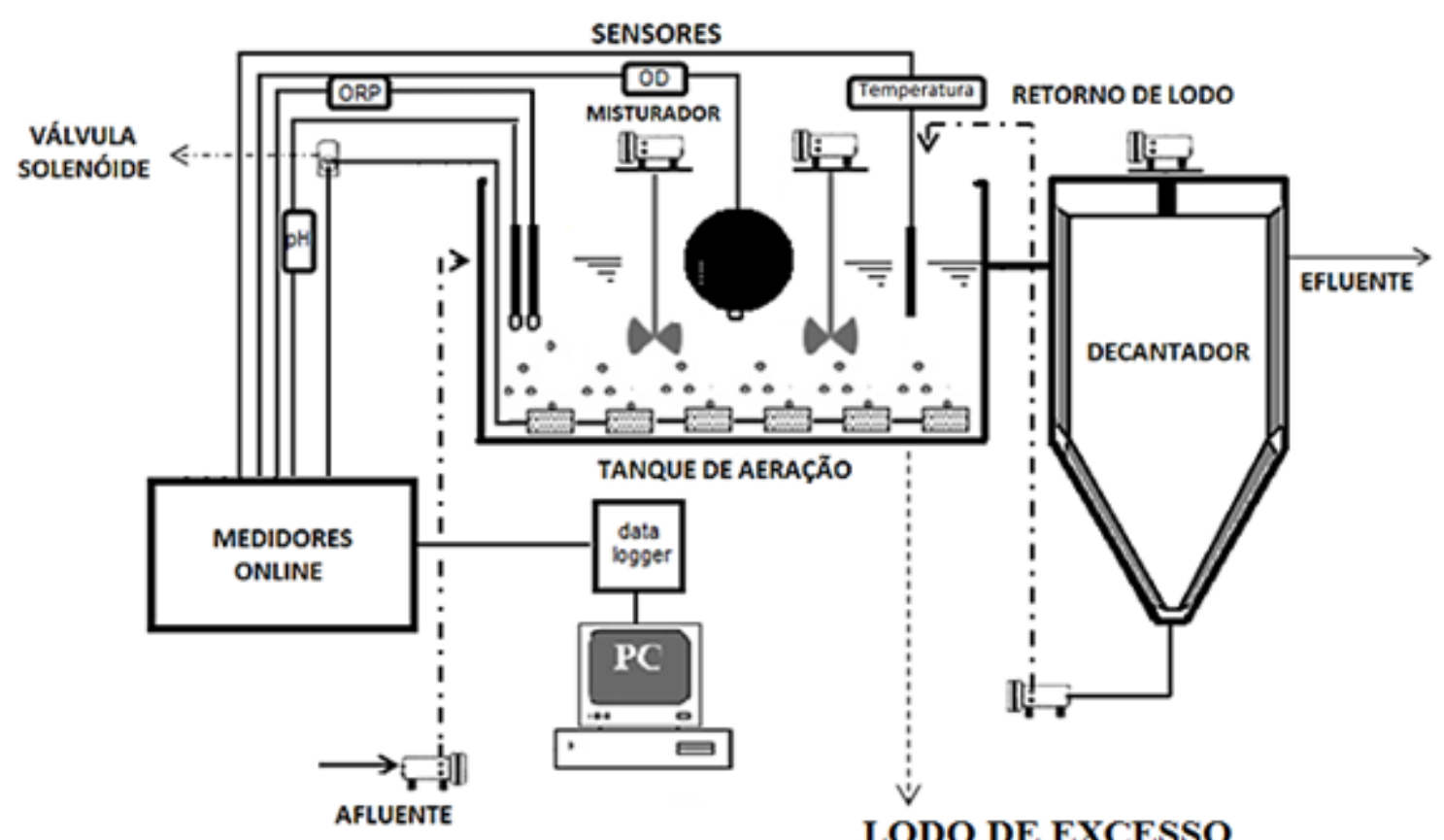

Figura 3.1: Corte esquemático do sistema de lodo ativado com sensores de medição online 


\subsubsection{Configuração da planta piloto}

- Tanque de Aeração: Construído em acrílico com as seguintes dimensões: 0,45 m de largura, $0,90 \mathrm{~m}$ de comprimento e $0,65 \mathrm{~m}$ de altura. $\mathrm{O}$ volume total é de 263 litros. O volume útil é de 183 litros (Figura 3.2).

- Bomba dosadora de esgoto bruto: O esgoto é introduzido no tanque de aeração por uma bomba dosadora Prominent, modelo Vario VAMB 0763.

- Fornecimento de ar: Produzido por um compressor de ar e distribuído por diversas mangueiras com pedras porosas em suas extremidades fixas no fundo do tanque.

- Decantador Secundário: Foi construído em acrílico, com forma circular, tem as seguintes proporções: parte superior cilíndrica com altura $1,05 \mathrm{~m}$ e diâmetro de $0,50 \mathrm{~m}$ e a parte inferior tipo cone invertido, com inclinação nas paredes de, aproximadamente, $60^{\circ}$ em relação horizontal e altura de 0,50 m. Há um raspador mecanizado de lodo para remoção do lodo das paredes do decantador que consiste em uma estrutura metálica com bordas de borracha acionada por um conjunto motoredutor $1 / 4 \mathrm{HP}$ com capacidade de variação da velocidade de rotação (Figura 3.3).

- Bomba de retorno de lodo: Bomba Prominent, modelo Vario VAMB 07063, que recalca o lodo até o reator aeróbio.

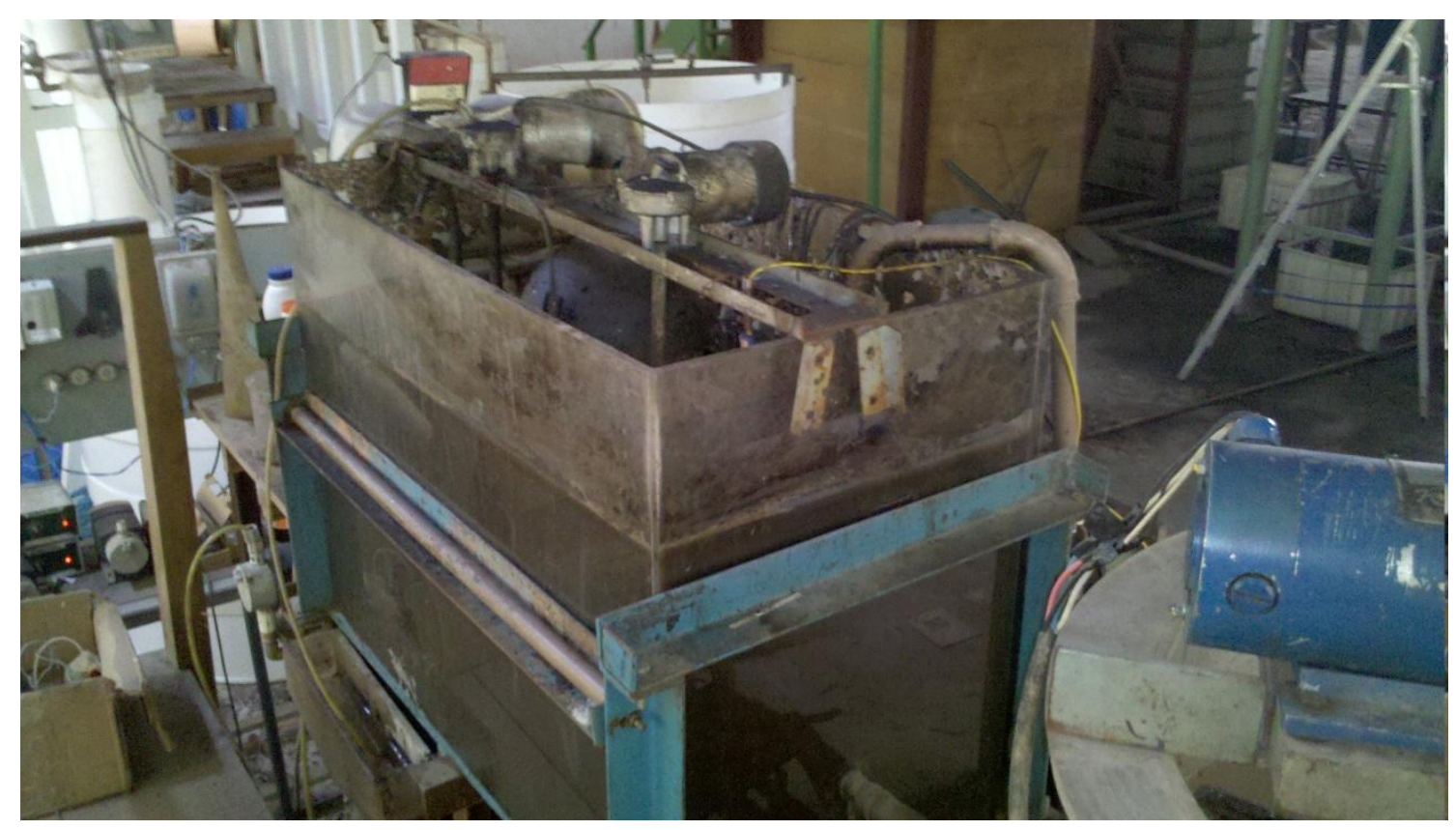

Figura 3.2: Visão geral do tanque de aeração com misturadores e sensores de controle online 


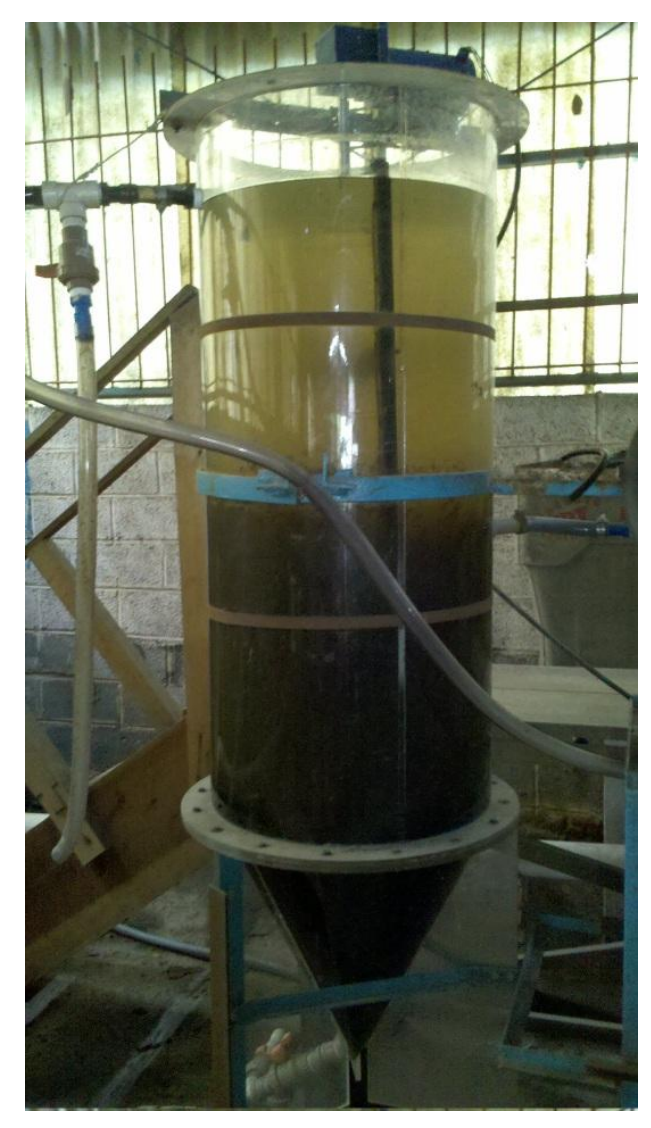

Figura 3.3: Visão geral do decantador com raspador automatizado

\subsection{Controle de oxigênio dissolvido}

O controle automatizado da aeração no sistema de lodo ativado com aeração prolongada de fluxo contínuo foi realizado através de um medidor/controlador de OD Prominent - Dulcometer D1Ca, com sinal de saída de 0/4-20mA, valor de controle. O sensor de oxigênio, com faixa de trabalho de 0,0 -10,0 mg. $\mathrm{L}^{-1}$ foi instalado no tanque de aeração em contato com o licor misto. $\mathrm{O}$ registro das leituras no computador (planilha Excel) foi feito por meio de um data logger de baixo custo - DMA easy lab AG que foi ligado nas saídas de controle (0/4-20mA) do medidor/controlador. As leituras foram registradas a cada 10 segundos diariamente (online) durante todo período do estudo. Para manter uma concentração baixa de oxigênio dissolvido (0,3-0,8 mg. $\left.\mathrm{L}^{-1}\right)$ no tanque de aeração, independente da variação da carga orgânica afluente, foi instalado no sistema medidor/controlador e na linha de ar, uma válvula solenóide CONAI 24VDC, que permitiu controlar a introdução de oxigênio no tanque na faixa de OD proposta no estudo. A Figura 3.4 mostra os principais equipamentos utilizados para o controle automatizado da aeração. 

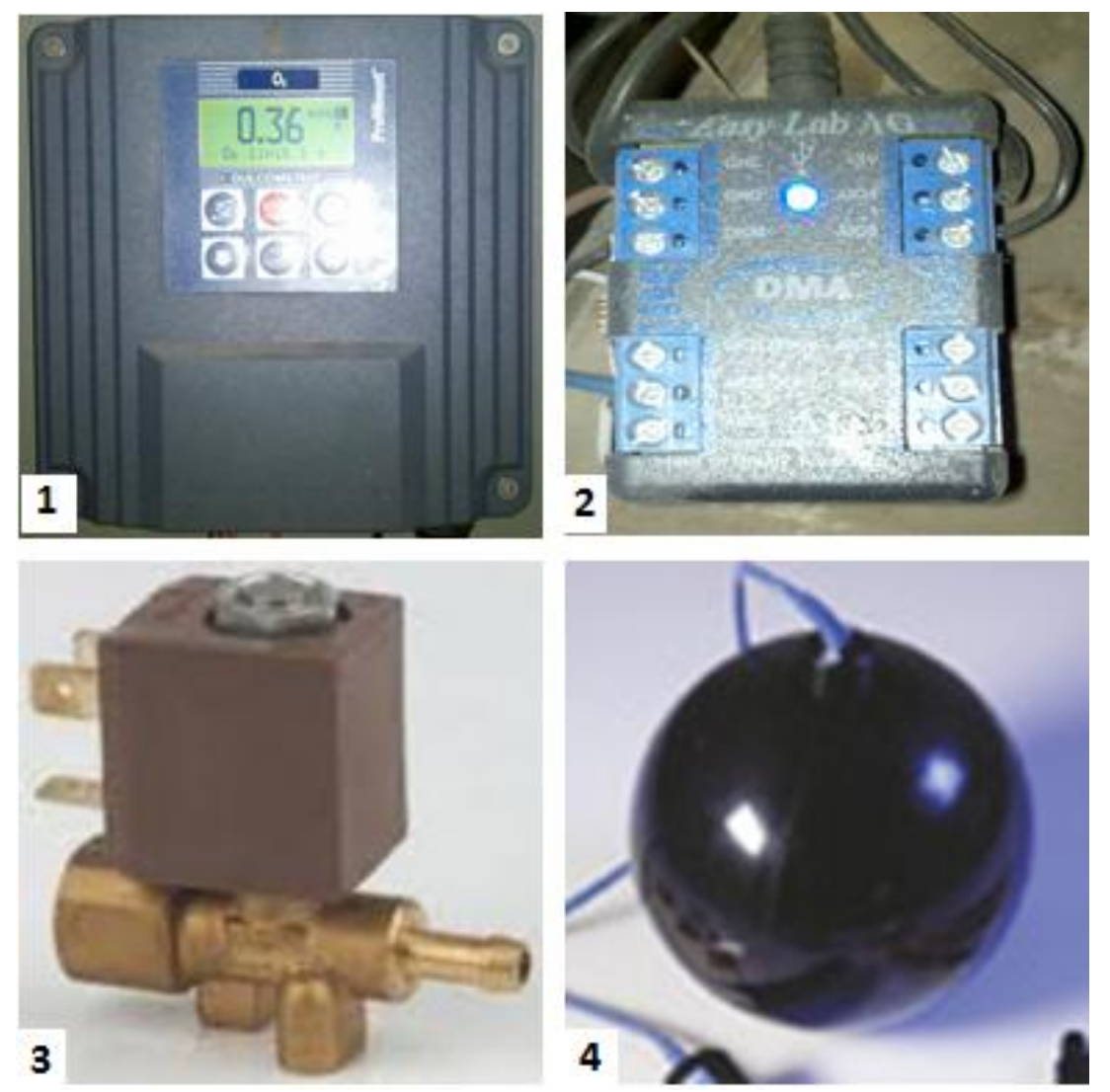

Figura 3.4: Representação do sistema de controle de oxigênio (1) medidor/controlador, (2) data logger, (3) válvula solenóide e (4) sensor de OD.

\subsection{Controle do ORP, pH e Temperatura}

O controle automatizado do ORP e pH no sistema de lodo ativado com aeração prolongada de fluxo contínuo foi realizado por meio de um medidor/controlador Prominent - Dulcometer DMTAW090R10S0000 e um Medidor Dulcometer DMTAW090P10S0000, respectivamente. Ambos, com sinal de saída de 4-20mA, valor de controle. Os sensores foram instalados no tanque de aeração em contato com o licor misto.

Para o monitoramento da Temperatura foi utilizado um Termopar para líquidos - Tipo K MINIPA, com faixa de trabalho de -40 a $240{ }^{\circ} \mathrm{C}$. O registro das leituras no computador (planilha Excel) foram feitas por meio de um data logger - DMA Easy Lab AG que foi ligado nas saídas de controle (4-20mA) do medidor/controlador. O termopar foi ligado diretamente ao data logger. As leituras foram registradas a cada 10 segundos diariamente (online) durante todo período do estudo. A Figura 3.5 e 3.6 mostram os equipamentos utilizados para o controle online das variáveis ORP, pH e Temperatura. 


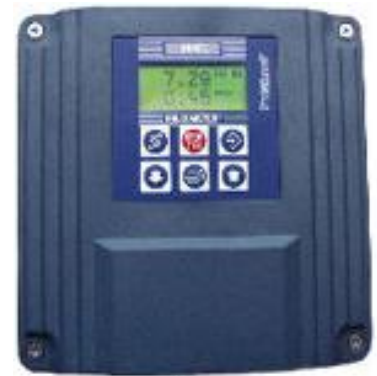

1

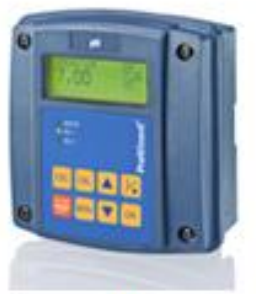

2

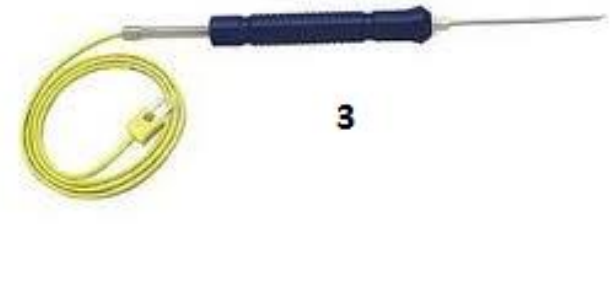

Figura 3.5: Controladores online, (1) medidor de ORP, (2) pH e (3) temperatura

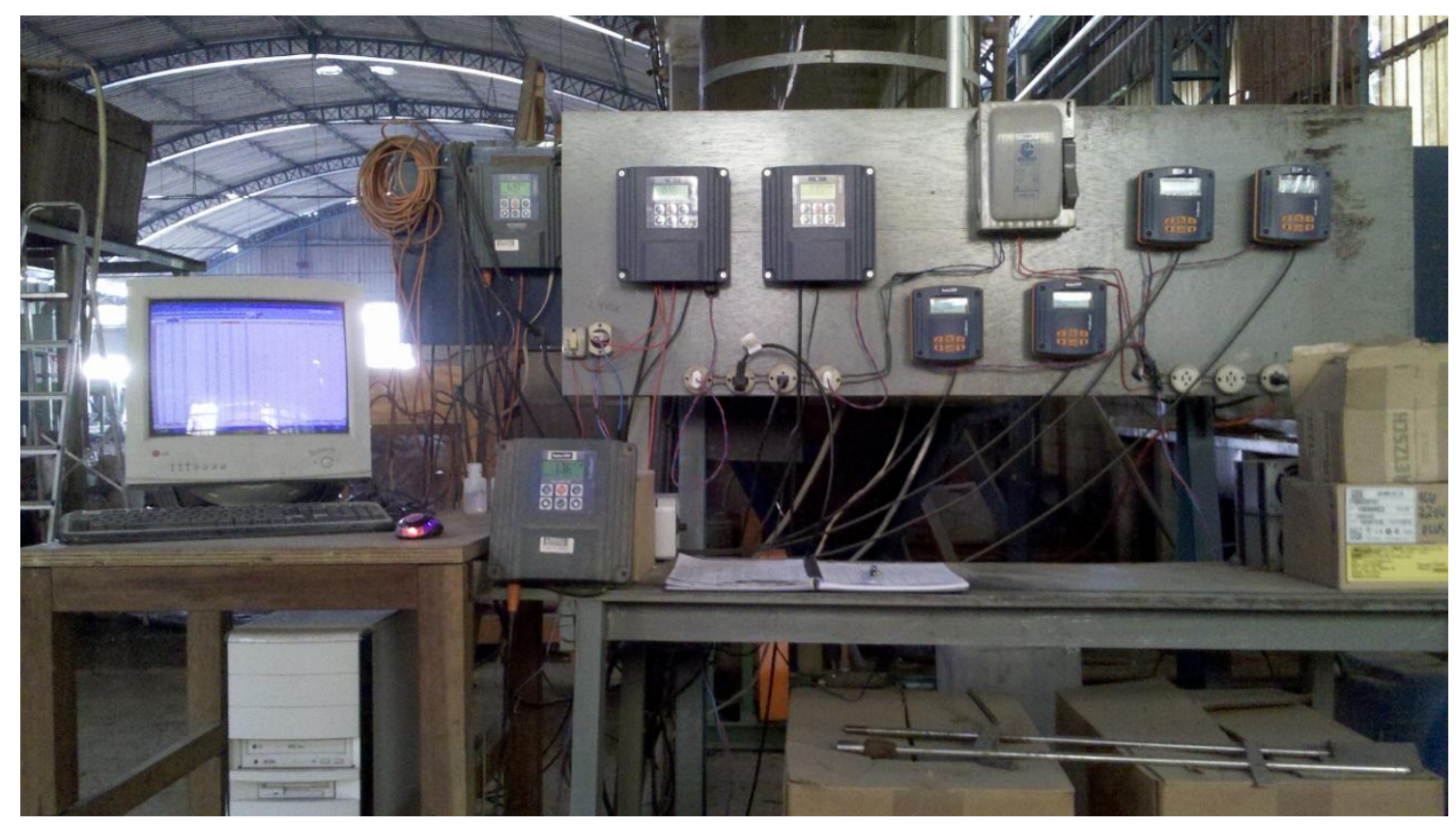

Figura 3.6: Visão geral dos equipamentos de controle/monitoramento online

\subsection{Características do esgoto sanitário}

O esgoto que alimenta o sistema vem do conjunto residencial (CRUSP) e do restaurante central da Universidade de São Paulo - USP. É bombeado para a entrada do tratamento preliminar, composto por uma grade mecanizada (step-screen) e uma caixa de areia, de onde é bombeado para o tanque de aeração, como se observa na Figura 3.7. Na Tabela 3.1, podem-se observar as principais características do esgoto sanitário bruto, nas Fases I, II e III do estudo. 


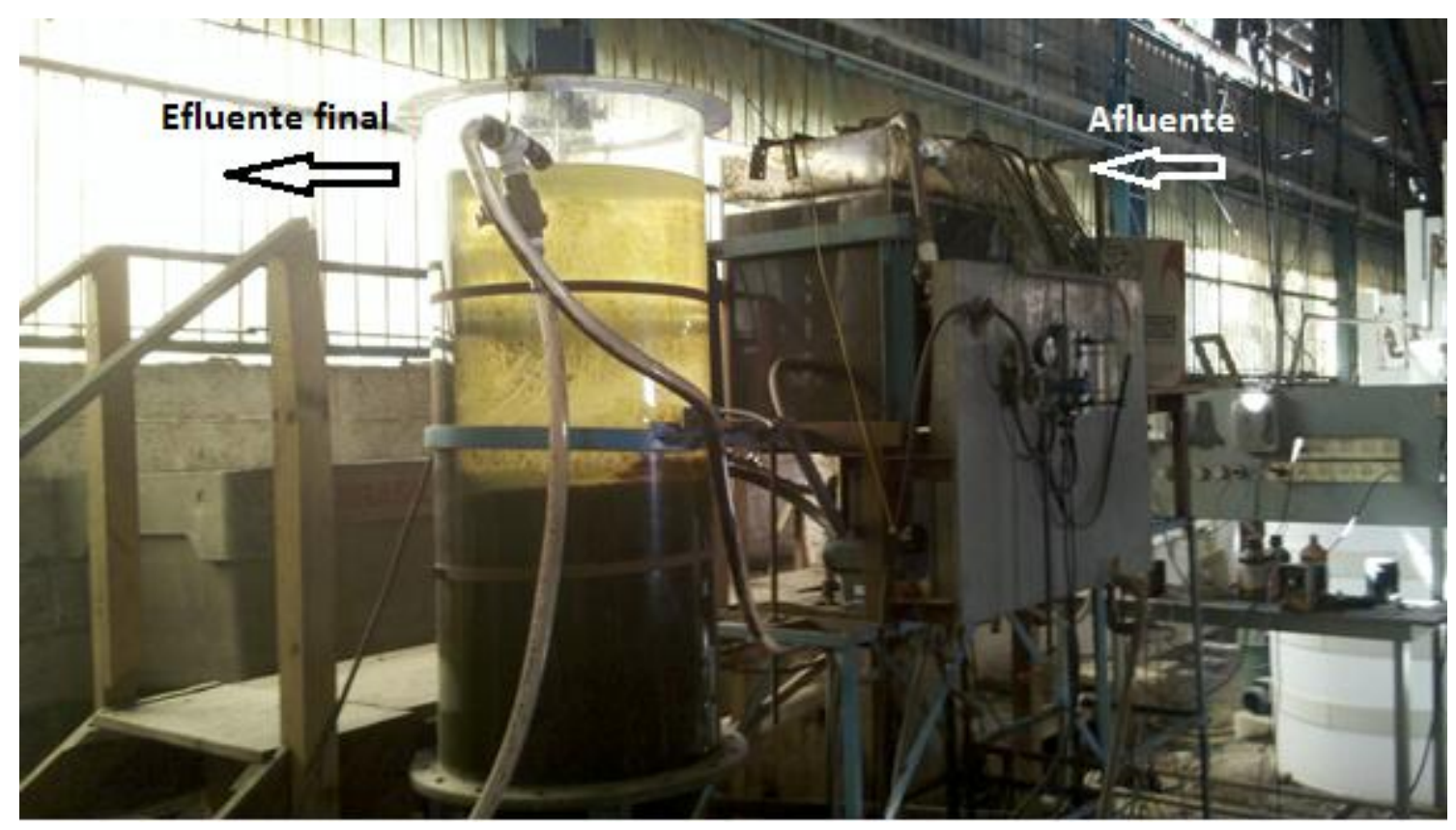

Figura 3.7: Sistema de lodo ativado com aeração prolongada de fluxo contínuo

Tabela 3.1: Características do esgoto sanitário afluente durante as Fases I, II e III do estudo.

\begin{tabular}{|c|c|c|c|}
\hline Variáveis & Fase I & Fase II & Fase III \\
\hline TDQO (mg.L $\left.\mathrm{L}^{-1}\right)$ & $511 \pm 87$ & $537 \pm 62$ & $587 \pm 172$ \\
\hline SDQO* $^{*}\left(m g . L^{-1}\right)$ & $238 \pm 59$ & $280 \pm 48$ & $282 \pm 123$ \\
\hline TDBO (mg.L $\left.\mathrm{L}^{-1}\right)$ & $245 \pm 42$ & $269 \pm 32$ & $384 \pm 122$ \\
\hline $\mathrm{SDBO}^{*}\left(\mathrm{mg} \cdot \mathrm{L}^{-1}\right)$ & $114 \pm 28$ & $139 \pm 24$ & $168 \pm 8$ \\
\hline SST (mg.L $\left.{ }^{-1}\right)$ & $107 \pm 53$ & $111 \pm 91$ & $94 \pm 34$ \\
\hline $\mathrm{NH}_{4}-\mathrm{N}\left(\mathrm{mgN} \cdot \mathrm{L}^{-1}\right)$ & $61 \pm 9$ & $64 \pm 5$ & $52 \pm 6$ \\
\hline $\mathrm{PO}_{4}-\mathrm{P}\left(\mathrm{mgP} . \mathrm{L}^{-1}\right)$ & $6 \pm 0,7$ & $8 \pm 1.1$ & $6 \pm 1.0$ \\
\hline NTK $\left(m g N . L^{-1}\right)$ & $77 \pm 12$ & $75 \pm 9$ & $61 \pm 8$ \\
\hline ALCALINIDADE $\left(\mathrm{mgCaCO}_{3} \cdot \mathrm{L}^{-1}\right)$ & $217 \pm 23$ & $232 \pm 15$ & $203 \pm 23$ \\
\hline $\mathrm{NO}_{\mathrm{x}}-\mathrm{N}\left(\mathrm{mgN} . \mathrm{L}^{-1}\right)$ & $<0,5$ & $<0,5$ & $<0,5$ \\
\hline $\mathrm{N}$ (amostras) & 19 & 17 & 23 \\
\hline
\end{tabular}

* Amostra solúvel, filtrada em papel de filtro de $0,45 \mu \mathrm{m}$

\subsection{Fase de Aclimatação}

Na partida do sistema, o tanque de aeração foi preenchido com lodo ativado, com concentração de sólidos de 3,5 g.L $\mathrm{L}^{-1}$. A concentração inicial de oxigênio dissolvido foi mantida na faixa de 0,3-0,8 mg. $\mathrm{L}^{-1}$ no tanque de aeração. O tempo de retenção de sólidos (TRS) foi mantido por 40 dias. Após 80 dias de operação, observou-se que o sistema encontrava-se em condições estáveis, com IVL de $100 \mathrm{~mL} \cdot \mathrm{g}^{-1}$, eficiência de remoção de DQO e de nitrogênio da ordem de $90 \%$, considerando-se o término da Fase de aclimatação. 


\subsection{Condições de operação e ensaios laboratoriais}

O sistema de lodo ativado com aeração prolongada de fluxo contínuo foi operado em três Fases, com variações na razão A/M e TRS, como mostra a Tabela 3.2. A concentração de OD na faixa de $0,3-0,8 \mathrm{mg} \cdot \mathrm{L}^{-1}$ foi definida de modo que não ocorra nenhum déficit ou excesso de demanda por oxigênio, apesar da variação da carga orgânica. Os métodos analíticos utilizados foram descritos no Standard Methods for Examination of Water and Wastewater, $21^{\text {th }}$ Edition (APHA, 2005). As concentrações de amônia, nitrito, nitrato e fósforo, foram quantificados em um cromatógrafo de íons (Dionex-100, coluna ASCR2_mm e CSCR2_mm) e Flow Injection Analysis (FIA). Os principais parâmetros físico-químicos e a frequência de amostragem realizada são apresentados na Tabela 3.3. As determinações laboratoriais foram realizadas no Laboratório de Saneamento Prof. Lucas Nogueira Garcez - Escola Politécnica da USP.

Tabela 3.2: Resumo das condições de operação das Fases I, II e III.

\begin{tabular}{|c|c|c|c|}
\hline Parâmetros & Fase I & Fase II & Fase III \\
\hline Dias de operação & 80 & 80 & 80 \\
\hline Volume do reator $\left(\mathrm{L}^{-1}\right)$ & 183 & 183 & 183 \\
\hline Vazão afluente média $\left({\left.\mathrm{L} . \mathrm{d}^{-1}\right)}^{-1}\right.$ & 136 & 178 & 183 \\
\hline Fator de recirculação de lodo (r) & $0,8-1,0$ & $0,8-1,0$ & $0,7-1,0$ \\
\hline TRS (dias) & 40 & 30 & 20 \\
\hline A/M (g.DBOg.SSV ${ }^{-1} d^{-1}$ ) & 0,050 & 0,075 & 0,100 \\
\hline Concentração de OD $\left(\mathrm{mg} . \mathrm{L}^{-1}\right)$ & $0,3-0,8$ & $0,3-0,8$ & $0,3-0,8$ \\
\hline $\mathrm{N}$ (amostras) & 19 & 17 & 23 \\
\hline
\end{tabular}

Tabela 3.3: Programa de monitoramento do sistema piloto durante as Fases I, II e III.

\begin{tabular}{|c|c|c|c|c|}
\hline Variáveis & Unidade & Afluente & Licor Misto & Efluente \\
\hline Temperatura & ${ }^{\circ} \mathrm{C}$ & - & Online & - \\
\hline REDOX & $\mathrm{mV}$ & - & Online & - \\
\hline $\mathrm{pH}$ & - & 2 x Semana & Online & 2 x Semana \\
\hline Oxigênio Dissolvido & mg.L ${ }^{-1}$ & - & Online & - \\
\hline DQO total & $\mathrm{mg} \cdot \mathrm{L}^{-1}$ & $2 \times$ Semana & $2 \times$ Semana & 2 x Semana \\
\hline DQO solúvel & mg.L. $\mathrm{L}^{-1}$ & 2 x Semana & $2 \times$ Semana & 2 x Semana \\
\hline $\mathrm{DBO}_{5,20}$ total & $\mathrm{mg} \cdot \mathrm{L}^{-1}$ & 2 x Semana & $2 \times$ Semana & 2 x Semana \\
\hline $\mathrm{DBO}_{5,20}$ solúvel & $\mathrm{mg} \cdot \mathrm{L}^{-1}$ & $2 \mathrm{x}$ Semana & $2 \times$ Semana & 2 x Semana \\
\hline Série de sólidos & $\mathrm{mg} . \mathrm{L}^{-1}$ & 2 x Semana & $2 \times$ Semana & $2 \times$ Semana \\
\hline N-NTK & mgN.L $\mathrm{L}^{-1}$ & 2 x Semana & $2 \times$ Semana & 2 x Semana \\
\hline $\mathrm{N}^{-\mathrm{NH}_{3}}{ }^{-}$ & mgN.L ${ }^{-1}$ & 2 x Semana & $2 \times$ Semana & 2 x Semana \\
\hline $\mathrm{N}^{-\mathrm{NO}_{2}}{ }^{-}$ & $\operatorname{mgN} . L^{-1}$ & 2 x Semana & $2 \times$ Semana & 2 x Semana \\
\hline $\mathrm{N}-\mathrm{NO}_{3}^{-}$ & mgN.L ${ }^{-1}$ & 2 x Semana & $2 \times$ Semana & $2 \times$ Semana \\
\hline $\mathrm{P}-\mathrm{PO}_{4}$ total & mgP.L ${ }^{-1}$ & $2 \mathrm{x}$ Semana & $2 \times$ Semana & 2 x Semana \\
\hline $\mathrm{P}_{-} \mathrm{PO}_{4}$ solúvel & $\mathrm{mgP} \cdot \mathrm{L}^{-1}$ & 2 x Semana & $2 \times$ Semana & 2 x Semana \\
\hline Alcalinidade & $\mathrm{mgCaCO}_{3} \cdot \mathrm{L}^{-1}$ & 2 x Semana & $2 \times$ Semana & 2 x Semana \\
\hline IVL & $\mathrm{mL} \cdot \mathrm{g}^{-1}$ & - & $2 \times$ Semana & - \\
\hline Respirometria (TCO) & $\mathrm{mgO}_{2} \cdot \mathrm{L} \cdot \mathrm{h}^{-1}$ & - & $1 \mathrm{x}$ Semana & - \\
\hline Microbiologia do lodo & 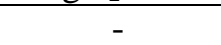 & - & $2 \times$ Semana & 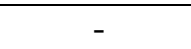 \\
\hline
\end{tabular}




\subsection{Medição da TCO total "in loco"}

A determinação da TCO no reator aeróbio foi feita online, por meio de medições de OD registradas em função do tempo, dentro da faixa de estudo $\left(0,3\right.$ a $\left.0,8 \mathrm{mg} \cdot \mathrm{L}^{-1}\right)$, ou seja, o OD inicial considerado para o teste foi $0,8 \mathrm{mg} \cdot \mathrm{L}^{-1} \mathrm{e}$, em seguida, quando a aeração era interrompida, os valores de OD foram registrados em função do tempo até que o valor de OD chegasse a uma concentração baixa $\left(0,3 \mathrm{mg} \cdot \mathrm{L}^{-1}\right)$ para, então, finalizar o teste e religar a aeração. Para o cálculo da TCO utilizou-se a equação 3.1. A TCO foi utilizada para monitorar a atividade metabólica do lodo e para calcular o balanço de massa.

$$
\mathrm{TCO}=\mathrm{dOD} / \mathrm{dt}=\left(\mathrm{OD}_{\text {máximo }}-\mathrm{OD}_{\text {mínimo }}\right) /\left(\mathrm{t}_{1}-\mathrm{t}_{\mathrm{o}}\right)
$$

\subsection{Balanços de massa do material orgânico e nitrogenado}

\subsubsection{Balanço de massa do material orgânico}

Os cálculos do balanço de massa do material orgânico do sistema de lodo ativado por aeração prolongada foram realizados conforme descrito no capítulo 2, seção 2.2.1. As equações referentes ao balanço encontram-se na Tabela 3.4. O detalhamento de cada termo contido nessas equações está descrito na Lista de Símbolos. A Equação 3.2.0, possibilita a determinação de $\left(\mathrm{mS}_{\mathrm{te}}\right)$ que é a massa de DQO detectada no efluente dos sistemas. Considerando os sistemas estudados em estado estacionário e, assim o valor de DQO determinado no efluente de cada sistema era equivalente ao material não biodegradável solúvel, já que somente esta fração da DQO poderia ter sido expulsa como efluente líquido. A Equação 3.2.1 apresenta a fração de DQO afluente que é descarregada com o lodo de excesso $\left(\mathrm{mS}_{\mathrm{xv}}\right)$. A Equação 3.2.2 expressa à fração de DQO afluente que é oxidada no sistema $\left(\mathrm{mS}_{\mathrm{o}}\right)$. Por fim, o balanço de massa do material orgânico para o sistema, $\left(\mathrm{B}_{\mathrm{o}}\right)$, pode ser determinado através do uso da Equação 3.2.3.

Tabela 3.4: Equações utilizadas para determinação do balanço de massa do material orgânico

\begin{tabular}{lc}
\hline Equações para o balanço de massa do material orgânico & Equação \\
\hline $\mathrm{mS}_{\mathrm{te}}=\mathrm{S}_{\mathrm{te}} / \mathrm{S}_{\mathrm{ta}}$ & $(3.2 .0)$ \\
\hline $\mathrm{mS}_{\mathrm{xv}}=\left(\mathrm{q} / \mathrm{Q}_{\mathrm{a}}\right) * \mathrm{f}_{\mathrm{cv}} * \mathrm{X}_{\mathrm{v}} / \mathrm{S}_{\mathrm{ta}}$ & $(3.2 .1)$ \\
\hline $\mathrm{mSo}=\left(\mathrm{V}_{\mathrm{r}} / \mathrm{Q}_{\mathrm{a}}\right) * \mathrm{TCO}_{\mathrm{c}} / \mathrm{S}_{\mathrm{ta}}$ & $(3.2 .2)$ \\
\hline $\mathrm{Bo}=\left(\mathrm{MS}_{\mathrm{te}}+\mathrm{MS}_{\mathrm{xv}}+\mathrm{MS}_{\mathrm{o}}\right)$ & $(3.2 .3)$ \\
\hline
\end{tabular}




\subsubsection{Balanço de massa do material nitrogenado}

Os cálculos do balanço de massa do material orgânico do sistema de lodo ativado por aeração prolongada foram realizados conforme descrito no capítulo 2, seção 2.3.1. As equações referentes ao sistema encontram-se na Tabela 3.5. O detalhamento de cada termo contido nessas equações está descrito na Lista de Símbolos. A Equação 3.3.0 possibilita a determinação do fluxo de material nitrogenado no lodo de excesso $\left(\mathrm{MN}_{\mathrm{l}}\right)$. A Equação 3.3.1 e 3.3.2 possibilitam a determinação do fluxo de material nitrogenado afluente $\left(\mathrm{MN}_{\mathrm{ta}}\right)$ e efluente $\left(\mathrm{MN}_{\mathrm{te}}\right)$ do sistema de lodo ativado. O fluxo de material nitrogenado desnitrificado no sistema pode ser determinado pela Equação 3.3.3. Por fim, o balanço de massa do material nitrogenado para o sistema de lodo ativado $\left(B_{n}\right)$, pode ser determinado através do uso da Equação 3.3.4.

Tabela 3.5: Equações utilizadas para determinação do balanço de massa do material nitrogenado

\begin{tabular}{lc}
\hline \multicolumn{1}{c}{ Equações para o balanço de massa do material nitrogenado } & Equação \\
\hline $\mathrm{MN}_{\mathrm{l}}=\mathrm{f}_{\mathrm{n}} * \mathrm{~V}_{\mathrm{r}} * \mathrm{X}_{\mathrm{v}} / \mathrm{R}_{\mathrm{s}}$ & $(3.3 .0)$ \\
\hline $\mathrm{MN}_{\mathrm{ta}}=\mathrm{Q}_{\mathrm{a}} *\left(\mathrm{~N}_{\mathrm{oa}}+\mathrm{N}_{\mathrm{aa}}+\mathrm{N}_{\mathrm{na}}\right)=\mathrm{Q}_{\mathrm{a}} * \mathrm{~N}_{\mathrm{ta}}$ & $(3.3 .1)$ \\
\hline $\mathrm{MN}_{\mathrm{te}}=\mathrm{Q}_{\mathrm{a}} *\left(\mathrm{~N}_{\mathrm{oe}}+\mathrm{N}_{\mathrm{ae}}+\mathrm{N}_{\mathrm{ne}}\right)=\mathrm{Q}_{\mathrm{a}} * \mathrm{~N}_{\mathrm{te}}$ & $(3.3 .2)$ \\
\hline $\mathrm{MN}_{\mathrm{d}}=\left(\mathrm{Q}_{\mathrm{a}}+\mathrm{q}\right) * \Delta \mathrm{N}_{\mathrm{n}}$ & $(3.3 .3)$ \\
\hline $\mathrm{B}_{\mathrm{n}}=\left(\mathrm{MN}_{\mathrm{l}}+\mathrm{MN}_{\mathrm{te}}+\mathrm{MN}_{\mathrm{d}}\right) / \mathrm{MN}_{\mathrm{ta}}$ & $(3.3 .4)$ \\
\hline
\end{tabular}

\subsection{Uso da Respirometria para determinação das constantes cinéticas da nitrificação}

Para a determinação das taxas de consumo de oxigênio (TCO), usou-se um respirômetro modelo Beluga do tipo aberto acoplado a um aerador e um agitador para medições de forma semicontínua, ligados a um computador e controlado através do software S4.0C, (Figura 3.8). A concentração de OD foi estabelecida na faixa de 0,3 a $0,8 \mathrm{mg} \cdot \mathrm{L}^{-1}$, reproduzindo as mesmas condições de operação da planta piloto promovendo a NDS. Foi possível manter essa baixa concentração de OD sem erros de leitura, pois o respirômetro foi configurado para ligar a aeração quando a concentração de OD era menor que o limite de referência inferior $(0,3$ mg.L-

$\left.{ }^{1}\right)$, aumentando a concentração de OD. Quando esta chegava ao valor de referência superior $(0,8$ mg. $\left.L^{-1}\right)$, a aeração era interrompida e observava-se a diminuição da concentração de OD devido a respiração. Ao atingir novamente o valor de referência inferior, a aeração era ligada novamente e iniciava-se outro ciclo. Desta maneira determinava-se a TCO semi-continuamente (VAN HAANDEL e CATUNDA, 1982), como é possível observar no respirograma de OD e TCO na Figura 3.9. Os dados de TCO, OD e temperatura foram registrados através do software em arquivos do Excel. 


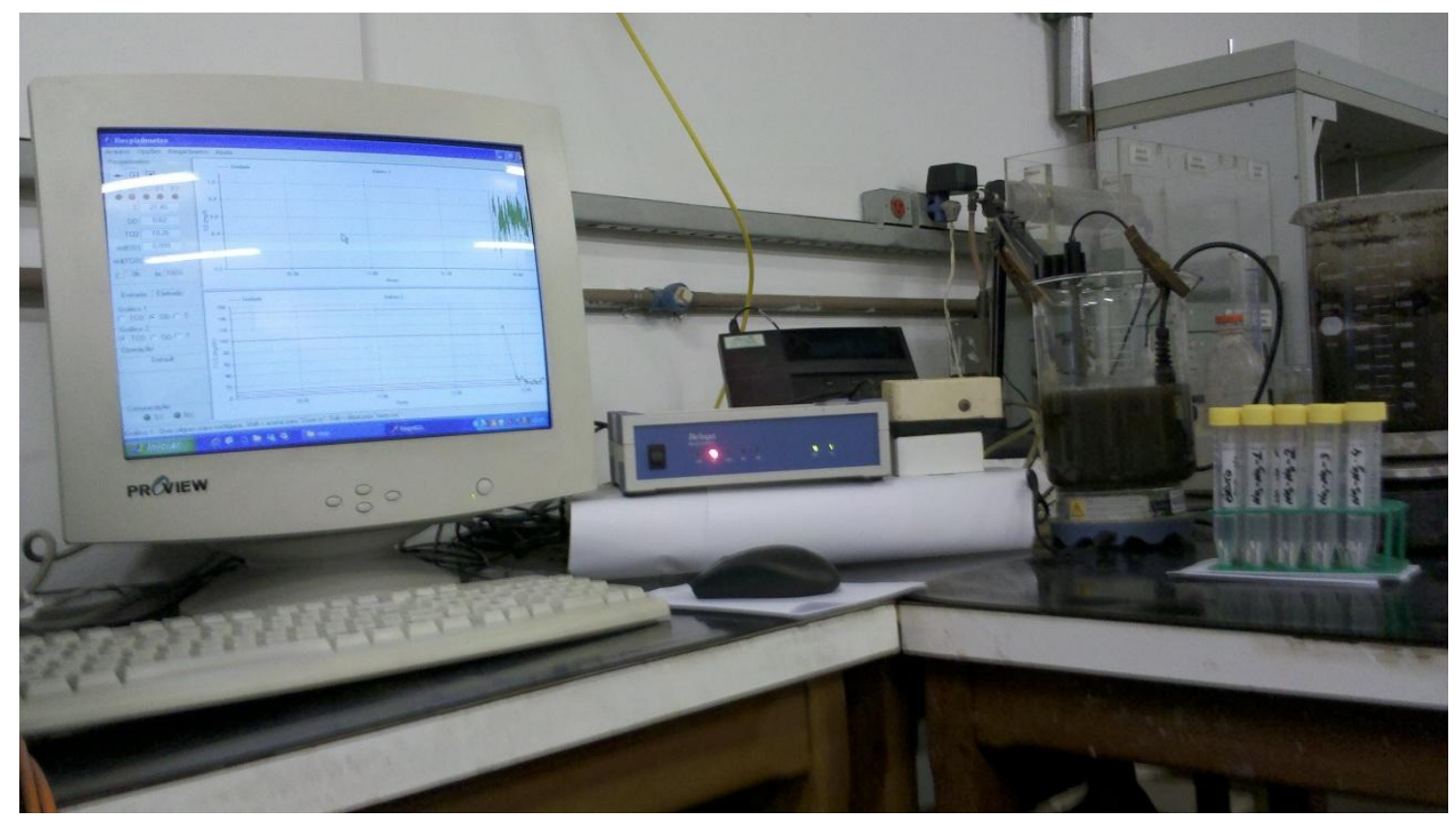

Figura 3.8: Respirômetro modelo Beluga S32c, do tipo aberto e semi-contínuo, desenvolvido no Departamento de Engenharia Elétrica da UFCG - Universidade Federal de Campina Grande.

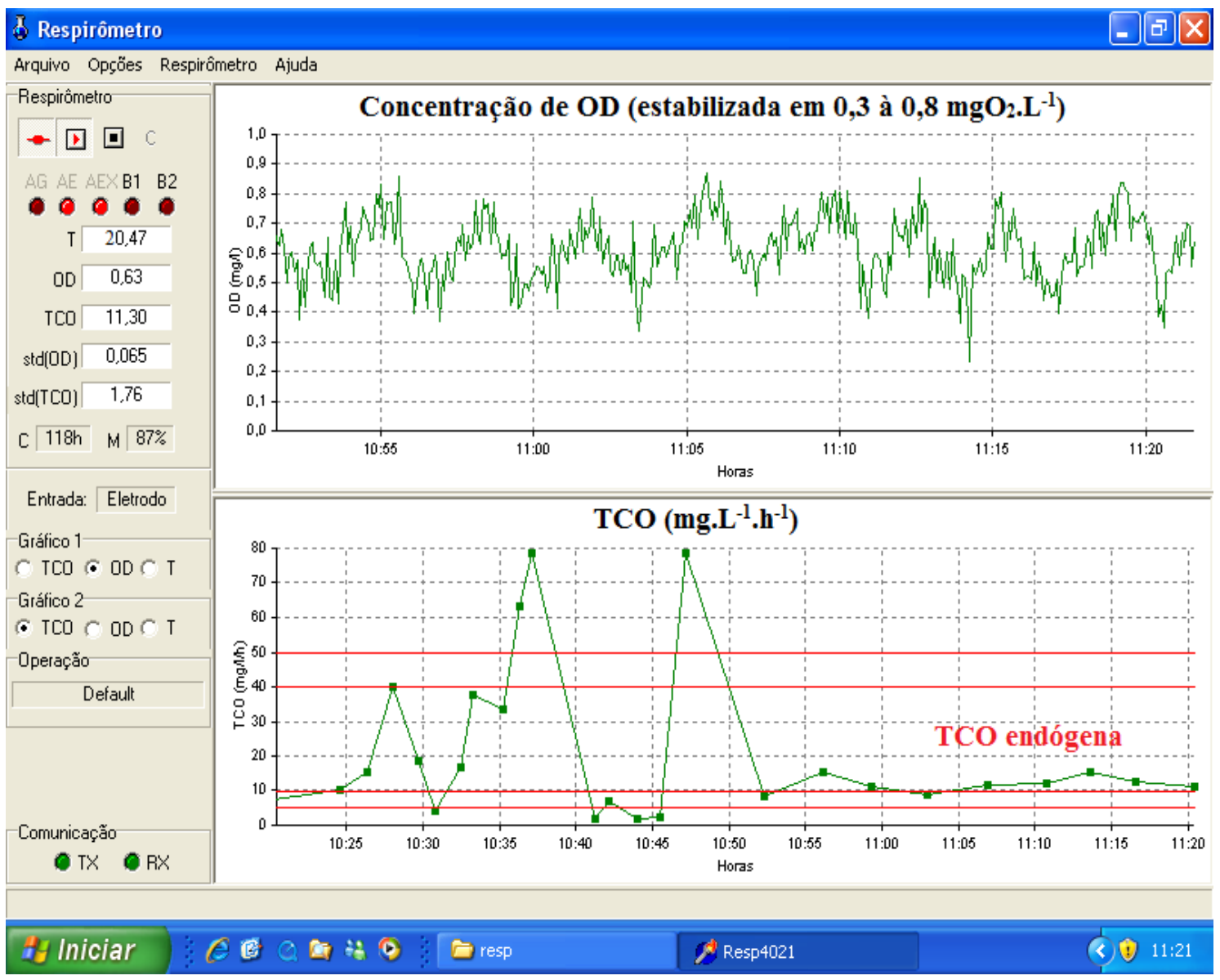

Figura 3.9: Respirograma experimental com medições de OD na faixa de $\left(0,3-0,8 \mathrm{mg} \cdot \mathrm{L}^{-1}\right)$ e TCO endógena. 


\subsubsection{Investigação experimental da atividade bacteriana autotrófica}

Para realização dos testes respirométricos e avaliação da atividade das bactérias autotróficas no licor misto do sistema de lodo ativado, foram utilizados substratos específicos para cada grupo de bactérias. O consumo de substrato adicionado era traduzido pelo consumo de OD, registrado pelo respirômetro, calculando também a TCO. Os substratos utilizados para os grupos de bactérias de interesse nesse estudo são apresentados na Tabela 3.6.

Tabela 3.6: Substratos para os testes respirométricos com bactérias autotróficas nitrificantes

\begin{tabular}{ccc}
\hline Grupo de bactéria & Substrato Específico & Oxidante \\
\hline Bactérias autotróficas nitritadoras & Cloreto de Amônio $\left(\mathrm{NH}_{4} \mathrm{Cl}\right)$ & Oxigênio \\
\hline Bactérias autotróficas nitratadoras & Nitrito de Sódio $\left(\mathrm{NaNO}_{2}\right)$ & Oxigênio \\
\hline
\end{tabular}

A metodologia usada na investigação experimental se resume como se segue:

(1) Inicialmente ligava-se o respirômetro e esperava-se 10 minutos para então se calibrar o eletrodo de oxigênio com o valor de saturação da temperatura ambiente e altitude local;

(2) Retirava-se uma alíquota (2 litros) do licor misto do sistema de lodo ativado sob condições estacionárias, desenvolvendo nitrificação. Esta alíquota era submetida à agitação e aeração controlada (condições previamente configuradas no respirômetro), afim de que todo substrato extracelular disponível no licor misto fosse utilizado, estabelecendo uma TCO mínima e constante correspondente à respiração endógena (TCO endógena);

(3) Depois de estabelecida a respiração endógena, a alíquota era separada em duas partes sendo (1 litro utilizado para análises de caracterização físico-químicas "usado como controle sem adição de substrato") e a outra alíquota (1 litro) efetivamente para o teste. Assim após atingir a TCO endógena era adicionado o substrato específico (Tabela 3.6). Adicionava-se quantidade suficiente de substrato para que o mesmo não fosse limitante do processo (substrato $\gg \mathrm{K}_{\mathrm{s}}$ ), permitindo que a nitritação ou nitratação se desenvolva sob taxa máxima;

(4) Determinava-se então a TCO em função do tempo, inicialmente a TCO era alta e constante (TCO máxima ou exógena), correspondente à taxa máxima de nitrificação e respiração endógena;

(5) A TCO permanece alta até que se conclua o consumo do substrato, observando-se então uma repentina diminuição, até que se obtenha o valor que existia antes da adição, ou seja, voltava para a TCO endógena; 
(6) Ainda, em paralelo foram retiradas alíquotas do licor misto $(10 \mathrm{~mL})$ durante o teste com intervalos de 10 minutos e logo em seguida era adicionado sulfato de mercúrio para inibir a atividade biológica. As alíquotas foram centrifugadas por 15 minutos à 3500rpm, e o sobrenadante (Fase líquida) foi utilizado para a determinação de amônia, nitrito e nitrato em função do tempo. Os ânions e cátions foram determinados em um cromatógrafo de íons (Dionex-100, coluna: ACSR_2mm e CSR_2mm) (Figura 3.10).

Na Figura 3.11, podem-se observar o comportamento de um respirograma genérico durante a adição de um substrato solúvel a uma batelada de lodo e, na Figura 3.12 um respirograma experimental obtido neste estudo, onde foi adicionado uma concentração de amônia como substrato $\left(10 \mathrm{mgN} \cdot \mathrm{L}^{-1}\right)$.

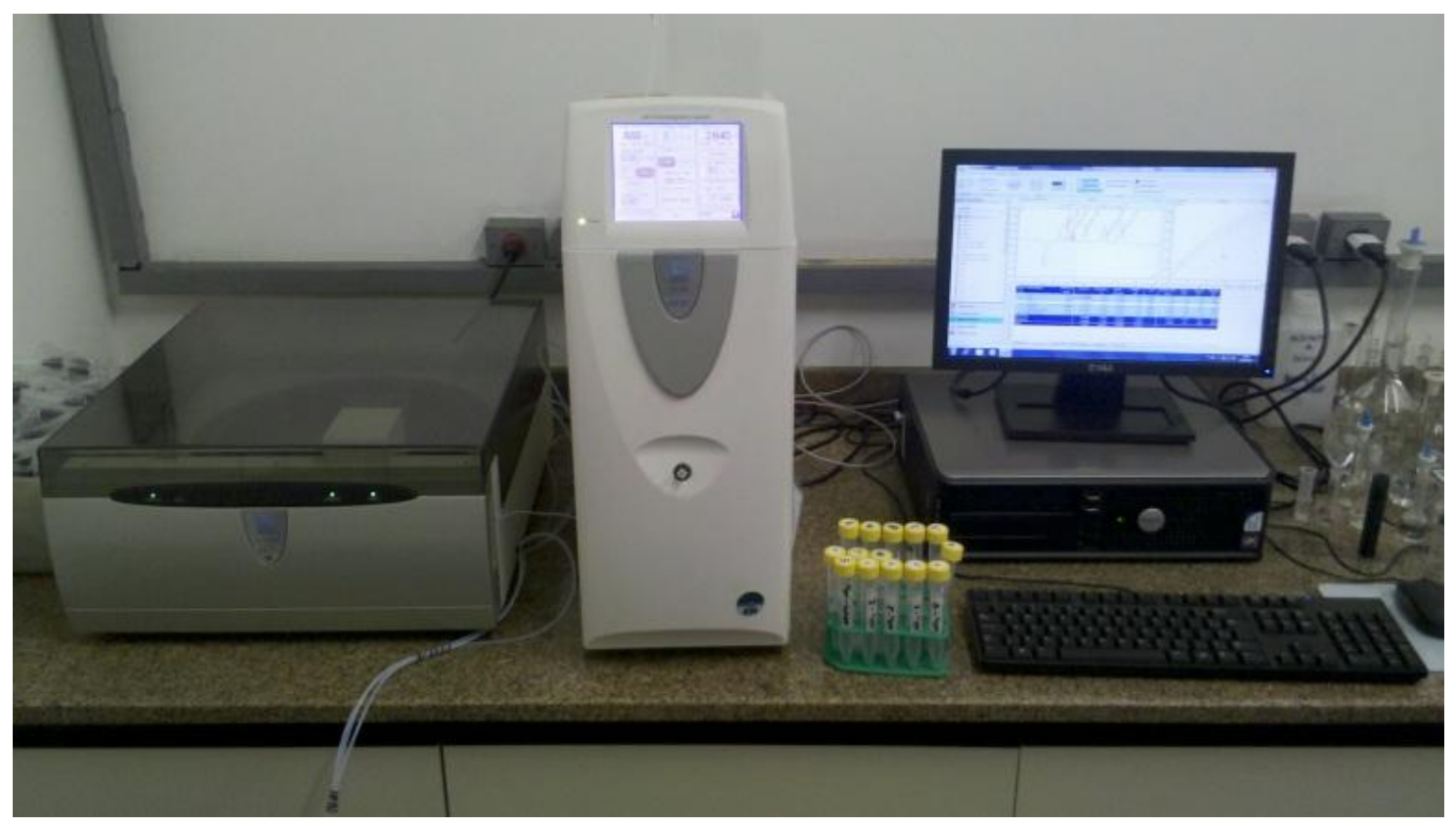

Figura 3.10: Cromatógrafo de íons Dionex com amostrador automático para análise de ânions e cátions 


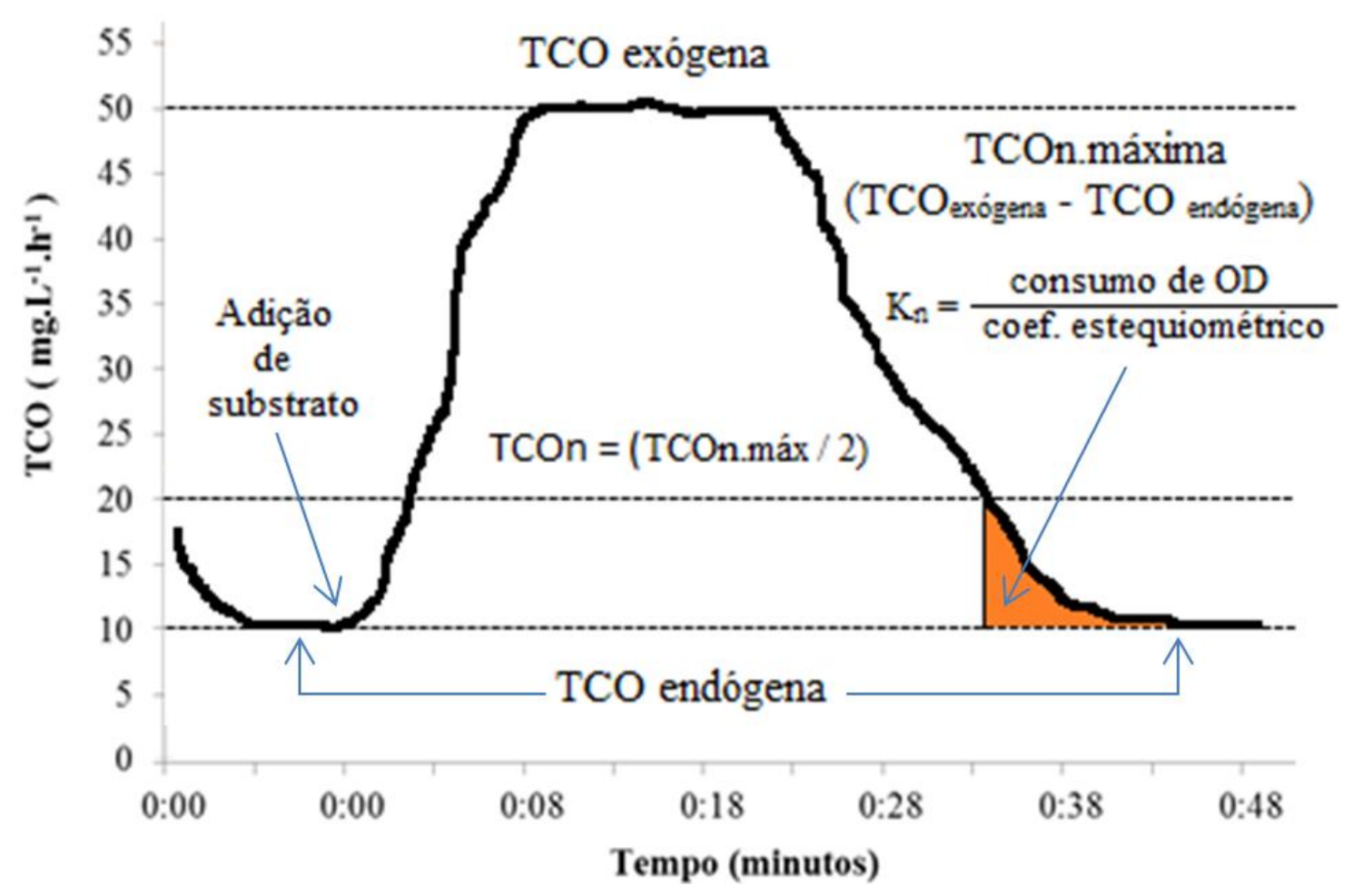

Figura 3.11: Respirograma genérico da adição de um substrato solúvel a uma batelada de lodo ativado

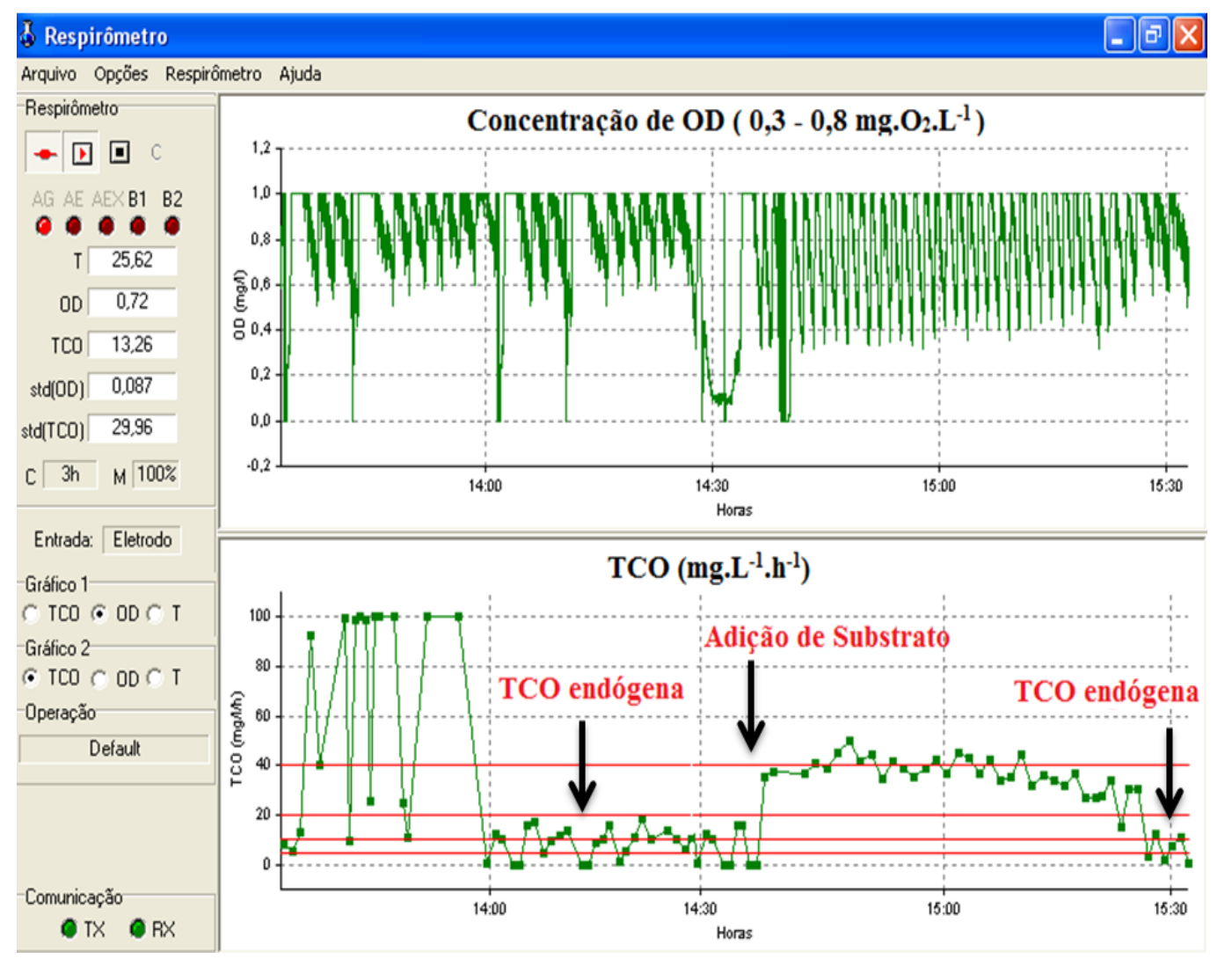

Figura 3.12: Exemplo de um respirograma experimental com adição de amônia como substrato em uma batelada de lodo ativado 


\subsubsection{Estimativa das constantes de crescimento específico $\left(\mu_{\mathrm{m}}\right)$, constante de meia saturação de Monod $\left(K_{n}\right)$ e da taxa máxima de nitritação e nitratação $\left(r_{n \text {.max }}\right)$.}

\subsubsection{Constante de crescimento específico máximo $\left(\mu_{\mathrm{m}}\right)$}

Para determinar a taxa específica de crescimento " $\mu_{\mathrm{m}}$ " foi utilizada a equação de Monod, Equação (3.4) (Monod, 1949).

$\mu_{\mathrm{m}}=\mu_{\text {máx }}\left[\mathrm{S} /\left(\mathrm{S}+\mathrm{K}_{\mathrm{S}}\right)\right]$

Sendo:

$\mu_{\mathrm{m}}$ : taxa específica de crescimento $\left(\mathrm{d}^{-1}\right)$;

$\mu_{\text {máx }}:$ taxa específica máxima de crescimento $\left(\mathrm{d}^{-1}\right)$;

$\mathrm{K}_{\mathrm{S}}$ : constante de meia saturação ( $\mathrm{K}_{\mathrm{n}}$ para as nitrificantes ou nitratadoras);

S: concentração de substrato.

Observa-se que se a quantidade de substrato adicionada é muito grande $\left(\mathrm{S}>\mathrm{K}_{\mathrm{S}}\right.$ ), o valor de $\mu_{\mathrm{m}}$ é igual ao valor de $\mu_{\text {máx }}$, sendo $\mu_{\text {máx }}$ determinado através da respirometria, conforme a Equação 3.4.1 (van Haandel \& Marais, 1999).

$\mu_{\text {máx }}=\left(\mathrm{Y} * \mathrm{r}_{\text {máx }}\right) / \mathrm{X}$

(Equação 3.4.1)

Sendo:

$\mathrm{X}$ : concentração ativa das bactérias $\left(\mathrm{X}_{\mathrm{n}}\right.$ para autotróficas, $\left.\mathrm{mgX} . \mathrm{L}^{-1}\right)$;

$\mathrm{Y}$ : coeficiente de rendimento das bactérias $\left(0,1 \mathrm{mgX} \mathrm{X}_{\mathrm{n}} \cdot \mathrm{mgN}^{-1}\right.$ para autotróficas);

$\mathrm{r}_{\text {máx }}$ : taxa máxima de consumo do substrato $\left(\mathrm{mgS} \cdot \mathrm{L}^{-1} \cdot \mathrm{h}^{-1}\right)$, determinada através da TCO.

Conforme a cinética de Monod, a concentração de bactérias autotróficas pode ser calculada a partir dos dados dos valores analíticos obtidos nas análises físico-químicas (VAN HAANDEL \& MARAIS, 1999). Para constante de decaimento $\left(b_{n}\right)$ foi adotado um valor típico de $0,04(1,13)^{(\mathrm{T}-20)}$, sugerido por EKAMA \& MARAIS (1976).

$X_{n}=Y_{n} R_{s} N_{c} /\left(1+b_{n} R_{s}\right) R_{h}$

(Equação 3.4.2)

Onde:

$\mathrm{Y}_{\mathrm{n}}$ : coeficiente de rendimento das bactérias nitrificantes $\left(0,10 \mathrm{mgN} \cdot \mathrm{L}^{-1}\right)$

$\mathrm{X}_{\mathrm{n}}$ : a concentração das bactérias autotróficas $\left(\operatorname{mgX}_{\mathrm{n}} \cdot \mathrm{L}^{-1}\right)$

$\mathrm{N}_{\mathrm{c}}$ : a concentração de amônia nitrificada $\left(\mathrm{mgN} . \mathrm{L}^{-1}\right)$

$\mathrm{R}_{\mathrm{s}}$ : a idade de lodo $\left(\mathrm{d}^{-1}\right)$

$\mathrm{R}_{\mathrm{h}}$ : o tempo de permanência $\left(\mathrm{d}^{-1}\right)$ 
$b_{n}$ : a constante de decaimento $\left(b n=0,04(1,03)^{(t-20)}\right.$ (VAN HAANDEL \& MARAIS (1999))

t: a temperatura $\left({ }^{\circ} \mathrm{C}\right)$

Onde se tem que:

$\mathrm{N}_{\mathrm{c}}=\mathrm{NTK}_{\mathrm{a}}-\mathrm{NTK}_{\mathrm{e}}-\mathrm{N}_{\mathrm{l}}$

A concentração de amônia nitrificada $\left(\mathrm{N}_{\mathrm{C}}\right)$ se calculou como a diferença entre a concentração do Nitrogênio Total Kejdhal (NTK) afluente e efluente do sistema, subtraindo-se a concentração de nitrogênio necessário para a produção de lodo, onde a fração de nitrogênio no lodo é de aproximadamente 0,1 (COURA, 2002; DERKS; 2007). Sendo $\mathrm{N}_{1}$ determinado conforme a Equação 3.4.3:

$\mathrm{N}_{\mathrm{l}}=\mathrm{f}_{\mathrm{n}} \mathrm{X}_{\mathrm{v}} \mathrm{V}_{\mathrm{r}} / \mathrm{R}_{\mathrm{s}} \mathrm{Q}_{\mathrm{a}}$

(Equação 3.4.3)

Onde:

$\mathrm{N}_{1}$ é a concentração de nitrogênio necessário para a produção de lodo $\left(\mathrm{mgN} \cdot \mathrm{L}^{-1}\right)$

$\mathrm{f}_{\mathrm{n}}$ é a fração de lodo volátil que é nitrogênio (10\%)

$\mathrm{X}_{\mathrm{v}}$ é a concentração de lodo volátil (mgN.L $\left.\mathrm{L}^{-1}\right)$

$\mathrm{V}_{\mathrm{r}}$ é o volume dos reatores do sistema de tratamento $\left(\mathrm{L}^{-1}\right)$

$\mathrm{Q}_{\mathrm{a}}$ é a vazão afluente $\left(\mathrm{L} \cdot \mathrm{d}^{-1}\right)$

Por outro lado, a TCO máxima da nitrificação das nitritadoras ou nitratadoras $\left(\mathrm{TCO}_{\text {n.máx }}\right)$ é obtida através dos dados do respirômetro como:

$\mathrm{TCO}_{\text {n.máx }}=\mathrm{TCO}_{\text {exo,máx }}-\mathrm{TCO}_{\text {end }}$

(Equação 3.4.4)

Onde:

$\mathrm{TCO}_{\text {exo,máx }}$ é a taxa de consumo de oxigênio exógena máxima $\left(\mathrm{mg} \cdot \mathrm{L}^{-1} \mathrm{~h}^{-1}\right)$

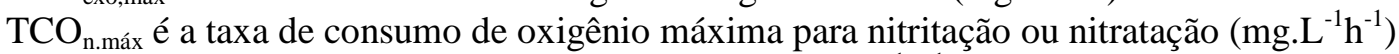

$\mathrm{TCO}_{\text {end }}$ é a taxa de consumo de oxigênio endógena $\left(\mathrm{mg} \cdot \mathrm{L}^{-1} \mathrm{~h}^{-1}\right)$

Assim, conforme a teoria de lodo ativado (van Haandel \& Marais, 1999), pode-se calcular a taxa máxima de nitritação ou nitratação como se segue:

$\mathrm{r}_{\text {n.máx }}=\mathrm{TCO}_{\text {n.máx }} / 4,57$

(Equação 3.4.5)

ou

$\mathrm{r}_{\text {n.máx }}=\mathrm{TCO}_{\text {n.máx }} / 1,14$

(Equação 3.4.6)

Sendo:

$\mathrm{TCO}_{\text {n.máx }}$ : TCO total devido à nitrificação $\left(\mathrm{mg} \cdot \mathrm{L}^{-1} \cdot \mathrm{h}^{-1}\right)$; 
$\mathrm{r}_{\mathrm{n} \text {.máx }}$ taxa de utilização máxima de amônia $\left(\mathrm{mgNH}_{4} \cdot \mathrm{mgX}_{\mathrm{n}} \cdot \mathrm{d}^{-1}\right)$;

$\mathrm{r}_{\mathrm{n} \text {.máx }}$ taxa de utilização máxima de nitrito $\left(\mathrm{mgNO}_{2} \cdot \mathrm{mgX}_{\mathrm{n}} \cdot \mathrm{d}^{-1}\right)$.

Os denominadores 4,57 e 1,14 da Equação 3.4.5 e 3.4.6 respectivamente dão o consumo estequiométrico de oxigênio por mol do substrato considerado (amônia e nitrito, respectivamente).

Agora se pode determinar a constante $\left(\mu_{\mathrm{m}}\right)$ usando a Equação 3.4.7, sendo:

$\mu_{m}=\left(Y_{n} * r_{n . m a ́ x}\right) / X_{n}$

(Equação 3.4.7)

\subsubsection{Constante de meia saturação de amônia e nitrito $\left(K_{n}\right)$}

Como se pode observar na Figura 3.11 e 3.12 da seção 3.9.1, quando a TCO começa a decrescer, o substrato (amônia ou nitrito) torna-se um fator limitante para o crescimento das bactérias nitrificantes. De acordo com a cinética de Monod, para estimar o valor da constante de meia saturação $\left(K_{n}\right)$ para nitritantes ou nitratantes, deve-se determinar a concentração de substrato no momento em que $\mu$ for $=1 / 2 \mu_{\text {máx }}$, ou que a TCOn $=1 / 2 \mathrm{TCO}_{\text {n.máx. }}$. Esta determinação pode ser feita através do respirograma obtido conforme a metodologia descrita na seção 3.9.1 desse Capítulo, sendo realizada da seguinte maneira:

(1) Após um teste respirométrico realizado conforme a seção 3.9.1, onde se adicionou um substrato de amônia ou nitrito, com uma concentração conhecida, obtemos um respirograma conforme já mostrado na Figura 3.11 e 3.12;

(2) Através do respirograma e dos dados armazenados no Excel, determina-se o momento em que a $\mathrm{TCO}_{\mathrm{n}}$ é metade da máxima $\left(\mathrm{TCO}_{\mathrm{n}}=1 / 2 \mathrm{TCO}_{\mathrm{n} \text {.máx }}\right)$;

(3) Após determinar a $\mathrm{TCO}_{\mathrm{n}}$, determina-se a área hachurada que corresponde ao substrato residual em $\left(\mathrm{mgO} . \mathrm{L}^{-1}\right)$, através da soma de trapézios.

(4) E por fim calcula-se a concentração do substrato amônia ou nitrito, como a razão do valor da área hachurada pelos respectivos coeficientes estequiométricos de oxigênio por mol do substrato considerado $\left(\mathrm{K}_{\mathrm{n}}=\right.$ amônia $/ 4,57$ e $\mathrm{K}_{\mathrm{n}}=$ nitrito /1,14).

\subsubsection{Frações biodegradáveis de matéria orgânica do esgoto sanitário}

Para a determinação das frações biodegradáveis da matéria orgânica do esgoto sanitário, foram realizados testes respirométricos, conforme já descrito na seção 3.9.1, deste capítulo, com os passos adicionais seguintes: 
(1) Após a sedimentação do lodo foi sifonado o sobrenadante, o volume sifonado foi completado com esgoto sanitário afluente;

(2) Antes de ser iniciada a aeração do conteúdo do béquer foram adicionados $10 \mathrm{mg} \cdot \mathrm{L}^{-1} \mathrm{de}$ uma solução de alil-tiouréia para inibir a atividade das bactérias autotróficas;

(3) O teste foi realizado, sendo controlado pelo respirômetro que mantinha a concentração de OD no intervalo adotado;

Na Figura 3.13, podem-se observar um respirograma experimental onde se vê na janela inferior o gráfico da TCO, expressa em mgO. $\mathrm{L}^{-1} \cdot \mathrm{h}^{-1}$. Identificam-se nesse gráfico, logo no começo do teste, a utilização do material biodegradável e solúvel e, portanto, rapidamente biodegradável e a do material biodegradável e particulado (que apresenta valor em declínio) e a TCO endógena que representa o valor medido mais baixo e constante do gráfico. As áreas definidas entre a respiração exógena e endógena dão o valor da DQO utilizada e, assim, determinam-se as frações biodegradáveis do esgoto.

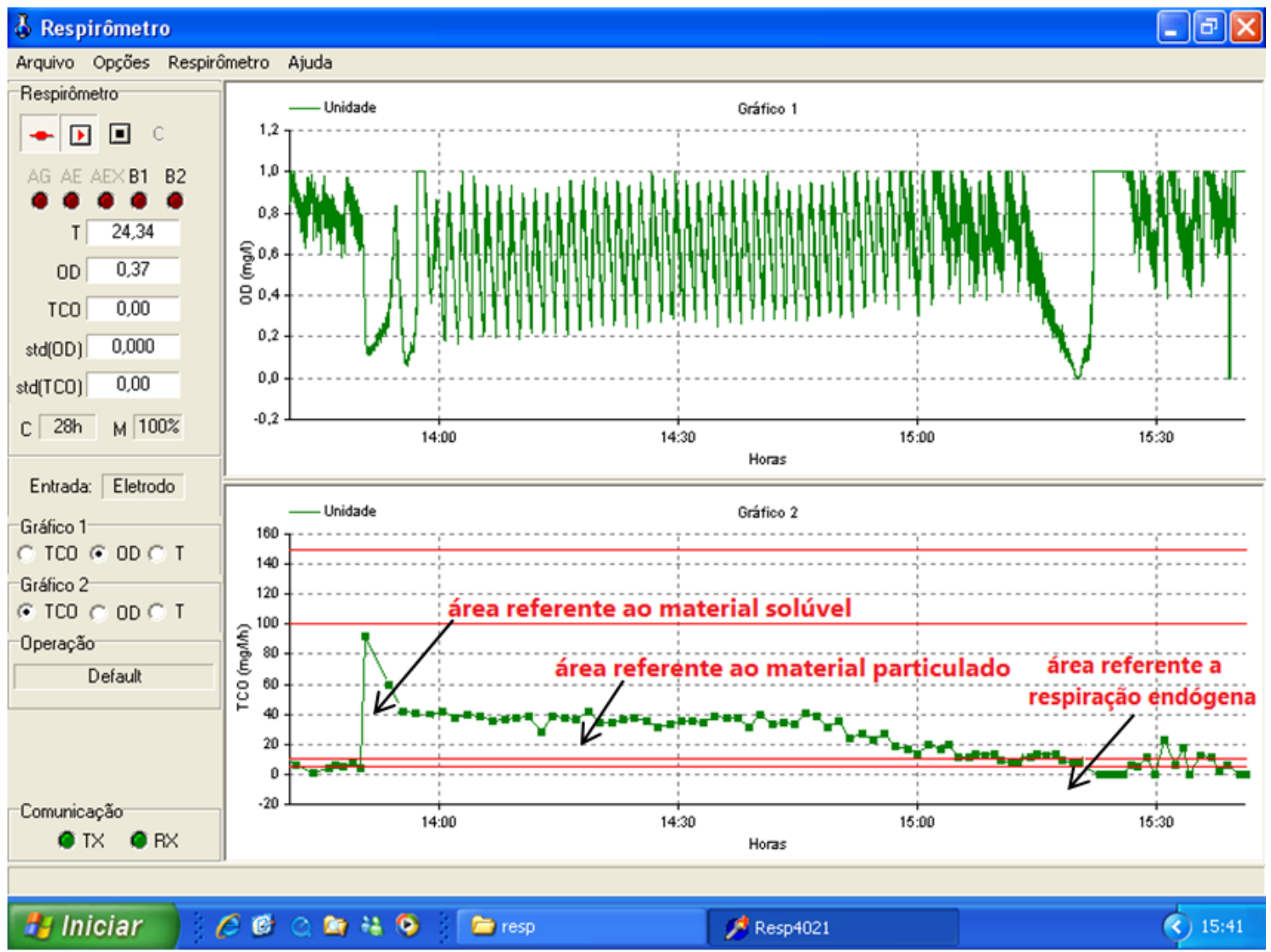

Figura 3.13: Respirograma experimental da determinação das frações do material orgânico. 
Segundo a teoria de lodo ativado (VAN HAANDEL e MARAIS, 1999) quanto à composição do material orgânico do afluente, a fração não biodegradável e solúvel $\left(f_{u s}\right)$ pode ser calculada a partir dos valores da concentração da DQO no efluente e no afluente conforme a Equação 3.4.8:

$\mathrm{f}_{\mathrm{us}}=\mathrm{S}_{\mathrm{te}} / \mathrm{S}_{\mathrm{ta}}$

(Equação 3.4.8)

A fração não biodegradável e particulada $\left(f_{\text {up }}\right)$ pode ser calculada a partir da concentração de lodo volátil (que é a soma da concentração de lodo ativo $\left(\mathrm{X}_{\mathrm{a}}\right)$, resíduo endógeno $\left(\mathrm{X}_{\mathrm{e}}\right)$ e lodo inerte $\left(\mathrm{X}_{\mathrm{i}}\right)$ ). Segundo Van Haandel e Marais:

$\mathrm{X}_{\mathrm{v}}=\mathrm{X}_{\mathrm{a}}+\mathrm{X}_{\mathrm{e}}+\mathrm{X}_{\mathrm{i}}=\left[\left(1+\mathrm{f}_{\mathrm{b}} * \mathrm{R}_{\mathrm{s}}\right) *\left(1-\mathrm{f}_{\mathrm{us}}-\mathrm{f}_{\mathrm{up}}\right) * \mathrm{Cr}+\mathrm{f}_{\mathrm{up}} * \mathrm{R}_{\mathrm{s}}\right] * \mathrm{~S}_{\mathrm{ta}} / \mathrm{R}_{\mathrm{h}}=\mathrm{X}_{\mathrm{t}} / \mathrm{f}_{\mathrm{v}}$

(Equação 3.4.9)

A fração biodegradável e solúvel ( $\mathrm{f}_{\mathrm{bs}}$ ) pode ser determinada com auxilio da Respirometria. Já a determinação da DQO biodegradável afluente ao sistema $\left(\mathrm{S}_{\mathrm{ba}}\right)$ foi determinada segundo a Equação 3.5 .

$\mathrm{S}_{\mathrm{ba}}=\left(1-\mathrm{f}_{\mathrm{us}}-\mathrm{f}_{\mathrm{up}}\right) * \mathrm{~S}_{\mathrm{ta}}$

(Equação 3.5)

\subsubsection{Investigação experimental da atividade bacteriana heterotrófica e determinação da cinética da desnitrificação}

Com uso da respirometria e determinações analíticas realizou-se uma investigação experimental para comparar a taxa de oxidação de material orgânico tendo como oxidante o oxigênio dissolvido e o nitrato em ambiente com baixa concentração de OD $\left(0,3-0,8 \mathrm{mgL}^{-1}\right)$ promovendo a NDS. Para tanto, usou-se bateladas do licor misto do sistema de lodo ativado. Destas bateladas foram determinadas a TCO e a TCO equivalente (via nitrato) com material orgânico solúvel (acetato de sódio), simulando uma DQO rapidamente biodegradável e com substrato particulado (suspensão de amido comercial) simulando uma DQO lentamente biodegradável e com o próprio esgoto sanitário afluente. Nos testes de TCO equivalente foi adicionado uma concentração de $10 \mathrm{mgN} . \mathrm{L}^{-1}$ de nitrato de potássio. Os testes foram realizados conforme a metodologia descrita a seguir:

(1) Após o estabelecimento da TCO endógena (conforme descrito na seção 3.9.1 deste Capítulo), mantinha-se a aeração na faixa de $\left(0,3-0,8 \mathrm{mg} \cdot \mathrm{L}^{-1}\right)$, para promover a NDS; 
(2) Verificou-se a TCO referente ao consumo endógeno. Em seguida era adicionada uma concentração de material orgânico como: acetato de sódio, amido ou esgoto sanitário, equivalente a (100 mg. $\mathrm{L}^{-1}$ de DQO). O mesmo procedimento foi utilizado para obter a TCO equivalente (via nitrato) com diferença da adição de $10 \mathrm{mgN} \cdot \mathrm{L}^{-1}$ de uma solução de nitrato de potássio padrão;

(3) A concentração de nitrato foi medida em diversos momentos conforme o item (6) descrito na seção 3.9.1, para que se observasse a depleção do substrato em função do tempo transcorrido.

(4) Os cálculos que possibilitaram a conversão dessas concentrações de nitrato para taxa de consumo de oxigênio equivalente se basearam na estequiometria da reação de oxirredução desses oxidantes que demonstra a equivalência estequiométrica, onde 1,0 $\mathrm{mgN}$ de nitrato equivale a $2,86 \mathrm{mgO}$ em termos oxidimétricos.

Ainda, após a determinação da TCO endógena inicial, calcula-se a concentração de lodo ativo (X $\mathrm{X}_{\mathrm{a}}$ ) pela Equação 3.5.1 (VAN HAANDEL e MARAIS, 1999):

$\mathrm{TCO}_{\text {end }}=\mathrm{f}_{\mathrm{cv}}(1-\mathrm{f}) * \mathrm{~b}_{\mathrm{n}} \mathrm{X}_{\mathrm{a}}$

Onde:

$\mathrm{TCO}_{\text {end }}$ : taxa de consumo de oxigênio para respiração endógena;

$\mathrm{f}_{\mathrm{cv}}$ : fator de conversão de sólidos voláteis em DQO;

f: fração de lodo ativo que ao decair permanece como resíduo endógeno $=0,2$;

$\mathrm{b}_{\mathrm{h}}$ : constante de decaimento de lodo ativo $=0,24(1,04)^{(\mathrm{T}-20)}$;

$\mathrm{X}_{\mathrm{a}}$ : concentração de lodo ativo.

Em seguida, a partir da taxa de diminuição da concentração de nitrato $\left(\mathrm{r}_{\mathrm{d}}\right)$ calculada pelo procedimento citado anteriormente, calcula-se a taxa equivalente de consumo de oxigênio, conforme a Equação 3.5.2:

$\mathrm{TCO}_{\text {eq }}=2,86 * r_{\text {d.máx }}$

Depois, calcula-se a taxa de consumo de oxigênio equivalente $\left(\mathrm{tco}_{\mathrm{eq}}\right)$ por unidade de massa de lodo ativo e por unidade de tempo, conforme Equação 3.5.3:

$\mathrm{tco}_{\mathrm{eq}}=\mathrm{TCO}_{\mathrm{eq}} / \mathrm{X}_{\mathrm{a}}$

(Equação 3.5.3) 


\section{CAPÍTULO 4}

\section{APRESENTAÇÃO DOS RESULTADOS E DISCUSSÕES}

\subsection{Introdução}

Neste capítulo são apresentados os dados determinados durante as Fases experimentais I, II e II, considerando-se os parâmetros de interesse para o processo de nitrificação e desnitrificação simultânea e desempenho do sistema, referentes à eficiência de remoção de matéria orgânica e ao processo de nitrificação e desnitrificação. Também serão apresentados dados da atividade metabólica das bactérias autotróficas e heterotróficos e as constantes de nitrificação e desnitrificação, obtidas por meio de testes respirométricos.

O desempenho do sistema de lodo ativado com aeração prolongada foi analisado a partir das variáveis citadas na Tabela 3.3, seção 3.6 do capítulo 3. Grande parte dos dados foi compilada em médias das determinações experimentais para cada idade de lodo e razão $\mathrm{A} / \mathrm{M}$ e são apresentadas na forma de tabelas e figuras.

Os valores pontuais são apresentados no apêndice desta dissertação, além destes, foram utilizados outros instrumentos de estatística básica como desvio padrão (DP), amplitude total (AT) e coeficiente de variação (CV) e testes estatísticos de correlação de Pearson. As seções a seguir estão organizadas em: série de sólidos, remoção de material orgânico, remoção de material nitrogenado, variação da alcalinidade, variáveis de controle (monitoramento online) e por último os resultados da cinética da nitrificação e desnitrificação obtidas por meio de testes analíticos e respirométricos. 


\subsection{Série de Sólidos}

\subsubsection{Esgoto sanitário afluente e efluente final após tratamento}

Nas Tabelas de 4.1 a 4.1.4, podem-se observar os resultados experimentais obtidos das concentrações médias de sólidos totais e em suspensão do esgoto sanitário afluente e efluente após o tratamento. Ao analisar os resultados, podem-se notar que, não ocorreram variações significativas nas concentrações de sólidos e suas respectivas frações no afluente nas Fases I, II e III. No entanto, quando se comparam os valores médios da série de sólidos afluente com os obtidos no efluente nas Fases I, II e III, observa-se que há uma ligeira redução na concentração de sólidos totais. No caso das concentrações de sólidos em suspensão essa redução é mais elevada, como se observa na Figura 4.1. Outro aspecto que fica claro a partir das Tabelas 4.1 a 4.1.4 é que os valores médios obtidos das concentrações de sólidos e suas frações no efluente final são relativamente baixos, independente da redução do TRS e aumento da razão A/M.

Tabela 4.1: Sólidos totais e suas frações no esgoto sanitário afluente

\begin{tabular}{cccc|ccc|ccc}
\hline \multicolumn{10}{c}{ Sólidos Totais - Afluente $\left(\mathbf{m g . L}^{-\mathbf{1}}\right)$} \\
\hline \multicolumn{9}{c}{ Fase I } & \multicolumn{3}{c}{ Fase II } & \multicolumn{3}{c}{ Fase III } \\
\hline Variável & Total & Fixo & Volátil & Total & Fixo & Volátil & Total & Fixo & Volátil \\
\hline média & 468 & 226 & 242 & 468 & 238 & 231 & 448 & 233 & 215 \\
\hline máximo & 850 & 330 & 520 & 600 & 350 & 330 & 570 & 290 & 300 \\
\hline mínimo & 360 & 120 & 120 & 390 & 190 & 180 & 250 & 120 & 130 \\
\hline DP & 105 & 45 & 78 & 60 & 44 & 37 & 73 & 43 & 48 \\
\hline CV (\%) & 22,4 & 20,1 & 32,3 & 12,7 & 18,5 & 16,2 & 16,3 & 18,6 & 22,6 \\
\hline AT & 490 & 210 & 400 & 210 & 160 & 150 & 320 & 170 & 170 \\
\hline n & 19 & & & 17 & & & 23 & \\
\hline
\end{tabular}

Tabela 4.1.2: Sólidos em suspensão e suas frações no esgoto sanitário afluente

\begin{tabular}{cccc|ccc|ccc}
\hline \multicolumn{10}{c}{ Sólidos em Suspensão - Afluente $\left(\right.$ mg.L $\left.^{-\mathbf{1}}\right)$} \\
\hline \multicolumn{10}{c}{ Fase I } \\
\hline Variável & Total & Fixo & Volátil & Total & Fixo & Volátil & Total & Fixo & Volátil \\
\hline média & 107 & 14 & 93 & 117 & 16 & 101 & 94 & 13 & 81 \\
\hline máximo & 276 & 50 & 264 & 222 & 80 & 190 & 190 & 32 & 158 \\
\hline mínimo & 22 & 2 & 19 & 70 & 4 & 62 & 50 & 5 & 35 \\
\hline DP & 53 & 14 & 54 & 36 & 18 & 33 & 34 & 6 & 29 \\
\hline CV (\%) & 49,4 & 98,4 & 58,5 & 31,3 & 113,7 & 32,2 & 35,8 & 44,7 & 35,7 \\
\hline AT & 254 & 48 & 245 & 152 & 76 & 128 & 140 & 27 & 123 \\
\hline $\mathrm{n}$ & & 19 & & & 17 & & & 23 & \\
\hline
\end{tabular}


Tabela 4.1.3: Sólidos totais e suas frações no efluente final

\begin{tabular}{cccc|ccc|ccc}
\hline \multicolumn{10}{c}{ Sólidos Totais - Efluente Final $\left(\right.$ mg.L $\left.^{-\mathbf{1}}\right)$} \\
\hline Fariável & Total & Fixo & Volátil & Total & Fixo & Volátil & Total & Fixo & Volátil \\
\hline média & 338 & 254 & 84 & 299 & 219 & 81 & 424 & 252 & 173 \\
\hline máximo & 400 & 300 & 140 & 390 & 280 & 130 & 580 & 450 & 360 \\
\hline mínimo & 280 & 220 & 60 & 250 & 150 & 40 & 290 & 180 & 90 \\
\hline DP & 33 & 25 & 25 & 37 & 37 & 24 & 99 & 66 & 70 \\
\hline CV (\%) & 9,7 & 9,8 & 30,1 & 12,5 & 16,9 & 30,2 & 23,3 & 26,3 & 40,5 \\
\hline AT & 120 & 80 & 80 & 140 & 130 & 90 & 290 & 270 & 270 \\
\hline n & & 19 & & & 17 & & & 23 & \\
\hline
\end{tabular}

Tabela 4.1.4: Sólidos em suspensão e suas frações no efluente final

\begin{tabular}{cccc|cccc|ccc}
\hline \multicolumn{10}{c}{ Sólidos em Suspensão - Efluente Final $\left(\mathbf{m g} . \mathbf{L}^{-\mathbf{1}}\right)$} \\
\hline \multicolumn{1}{c}{ Fase I } & \multicolumn{7}{c}{ Fase II } & \multicolumn{3}{c}{ Fase III } \\
\hline Variável & Total & Fixo & Volátil & Total & Fixo & Volátil & Total & Fixo & Volátil \\
\hline média & 13 & 4 & 9 & 10 & 1 & 9 & 8 & 2 & 6 \\
\hline máximo & 32 & 16 & 25 & 24 & 5 & 24 & 16 & 5 & 14 \\
\hline mínimo & 1 & 0 & 1 & 0 & 0 & 0 & 2 & 0 & 2 \\
\hline DP & 9 & 5 & 6 & 7 & 2 & 7 & 4 & 2 & 3 \\
\hline CV $(\%)$ & 75,6 & 120,2 & 69,1 & 74,7 & 173,2 & 80,3 & 49,3 & 74,4 & 51,7 \\
\hline AT & 31 & 16 & 24 & 24 & 5 & 24 & 14 & 5 & 12 \\
\hline n & 19 & & & 17 & & & 23 & \\
\hline
\end{tabular}
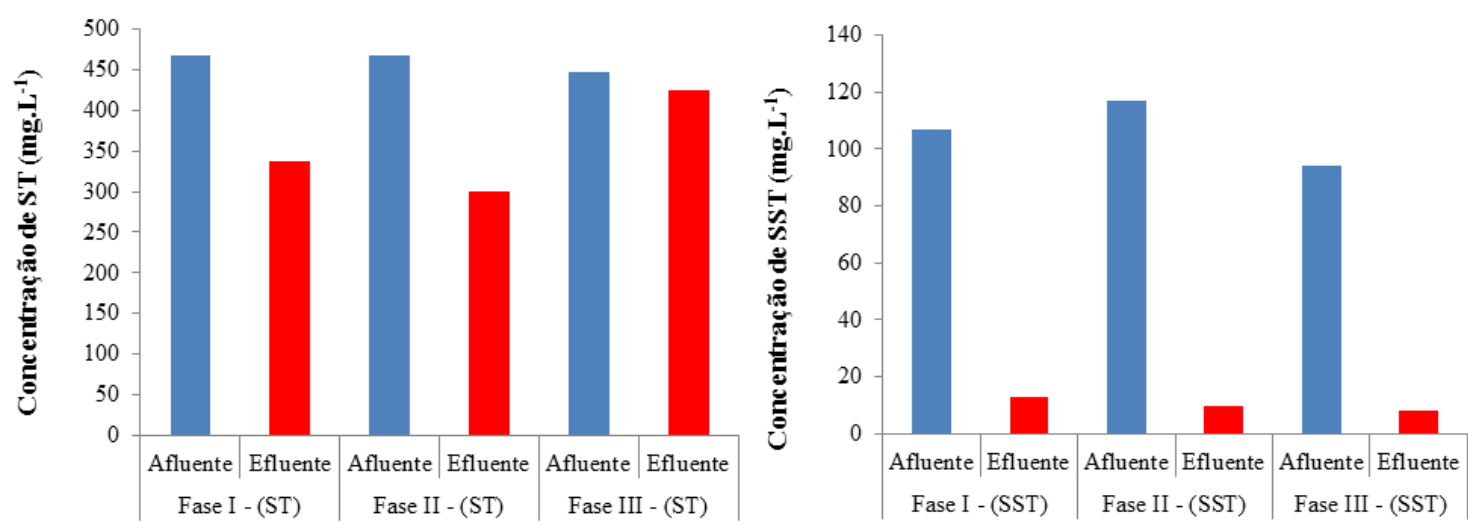

Figura 4.1: Concentrações de sólidos totais e em suspensão no afluente (entrada) e efluente final (saída) durante as Fases I, II e III do estudo. 


\subsubsection{Licor misto do sistema de lodo ativado}

Nas Tabelas 4.2.2 a 4.2.5, podem-se observar os valores médios obtidos das concentrações de sólidos totais e em suspensão do licor misto e do retorno de lodo, nas Fases I, II e III. Os valores médios de SSV no licor misto obtidos nas Fases I, II e III foi superior a 3,0g. $\mathrm{L}^{-1}$, dentro da faixa usual para lodo ativado (2 a 5 g.L -1 $^{-1}$ (VAN HAANDEL e MARAIS, 1999). Quando se comparam os resultados médios de IVL obtido nos testes realizados com o licor misto com a redução da idade do lodo, nota-se que não há uma correlação, como se observa na Tabela 4.2.1. No entanto, mesmo com os valores médios de IVL elevado, não houve problemas na sedimentação do lodo como podemos observar visualmente na Figura 3.3. Neste caso, o teste de IVL não teve utilidade na avaliação da sedimentabilidade do licor misto.

Tabela 4.2.1: Relação entre as variáveis de IVL, TRS e A/M

\begin{tabular}{cccc}
\hline Variável & Fase I & Fase II & Fase III \\
\hline IVL $\left(\mathrm{mL} \cdot \mathrm{g}^{1}\right)$ & $189 \pm 41$ & $210 \pm 9$ & $170 \pm 9$ \\
\hline TRS $\left(\mathrm{d}^{-1}\right)$ & 40 & 30 & 20 \\
\hline
\end{tabular}

Outro aspecto que fica claro a partir dos resultados médios obtidos de sólidos e suas frações no tanque de aeração (Tabela 4.2.2 a 4.2.5) quando comparado com os resultados dos sólidos obtidos no efluente após o tratamento, é a produção de um efluente com baixas concentrações de sólidos. Demonstrando que a baixa concentração de oxigênio dissolvido no tanque de aeração e as condições de operação para o desenvolvimento do processo de NDS não causaram problemas na floculação biológica do lodo ativado durante todo o período do estudo.

No entanto, quando se calculam as proporções de sólidos voláteis e sólidos totais no licor misto,

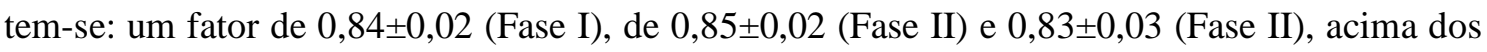
valores obtidos por meio de um sistema de lodo ativado de baixa taxa com OD elevado. Essa diferença pode ser atribuída pelas características do esgoto afluente. Desse modo, conclui-se que independente do TRS do estudo o lodo excedente do sistema de lodo ativado com aeração prolongada operado com baixas concentrações de OD pode se apresentar menos estabilizado do que em um sistema de lodo ativado com aeração prolongada convencional.

Outro aspecto importante no desenvolvimento do processo de NDS foi às características do floco do lodo ativado. Por meio de análises microscópicas, se observou flocos com boa estrutura e formação, com tamanhos superiores a $0,15 \mathrm{~mm}$. Segundo VAN LOOSDRECHT e JETTEN, 1998 flocos maiores que $0,15 \mathrm{~mm}$ permitem a ocorrência de zonas anóxicas dentro do floco, criando condições para o desenvolvimento da desnitrificação. Em relação aos microrganismos, nota-se uma rica comunidade biológica ativa, característica de lodo ativado incluindo: Protozoários, amebas, ciliados e bactérias filamentosas, essas últimas em número inexpressivo 
durante todo período de estudo independente da concentração de OD no tanque de aeração e da redução do TRS.

Tabela 4.2.2: Sólidos totais e suas frações no licor misto

\begin{tabular}{|c|c|c|c|c|c|c|c|c|c|}
\hline \multicolumn{10}{|c|}{ Sólidos Totais - Licor Misto $\left(\mathrm{mg.L}^{-1}\right)$} \\
\hline \multicolumn{4}{|c|}{ Fase I } & \multicolumn{3}{|c|}{ Fase II } & \multicolumn{3}{|c|}{ Fase III } \\
\hline Variável & Total & Fixo & Volátil & Total & Fixo & Volátil & Total & Fixo & Volátil \\
\hline média & 4552 & 738 & 3813 & 4312 & 675 & 3636 & 3832 & 678 & 3154 \\
\hline máximo & 5310 & 870 & 4500 & 4590 & 840 & 3900 & 4660 & 860 & 4020 \\
\hline mínimo & 3700 & 470 & 3050 & 4100 & 600 & 3420 & 2750 & 480 & 2110 \\
\hline $\mathrm{DP}$ & 578 & 111 & 498 & 134 & 79 & 129 & 469 & 97 & 458 \\
\hline $\mathrm{CV}(\%)$ & 12,7 & 15,0 & 13,1 & 3,1 & 11,6 & 3,5 & 12,2 & 14,3 & 14,5 \\
\hline AT & 1610 & 400 & 1450 & 490 & 240 & 480 & 1910 & 380 & 1910 \\
\hline $\mathrm{n}$ & & 19 & & & 17 & & & 23 & \\
\hline
\end{tabular}

Tabela 4.2.3: Concentrações de sólidos em suspensão e suas frações no licor misto

\begin{tabular}{cccc|ccccccc}
\hline \multicolumn{8}{c}{ Sólidos em Suspensão - Licor Misto $\left(\mathbf{m g . L ^ { - 1 }}\right)$} \\
\hline \multicolumn{9}{c}{ Fase I } & \multicolumn{3}{c}{ Fase II } & \multicolumn{3}{c}{ Fase III } \\
\hline Variável & Total & Fixo & Volátil & Total & Fixo & Volátil & Total & Fixo & Volátil \\
\hline média & 4133 & 591 & 3541 & 4068 & 634 & 3434 & 3581 & 574 & 3007 \\
\hline máximo & 4730 & 785 & 3975 & 4465 & 810 & 3800 & 4530 & 645 & 3980 \\
\hline mínimo & 3570 & 415 & 3030 & 3725 & 480 & 3245 & 2500 & 480 & 2000 \\
\hline DP & 370 & 109 & 341 & 207 & 89 & 190 & 489 & 49 & 464 \\
\hline CV (\%) & 8,9 & 18,4 & 9,6 & 5,1 & 14,1 & 5,5 & 13,7 & 8,5 & 15,4 \\
\hline AT & 1160 & 370 & 945 & 740 & 330 & 555 & 2030 & 165 & 1980 \\
\hline n & & 19 & & & 17 & & & 23 & \\
\hline
\end{tabular}

Tabela 4.2.4: Sólidos totais e suas frações no retorno de lodo

\begin{tabular}{cccc|ccc|ccc}
\hline \multicolumn{10}{c}{ Sólidos Totais - Retorno de Lodo $\left(\mathbf{m g . L} \mathbf{L}^{-\mathbf{1}}\right.$} \\
\hline \multicolumn{1}{c}{ Fase I } & \multicolumn{7}{c}{ Fase II } & \multicolumn{3}{c}{ Fase III } \\
\hline Variável & Total & Fixo & Volátil & Total & Fixo & Volátil & Total & Fixo & Volátil \\
\hline média & 5009 & 814 & 4196 & 4624 & 712 & 3912 & 4122 & 698 & 3424 \\
\hline máximo & 6090 & 950 & 5200 & 4850 & 870 & 4150 & 5040 & 850 & 4365 \\
\hline mínimo & 3870 & 570 & 3240 & 4380 & 600 & 3640 & 3100 & 350 & 2420 \\
\hline DP & 755 & 101 & 682 & 116 & 79 & 127 & 494 & 104 & 502 \\
\hline CV (\%) & 15,1 & 12,4 & 16,3 & 2,5 & 11,1 & 3,2 & 12,0 & 14,9 & 14,7 \\
\hline AT & 2220 & 380 & 1960 & 470 & 270 & 510 & 1940 & 500 & 1945 \\
\hline n & & 19 & & & 17 & & & 23 & \\
\hline
\end{tabular}


Tabela 4.2.5: Sólidos em suspensão e suas frações no retorno de lodo

\begin{tabular}{cccc|ccc|ccc}
\hline \multicolumn{8}{c}{ Sólidos em Suspensão - Retorno de Lodo $\left(\mathbf{m g . L} \mathbf{L}^{-\mathbf{1}}\right)$} \\
\hline \multicolumn{4}{c}{ Fase I } & \multicolumn{7}{c}{ Fase II } & \multicolumn{3}{c}{ Fase III } \\
\hline Variável & Total & Fixo & Volátil & Total & Fixo & Volátil & Total & Fixo & Volátil \\
\hline média & 4612 & 615 & 3997 & 4394 & 698 & 3696 & 3749 & 576 & 3173 \\
\hline máximo & 5510 & 845 & 4820 & 4795 & 780 & 4105 & 4570 & 690 & 3890 \\
\hline mínimo & 3805 & 310 & 3270 & 4035 & 635 & 3400 & 2800 & 510 & 2220 \\
\hline DP & 504 & 128 & 434 & 185 & 33 & 175 & 450 & 51 & 455 \\
\hline CV (\%) & 10,9 & 20,7 & 10,8 & 4,2 & 4,8 & 4,7 & 12,0 & 8,9 & 14,3 \\
\hline AT & 1705 & 535 & 1550 & 760 & 145 & 705 & 1770 & 180 & 1670 \\
\hline n & & 19 & & & 17 & & & 23 & \\
\hline
\end{tabular}

\subsection{Remoção de material orgânico}

\subsubsection{Resultados da TCO "in loco" e TCOc correspondente à oxidação de material orgânico}

Na Tabela 4.3, podem-se observar os resultados das determinações da taxa de consumo de oxigênio (TCO) "in loco" no sistema de lodo ativado, determinada conforme descrito na seção 3.7 do capítulo 3. Ao analisar os resultados experimentais, pode-se notar que os valores médios da TCO total "in loco" (bactérias heterotróficas e autotróficas) foram semelhantes entre todas as Fases do estudo, independente da variação do TRS e da razão A/M. Esses valores foram utilizados para a determinação da $\left(\mathrm{TCO}_{\mathrm{c}}\right)$ correspondente a oxidação de material orgânico para o cálculo do balanço de massa. Exemplificando-se para Fase III tem-se:

$\mathrm{TCO}_{\mathrm{c}}=\left(\mathrm{TCO}_{\mathrm{t}}-\mathrm{TCO}_{\mathrm{n}}\right)=45-33=12 \mathrm{mgO}_{2} \mathrm{~L}^{-1} \cdot \mathrm{h}^{-1}$

Onde:

$\mathrm{TCO}_{\mathrm{c}}$ : taxa de consumo de oxigênio devido a oxidação de material orgânico; $\mathrm{TCO}_{\mathrm{n}}$ : taxa de consumo de oxigênio devido a nitrificação (obtida experimentalmente por meio de testes respirométricos com o licor misto, conforme descrito na seção 3.9.1 do capítulo 3;

$\mathrm{TCO}_{\mathrm{t}}$ : taxa de consumo de oxigênio total ou exógena.

Tabela 4.3: Taxa de consumo de oxigênio "in loco" no licor misto durante as Fases I, II e III

\begin{tabular}{cccc}
\hline \multicolumn{4}{c}{ Taxas de Consumo de Oxigênio "in loco" $\left(\mathbf{m g O} \mathbf{O}_{\mathbf{2}} \cdot \mathbf{L}^{\mathbf{- 1}} \cdot \mathbf{h}^{\mathbf{- 1}}\right)$} \\
\hline Variável & Fase I & Fase II & Fase III \\
\hline média & 45 & 47 & 45 \\
\hline máximo & 69 & 67 & 68 \\
\hline mínimo & 27 & 24 & 23 \\
\hline DP & 12 & 10 & 11 \\
\hline CV $(\%)$ & 26,1 & 21,4 & 25,4 \\
\hline AT & 42 & 43 & 45 \\
\hline $\mathrm{n}$ & 40 & 43 & 59 \\
\hline
\end{tabular}




\subsubsection{Resultados do balanço de massa do material orgânico}

Os cálculos do balanço de massa do material orgânico do sistema de lodo ativado com aeração prolongada foram realizados conforme descrito no capítulo 3, seção 3.8.1. O detalhamento de cada termo está descrito na lista de símbolos. Na Tabela 4.3.1 estão apresentados os resultados referentes aos balanços de massa de material orgânico do sistema de lodo ativado durante a operação com TRS de 40, 30 e 20 dias. Constata-se que os valores médios tiveram boa aproximação ao valor teórico $\mathrm{B}_{\mathrm{o}}=1 \mathrm{em}$ todas as Fases do estudo, estando menos que $10 \%$ distante desse resultado. Conclui-se que, em boa aproximação, o balanço de massa do material orgânico demonstrou-se consistente. Portanto os dados experimentais são confiáveis e o sistema de lodo ativado foi operado sob condições estacionárias (VAN HAANDEL e MARAIS, 1999).

Tabela 4.3.1: Balanço de massa de material orgânico no sistema de lodo ativado, referente às idades de lodo de 40, 30 e 20 dias.

\begin{tabular}{cccc}
\hline \multicolumn{4}{c}{ Balanços de massa do material orgânico do sistema de lodo ativado } \\
\hline Variável & Fase I & Fase II & Fase III \\
\hline média & 1,02 & 0,90 & 0,92 \\
\hline máximo & 1,11 & 1,10 & 1,07 \\
\hline mínimo & 0,90 & 0,78 & 0,76 \\
\hline DP & 0,06 & 0,11 & 0,10 \\
\hline CV $(\%)$ & 6,2 & 12,5 & 10,8 \\
\hline AT & 0,2 & 0,3 & 0,30 \\
\hline $\mathrm{n}$ & 19 & 17 & 23 \\
\hline
\end{tabular}

Exemplificando-se para Fase III (Tabela 4.3.1), tem-se os seguintes valores: $\mathrm{S}_{\mathrm{ta}}=587 \mathrm{mg} . \mathrm{L}^{-1}$;

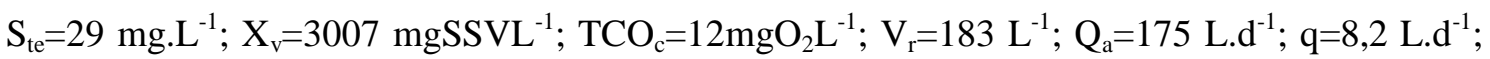
$\mathrm{f}_{\mathrm{cr}}=$ adotado 1,5 mgDQO.mgSSV ${ }^{-1}$ (VAN HAANDEL e MARAIS, 1999). Portanto calcula-se:

Fração da DQO afluente descarregada no efluente $\left(\mathrm{mS}_{\mathrm{te}}\right)$ : $\mathrm{mS}_{\mathrm{te}}=\mathrm{S}_{\mathrm{te}} / \mathrm{S}_{\mathrm{ta}}=29 / 587=0,05$

Fração da DQO afluente descarregada como lodo de excesso $\left(\mathrm{mS}_{\mathrm{xv}}\right)$ : $\mathrm{mS}_{\mathrm{xv}}=\left(\mathrm{q} / \mathrm{Q}_{\mathrm{a}}\right) * \mathrm{f}_{\mathrm{cv}} * \mathrm{X}_{\mathrm{v}} / \mathrm{S}_{\mathrm{ta}}=(8,2 / 175) * 1,5 * 3007 / 587=0,36$

Fração de DQO afluente que é oxidada no sistema $\left(\mathrm{mS}_{\mathrm{o}}\right)$ : $\mathrm{mS}_{\mathrm{o}}=\left(\mathrm{V}_{\mathrm{r}} / \mathrm{Q}_{\mathrm{a}}\right) * \mathrm{TCO}_{\mathrm{c}} * 24 / \mathrm{S}_{\mathrm{ta}}=(183 / 175) * 12 * 24 / 587=0,51$

A soma das três frações dá o valor do balanço de massa do material orgânico $\left(\mathrm{B}_{\mathrm{o}}\right)$ : $\mathrm{B}_{\mathrm{o}}=\left(\mathrm{mS}_{\mathrm{te}}+\mathrm{mS}_{\mathrm{xv}}+\mathrm{mS}_{\mathrm{o}}\right)=(0,05+0,36+0,51)=0,92$ 


\subsection{Resultados da DQO e DBO no afluente e efluente do sistema de lodo ativado}

Nas Tabelas 4.4.1 e 4.4.2, podem-se observar os valores médios das concentrações afluente e efluente da DQO e DBO (total e solúvel) obtidos nas Fases I, II e III. Ao analisarmos os resultados, nota-se que os valores experimentais das concentrações de DQO e DBO após o tratamento foram consideravelmente baixas, independente da redução do TRS e do aumento da razão A/M como se observa na Figura 4.2 e 4.2.1. Ainda, com base nos resultados nota-se uma elevada eficiência na remoção de material orgânico biodegradável em termos de DQO e DBO, sendo superiores a 90\% na Fase I, de $95 \%$ na Fase II e de $93 \%$ na Fase III como se observa claramente nas Figuras 4.2.2 e 4.2.3. Desse modo, conclui-se que a baixa concentração de OD e as de mais condições operacionais estabelecidas não afetou negativamente a remoção de material orgânico.

Tabela 4.4.1: Concentrações médias de DQO e DBO no esgoto sanitário afluente

\begin{tabular}{|c|c|c|c|c|c|c|c|c|c|c|c|c|}
\hline \multicolumn{13}{|c|}{ DQO e DBO - Afluente (mg. L $\left.^{-1}\right)$} \\
\hline \multirow{3}{*}{ Variável } & \multicolumn{4}{|c|}{ FASE I } & \multicolumn{4}{|c|}{ FASE II } & \multicolumn{4}{|c|}{ FASE III } \\
\hline & \multicolumn{2}{|c|}{ DQO } & \multicolumn{2}{|c|}{ DBO } & \multicolumn{2}{|c|}{ DQO } & \multicolumn{2}{|c|}{ DBO } & \multicolumn{2}{|c|}{ DQO } & \multicolumn{2}{|c|}{ DBO } \\
\hline & (T) & (S) & (T) & (S) & (T) & (S) & (T) & (S) & (T) & (S) & (T) & (S) \\
\hline média & 511 & 238 & 245 & 114 & 537 & 280 & 269 & 139 & 587 & 282 & 348 & 168 \\
\hline máximo & 736 & 360 & 353 & 173 & 664 & 400 & 332 & 195 & 1040 & 680 & 676 & 442 \\
\hline mínimo & 400 & 119 & 192 & 57 & 440 & 184 & 220 & 90 & 256 & 56 & 128 & 60 \\
\hline DP & 87 & 59 & 42 & 28 & 62 & 48 & 32 & 24 & 172 & 123 & 122 & 80 \\
\hline $\mathrm{CV}(\%)$ & 17,0 & 24,9 & 16,9 & 24,9 & 11,5 & 17,2 & 11,9 & 17,3 & 29,2 & 43,7 & 35,1 & 47,5 \\
\hline AT & 336 & 241 & 161 & 116 & 224 & 216 & 112 & 106 & 784 & 624 & 548 & 382 \\
\hline $\mathrm{n}$ & & & & & & & & & & & & \\
\hline
\end{tabular}

Legenda: (T) total e (S) solúvel

Tabela 4.4.2: Concentrações médias de DQO e DBO no efluente final

\begin{tabular}{|c|c|c|c|c|c|c|c|c|c|c|c|c|}
\hline \multicolumn{13}{|c|}{ DQO e DBO - Efluente (mg. L $^{-1}$ ) } \\
\hline \multirow{3}{*}{ Variável } & \multirow{2}{*}{\multicolumn{4}{|c|}{\begin{tabular}{l}
\multicolumn{2}{c}{ FASE I } \\
DOO
\end{tabular}}} & \multicolumn{4}{|c|}{ FASE II } & \multicolumn{4}{|c|}{ FASE III } \\
\hline & & & & & \multicolumn{2}{|c|}{ DQO } & \multicolumn{2}{|c|}{ DBO } & \multicolumn{2}{|c|}{ DQO } & \multicolumn{2}{|c|}{ DBO } \\
\hline & (T) & (S) & (T) & (S) & $(\mathbf{T})$ & (S) & $(\mathbf{T})$ & (S) & (T) & (S) & (T) & (S) \\
\hline média & 46 & 28 & 23 & 13 & 35 & 17 & 20 & 9 & 29 & 13 & 17 & 8 \\
\hline máximo & 96 & 80 & 46 & 38 & 116 & 44 & 61 & 21 & 100 & 40 & 53 & 26 \\
\hline mínimo & 8 & 4 & 4 & 2 & 8 & 4 & 4 & 4 & 4 & 2 & 2 & 2 \\
\hline DP & 26 & 19 & 12 & 9 & 30 & 13 & 15 & 5 & 27 & 13 & 17 & 8 \\
\hline CV (\%) & 55,2 & 67,1 & 50,4 & 67,0 & 85,9 & 76,4 & 76,7 & 58,9 & 93,4 & 102,4 & 96,2 & 96,4 \\
\hline AT & 88 & 76 & 42 & 36 & 108 & 40 & 57 & 17 & 96 & 38 & 51 & 24 \\
\hline $\mathrm{n}$ & & 1 & & & & & & & & 23 & & \\
\hline
\end{tabular}

Legenda: (T) total e (S) solúvel 
Fase I
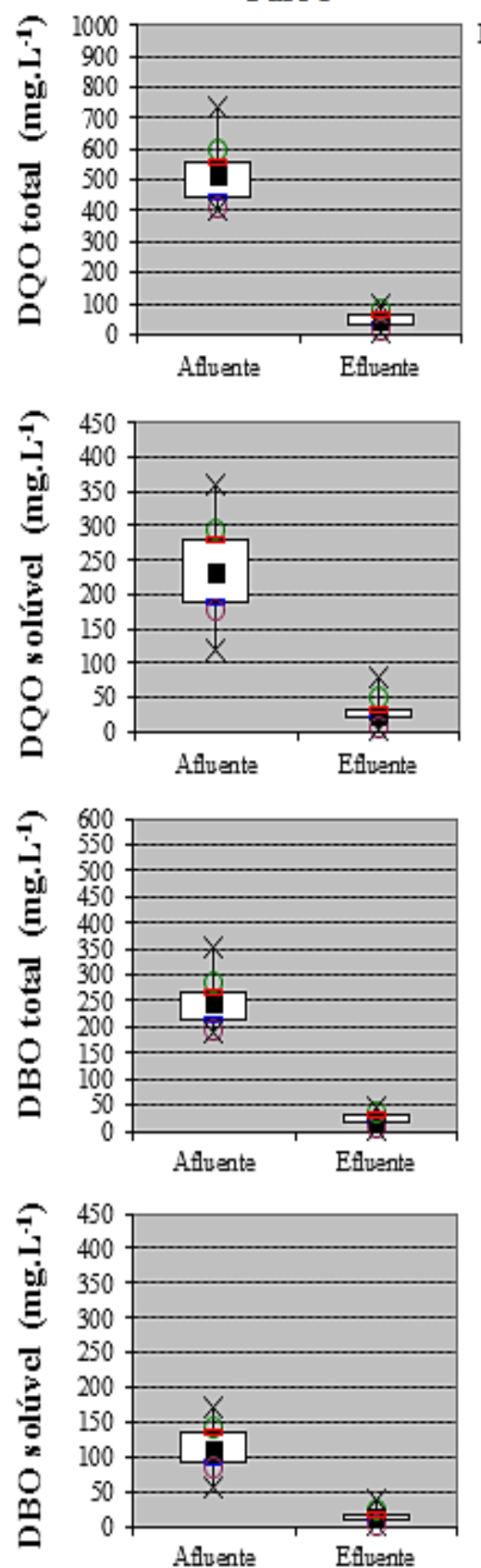

Fase II
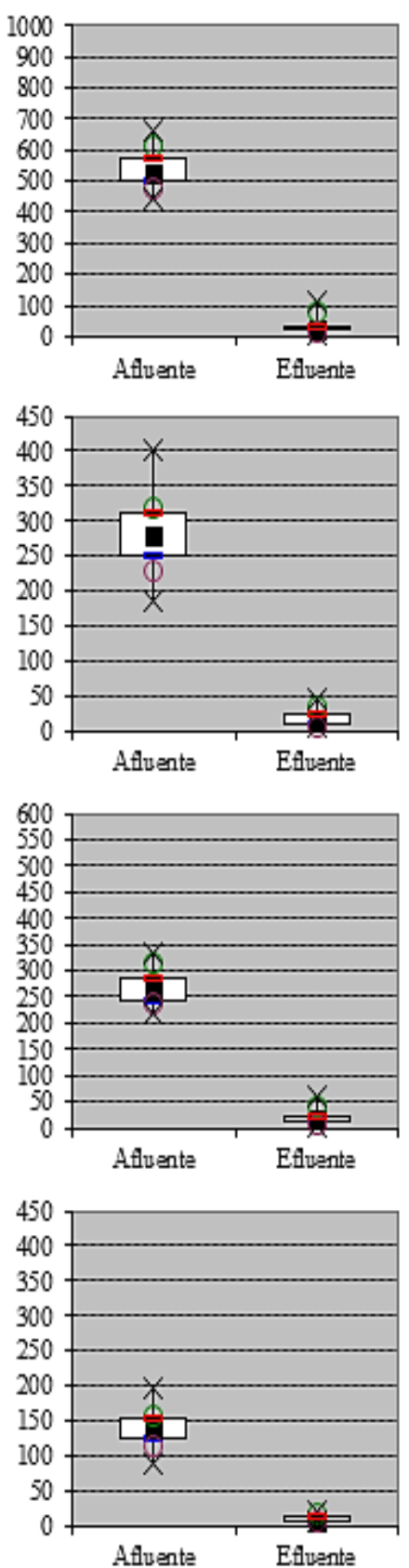

Fase III
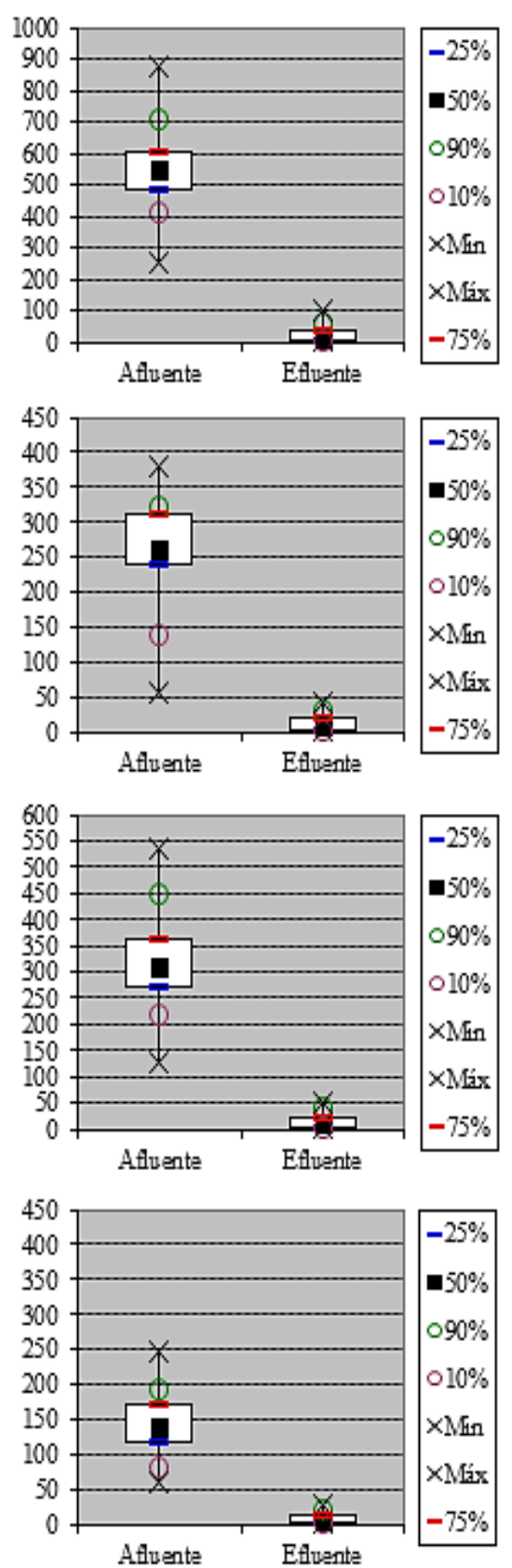

Figura 4.2: Diagrama Box-Whiskers: Análises médias da DQO e DBO total e solúvel do afluente e efluente nas Fases I, II e III. 
Fase I
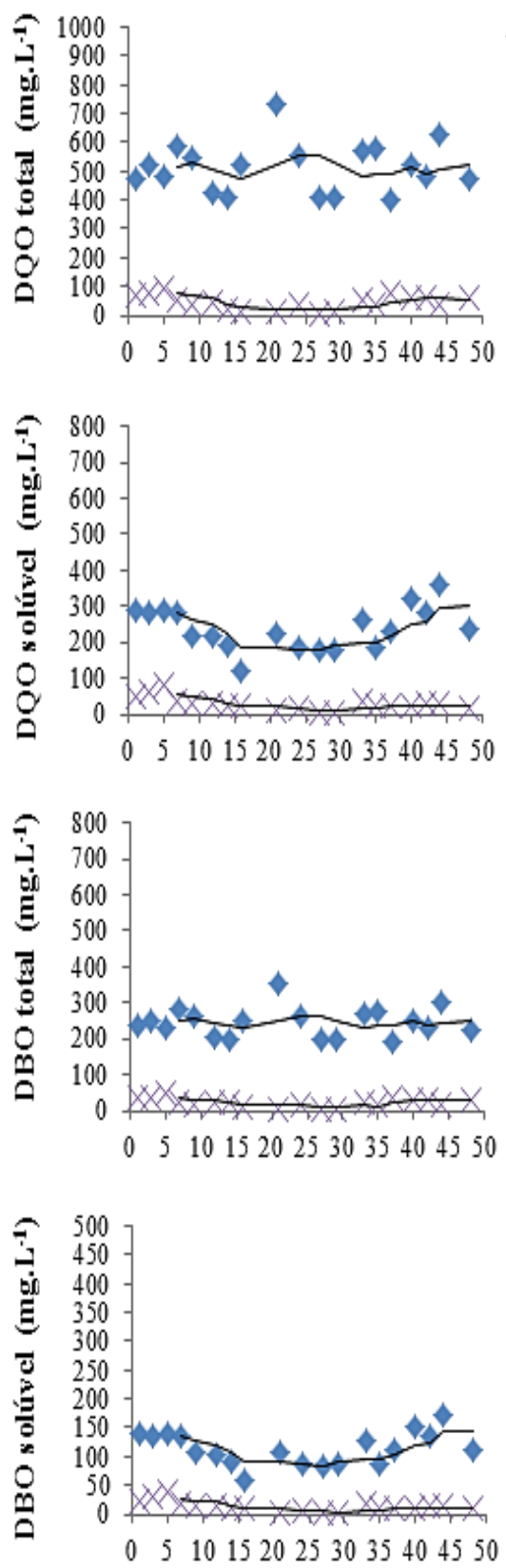

$\leadsto$ Afluente $*$ Efluente
Fase II
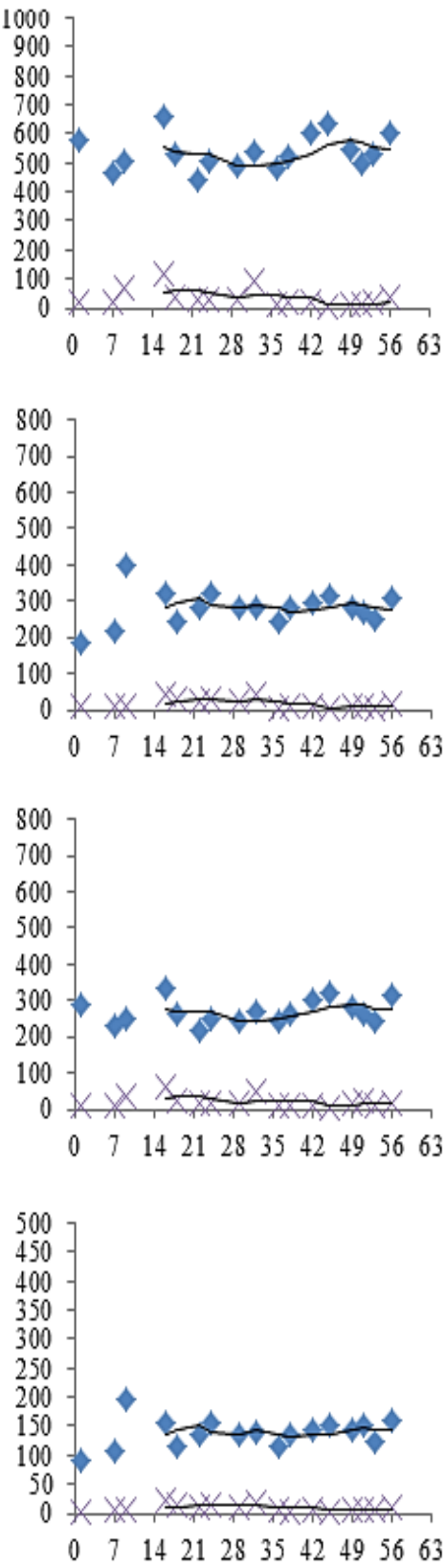

Diss
Fase III
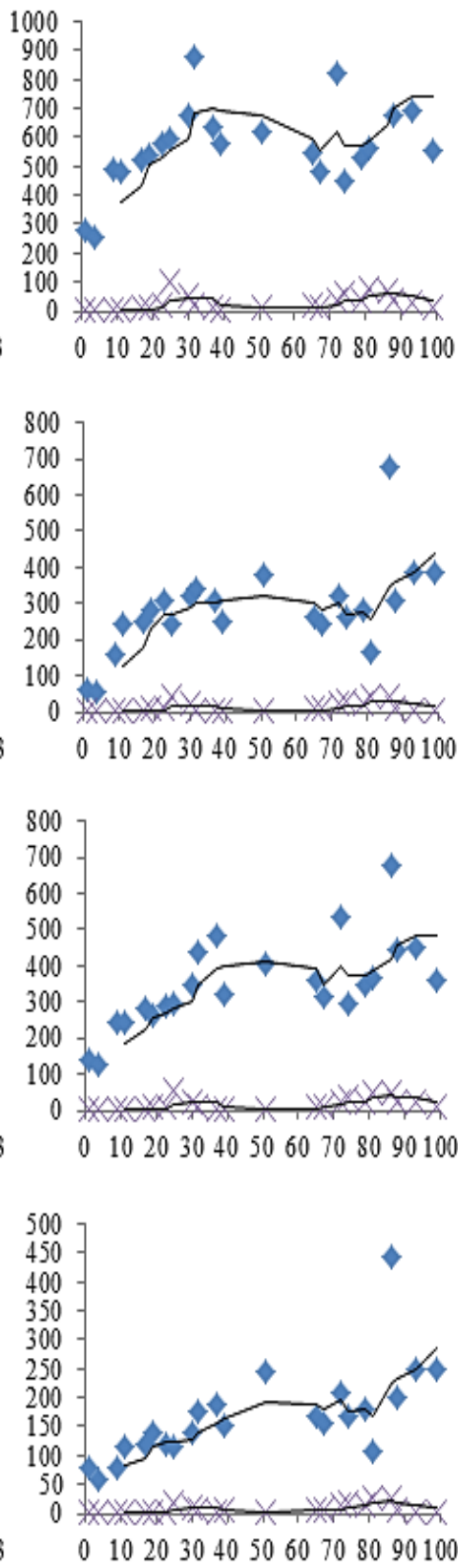

Figura 4.2.1: Série temporal com médias móveis de 4 termos: Análise da DQO e DBO total e solúvel do afluente e efluente nas Fases I, II e III. 

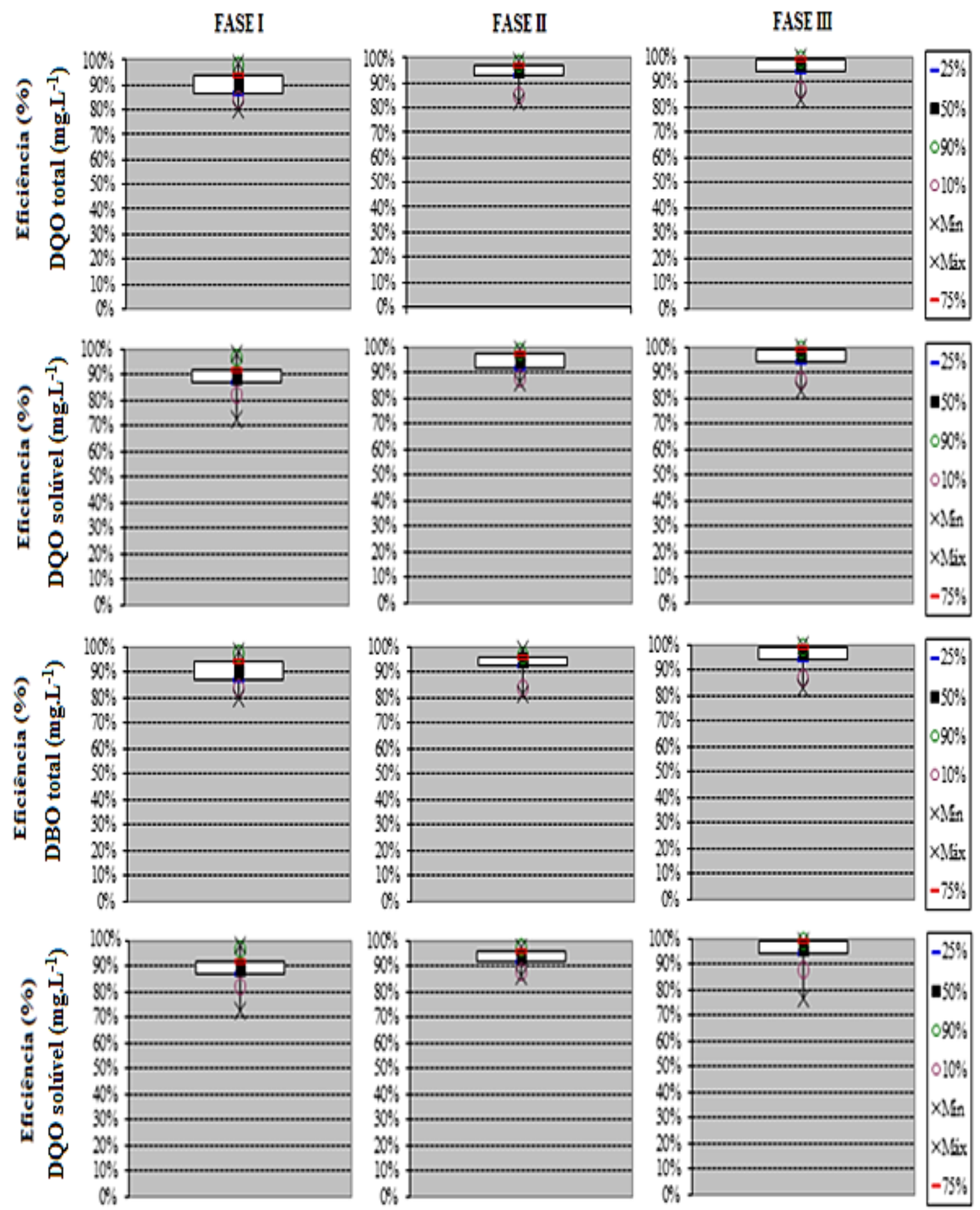

Eficiência na remoção da DQO e DBO

Figura 4.2.2: Diagrama Box-Whiskers: Eficiência na remoção da DQO e DBO total e solúvel nas Fases I, II e III. 

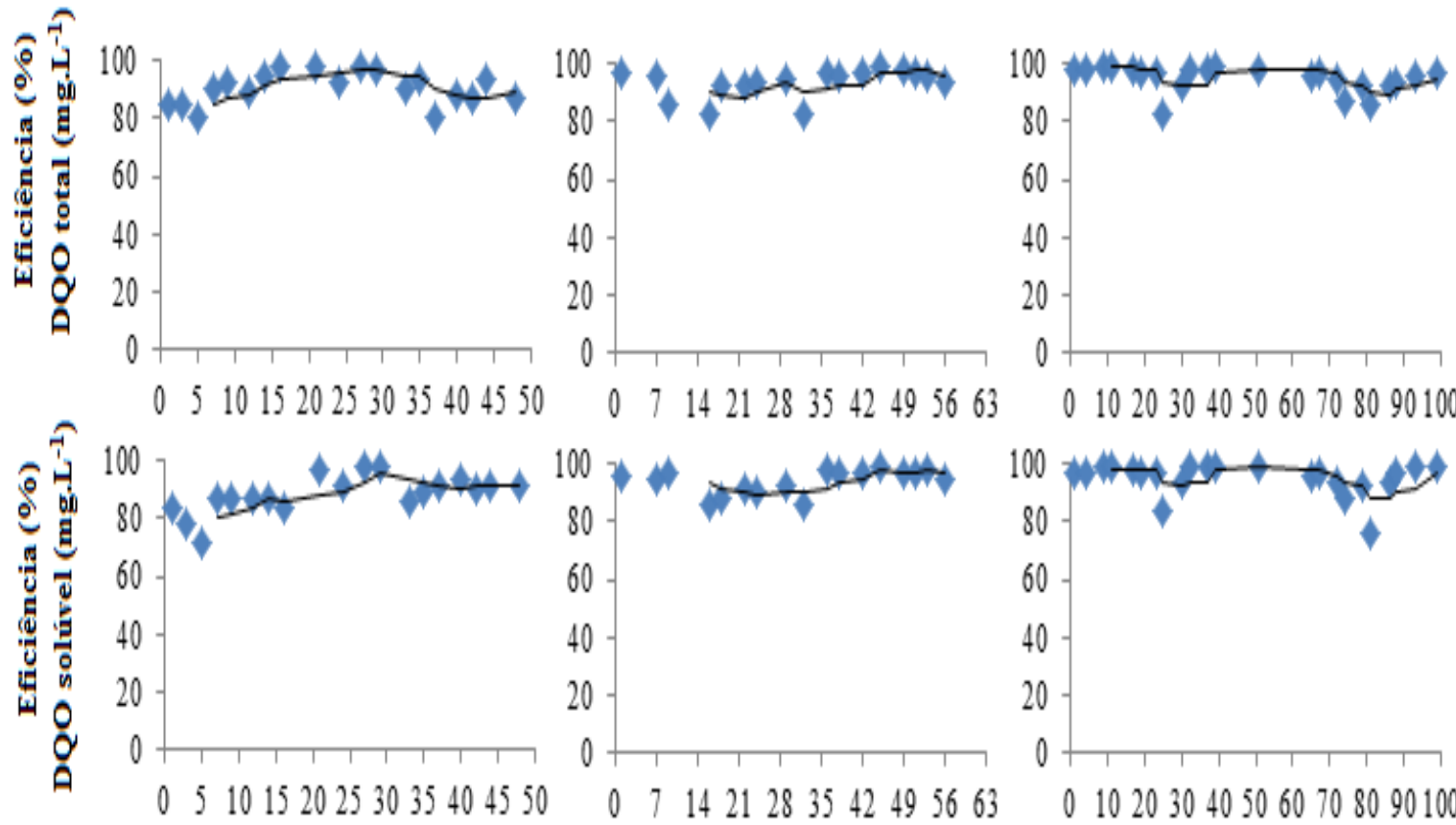

0102030405060708090100
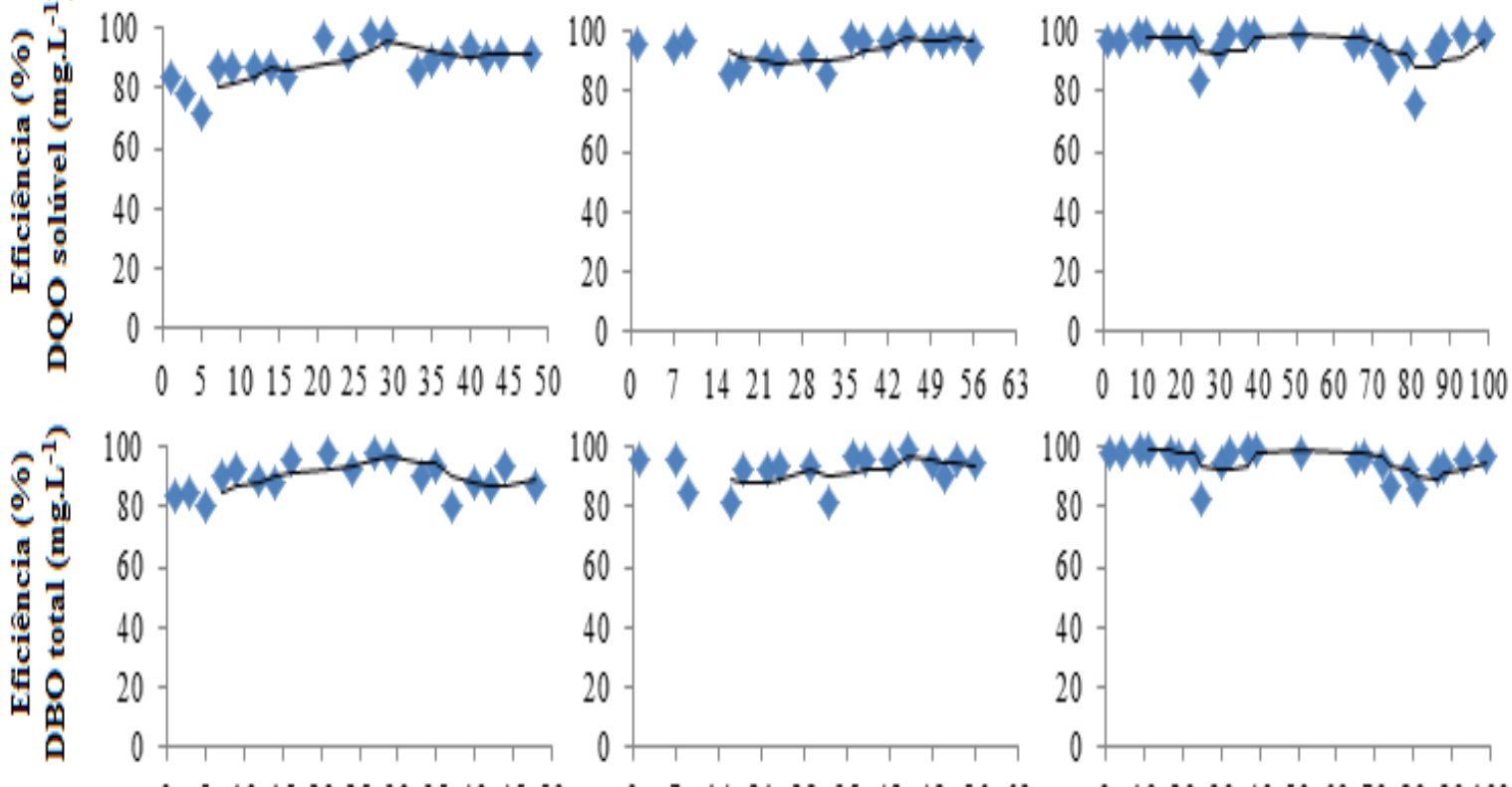

$05101520253035404550 \quad 0 \quad 71421283542495663$
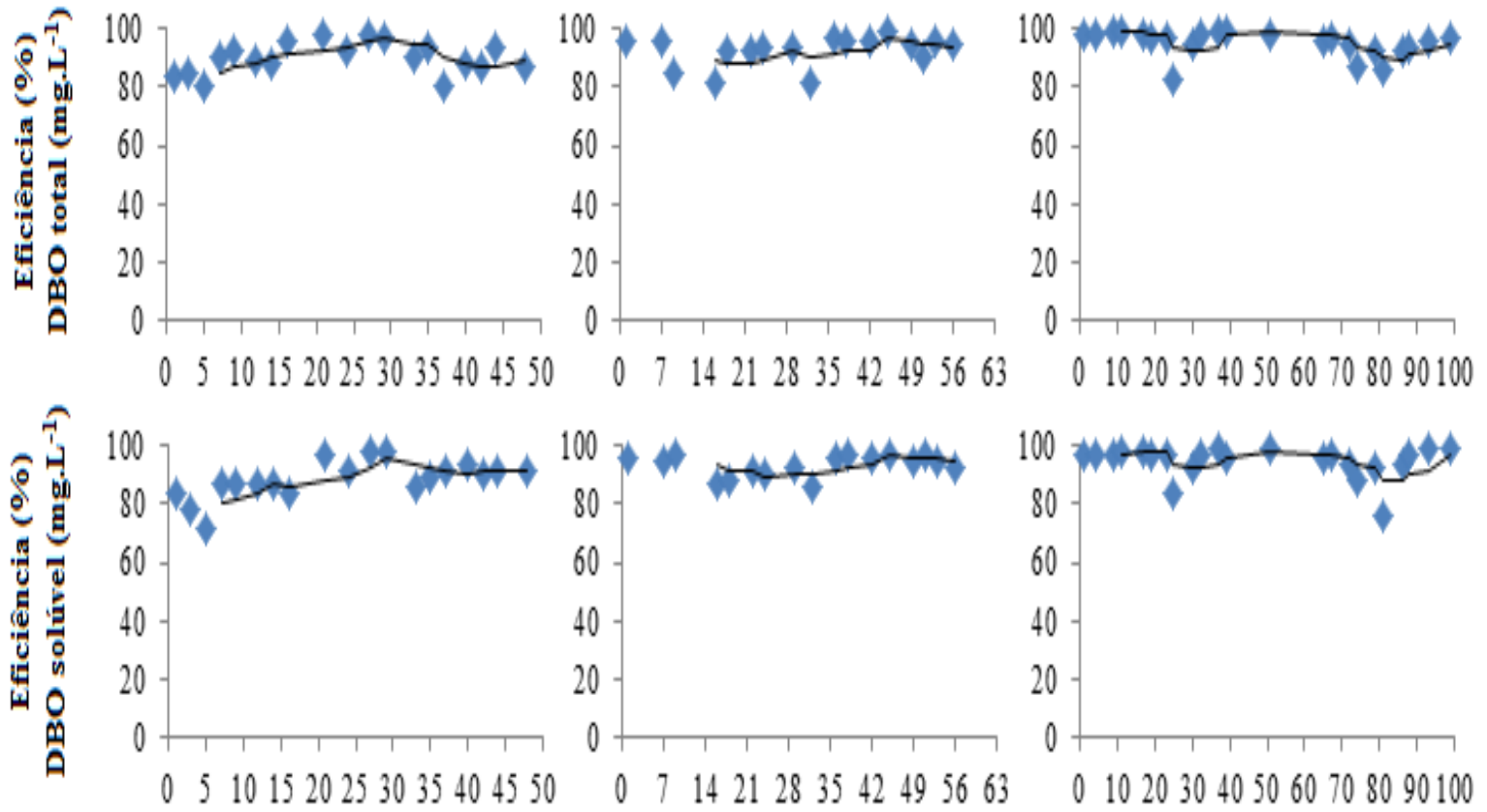

Eficiência na remoçăo da DQ0 e DBO

Figura 4.2.3: Série temporal com médias móveis de 4 termos: Eficiência na remoção de DQO e DBO total e solúvel nas Fases I, II e III. 


\subsection{Remoção do material nitrogenado}

\subsubsection{Resultados do balanço de massa do material nitrogenado}

Na Tabela 4.5, podem-se observar os resultados obtidos referentes aos balanços de massa de material nitrogenado do sistema de lodo ativado durante a operação com TRS de 40, 30 e 20 dias calculado conforme descrito na seção 3.8.2 do capítulo 3. O detalhamento de cada termo está descrito na lista de símbolos. Os valores médios do balanço de massa nas Fases I, II e III tiveram boa aproximação ao valor teórico $B_{n}=1$, estando menos que $10 \%$ distante desse resultado. Conclui-se que, em boa aproximação, o balanço de massa de material nitrogenado demonstrou-se consistente. Portanto os dados experimentais são confiáveis e o sistema de lodo ativado foi operado sob condições estacionárias (VAN HAANDEL e MARAIS, 1999).

Tabela 4.5: Balanço de massa de material nitrogenado no sistema de lodo ativado, referente às idades de lodo de 40, 30 e 20 dias.

\begin{tabular}{cccc}
\hline \multicolumn{4}{c}{ Balanço de massa do material nitrogenado no sistema de lodo ativado } \\
\hline Variável & Fase I & Fase II & Fase III \\
\hline média & 1,01 & 0,93 & 1,04 \\
\hline máximo & 1,13 & 0,99 & 1,34 \\
\hline mínimo & 0,94 & 0,89 & 0,94 \\
\hline DP & 0,05 & 0,04 & 0,10 \\
\hline CV $(\%)$ & 5,0 & 4,0 & 9,0 \\
\hline AT & 0,19 & 0,11 & 0,40 \\
\hline $\mathrm{n}$ & 19 & 17 & 23 \\
\hline
\end{tabular}

Exemplificando-se para Fase III (Tabela 4.5), tem-se os seguintes valores: $\mathrm{f}_{\mathrm{n}}=$ adotado 0,1 (VAN HAANDEL e MARAIS, 1999); $\mathrm{R}_{\mathrm{S}}=20 \mathrm{~d}^{-1} ; \mathrm{Vr}=183 \mathrm{~L}^{-1} ; \mathrm{N}_{\mathrm{oa}}=9,3 \mathrm{mgN} . \mathrm{L}^{-1} ; \mathrm{N}_{\mathrm{oe}}=2,7$ $\operatorname{mgN} . L^{-1} ; \mathrm{N}_{\mathrm{aa}}=52,2 \mathrm{mgN} \cdot \mathrm{L}^{-1} ; \mathrm{N}_{\mathrm{ae}}=1,8 \mathrm{mgN} . \mathrm{L}^{-1} ; \mathrm{N}_{\mathrm{ne}}=7,2 \mathrm{mgN} \cdot \mathrm{L}^{-1} ; \mathrm{X}_{\mathrm{v}}=3007 \mathrm{mgSSVL}{ }^{-1} ;$ $\mathrm{Q}_{\mathrm{a}}=175 \mathrm{~L} \cdot \mathrm{d}^{-1} ; \mathrm{r}=0,7$. Portanto calcula-se:

Fluxo de material nitrogenado no lodo de excesso $\left(\mathrm{MN}_{\mathrm{l}}\right)$ :

$\mathrm{MN}_{\mathrm{l}}=\mathrm{f}_{\mathrm{n}} * \mathrm{~V}_{\mathrm{r}} * \mathrm{X}_{\mathrm{v}} / \mathrm{R}_{\mathrm{s}}=0,1 * 183 * 3007 / 20=2751,4$

Fluxo de material nitrogenado afluente $\left(\mathrm{MN}_{\mathrm{ta}}\right)$ :

$\mathrm{MN}_{\mathrm{ta}}=\mathrm{Q}_{\mathrm{a}} *\left(\mathrm{~N}_{\mathrm{oa}}+\mathrm{N}_{\mathrm{aa}}+\mathrm{N}_{\mathrm{na}}\right)=\mathrm{Q}_{\mathrm{a}} * \mathrm{~N}_{\mathrm{ta}}=175 * 61,5=10762,5$

Fluxo de material nitrogenado efluente $\left(\mathrm{MN}_{\mathrm{te}}\right)$ :

$\mathrm{MN}_{\mathrm{te}}=\mathrm{Q}_{\mathrm{a}} *\left(\mathrm{~N}_{\mathrm{oe}}+\mathrm{N}_{\mathrm{ae}}+\mathrm{N}_{\mathrm{ne}}\right)=\mathrm{Q}_{\mathrm{a}} * \mathrm{~N}_{\mathrm{te}}=175 * 11,7=2047,5$

Fluxo de material nitrogenado desnitrificado no sistema de lodo ativado $\left(\mathrm{MN}_{\mathrm{d}}\right)$ :

$\mathrm{MN}_{\mathrm{d}}=\left(\mathrm{Q}_{\mathrm{a}}+\mathrm{q}\right) * \Delta \mathrm{N}_{\mathrm{n}}=\left(175^{*} 0,7\right)^{*}(9,3+52,2-1,8-7,2)=6431,3$ 
Por fim, o balanço de massa do material nitrogenado para o sistema de lodo ativado $\left(\mathrm{B}_{\mathrm{n}}\right)$, pode ser determinado como se segue:

$\mathrm{B}_{\mathrm{n}}=\left(\mathrm{MN}_{\mathrm{l}}+\mathrm{MN}_{\mathrm{te}}+\mathrm{MN}_{\mathrm{d}}\right) / \mathrm{MN}_{\mathrm{ta}}=(2751,4+2047,5+6431,3) / 10762,5=1,04$

\subsubsection{Resultados de nitrogênio amoniacal e orgânico no afluente e efluente do sistema de lodo ativado}

Nas Tabelas 4.5.1 e 4.5.2, podem-se observar os valores médios das concentrações afluente e efluente de nitrogênio amoniacal e orgânico, assim como o NTK, obtidos durante as Fases I, II e III do estudo. Ao analisar os resultados experimentais, pode-se notar que as concentrações de nitrogênio amoniacal e orgânico no efluente após o tratamento foram consideravelmente baixas (Figura 4.3 e 4.3.1), mesmo quando o TRS foi reduzido para 20 dias (Fase III) valor que coincide com o limite mínimo para lodo ativado com aeração prolongada e, mesmo assim não foi constatado qualquer prejuízo para a nitrificação. Demonstrando, que a influência da baixa concentração de OD $\left(0,3-0,8 \mathrm{mg} \cdot \mathrm{L}^{-1}\right)$ no licor misto e as condições operacionais estabelecidas não foi limitante no desenvolvimento da nitrificação. Outro aspecto que fica claro a partir dos valores obtidos é a ocorrência e estabilidade no processo de nitrificação durante todo o estudo.

Tabela 4.5.1: Concentrações médias de NTK, N-orgânico e $\mathrm{NH}_{3}{ }^{-}$no afluente nas Fases I, II e III

\begin{tabular}{cccc|ccc|ccc}
\hline \multicolumn{7}{c}{ Afluente $\left(\mathbf{m g N . L}^{-\mathbf{1}}\right)$} \\
\hline Variável & NTK & N org. & $\mathbf{N H}_{\mathbf{3}}$ & $\mathbf{N T K}$ & $\mathbf{N ~ o r g .}$ & $\mathbf{N H}_{\mathbf{3}}$ & $\mathbf{N T K}$ & $\mathbf{N ~ o r g . ~}$ & $\mathbf{N H}_{\mathbf{3}}$ \\
\hline média & 77,0 & 15,7 & 61,4 & 74,9 & 10,6 & 64,3 & 61,4 & 9,3 & 52,2 \\
\hline máximo & 100,8 & 37,5 & 79,5 & 85,1 & 21,8 & 75,6 & 81,2 & 21,8 & 72,8 \\
\hline mínimo & 53,8 & 1,7 & 50,4 & 58,8 & 2,8 & 56,0 & 43,7 & 2,0 & 39,2 \\
\hline DP & 12,4 & 8,7 & 9,1 & 8,7 & 6,7 & 5,0 & 8,5 & 5,1 & 6,1 \\
\hline CV $(\%)$ & 16,1 & 55,7 & 14,9 & 11,6 & 62,6 & 7,8 & 13,9 & 55,5 & 11,6 \\
\hline AT & 47,0 & 35,8 & 29,1 & 26,3 & 19,0 & 19,6 & 37,5 & 19,8 & 33,6 \\
\hline $\mathrm{n}$ & & 19 & & & 17 & & & 23 & \\
\hline
\end{tabular}

Tabela 4.5.2: Concentrações médias de NTK, N-orgânico e $\mathrm{NH}_{3}{ }^{-}$no efluente nas Fases I, II e III

\begin{tabular}{cccc|ccc|ccc}
\hline \multicolumn{8}{c}{ Fase I } & & \multicolumn{3}{c|}{ Fase II } & \multicolumn{3}{c}{ Fase III } \\
\hline Variável & NTK & N org. & $\mathbf{N H}_{\mathbf{3}}$ & NTK & N org. & $\mathbf{N H}_{\mathbf{3}}$ & NTK & N org. & $\mathbf{N H}_{\mathbf{3}}$ \\
\hline média & 5,9 & 3,0 & 2,9 & 4,3 & 2,1 & 2,2 & 4,6 & 2,7 & 1,8 \\
\hline máximo & 9,5 & 6,7 & 7,8 & 9,5 & 4,5 & 5,6 & 11,2 & 6,7 & 5,6 \\
\hline mínimo & 1,1 & 0,6 & 0,0 & 1,7 & 0,6 & 0,0 & 1,0 & 0,8 & 0,0 \\
\hline DP & 2,9 & 1,9 & 2,5 & 2,1 & 1,1 & 1,4 & 2,5 & 1,4 & 1,6 \\
\hline CV $(\%)$ & 49,3 & 64,0 & 86,3 & 48,1 & 50,0 & 63,7 & 54,5 & 52,0 & 88,7 \\
\hline AT & 8,4 & 6,2 & 7,8 & 7,8 & 3,9 & 5,6 & 10,2 & 5,9 & 5,6 \\
\hline n & & 19 & & & 17 & & & 23 & \\
\hline
\end{tabular}



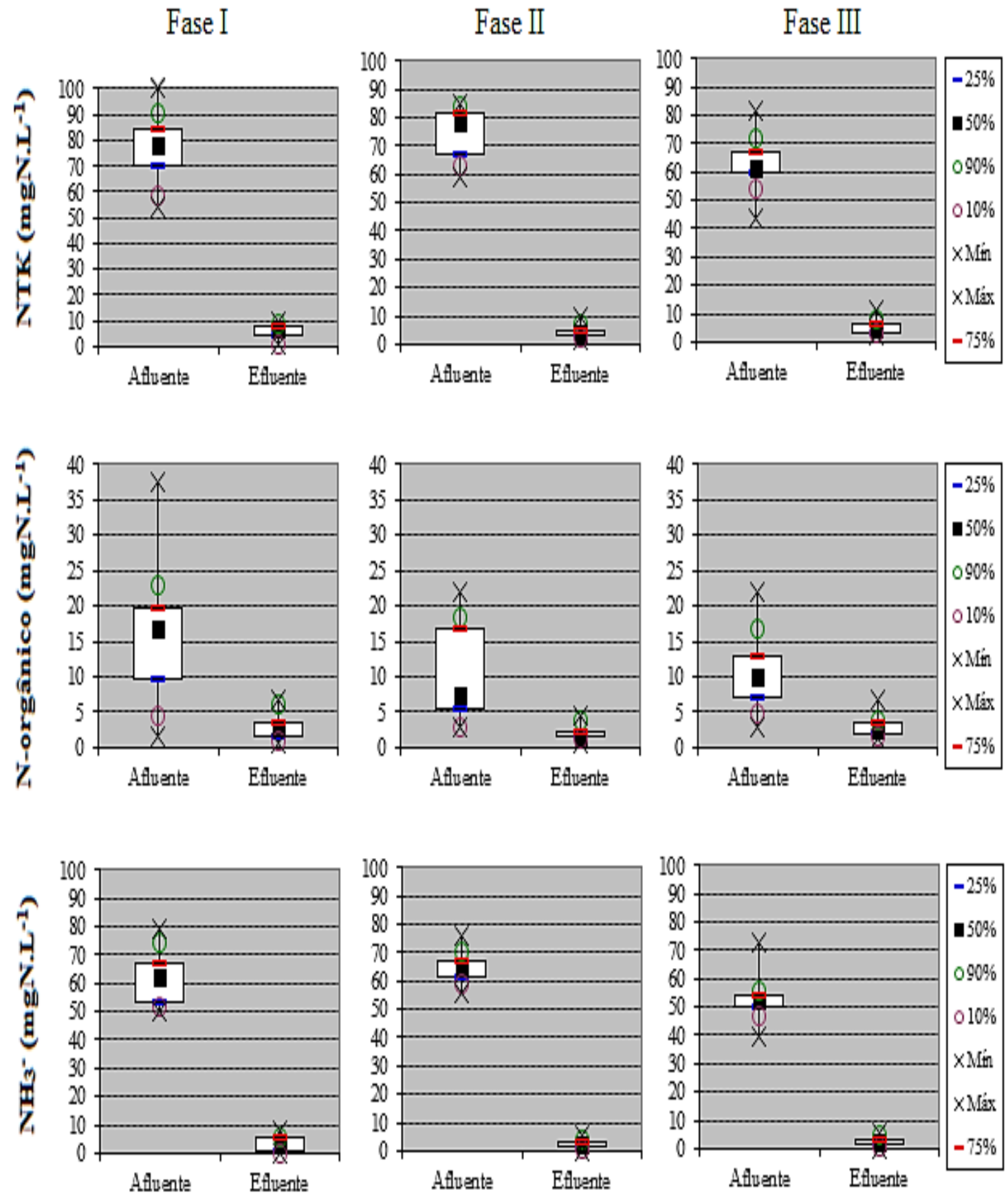

Figura 4.3: Diagrama Box-Whiskers: Análises médias da NTK, $\mathrm{N}$-orgânico e $\mathrm{NH}_{3}{ }^{-}$do afluente e efluente nas Fases I, II e III. 

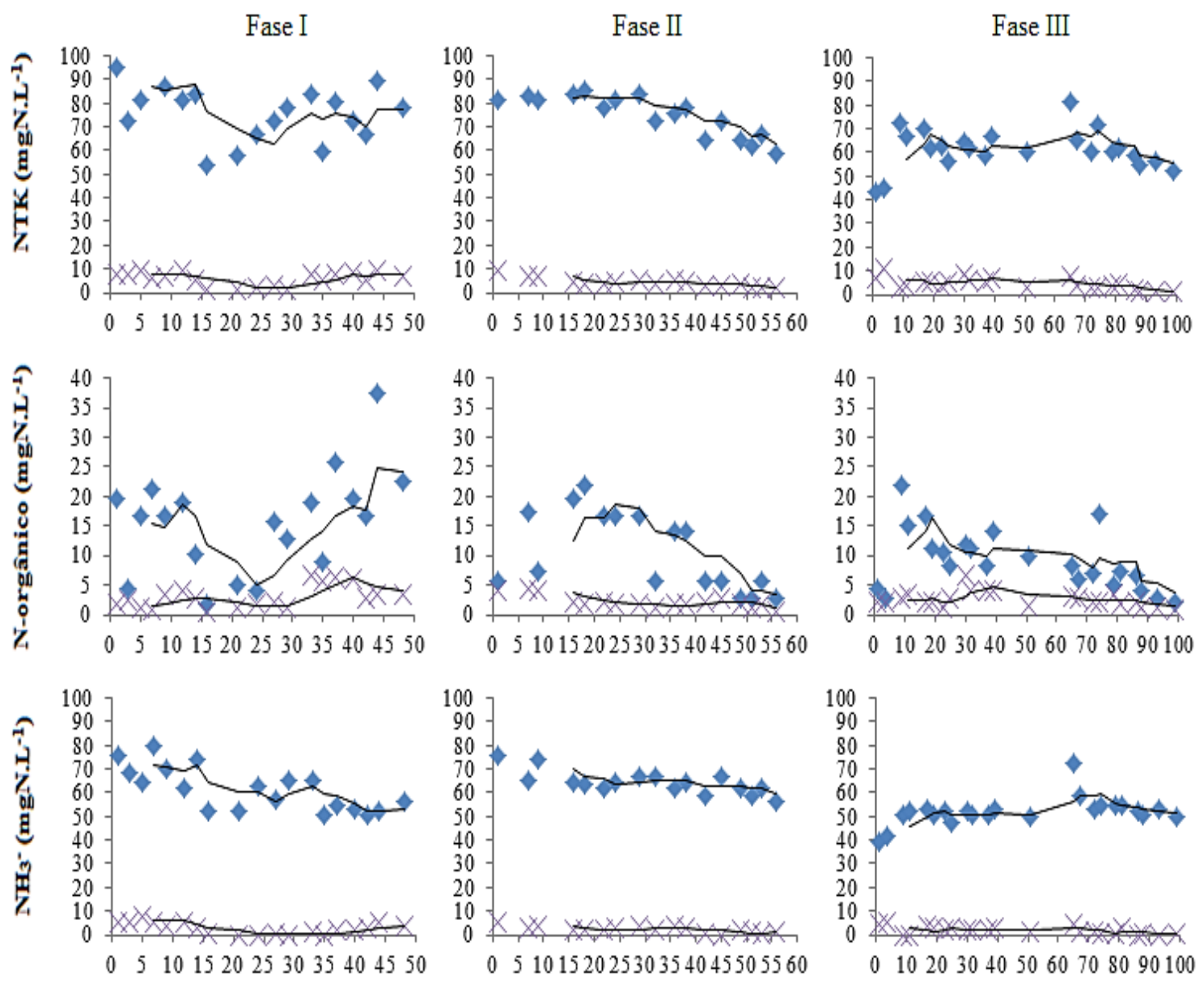

$\leadsto$ Afluente $\approx$ Efluente

Dias

Figura 4.3.1: Série temporal com médias móveis de 4 termos: Análise do NTK, N-orgânico e $\mathrm{NH}_{3}{ }^{-}$do afluente e efluente nas Fases I, II e III.

\subsubsection{Resultados de nitrito e nitrato no afluente e efluente do sistema de lodo ativado}

As concentrações de nitrito e nitrato no afluente e do nitrito no efluente final durante todo o período do estudo, foi menor que $0,5 \mathrm{mgN} . \mathrm{L}^{-1}$, que, para todos os efeitos, foi desconsiderada. $\mathrm{Na}$ Tabela 4.5.3, podem-se observar os valores médios obtidos das concentrações de nitrato $(\mathrm{N}$ $\mathrm{NO}_{3}^{-}$) no efluente após o tratamento nas Fases I, II e III. Ao analisar os resultados experimentais, podem-se notar um aumento na concentração do nitrato no efluente quando o TRS é reduzido para 20 dias, como se observa na Figura 4.4. No entanto, os valores médios manteve-se abaixo de $10 \mathrm{mgN} . \mathrm{L}^{-1} \mathrm{em}$ ambas as Fases, como se observa na Tabela 4.5.3. 
Outro aspecto que fica claro a partir dos resultados experimentais de nitrato no efluente após o tratamento quando comparado com os resultados experimentais de nitrogênio (amoniacal e orgânico) (Tabela 4.5.1 e 4.5.2, seção 4.5.2) e os dados obtidos no balanço de massa do material nitrogenado (Tabela 4.5, seção 4.5.1) é a ocorrência do processo de nitrificação e desnitrificação simultânea no tanque de aeração durante todas as Fases do estudo. Portanto, conclui-se que:

(1) A nitrificação ocorreu com elevada eficiência no tanque de aeração em uma faixa estreita de oxigênio dissolvido $\left(0,3-0,8 \mathrm{mg} \cdot \mathrm{L}^{-1}\right)$;

(2) Foi possível estabelecer um ambiente anóxico no interior dos flocos para o desenvolvimento do processo de desnitrificação na presença de baixas concentrações de oxigênio dissolvido, não descartando a hipótese da ocorrência da desnitrificação autotrófica;

(3) Ocorreu no tanque de aeração o desenvolvimento da nitrificação e desnitrificação simultânea (NDS).

Tabela 4.5.3: Concentrações médias de $\mathrm{N}_{-} \mathrm{NO}_{3}{ }^{-}$no efluente final nas Fases I, II e III.

\begin{tabular}{cccc}
\hline & \multicolumn{4}{c}{ Efluente $\left(\mathbf{m g . ~}^{-\mathbf{1}}\right)$} & \\
\hline & Fase I & Fase II & Fase III \\
\hline Variável & $\mathbf{N O}_{\mathbf{3}}{ }^{-}$ & $\mathbf{N O}_{\mathbf{3}}{ }^{-}$ & $\mathbf{N O}_{\mathbf{3}}{ }^{-}$ \\
\hline média & 0,8 & 6,5 & 7,2 \\
\hline máximo & 1,9 & 9,0 & 14,0 \\
\hline mínimo & 0,0 & 4,5 & 1,0 \\
\hline $\mathrm{DP}$ & 0,7 & 1,4 & 3,9 \\
\hline $\mathrm{CV}(\%)$ & 86,6 & 22,1 & 53,9 \\
\hline $\mathrm{AT}$ & 1,9 & 4,5 & 13,0 \\
\hline $\mathrm{n}$ & 19 & 17 & 23 \\
\hline
\end{tabular}

Fase I

Fase II

Fase III
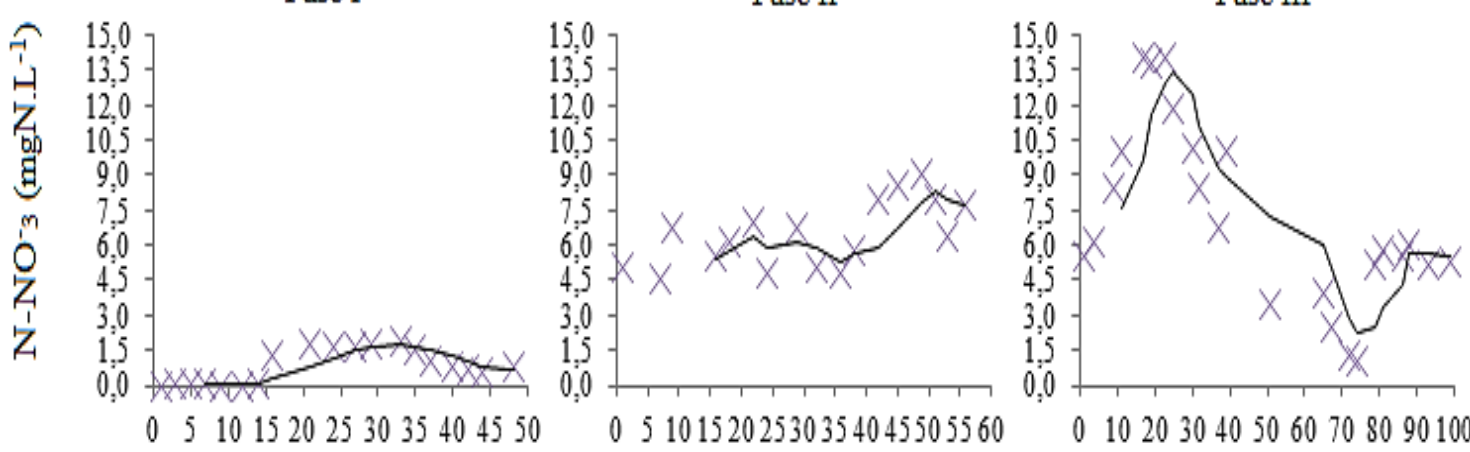

Dias

Figura 4.4: Série temporal com médias móveis de 4 termos: Concentração de $\mathrm{NO}_{3}^{-}$no efluente final após tratamento nas Fases I, II e III. 


\subsection{Variação da alcalinidade devido a amonificação, nitrificação e desnitrificação}

A variação da alcalinidade $\left(\mathrm{CaCO}_{3}\right)$ devido à amonificação, nitrificação e desnitrificação foram calculadas conforme descrito na seção 2.5 do capítulo 2, usando a Equação 2.31. Na Tabela 4.6, podem-se observar a variação da alcalinidade teórica causada pelo efeito estequiométrico combinado de amonificação, nitrificação e desnitrificação. Na Tabela 4.6.1, podem-se observar os resultados experimentais da alcalinidade total no afluente e efluente e, a variação da alcalinidade observada no sistema, durante as Fases I, II e III do estudo. Quando se comparam estatisticamente os valores médios, pelo método de Pearson, nota-se uma correlação positiva entre a teoria e o experimento, como se observa na Figura 4.5. Na Fase I, se observa uma correlação positiva substancial $r=(+0,50$ a 0,69$)$ e na Fase II e III uma correlação positiva moderada $r=(+0,30$ a 0,49$)$, sendo que $r=(-1,0)$ indica uma correlação negativa perfeita e $r=$ $(+1,0)$ indica uma correlação positiva perfeita. Desse modo, conclui-se que o balanço de alcalinidade no sistema torna-se compatível com a ocorrência simultânea do processo de amonificação, nitrificação e desnitrificação. Dependendo da concentração de amônia e da alcalinidade no afluente, torna-se necessário a introdução de alcalinizante artificial, para não ocorrer limitações no processo de NDS.

Tabela 4.6: Variação da alcalinidade teórica causada pelo efeito estequiométrico devido à amonificação, nitrificação e desnitrificação durante as Fases I, II e III do estudo

\begin{tabular}{|c|c|c|c|c|c|c|c|c|c|c|c|c|}
\hline \multicolumn{13}{|c|}{ Variação da alcalinidade no sistema de lodo ativado $\left(\mathrm{mgCaCO}_{3} \cdot \mathrm{L}^{-1}\right)$} \\
\hline \multicolumn{5}{|c|}{ Fase I } & \multicolumn{4}{|c|}{ Fase II } & \multicolumn{4}{|c|}{ Fase III } \\
\hline Variável & $\Delta \mathbf{a l c}_{\mathrm{am}}$ & $\Delta \mathbf{a l c} \mathbf{c}_{\mathbf{n}}$ & $\Delta \mathbf{a l c}_{\mathbf{d}}$ & $\Delta \mathbf{a l c} \mathbf{c}_{\mathrm{t}}$ & $\Delta \mathbf{a l c}_{\mathrm{am}}$ & $\Delta \mathbf{a l c} \mathbf{c}_{\mathbf{n}}$ & $\Delta \mathbf{a l c} \mathbf{c}_{\mathbf{d}}$ & $\Delta \mathbf{a l c}_{\mathbf{t}}$ & $\Delta \mathbf{a l c}_{\mathrm{am}}$ & $\Delta \mathbf{a l c}_{\mathrm{n}}$ & $\Delta \mathbf{a l c}_{\mathbf{d}}$ & $\Delta \mathbf{a l c}_{\mathrm{t}}$ \\
\hline média & -24 & -370 & 182 & -211 & -37 & -370 & 162 & -245 & -32 & -296 & 123 & -205 \\
\hline máximo & 42 & -278 & 246 & -168 & -4 & -303 & 194 & -223 & 3 & -160 & 180 & -144 \\
\hline mínimo & -58 & -493 & 134 & -264 & -66 & -432 & 124 & -276 & -53 & -381 & 58 & -258 \\
\hline DP & 23 & 57 & 30 & 29 & 19 & 38 & 22 & 15 & 14 & 50 & 29 & 24 \\
\hline CV (\%) & $-1,0$ & $-0,2$ & 0,2 & $-0,1$ & $-0,5$ & $-0,1$ & 0,1 & $-0,1$ & $-0,4$ & $-0,2$ & 0,2 & $-0,1$ \\
\hline AT & 99 & 215 & 112 & 96 & 62 & 129 & 70 & 53 & 56 & 221 & 122 & 115 \\
\hline
\end{tabular}

Tabela 4.6.1: Valores médios de alcalinidade no afluente e efluente e a variação obtida experimentalmente devido à amonificação, nitrificação e desnitrificação nas Fases I, II e III.

\begin{tabular}{cccc|ccc|ccc}
\hline \multicolumn{8}{c}{ Alcalinidade total Afluente e Efluente - $\left(\mathbf{m g C a C O}_{\mathbf{3}} \cdot \mathbf{L}^{-\mathbf{1}}\right)$} \\
\hline \multicolumn{8}{c}{ Fase I } & \multicolumn{3}{c}{ Fase II } & \multicolumn{3}{c}{ Fase III } \\
\hline Variável & Afluente & Efluente & $\Delta \mathbf{a l c}_{\mathbf{t}}$ & Afluente & Efluente & $\Delta \mathbf{a l c}_{\mathbf{t}}$ & Afluente & Efluente & $\Delta$ alc $_{\mathbf{t}}$ \\
\hline média & 217 & 35 & -183 & 232 & 50 & -182 & 203 & 91 & -114 \\
\hline máximo & 275 & 75 & -115 & 250 & 70 & -145 & 270 & 180 & -40 \\
\hline mínimo & 185 & 15 & -225 & 200 & 15 & -215 & 170 & 55 & -160 \\
\hline DP & 23 & 20 & 35 & 15 & 12 & 19 & 23 & 28 & 34 \\
\hline CV (\%) & 10,7 & 57,1 & $-0,2$ & 6,5 & 24,2 & $-0,1$ & 11,5 & 31,0 & $-0,3$ \\
\hline AT & 90 & 60 & 110 & 50 & 55 & 70 & 100 & 125 & 120 \\
\hline
\end{tabular}

Onde: $\Delta \mathbf{a l c}_{\mathbf{a m}}$ : Variação da alcalinidade devido à amonificação; $\Delta \mathbf{a l c}_{\mathbf{n}}$ : Variação da alcalinidade devido à nitrificação; $\Delta \mathbf{a l c}_{\mathbf{d}}$ : Variação da alcalinidade devido à desnitrificação; $\Delta \mathbf{a l c}_{\mathbf{t}}$ : Variação da alcalinidade devido à amonificação, nitrificação e desnitrificação. 


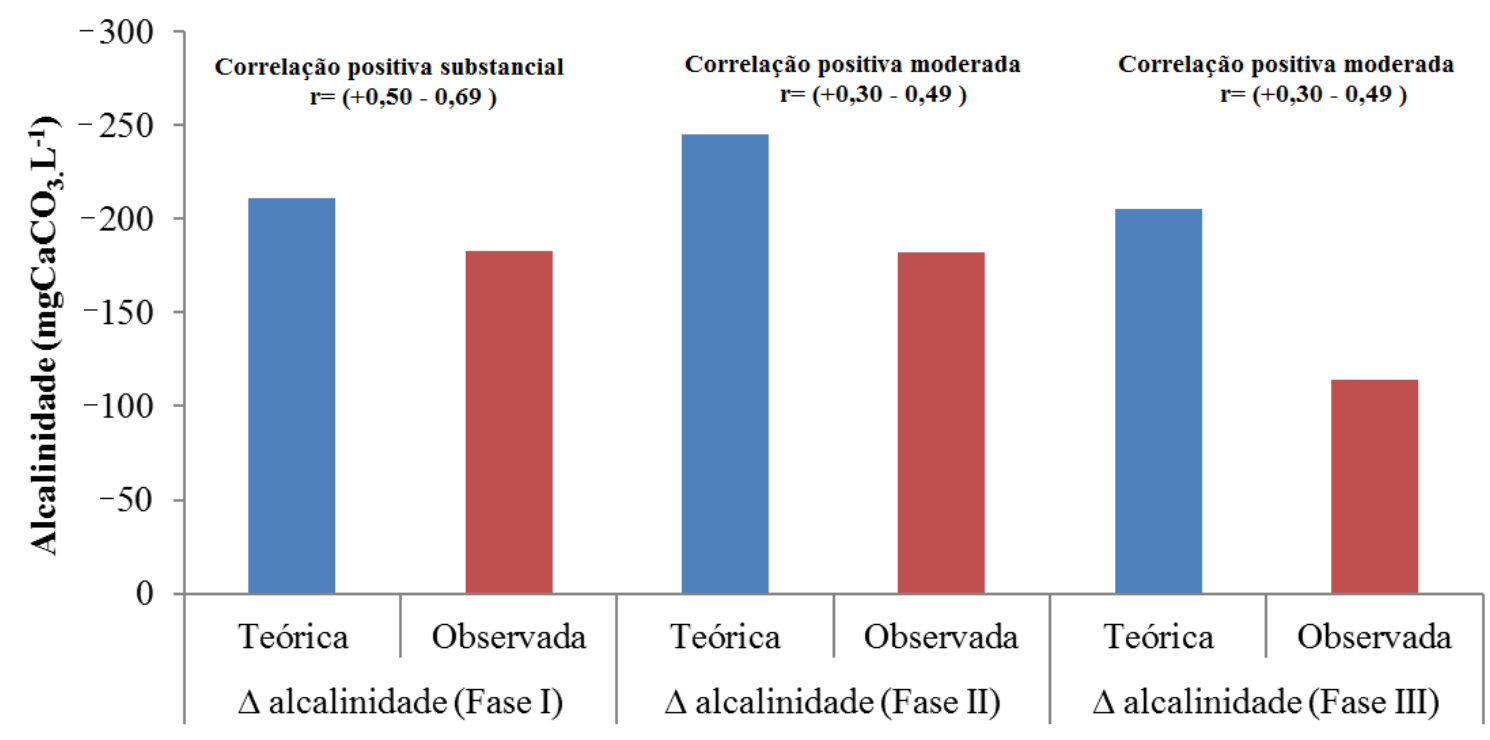

Figura 4.5: Comparação entre a variação da alcalinidade teórica causada pelo efeito estequiométrico combinado de amonificação, nitrificação e desnitrificação com o valor experimental observado no sistema de lodo ativado.

\subsection{Variáveis de controle pelo monitoramento online}

\subsubsection{Oxigênio dissolvido}

Na Tabela 4.7, podem-se observar os valores médios das concentrações de oxigênio dissolvido obtidos por meio do monitoramento online do licor misto no tanque de aeração, durante as Fases I, II e III do estudo. Na Figura 4.6, se observam os valores médios diários em série temporal com médias móveis de 4 termos. Esses valores correspondem à média das medições de OD realizada e registrada a cada 10 segundos diariamente durante todo o período do estudo. Ao analisar os resultados médios a partir da Tabela 4.7 e Figura 4.6, nota-se claramente que o sistema de lodo ativado foi operado dentro da faixa de OD estabelecida de 0,3 a 0,8 mg. $\mathrm{L}^{-1}$ durante todo o período do estudo, independente da redução do TRS e variações de carga no esgoto sanitário afluente. Desse modo, conclui-se que: Um sistema de lodo ativado com aeração prolongada e, com um controle automatizado no sistema de aeração por meio de ar difuso (introduzido no fundo do reator), pode operar com baixas concentrações de oxigênio dissolvido no tanque de aeração, de uma maneira estável, criando condições para o desenvolvimento do processo de NDS. 
Tabela 4.7: Valores médios das concentrações de OD no licor misto nas Fases I, II e III.

\begin{tabular}{cccc}
\hline & OD $\left(\mathbf{m g . L}^{\mathbf{- 1}}\right)$ - Licor misto & \\
\hline Variável & Fase I & Fase II & Fase III \\
\hline média & 0,46 & 0,49 & 0,38 \\
\hline máximo & 0,80 & 0,80 & 0,80 \\
\hline mínimo & 0,30 & 0,22 & 0,13 \\
\hline DP & 0,09 & 0,10 & 0,13 \\
\hline CV (\%) & 20,0 & 20,8 & 33,4 \\
\hline AT & 0,50 & 0,58 & 0,67 \\
\hline
\end{tabular}

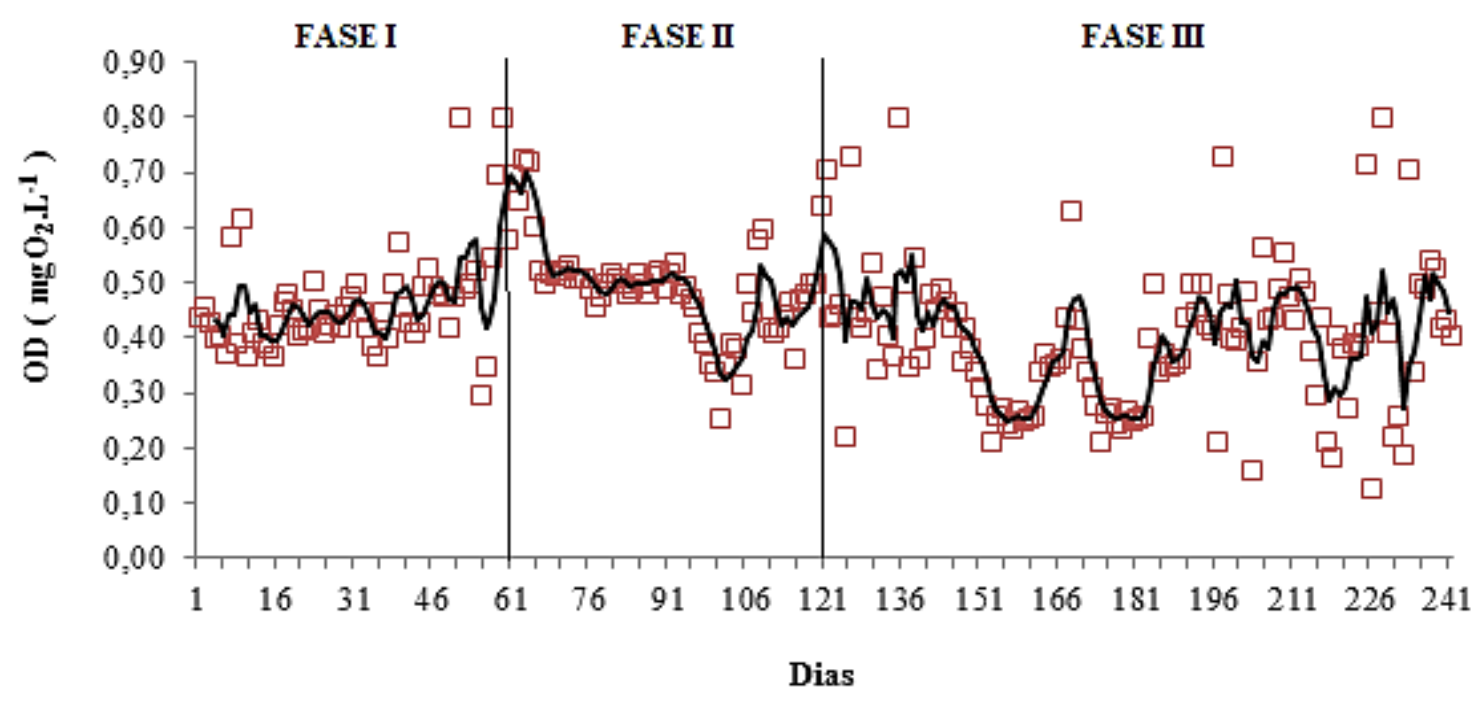

Figura 4.6: Série temporal com médias móveis de 4 termos: Monitoramento online da concentração de OD no licor misto durante as Fases I, II e III.

\subsubsection{Potencial de oxirredução}

Na Tabela 4.7.1, podem-se observar os valores médios do potencial de oxirredução obtidos por meio do monitoramento online do licor misto no tanque de aeração, durante as Fases I, II e III do estudo. Na Figura 4.6.1, se observam os valores médios diários em série temporal com médias móveis de 4 termos. Esses valores correspondem à média das medições de ORP realizada e registrada a cada 10 segundos diariamente durante todo o período do estudo. Ao analisar os resultados médios a partir da Tabela 4.7.1 e Figura 4.6.1. Nota-se, que os valores obtidos de ORP oscilaram entre +24 a $+161 \mathrm{mV}$ e foram semelhantes em todas as Fases do estudo, resultando em um valor médio de $+115 \mathrm{mV}$, independente do TRS e do aumento da relação A/M. Valores semelhantes foram descritos por (Hong W. Zhao, et al, 1999 and D. Thauré, et al., 2008), quando operaram sistemas promovendo a NDS. Quando se aplica o teste estatístico de correlação de Pearson aos dados obtidos de OD e ORP, nota-se uma correlação positiva baixa $r=(+0,10$ a 0,29$)$. Neste caso, é de interesse o uso do potencial de oxirredução 
como complemento na monitoração do processo de NDS. Porém não descarta a necessidade do monitoramento do OD no tanque de aeração.

Tabela 4.7.1: Valores médios do potencial de oxirredução no licor misto nas Fases I, II e III.

\begin{tabular}{cccc}
\hline \multicolumn{4}{c}{ Potencial de oxirredução $(\mathbf{m V})$ - Licor misto } \\
\hline Variável & Fase I & Fase II & Fase III \\
\hline média & 128 & 116 & 102 \\
\hline máximo & 147 & 148 & 161 \\
\hline mínimo & 82 & 24 & 46 \\
\hline DP & 9 & 26 & 27 \\
\hline CV $(\%)$ & 6,7 & 22,5 & 26,6 \\
\hline AT & 65 & 124 & 115 \\
\hline
\end{tabular}

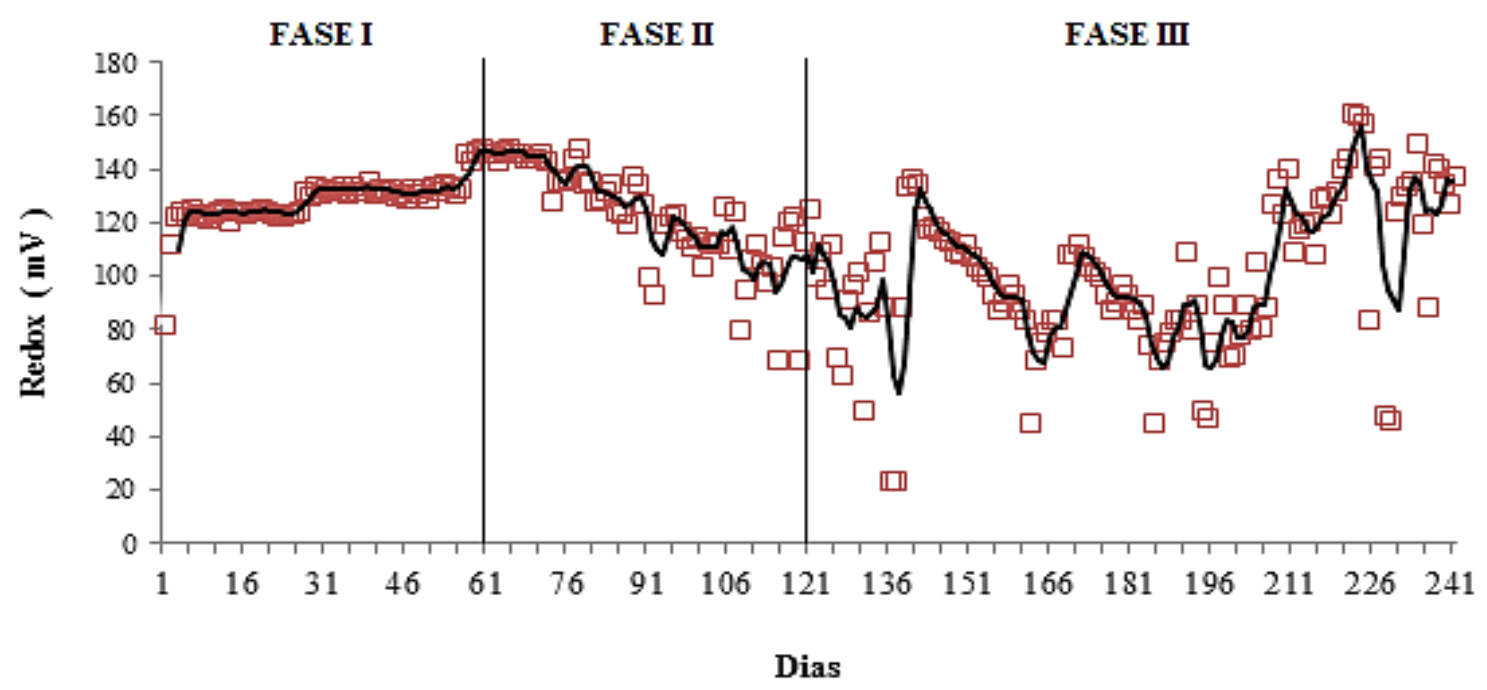

Figura 4.6.1: Série temporal com médias móveis de 4 termos: Monitoramento online do potencial de oxirredução no licor misto durante as Fases I, II e III.

\subsubsection{Temperatura do licor misto}

Na Tabela 4.7.2, podem-se observar os valores médios da temperatura $\left({ }^{\circ} \mathrm{C}\right)$ obtidos por meio do monitoramento online do licor misto no tanque de aeração, durante as Fases I, II e III do estudo. Na Figura 4.6.2, se observam os valores médios diários em série temporal com médias móveis de 4 termos, esses valores correspondem à média das medições da temperatura realizada e registrada a cada 10 segundos diariamente durante todo o período do estudo. Ao analisar os resultados médios a partir da Tabela 4.7.2 e Figura 4.6.2. Nota-se, que os valores oscilaram entre $15-25^{\circ} \mathrm{C}$ na Fase I, de $18-28^{\circ} \mathrm{C}$ na Fase II e de $19-27^{\circ} \mathrm{C}$ na Fase III, resultando em uma temperatura média superior a $20^{\circ} \mathrm{C}$. Portanto, a temperatura média foi favorável durante todo do estudo, dando condições para o desenvolvimento da nitrificação no sistema de lodo ativado. 
Tabela 4.7.2: Valores médios de temperatura no licor misto durante as Fases I, II e III.

\begin{tabular}{cccc}
\hline & Temperatura $\left({ }^{\mathbf{0}} \mathbf{C}\right)$ - Licor misto & \\
\hline Variável & Fase I & Fase II & Fase III \\
\hline média & 20,7 & 23,2 & 23,6 \\
\hline máximo & 24,7 & 28,1 & 26,9 \\
\hline mínimo & 14,7 & 17,8 & 18,6 \\
\hline DP & 2,3 & 2,0 & 1,7 \\
\hline CV $(\%)$ & 11,1 & 8,4 & 7,4 \\
\hline AT & 10,0 & 10,4 & 8,3 \\
\hline
\end{tabular}

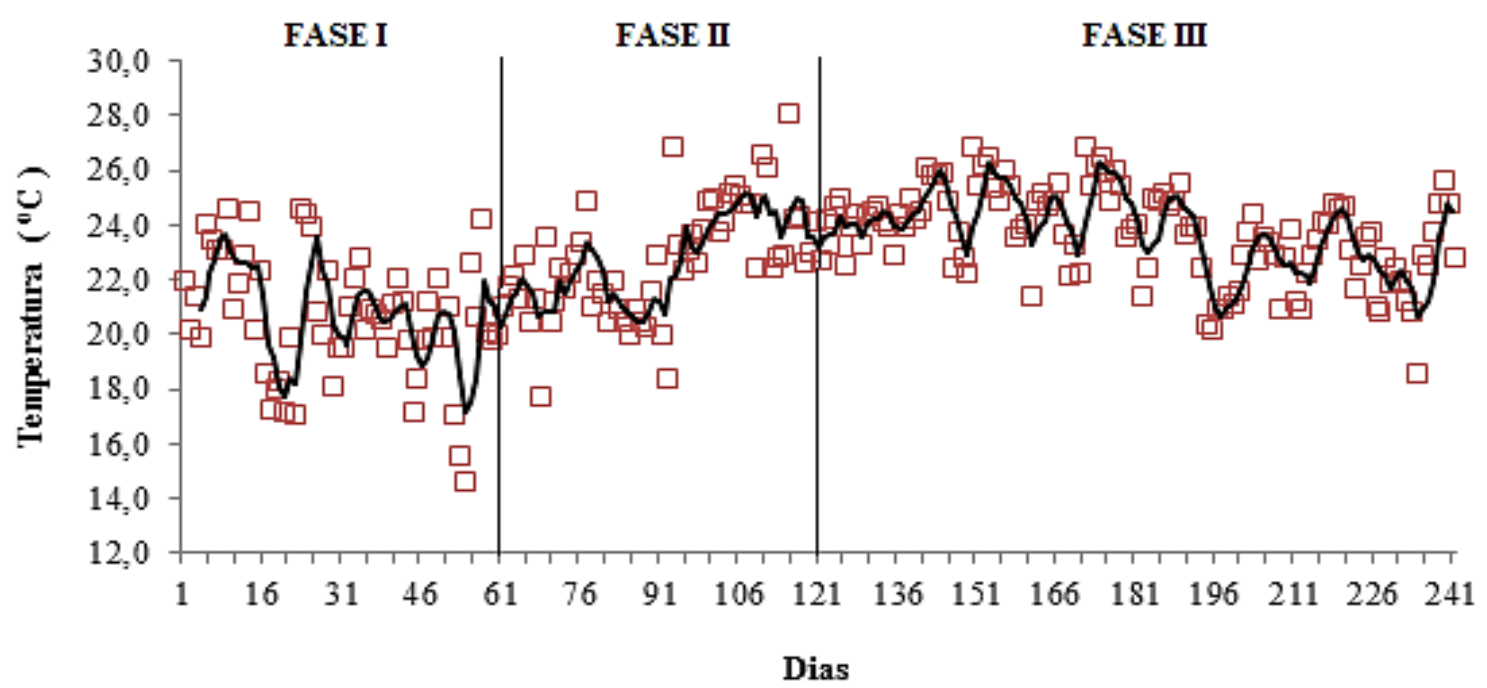

Figura 4.6.2: Série temporal com médias móveis de 4 termos: Monitoramento online de temperatura no licor misto durante as Fases I, II e III.

\subsection{4 pH do licor misto}

$\mathrm{Na}$ Tabela 4.7.3, podem-se observar os valores médios do $\mathrm{pH}$ obtidos por meio do monitoramento online do licor misto no tanque de aeração, durante as Fases I, II e III do estudo. Na Figura 4.6.3, se observam os valores médios diários em série temporal com médias móveis de 4 termos, esses valores correspondem à média das medições do $\mathrm{pH}$ realizada e registrada a cada 10 segundos diariamente durante todo o período do estudo. Ao analisar os resultados médios a partir da Tabela 4.7.3 e Figura 4.6.3. Nota-se, que os valores ficaram próximos a neutralidade 7,0. Durante o fim da Fase II (período de 106 a 121) Figura 4.6.3, houve uma instabilidade no sistema devido a alterações no esgoto afluente e problemas na operação, onde foi necessário a correção do pH para não comprometer o processo de NDS no sistema. 
Tabela 4.7.3: Valores médios de pH no licor misto durante as Fases I, II e III.

\begin{tabular}{cccc}
\hline \multicolumn{5}{c}{$\mathbf{p H}$ - Licor misto } \\
\hline Variável & Fase I & Fase II & Fase III \\
\hline média & 6,8 & 6,8 & 7,0 \\
\hline máximo & 6,9 & 7,4 & 7,2 \\
\hline mínimo & 6,7 & 6,0 & 6,5 \\
\hline DP & 0,1 & 0,2 & 0,2 \\
\hline CV $(\%)$ & 1,1 & 3,3 & 2,7 \\
\hline AT & 0,2 & 1,4 & 0,7 \\
\hline
\end{tabular}

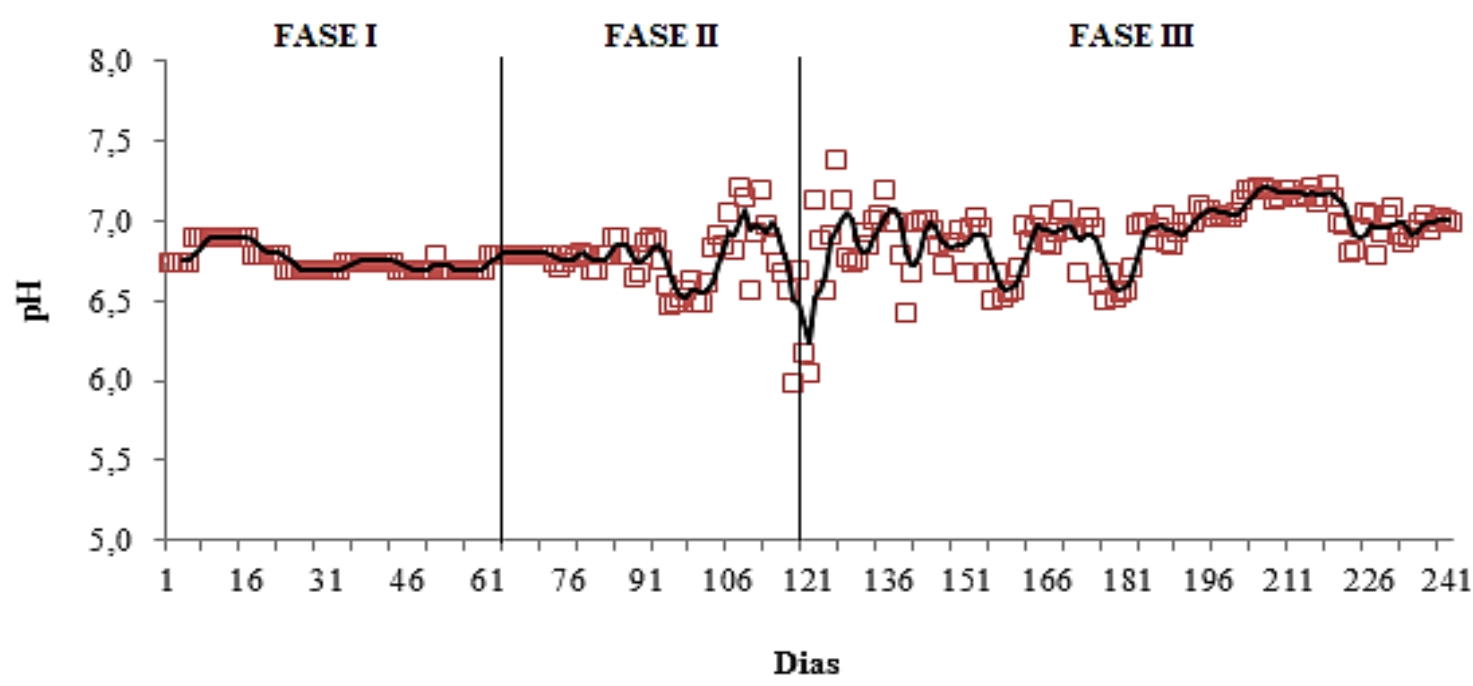

Figura 4.6.3: Série temporal com médias móveis de 4 termos: Monitoramento online de $\mathrm{pH}$ no licor misto durante as Fases I, II e III.

\subsection{Testes Respirométricos}

\subsubsection{Resultados das frações de matéria orgânica no esgoto sanitário afluente}

A Tabela 4.8 e 4.8.1 mostram os resultados experimentais das frações do material orgânico (biodegradável e não biodegradável) no esgoto sanitário afluente, determinados através de testes respirométricos. Quando se compara os resultados desse estudo com os obtidos por diferentes pesquisadores (Tabela 2, seção 2.1 do capítulo 2), nota-se que para as frações do material orgânico afluente (biodegradáveis e não biodegradáveis) tiveram boa aproximação. No entanto, a fração biodegradável solúvel ( $\mathrm{f}_{\mathrm{bs}}$ ) obtida nesta pesquisa de $12 \%$ se resultou menor do que os valores encontrados na literatura, já a fração biodegradável particulada $\left(f_{b p}\right)$ de $61 \%$ foi bem próxima. Embora sendo a fração biodegradável $\left(\mathrm{f}_{\mathrm{b}}\right)$ elevada, chegando a $73 \%$, apenas $12 \%$ deste percentual está associado ao material solúvel e rapidamente biodegradável. A Figura 4.7 mostra 
a composição geral do material orgânico do esgoto sanitário e o valor médio da DQO correspondente.

Tabela 4.8: Valores médios das frações de matéria orgânica biodegradável presente no esgoto sanitário obtido através de testes respirométricos.

\begin{tabular}{|c|c|c|c|c|c|c|c|c|}
\hline \multicolumn{9}{|c|}{ Frações de matéria orgânica biodegradável } \\
\hline Testes & $\begin{array}{c}\mathbf{S}_{\mathrm{ta}} \\
(\mathrm{mg} / \mathrm{L})\end{array}$ & $\begin{array}{c}\mathrm{S}_{\mathrm{te}} \\
(\mathrm{mg} / \mathrm{L})\end{array}$ & $\begin{array}{c}\mathrm{S}_{\mathrm{bsa}} \\
(\mathrm{mg} / \mathrm{L})\end{array}$ & $\begin{array}{c}\mathrm{S}_{\mathrm{bpa}} \\
(\mathrm{mg} / \mathrm{L})\end{array}$ & $\begin{array}{c}S_{b a} \\
\left(S_{b s a}+S_{b p a}\right)\end{array}$ & $\begin{array}{c}\mathbf{f}_{\mathrm{bs}} \\
\left(\mathbf{S}_{\mathrm{bsa}} / \mathbf{S}_{\mathrm{ba}}\right)\end{array}$ & $\begin{array}{c}\mathbf{f}_{\mathbf{b}} \\
\left(\mathbf{S}_{\mathrm{ba}} / \mathbf{S}_{\mathrm{ta}}\right)\end{array}$ & $\begin{array}{c}\mathbf{f}_{\mathrm{bp}} \\
\left(\mathbf{f}_{\mathbf{b}}-\mathbf{f}_{\mathbf{b s}}\right)\end{array}$ \\
\hline Fase I & $511 \pm 87$ & $46 \pm 26$ & $45 \pm 9$ & $326 \pm 36$ & $370 \pm 30$ & $0,12 \pm 0,03$ & $0,72 \pm 0,06$ & $0,60 \pm 0,08$ \\
\hline Fase II & $537 \pm 62$ & $35 \pm 30$ & $47 \pm 8$ & $386 \pm 25$ & $433 \pm 33$ & $0,11 \pm 0,01$ & $0,81 \pm 0,06$ & $0,70 \pm 0,05$ \\
\hline Fase III & $587 \pm 172$ & $29 \pm 27$ & $48 \pm 10$ & $338 \pm 78$ & $385 \pm 85$ & $0,13 \pm 0,02$ & $0,66 \pm 0,14$ & $0,53 \pm 0,16$ \\
\hline Média & 545 & 37 & 47 & 350 & 396 & 0,12 & 0,73 & 0,61 \\
\hline
\end{tabular}

Tabela 4.8.1: Valores médios das frações de matéria orgânica biodegradável presente no esgoto sanitário obtido através de testes respirométricos.

\begin{tabular}{cccc}
\hline \multicolumn{4}{c}{ Frações de matéria orgânica não biodegradável } \\
\hline \multirow{2}{*}{ Testes } & $\begin{array}{c}\mathbf{f}_{\mathbf{u}} \\
\left(\mathbf{1 - \mathbf { f } _ { \mathbf { b } }}\right)\end{array}$ & $\begin{array}{c}\mathbf{f}_{\mathbf{u s}} \\
\left(\mathbf{S}_{\mathrm{ta}} / \mathbf{S}_{\mathbf{t e}}\right)\end{array}$ & $\begin{array}{c}\mathbf{f}_{\mathbf{u p}} \\
\left(\mathbf{f}_{\mathbf{u}} \mathbf{f}\right.\end{array}$ \\
\hline Fase I & $0,28 \pm 0,06$ & $0,09 \pm 0,00$ & $0,19 \pm 0,06$ \\
\hline Fase II & $0,19 \pm 0,06$ & $0,07 \pm 0,00$ & $0,13 \pm 0,06$ \\
\hline Fase III & $0,34 \pm 0,14$ & $0,05 \pm 0,00$ & $0,29 \pm 0,14$ \\
\hline Média & 0,27 & 0,07 & 0,20 \\
\hline
\end{tabular}

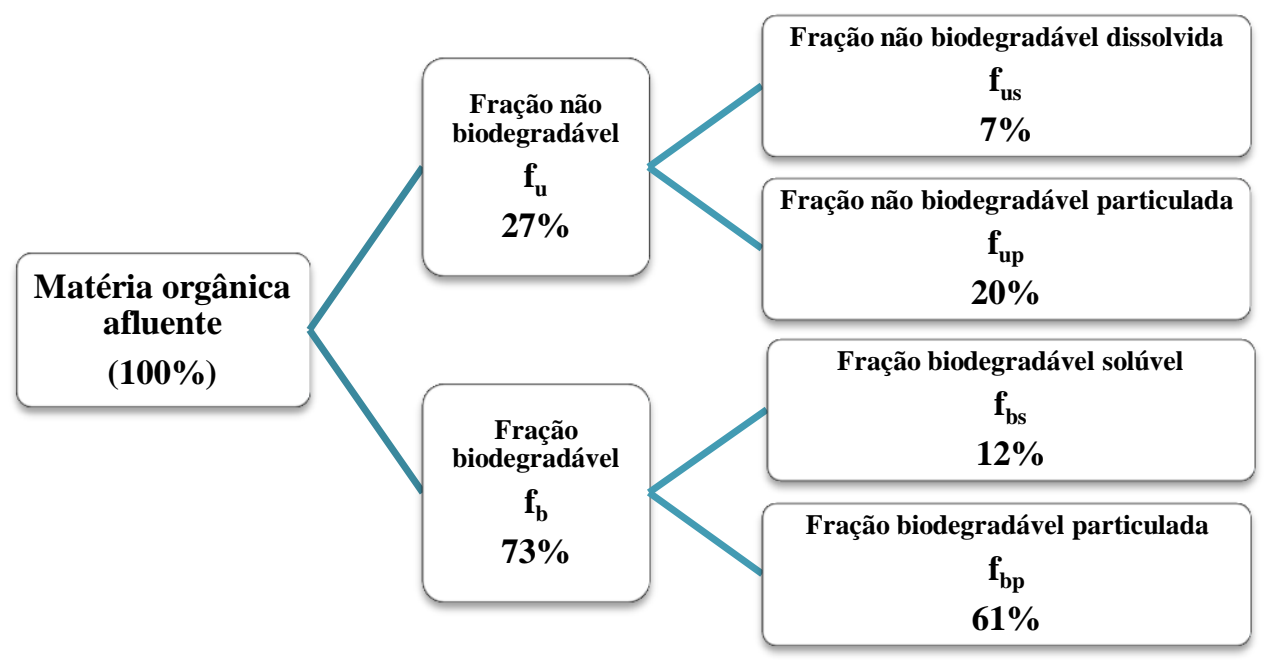

Figura 4.7: Fluxograma geral referente às frações de material orgânico, determinadas a partir de testes respirométricos com o esgoto sanitário proveniente do CRUSP e restaurante central da USP. 


\subsubsection{Fatores cinéticos de utilização de material orgânico}

Com os dados obtidos pela respirometria e determinações analíticas, calcularam-se, para as Fases I, II e III do sistema de lodo ativado, as constantes de crescimento específico máximo das bactérias heterotróficas $\left(\mu_{\mathrm{m}}\right)$ e as taxas de utilização de material orgânico das bactérias heterotróficas $\left(\mathrm{r}_{\text {máx }}\right)$, conforme descrito na seção 2.2.2 do capítulo 2. O detalhamento de cada termo utilizado nessa seção está descrito na lista de símbolos. Para os cálculos foram considerados as médias da TCO obtida nos testes respirométricos com esgoto sanitário, sendo: $\mathrm{TCO}_{\text {exo }}=62,5 \mathrm{mg} \cdot \mathrm{L}^{-1} \cdot \mathrm{h}^{-1}$ e $\mathrm{TCO}_{\text {end }}=10,0 \mathrm{mg} \cdot \mathrm{L}^{-1} \cdot \mathrm{h}^{-1}$. A concentração de lodo ativo $\left(\mathrm{X}_{\mathrm{a}}\right)$ foi determinada de duas maneiras (Equação 2.4 e 2.5 seção 2.2.2 do capítulo 2):

(1) Pela $\mathrm{TCO}_{\text {end }}$ obtida no teste respirométrico, onde os valores médios foram praticamente idênticos em ambas as Fases, considerando-se o valor médio de $801 \mathrm{mgX} \cdot \mathrm{X}^{-1}$. Exemplificandose para Fase III, tem-se os seguintes valores: $\mathrm{Y}=0,45 \mathrm{mgXa}^{*} \mathrm{mgDQO}{ }^{-1} ; \mathrm{R}_{\mathrm{h}}=1,16\left(\mathrm{~d}^{-1}\right) ; \mathrm{S}_{\mathrm{ta}}=587$ $\mathrm{mg} . \mathrm{L}^{-1} ; \mathrm{b}_{\mathrm{h}}=0,25\left(\mathrm{~d}^{-1}\right) ; \mathrm{R}_{\mathrm{s}}=20\left(\mathrm{~d}^{-1}\right) ; \mathrm{TCO}_{\mathrm{end}}=10,0 \mathrm{mgO} \cdot \mathrm{L}^{-1} \cdot \mathrm{h}^{-1} ; \mathrm{f}_{\mathrm{cr}}=1,5 \mathrm{mgDQO} \cdot \mathrm{mgSSV}^{-1} ; \mathrm{f}=$ 0,2 . Portanto, calcula-se $\left(\mathrm{X}_{\mathrm{a}}\right)$, como se segue:

$\mathrm{X}_{\mathrm{a}}=\mathrm{TCO}_{\text {end }} /\left[\mathrm{f}_{\mathrm{cv}} *(1-\mathrm{f}) * \mathrm{~b}_{\mathrm{h}}\right]=\left(10,0 * 24 /[1,5 *(1-0,2) * 0,25]=801 \mathrm{mgX} \cdot \mathrm{L}^{-1}\right.$

(Equação 2.4)

(2) Pela teoria de lodo ativado, onde os valores médios foram: de 502, de 683 e de 1057 $\operatorname{mgX}_{a} \cdot L^{-1}$ nas Fases I, II e III, respectivamente. Portanto, para Fase III tem-se:

(Equação 2.5)

$\mathrm{X}_{\mathrm{a}}=\mathrm{Y}^{*} \mathrm{R}_{\mathrm{h}} * \mathrm{~S}_{\mathrm{ta}} /\left(1+\mathrm{b}_{\mathrm{h}} * \mathrm{R}_{\mathrm{s}}\right) * \mathrm{R}_{\mathrm{h}}=(0,45 * 1,16 * 587 /(1+0,25 * 20) * 1,16) * 24=1057 \mathrm{mgX} \mathrm{X}_{\mathrm{a}} \cdot \mathrm{L}^{-1}$

Para melhor estimativa de $\left(\mathrm{X}_{\mathrm{a}}\right)$, utilizou-se a média dos resultados obtidos pelos dois métodos, onde os valores médios foram: de $652 \mathrm{mgX}_{\mathrm{a}} \cdot \mathrm{L}^{-1}$ na Fase I, de $742 \mathrm{mgX} \cdot \mathrm{L}^{-1}$ na Fase II e de 929 $\operatorname{mgX} \mathrm{X}_{\mathrm{a}} \cdot \mathrm{L}^{-1}$ na Fase III.

Na Tabela 4.8.2 são apresentados os valores médios das constantes cinéticas de crescimento e de utilização de material orgânico, obtidos por meio das equações 2.2 e 2.3 , apresentadas na seção 2.2.2 do capitulo 2. Os valores médios da taxa de crescimento específico máximo $\left(\mu_{\mathrm{m}}\right)$ das bactérias heterotróficas foram de 3,1 $\mathrm{d}^{-1}$ na Fase I, de 2,7 $\mathrm{d}^{-1}$ na Fase II e de 2,2 $\mathrm{d}^{-1}$ na Fase III, esses valores foram compatíveis aos encontrados na literatura $\mu_{\mathrm{m}}=\left(1,5-7,2 \mathrm{~d}^{-1}\right)$, como se observa na Tabela de 2.3, na seção 2.2.2 do capítulo 2. No entanto, ao analisar os valores médios das constantes $\mu_{\mathrm{m}}$ e $r_{\text {máx }}$ a partir da Tabela 4.8.2, nota-se que não ocorreu aumento significativo nas taxas devido à redução da idade do lodo. 
Tabela 4.8.2: Valores médios das constantes cinéticas de utilização de material orgânico

\begin{tabular}{|c|c|c|c|c|c|c|}
\hline \multicolumn{7}{|c|}{ Constantes cinéticas das bactérias heterotróficas } \\
\hline & \multicolumn{2}{|r|}{ Fase I } & \multicolumn{2}{|c|}{ Fase II } & \multicolumn{2}{|r|}{ Fase III } \\
\hline Constante & $\begin{array}{l}\mu_{\mathrm{m} 20} \\
\left(d^{-1}\right)\end{array}$ & $\begin{array}{c}\mathbf{r}_{\text {máx }} \\
\left(\mathrm{mgDQ} \mathrm{mgX}_{\mathrm{a}} \cdot \mathrm{d}^{-1}\right)\end{array}$ & $\begin{array}{l}\mu_{\mathrm{m} 20} \\
\left(d^{-1}\right)\end{array}$ & $\begin{array}{c}\mathbf{r}_{\text {máx }} \\
\left(m g D Q O . m g X_{\mathrm{a}} \cdot d^{-1}\right)\end{array}$ & $\begin{array}{l}\mu_{\mathrm{m} 20} \\
\left(d^{-1}\right)\end{array}$ & $\begin{array}{c}\mathbf{r}_{\text {máx }} \\
\left(\mathrm{mgDQQ} \mathrm{mgX}_{\mathrm{a}} \cdot \mathrm{d}^{-1}\right)\end{array}$ \\
\hline média & 3,1 & 6,9 & 2,7 & 6,1 & 2,2 & 5,0 \\
\hline máxima & 3,4 & 7,5 & 3,0 & 6,6 & 3,2 & 7,1 \\
\hline mínima & 2,7 & 5,9 & 2,5 & 5,5 & 1,5 & 3,4 \\
\hline DP & 0,2 & 0,4 & 0,1 & 0,3 & 0,4 & 0,8 \\
\hline $\mathrm{CV}(\%)$ & 6,3 & 6,3 & 5,2 & 5,2 & 16,9 & 16,9 \\
\hline AT & 1 & 2 & 1 & 1 & 2 & 4 \\
\hline
\end{tabular}

\subsection{Constantes cinéticas das bactérias autotróficas nitritantes e nitratantes}

Com os dados obtidos pela Respirometria e determinações analíticas, calcularam-se, para as Fases I, II e III do sistema de lodo ativado, as constantes de crescimento específico máximo $\left(\mu_{\mathrm{m}}\right)$, as de meia saturação de Monod $\left(\mathrm{K}_{\mathrm{n}}\right)$ e a taxa máxima de utilização de amônia e nitrito $\left(\mathrm{r}_{\text {n.máx }}\right)$ para as para as bactérias nitritantes e nitratantes, (conforme descrito na seção 3.9.2 do capítulo 3). Para constante de decaimento $\left(b_{n}\right)$ foi adotado um valor típico de 0,04(1,04) ${ }^{(\mathrm{T}-20)}$, sugerido por EKAMA \& MARAIS (1976), conforme Tabela 2.4 (seção 2.3.6, do capítulo 2). Os dados apresentados foram corrigidos para uma temperatura de $20^{\circ} \mathrm{C}$.

\subsubsection{Verificação do balanço de massa para validação do teste respirométrico}

Inicialmente, para validar os dados obtidos, verificou-se se a TCO exercida corresponde à concentração do substrato adicionado. Foram realizados testes iniciais para cada substrato (cloreto de amônio e nitrito de sódio), para verificar se o balanço entre a área abaixo da curva da TCO e a concentração adicionada de substratos são consistentes. Conforme o procedimento apresentado na seção 3.9.1 do capítulo 3, foi adicionado nos testes uma concentração de uma solução padrão de (10mgN.L ${ }^{-1}$ ) (amônia e nitrito) para nitritantes e nitratantes. Para a curva referente às nitritadoras, a área média calculada foi de $44,2 \mathrm{mgO}_{2} \cdot \mathrm{L}^{-1}$, o que representa, estequiometricamente, uma concentração de $(44,2 / 4,57)=9,67 \mathrm{mgN} . \mathrm{L}^{-1}$. Da mesma forma, com a curva correspondente as nitratadoras, encontra-se uma área média de $11,2 \mathrm{mgO}_{2} \cdot \mathrm{L}^{-1}$, o que representa, estequiometricamente, uma concentração de $(11,4 / 1,14)=9,82 \mathrm{mgN} \cdot \mathrm{L}^{-1}$. Ambos os testes apresentaram um valor alto de recuperação $(96,7 \%)$ nitritantes e $(98,2 \%)$ nitratantes, logo, conclui-se que o consumo de oxigênio foi compatível com a demanda pelo substrato adicionado, validando o teste para as condições estabelecidas neste estudo. A Figura 4.8 mostra um exemplo de um dos testes realizado com adição de cloreto de amônio. 


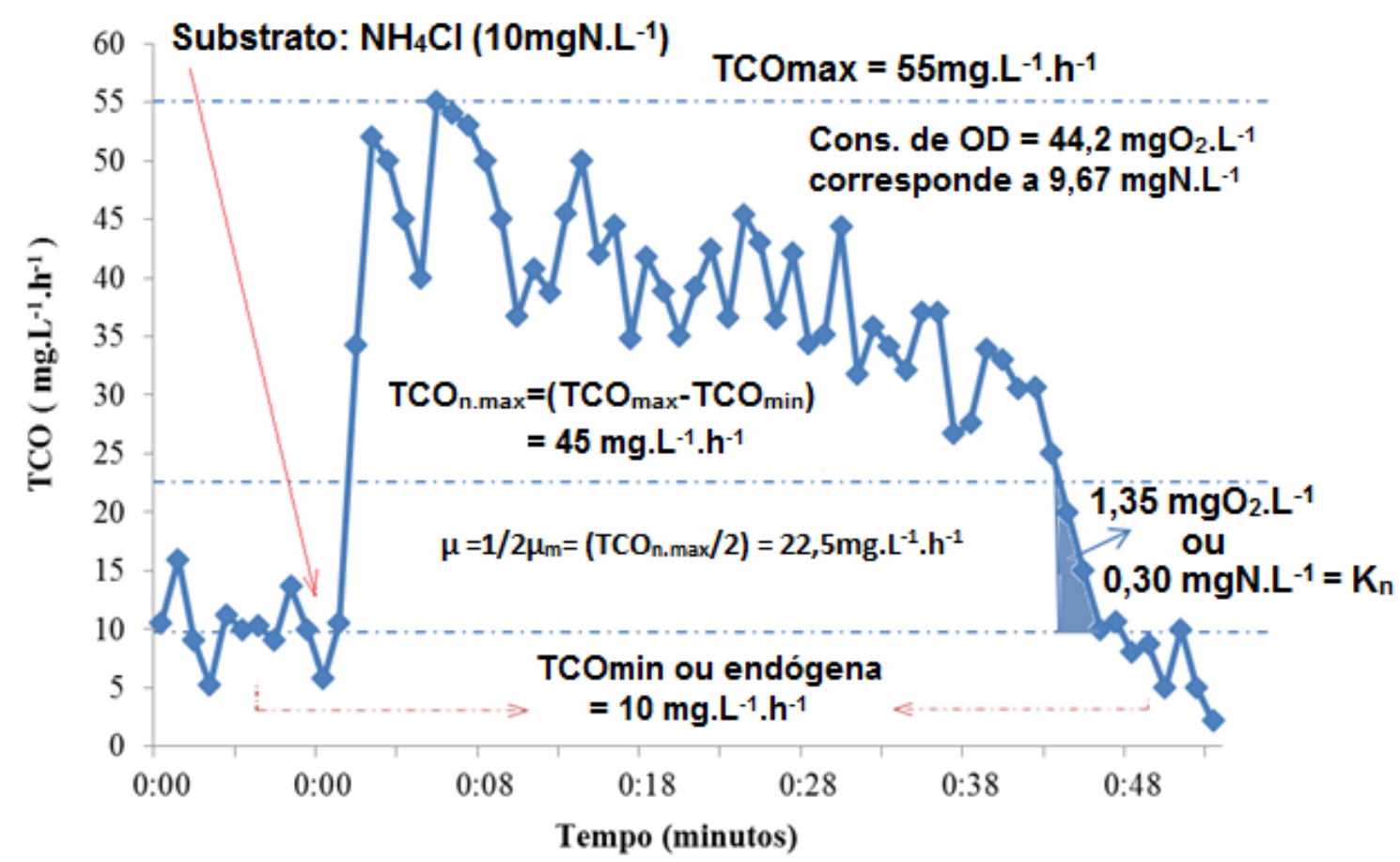

Figura 4.8: Exemplo de um respirograma experimental de uma batelada de lodo ativado com substrato de cloreto de amônio obtido durante a Fase III do estudo.

4.9.2 Resultados da taxa de consumo de oxigênio devido ao consumo de amônia e nitrito por meio de testes respirométricos

Na Tabela 4.9 e 4.9.1, podem-se observar os resultados médios da taxa de consumo de oxigênio exógena $\left(\mathrm{TCO}_{\text {exo }}\right)$ e a taxa de consumo de oxigênio máxima $\left(\mathrm{TCO}_{\text {n.máx }}\right)$ devido ao consumo de amônia e nitrito, respectivamente. A TCO endógena obtida durante os testes foi semelhante durante todas as fases sendo: $10 \mathrm{mgO} \cdot \mathrm{L} \cdot \mathrm{h}^{-1}$. Ao se analisar os resultados da $\mathrm{TCO}_{\text {exo }}$ e $\mathrm{TCO}_{\mathrm{n} \cdot \operatorname{máx}}$ obtidos nos testes, se observa que há um ligeiro aumento na TCO quando a idade de lodo é reduzida em ambas as fases. 
Tabela 4.9: Valores médios da TCO devido ao consumo de amônia pelas bactérias nitritantes

\begin{tabular}{|c|c|c|c|c|c|c|}
\hline \multicolumn{7}{|c|}{ Taxa de consumo de oxigênio para bactérias nitritantes $\left(\mathrm{mg} . \mathrm{L}^{-1} \cdot \mathrm{h}^{-1}\right)$} \\
\hline \multirow[t]{2}{*}{$\mathrm{TCO}_{\mathrm{end}}=10,0$} & \multicolumn{2}{|c|}{ Fase I } & \multicolumn{2}{|c|}{ Fase II } & \multicolumn{2}{|c|}{ Fase III } \\
\hline & TCOexo & TCO $\mathbf{O n a ́ x}$ & TCOexo & TCO $\mathbf{O}_{\text {náx }}$ & TCOexo & TCO nmáx $_{1}$ \\
\hline média & 43 & 33 & 52 & 42 & 55 & 45 \\
\hline máximo & 55 & 45 & 55 & 45 & 60 & 50 \\
\hline mínimo & 29 & 19 & 48 & 38 & 38 & 28 \\
\hline DP & 7,1 & 7,1 & 3,0 & 3,0 & 4,5 & 4,5 \\
\hline $\mathrm{CV}(\%)$ & 16,5 & 21,6 & 5,8 & 7,2 & 8,2 & 10,1 \\
\hline AT & 26,0 & 26,0 & 7,0 & 7,0 & 22,0 & 22,0 \\
\hline
\end{tabular}

Tabela 4.9.1: Valores médios da TCO devido ao consumo de nitrito pelas bactérias nitratantes

\begin{tabular}{ccc|cc|cc}
\hline \multicolumn{7}{c}{ Taxa de consumo de oxigênio nitratantes $\left(\mathbf{m g . L}^{-\mathbf{1}} \cdot \mathbf{h}^{-\mathbf{1}}\right)$} \\
\hline TCO $_{\text {end }}=\mathbf{1 0 , 0}$ & \multicolumn{2}{c|}{ Fase I } & \multicolumn{2}{c}{ Fase II } & \multicolumn{2}{c}{ Fase III } \\
\hline & TCOexo & TCO $_{\text {n.máx }}$ & TCOexo & TCO $_{\text {n.máx }}$ & TCOexo & TCO $_{\text {n.máx }}$ \\
\hline média & 18 & 8 & 20 & 10 & 21 & 11 \\
\hline máximo & 20 & 10 & 22 & 12 & 26 & 16 \\
\hline mínimo & 15 & 5 & 18 & 8 & 15 & 5 \\
\hline DP & 1,9 & 1,9 & 1,3 & 1,3 & 2,5 & 2,5 \\
\hline CV $(\%)$ & 10,7 & 24,8 & 6,4 & 12,8 & 12,4 & 24,1 \\
\hline AT & 5,0 & 5,0 & 4,0 & 4,0 & 11,0 & 11,0 \\
\hline
\end{tabular}

\subsubsection{Determinação da constante de crescimento específico $\left(\mu_{\mathrm{m}}\right)$}

As constantes de crescimento máximo das bactérias envolvidas na nitrificação $\left(\mu_{\mathrm{m}}\right)$ é um parâmetro de grande importância para projetos racionais de sistemas de lodo ativado, porem seu valor pode variar muito dependendo das características da água residuária, por esta razão, tornase importante determinar o valor da constante. Com os dados obtidos pela respirometria, calcularam-se, para as Fases I, II e III do sistema de lodo ativado, as constantes de crescimento específico máximo das bactérias envolvidas na nitrificação $\left(\mu_{m}\right)$, conforme descrito na seção 3.9.2.1 do capítulo 3.

$\mathrm{Na}$ Tabela 4.9.2, podem-se observar os resultados médios das constantes corrigidas para temperatura de $20^{\circ} \mathrm{C}$. Ao analisar os resultados, nota-se que o valor médio da constante $\mu_{\mathrm{m}}$ para as bactérias nitritantes foi maior, porém próximos aos valores obtidos pelas bactérias nitratantes nas Fases I, II e III do estudo. Outro aspecto que fica claro a partir da Tabela 4.9.2 é o aumento significativo da constante $\mu_{\mathrm{m}}$ das bactérias nitritantes e nitratantes com a redução do TRS da Fase I $\left(40 \mathrm{~d}^{-1}\right)$ para Fase II $\left(20 \mathrm{~d}^{-1}\right)$, sendo um fator de 2,4 maior. No entanto, não houve aumento significativo quando o TRS é reduzido da Fase I ( $\left.40 \mathrm{~d}^{-1}\right)$ para Fase II $\left(30 \mathrm{~d}^{-1}\right)$. Quando se comparam os valores das constantes de crescimento específico máximo das bactérias nitritantes com os valores típicos da literatura $\left(0,20-1,02 \mathrm{~d}^{-1}\right)$ Tabela 2.6, seção 2.3.6 do Capítulo 2, nota-se uma boa proximidade. 
Tabela 4.9.2: Valores médios das constantes de crescimento específico máximo das bactérias envolvidas na nitrificação $\left(\mu_{\mathrm{m}}\right)$.

\begin{tabular}{ccc|cc|cc}
\hline \multicolumn{7}{c}{ Constantes de crescimento específico máximo $\left(\boldsymbol{\mu}_{\mathbf{m}}\right)$} \\
\hline $\boldsymbol{\mu}_{\mathbf{m} 20}\left(\mathbf{d}^{\mathbf{- 1}}\right)$ & \multicolumn{2}{c}{ Fase I } & \multicolumn{2}{c|}{ Fase II } & \multicolumn{2}{c}{ Fase III } \\
\hline Frações & Nitritantes & Nitratantes & Nitritantes & Nitratantes & Nitritantes & Nitratantes \\
\hline média & 0,28 & 0,26 & 0,30 & 0,29 & 0,68 & 0,62 \\
\hline máximo & 0,68 & 0,57 & 0,43 & 0,44 & 1,94 & 1,35 \\
\hline mínimo & 0,16 & 0,13 & 0,19 & 0,16 & 0,31 & 0,23 \\
\hline DP & 0,13 & 0,11 & 0,07 & 0,08 & 0,37 & 0,29 \\
\hline CV (\%) & 44,3 & 42,7 & 23,7 & 28,3 & 54,7 & 46,7 \\
\hline AT & 0,5 & 0,4 & 0,2 & 0,3 & 1,6 & 1,1 \\
\hline
\end{tabular}

Exemplificando-se para $\mu_{\mathrm{m}}$ na Fase III (nitritantes) Tabela 4.9.2, tem-se os seguintes valores: $\mathrm{f}_{\mathrm{n}}=$ adotado 0,10 (VAN HAANDEL e MARAIS, 1999); $\mathrm{R}_{\mathrm{S}}=20 \mathrm{~d}^{-1} ; \mathrm{V}_{\mathrm{r}}=183 \mathrm{~L}^{-1} ; \mathrm{NTK}_{\mathrm{a}}=61,4$ $\operatorname{mgN} . L^{-1} ; \mathrm{NTK}_{\mathrm{e}}=4,6 \mathrm{mgN} \cdot \mathrm{L}^{-1} ; \mathrm{X}_{\mathrm{v}}=3007 \mathrm{mgSSVL}{ }^{-1} ; \mathrm{Q}_{\mathrm{a}}=175 \mathrm{~L} \cdot \mathrm{d}^{-1} ; \mathrm{Y}_{\mathrm{n}}=0,1 ; \mathrm{b}_{\mathrm{n}}=0,04 ;$ TCOexo $=55,0 \mathrm{mgO} \cdot \mathrm{L}^{-1} \cdot \mathrm{h}^{-1} ;$ TCOend $=10,0 \mathrm{mgO} \cdot \mathrm{L}^{-1} \cdot \mathrm{h}^{-1}$. Portanto calcula-se:

Concentração das bactérias autotróficas:

$\mathrm{X}_{\mathrm{n}}=\mathrm{Y}_{\mathrm{n}} \mathrm{R}_{\mathrm{s}} \mathrm{N}_{\mathrm{c}} /\left(1+\mathrm{b}_{\mathrm{n}} \mathrm{R}_{\mathrm{s}}\right) \mathrm{R}_{\mathrm{h}}=0,1 * 20 * 41,1 /(1+0,04 * 20) * 1,2=37,4 \mathrm{mgX}_{\mathrm{n}} \cdot \mathrm{L}^{-1}$

Concentração de amônia nitrificada:

$\mathrm{N}_{\mathrm{c}}=\mathrm{NTK}_{\mathrm{a}}-\mathrm{NTK}_{\mathrm{e}}-\mathrm{N}_{\mathrm{l}}=61,4-4,6-15,7=41,1 \mathrm{mgN} \cdot \mathrm{L}^{-1}$

Concentração de nitrogênio necessário para a produção de lodo:

$\mathrm{N}_{\mathrm{l}}=\mathrm{f}_{\mathrm{n}} \mathrm{X}_{\mathrm{v}} \mathrm{V}_{\mathrm{r}} / \mathrm{R}_{\mathrm{s}} \mathrm{Q}_{\mathrm{a}}=0,1 * 3007 * 183 / 20 * 175=16,0 \mathrm{mgN} \cdot \mathrm{L}^{-1}$

TCO máxima das bactérias nitritantes obtida por meio dos testes respirométricos:

$\mathrm{TCO}_{\text {n.máx }}=$ TCOexo $-\mathrm{TCO}_{\text {end }}=55,0-10,0=45,0 \mathrm{mgO} \cdot \mathrm{L}^{-1} \cdot \mathrm{h}^{-1}$

Conforme a teoria de lodo ativado (VAN HAANDEL e MARAIS, 1999), pode-se calcular a taxa máxima de nitritação ou nitratação como se segue:

$\mathrm{r}_{\mathrm{n}}=\mathrm{TCO}_{\mathrm{n} \cdot \text { máx }} / 4,57=45,0 / 4,57=10,0 \mathrm{mg} \cdot \mathrm{L}^{-1} \cdot \mathrm{h}^{-1}$ ou $240 \mathrm{mg} \cdot \mathrm{L}^{-1} \cdot \mathrm{d}^{-1}$

Portanto, se calcula a constante máxima das bactérias nitritantes $\left(\mu_{\mathrm{m}}\right)$ como se segue:

$\mu_{\mathrm{m} 20}=\left(\mathrm{Y}_{\mathrm{n}} * \mathrm{r}_{\mathrm{n} \text {.máx }} / \mathrm{X}_{\mathrm{n}}\right) * 24=(0,1 * 10,0 * 24 / 37)=0,68 \mathrm{~d}^{-1}$ 


\subsubsection{Constante de meia saturação de amônia e nitrito $\left(K_{n}\right)$}

Com os dados obtidos pela respirometria, calcularam-se, para as Fases I, II e III do sistema de lodo ativado, as constantes de meia saturação de Monod $\left(\mathrm{K}_{\mathrm{n}}\right)$, conforme descrito na seção 3.9.2.2 do capítulo 3. Na Tabela 4.9.3, podem-se observar os resultados médios das constantes corrigidas para temperatura de $20^{\circ} \mathrm{C}$. Ao analisar os resultados, nota-se que o valor médio da constante $\mathrm{K}_{\mathrm{n}}$ para as bactérias nitratantes foi maior quando comparado com as obtidas pelas bactérias nitritantes nas Fases II e III, o inverso ocorreu na Fase I. Outro aspecto que fica claro a partir da Tabela 4.9.3 é o aumento de $\mathrm{K}_{\mathrm{n}}$ com a redução do TRS para as bactérias nitritantes e nitratantes. Quando se comparam os valores das constantes de meia saturação das bactérias nitritantes com os valores típicos da literatura $\left(0,04-1,0 \mathrm{~d}^{-1}\right)$ Tabela 2.5, seção 2.3.6 do capítulo 2, nota-se uma boa proximidade.

Tabela 4.9.3: Valores médios das constantes de meia saturação de amônia na equação de Monod para o crescimento das bactérias envolvidas na nitrificação $\left(\mathrm{K}_{\mathrm{n}}\right)$

\begin{tabular}{ccc|cc|cc}
\hline \multicolumn{6}{c}{ Constante de meia saturação para as bactérias nitrificadoras $\left(\mathbf{K}_{\mathbf{n}}\right)$} \\
\hline $\mathbf{K}_{\mathbf{n} 2 \mathbf{0}}\left(\mathbf{d}^{-1}\right)$ & \multicolumn{2}{c}{ Fase I } & \multicolumn{2}{c|}{ Fase II } & \multicolumn{2}{c}{ Fase III } \\
\hline Fraçóes & Nitritantes & Nitratantes & Nitritantes & Nitratantes & Nitritantes & Nitratantes \\
\hline média & 0,34 & 0,28 & 0,39 & 0,41 & 0,42 & 0,54 \\
\hline máximo & 0,47 & 0,74 & 0,52 & 0,74 & 1,20 & 0,88 \\
\hline mínimo & 0,18 & 0,03 & 0,28 & 0,16 & 0,11 & 0,16 \\
\hline DP & 0,11 & 0,27 & 0,11 & 0,28 & 0,30 & 0,31 \\
\hline CV (\%) & 32,1 & 97,0 & 28,2 & 68,0 & 71,0 & 57,9 \\
\hline AT & 0,3 & 0,4 & 0,2 & 0,6 & 1,1 & 0,7 \\
\hline
\end{tabular}

\subsubsection{Taxa máxima de utilização de amônia e nitrito $\left(r_{n . m a ́ x}\right)$}

Com os dados obtidos pela respirometria e análises experimentais, calcularam-se, para as Fases I, II e III do sistema de lodo ativado, as taxas de utilização máxima de amônia e nitrito ( $\mathrm{r}_{\text {n.máx }}$ ), conforme descrito na seção 3.9.2.1 do capítulo 3, exemplificado na seção 4.9.3. Os valores médios das taxas obtidas pela respirometria são apresentados na Tabela 4.9.4. As Figuras 4.9 e 4.9.1 mostram os dados analíticos de diminuição de amônia, de nitrito e o acúmulo de nitrato, realizadas durante a Fase III, em paralelo aos testes respirométricos.

Quando se comparam os valores médios da taxa de utilização de amônia obtidos por meio dos testes respirométricos, com os valores médios por meio dos testes analíticos (Fase III), nota-se uma boa consistência nos resultados, sendo: $\mathrm{O}$ valor médio da taxa de utilização de amônia de $r_{n . m a ́ x}=12,0 \mathrm{mgN} \cdot \mathrm{L}^{-1} \cdot \mathrm{h}^{-1}$ (teste analítico) e de $\mathrm{r}_{\text {n.máx }}=10,0 \mathrm{mgN} \cdot \mathrm{L}^{-1} \cdot \mathrm{h}^{-1}$ (teste respirométrico). $\mathrm{O}$ mesmo ocorreu com os resultados da taxa de utilização máxima de nitrito, onde: $\mathrm{O}$ valor médio foi de $r_{n \cdot m a ́ x}=9,3 \mathrm{mgN} \cdot \mathrm{L}^{-1} \cdot \mathrm{h}^{-1}$ (teste analítico) e de $\mathrm{r}_{\text {n.máx }}=9,2 \mathrm{mgN} \cdot \mathrm{L}^{-1} \cdot \mathrm{h}^{-1}$ (teste respirométrico). 
Ao analisar os resultados por meio das Figuras 4.9 e 4.9.1, pode-se notar que, a taxa de nitritação e nitratação é mais rápida nos primeiros 5 a 10 minutos de reação. Ainda, na Figura 4.9 e 4.9 .1 observa-se o acúmulo de nitrato em função da diminuição de amônia e nitrito durante os testes analíticos. Nota-se que a velocidade de conversão de amônia a nitrato é maior do que a de nitrito a nitrato, sendo: de 10,9 $\mathrm{mgN} \cdot \mathrm{L}^{-1} \cdot \mathrm{h}^{-1}$ (amônia-nitrato) e de $8,3 \mathrm{mgN} \cdot \mathrm{L}^{-1} \cdot \mathrm{h}^{-1}$ (nitritonitrato).

Quando se comparam estatisticamente os valores médios, nota-se, que o processo segue uma cinética de ordem zero, com $\mathrm{R}^{2}>0,91 \mathrm{e}$, quando se aplica o método estatístico de correlação de Pearson, com os dados de (amônia-nitrato) e (nitrito-nitrato) nota-se uma correlação negativa muito forte $r=(-0,90$ a $-0,99)$, como se observa mais uma vez na Figura 4.9 e 4.9.1. Indicando claramente que o acúmulo de nitrato se deve a diminuição da concentração da amônia adicionada.

Durante os testes analíticos da diminuição de amônia, não houve acúmulo de nitrito, indicando uma oxidação direta a nitrato. Desse modo, conclui-se que a nitrificação no sistema foi governada pelas bactérias nitritantes. No entanto as constantes cinéticas obtidas para as bactérias nitritantes e nitratantes se resultaram próximas. $\mathrm{O}$ acúmulo de nitrato durante os testes respirométricos com baixa concentração de OD foi possível devido à falta de uma fonte de carbono, inibindo a desnitrificação simultânea.

Tabela 4.9.4.: Valores médios das taxas máximas de utilização de amônia e nitrito

\begin{tabular}{ccc|cc|cc}
\hline \multicolumn{7}{c}{ Taxa de utilização máxima de amônia e nitrito $\left(\mathbf{m g N . L ^ { - 1 }} \mathbf{h}^{-1}\right)$} \\
\hline \multirow{2}{*}{ Fase I } & \multicolumn{2}{c}{ Fase II } & \multicolumn{2}{c}{ Fase III } \\
\hline \multirow{2}{*}{ Constante } & $\begin{array}{c}\mathbf{r}_{\text {n.máx }} \\
\text { Nitritante }\end{array}$ & $\begin{array}{c}\mathbf{r}_{\text {n.máx }} \\
\text { Nitratante }\end{array}$ & $\begin{array}{c}\mathbf{r}_{\text {n.máx }} \\
\text { Nitritante }\end{array}$ & $\begin{array}{c}\mathbf{r}_{\text {n.máx }} \\
\text { Nitratante }\end{array}$ & $\begin{array}{c}\mathbf{r}_{\text {n.máx }} \\
\text { Nitritante }\end{array}$ & $\begin{array}{c}\mathbf{r}_{\text {n.máx }} \\
\text { Nitratante }\end{array}$ \\
\hline média & 7,2 & 6,6 & 9,2 & 8,7 & 10,0 & 9,2 \\
\hline máxima & 9,8 & 8,8 & 9,8 & 10,5 & 11,0 & 14,0 \\
\hline mínima & 4,2 & 4,4 & 8,3 & 7,0 & 6,1 & 4,4 \\
\hline DP & 1,5 & 1,6 & 0,7 & 1,1 & 1,0 & 2,2 \\
\hline CV $(\%)$ & 21,6 & 24,8 & 7,2 & 12,8 & 10,1 & 24,1 \\
\hline AT & 5,7 & 4,4 & 1,5 & 3,5 & 4,8 & 9,6 \\
\hline
\end{tabular}




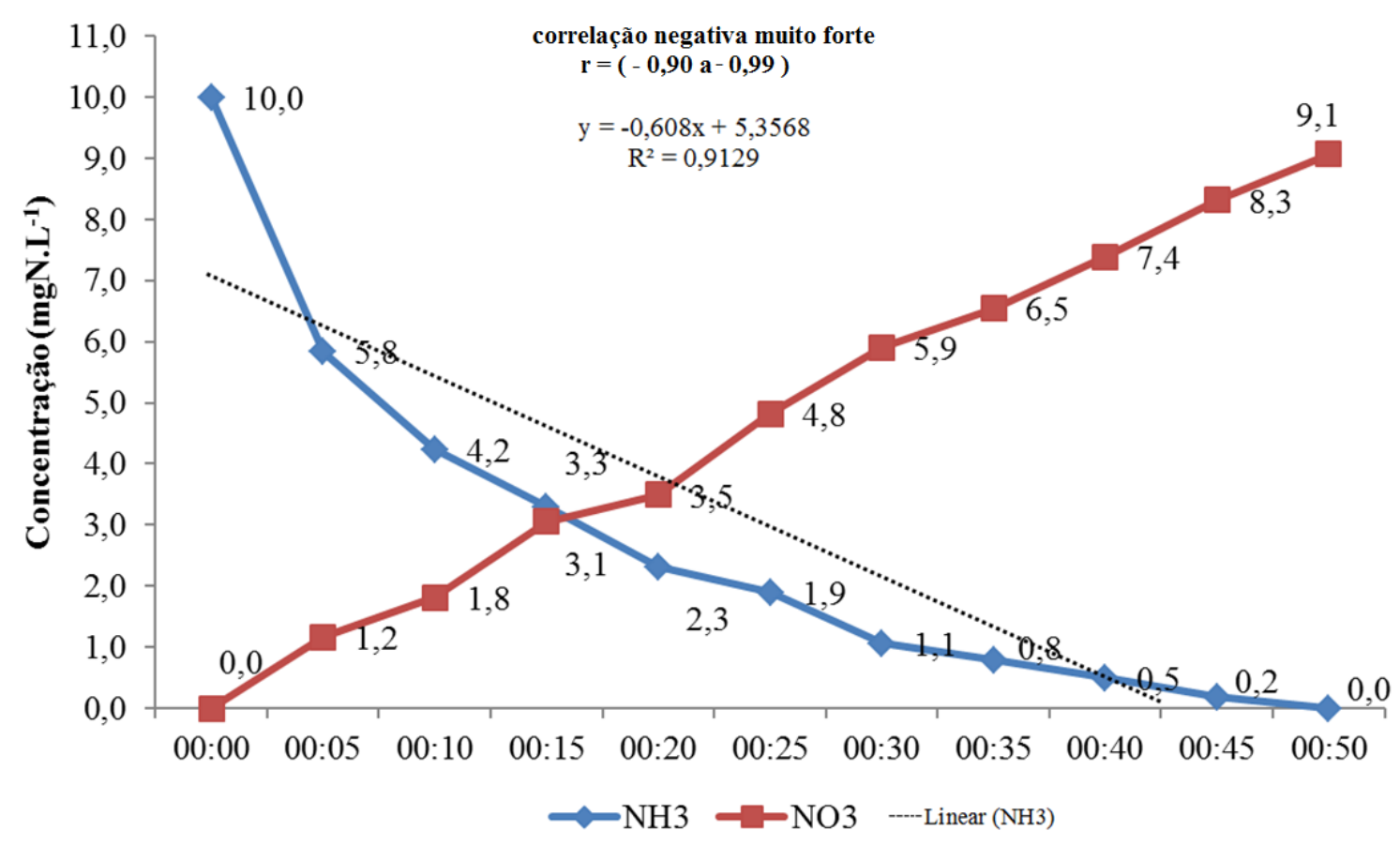

Figura 4.9: Diminuição na concentração de amônia e acúmulo de nitrato durante os testes respirométricos na Fase III.

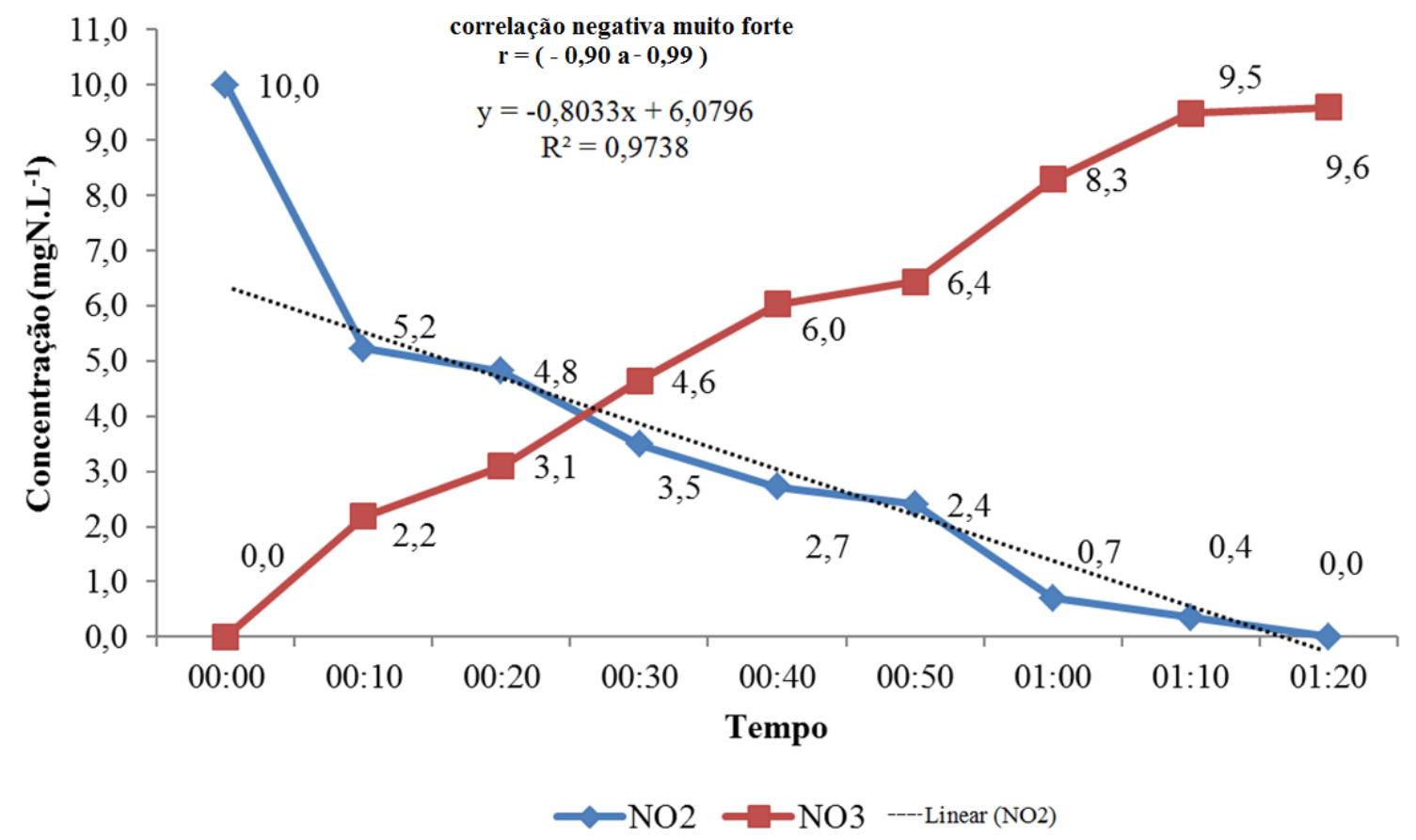

Figura 4.9.1: Diminuição na concentração de nitrito e acúmulo de nitrato durante os testes respirométricos na Fase III. 


\subsection{Determinação das constantes cinéticas da desnitrificação e comparação da taxa de oxidação de material orgânico tendo como oxidante o oxigênio dissolvido e o nitrato}

Conforme descrito na seção 3.9.4 do capítulo 3, realizou-se uma investigação experimental para comparar a taxa de oxidação de material orgânico tendo-se como oxidantes o oxigênio dissolvido e o nitrato, em um ambiente com baixa concentração de oxigênio dissolvido (0,3-0,8 $\mathrm{mgOL}^{-1}$ ) promovendo o processo de NDS. Foi utilizado como fonte de carbono o acetato de sódio (material rapidamente biodegradável) e amido (lentamente biodegradável). Ainda, realizaram-se testes com o próprio esgoto sanitário.

Os resultados são apresentados na Figura 4.10. A taxa de utilização máxima de nitrato com adição de substrato solúvel foi de $\mathrm{r}_{\mathrm{d} \cdot \operatorname{máx}}=11,2 \mathrm{mgN} \cdot \mathrm{L}^{-1} \cdot \mathrm{h}^{-1}$ e de $\mathrm{r}_{\mathrm{d} \text {.máx }}=2,3 \mathrm{mgN} \cdot \mathrm{L}^{-1} \cdot \mathrm{h}^{-1}$ com adição de substrato particulado e de $\mathrm{r}_{\text {d.máx }}=5,0 \mathrm{mgN} \cdot \mathrm{L}^{-1} \cdot \mathrm{h}^{-1}$ com esgoto sanitário. Ao analisar os resultados, pode-se notar que, a taxa de desnitrificação é mais rápida nos primeiros 10 minutos tendo como substrato o material rapidamente biodegradável e com o esgoto sanitário, o que não acontece com o material lentamente biodegradável. Os resultados seguem uma cinética de ordem zero com $\mathrm{R}^{2}>0,94$. Durante os testes analíticos da diminuição de nitrato, não houve formação de nitrito, indicando que a desnitrificação de nitrato é uma redução de uma vez para nitrogênio molecular.

A taxa de utilização de nitrato tendo como substrato material orgânico rapidamente biodegradável foi um fator 5,0 maior do que o do material lentamente biodegradável, confirmando que a disponibilidade de carbono é um fator limitante para ocorrência da desnitrificação. No entanto, quando se compara a taxa de utilização do nitrato tendo como substrato o próprio esgoto sanitário, nota-se um valor intermediário devido ao esgoto apresentar as duas condições (material rapidamente e lentamente biodegradável). Portanto, a concentração de carbono disponível no esgoto sanitário não foi limitante para ocorrência da desnitrificação nas condições de operação estabelecida no estudo. 


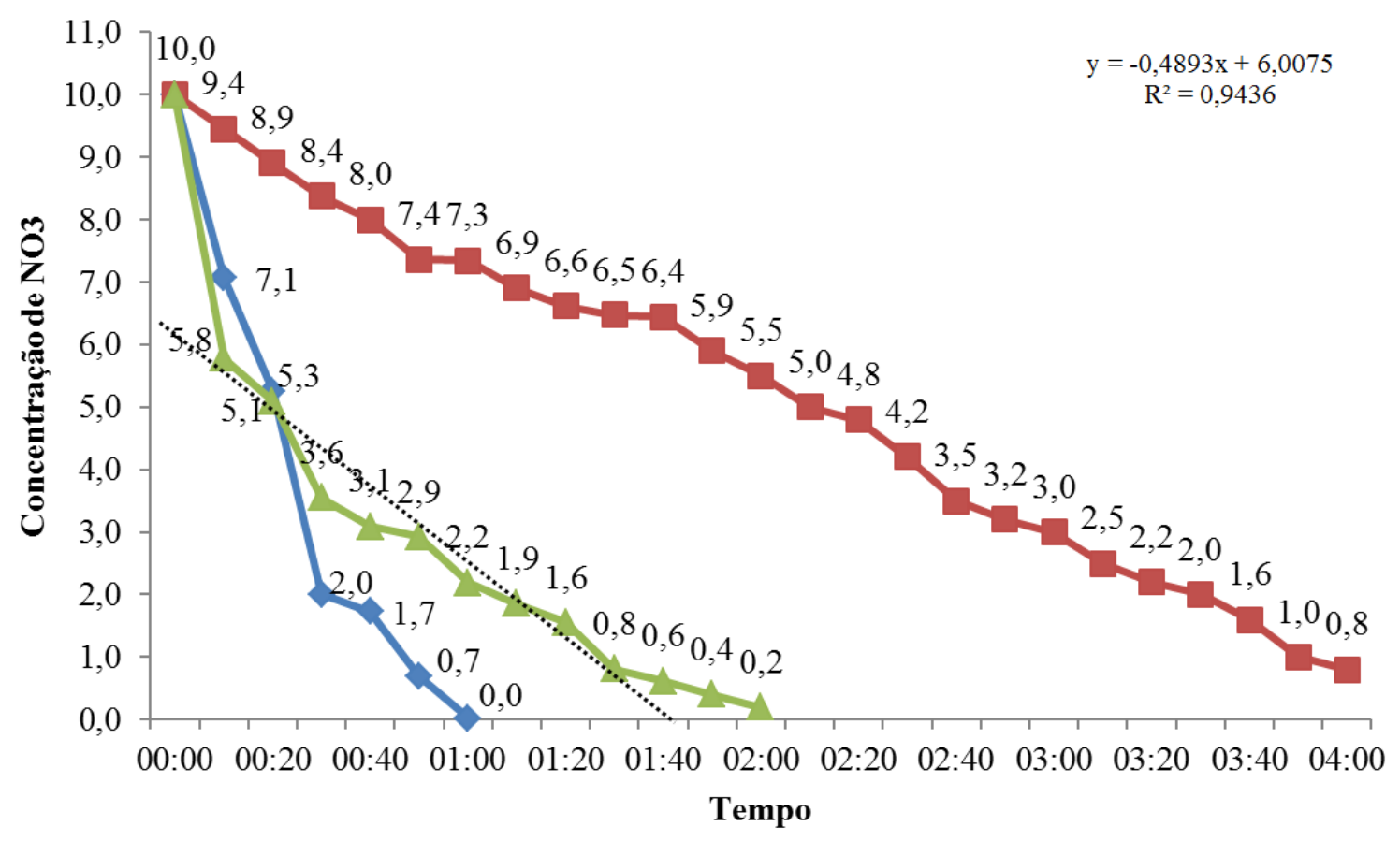
$\smile$ Substrato solúvel + NO3 $\neg$ Substrato particulado + NO3 - Esgoto sanitário + NO3
-----Linear (Esgoto sanitário + NO3)

Figura 4.10: Diminuição na concentração de nitrato em função do tempo com diferentes substratos e adição de $10 \mathrm{mgN} . \mathrm{L}^{-1}$ de nitrato de potássio na Fase III do estudo.

Com os dados da taxa de utilização máxima de nitrato obtidas nos testes analíticos apresentado anteriormente (Fase III), calculou-se as constantes de desnitrificação $\left(\mathrm{K}_{\mathrm{d}}\right)$ em relação a massa ativa $\left(\mathrm{X}_{\mathrm{a}}\right)$ por dia, para os diferentes substratos (Tabela 10).

Tabela 4.10: Valores médios das constantes de desnitrificação $\left(K_{d}\right)$.

\begin{tabular}{cccc}
\hline \multicolumn{4}{c}{ Constantes de desnitrificação $\left(\mathbf{m g N} \cdot \mathbf{m g X}_{\left.\mathbf{a} \cdot \mathbf{d}^{-1}\right)}\right.$} \\
\hline $\mathbf{X}_{\mathrm{a}}=\mathbf{9 2 9} \mathbf{~ m g X}_{\mathrm{a}} \cdot \mathbf{L}^{-\mathbf{1}}$ & \multicolumn{4}{c}{ Particulado } & Esgoto sanitário \\
\hline Substrato & Solúvel & 0,06 & 0,13 \\
\hline $\mathrm{K}_{\mathrm{d}}$ & 0,29 & &
\end{tabular}

$\mathrm{Na}$ Tabela 4.10.1, podem-se observar os resultados experimentais obtidos da $\mathrm{TCO}_{\text {exo }}$ (exógena) e $\mathrm{TCO}_{\text {eq }}$ (equivalente) (Equação3.5.1, seção 3.9.4 do capítulo 3) para os diferentes substratos após adição de $10 \mathrm{mgN} . \mathrm{L}^{-1}$ de nitrato de potássio em um ambiente com baixa concentração de OD. Quando se comparam os valores médios da TCO exógena com a TCO endógena observa-se o seguinte: No caso de substrato particulado a TCO equivalente e a TCO exógena são um fator 1,1 a 2,0 maior que a TCO endógena. No caso de material orgânico solúvel a TCO exógena e a TCO equivalente foi um fator 4,0 maior que a TCO endógena e, no caso de material orgânico do esgoto sanitário a TCO equivalente foi um fator 1,9 maior que a TCO endógena. A Figura 4.11 demonstra que a TCO devido à utilização do material rapidamente biodegradável (solúvel) foi 
muito próxima a TCO equivalente no teste com adição de nitrato, indicando uma preferência cerca de $90 \%$ na utilização do oxigênio do nitrato. Nos testes com material lentamente biodegradável (particulado) nota-se que o TCO foi maior do que a TCO equivalente obtida no teste com adição de nitrato, indicando uma preferência de $56 \%$ na utilização do oxigênio dissolvido e de $44 \%$ na utilização do oxigênio do nitrato. Já nos testes com o esgoto bruto a utilização do oxigênio dissolvido como oxidante foi de $60 \%$ e a utilização do oxigênio do nitrato foi de $40 \%$. Conclui-se que na faixa de OD estabelecida nos testes $\left(0,3-0,8 \mathrm{mg} . \mathrm{L}^{-1}\right)$ é possível estabelecer condições para o desenvolvimento do processo de desnitrificação mesmo tendo baixas concentrações de oxigênio e que a forma e disponibilidade de carbono podem afetar significativamente o processo.

Tabela 4.10.1: Taxa de consumo de oxigênio utilizando substrato solúvel, particulado e esgoto sanitário e taxa equivalente de consumo de oxigênio utilizando como substrato o nitrato.

\begin{tabular}{cccccccc}
\hline \multicolumn{7}{c}{ Taxa de consumo de oxigênio exógena e equivalente $\left(\mathbf{m g O . L}^{-1} \cdot \mathbf{h}^{-1}\right)$} \\
\hline Substrato & $\begin{array}{c}\text { Solúvel } \\
\left(\mathbf{T C O}_{\text {exo }}\right)\end{array}$ & $\begin{array}{c}\text { Particulado } \\
\left(\mathbf{T C O}_{\mathbf{e x o}}\right)\end{array}$ & $\begin{array}{c}\text { Esgoto } \\
\left(\mathbf{T C O}_{\text {exo }}\right)\end{array}$ & $\begin{array}{c}\text { Solúvel+ } \\
\mathbf{N O}_{3}^{-} \\
\left(\mathbf{T C O}_{\mathbf{e q}}\right)\end{array}$ & $\begin{array}{c}\text { Particulado+ } \\
\mathbf{N O}_{3}^{-} \\
\left(\mathbf{T C O}_{\mathbf{e q}}\right)\end{array}$ & $\begin{array}{c}\text { Esgoto } \\
+ \\
\mathbf{N O}_{3}^{-} \\
\left(\mathbf{T C O}_{\mathbf{e q}}\right)\end{array}$ & $\begin{array}{c}(\mathbf{T C O}) \\
\text { endógena }\end{array}$ \\
\hline média & 35 & 16 & 37 & 32 & 9 & 15 & 8 \\
\hline máxima & 44 & 22 & 67 & 34 & 11 & 16 & 13 \\
\hline mínima & 28 & 12 & 11 & 26 & 7 & 14 & 5 \\
\hline DP & 6 & 4 & 10,5 & 4 & 2 & 1 & 3 \\
\hline CV $(\%)$ & 17,0 & 22,7 & 28,0 & 12,5 & 22,5 & 6,5 & 30,1 \\
\hline AT & 16,0 & 10,0 & 56 & 8,0 & 4,0 & 2,0 & 8,0 \\
\hline
\end{tabular}

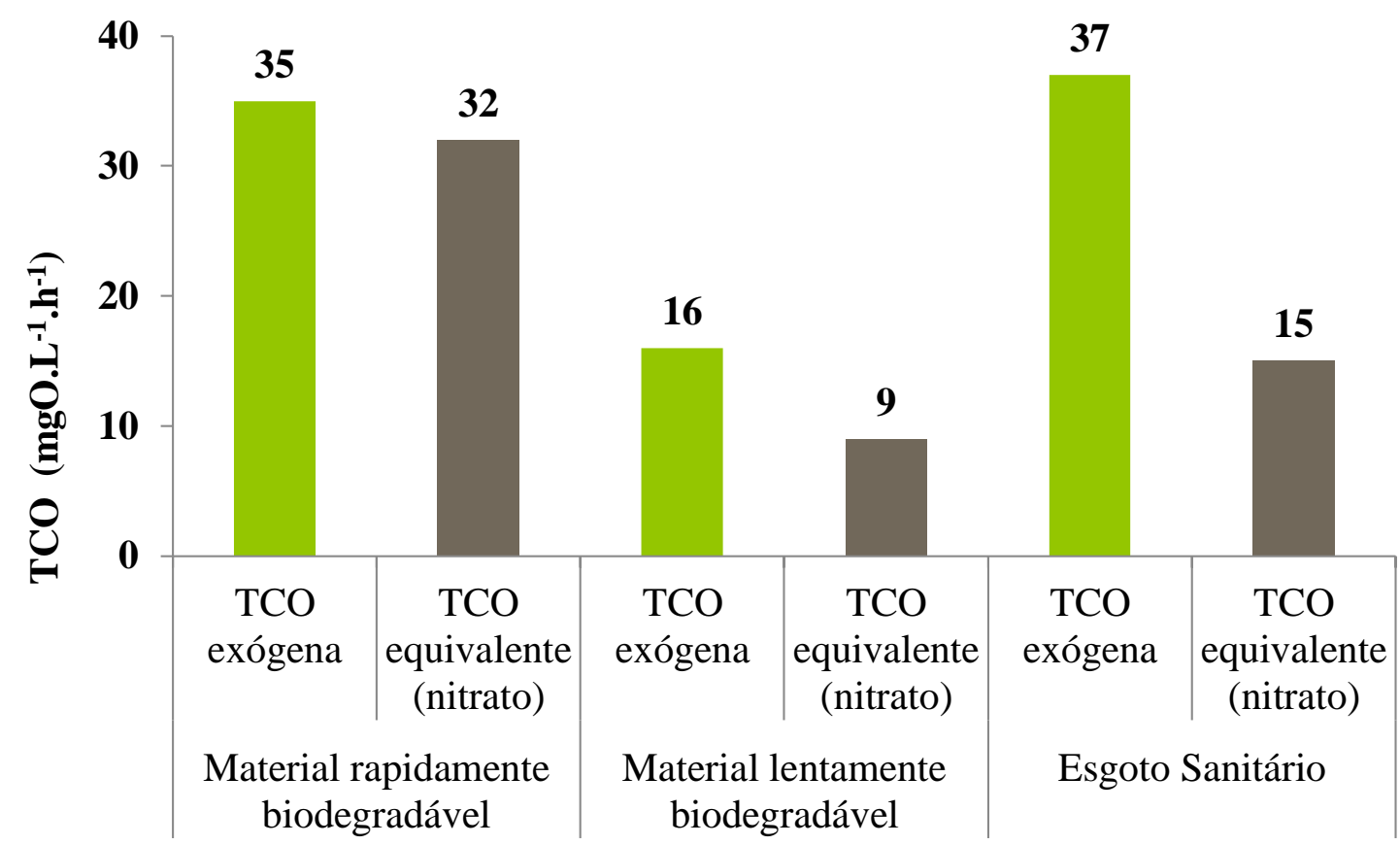

Figura 4.11: Taxa de consumo de oxigênio em ambiente aeróbio e taxa equivalente de consumo de oxigênio em ambiente com baixa concentração de oxigênio e nitrato 
$\mathrm{Na}$ Tabela 4.10.2, podem-se observar os resultados das taxas de utilização de oxigênio dissolvido devido a respiração endógena e as taxas equivalentes ao nitrato, representado em termos de $\left(\mathrm{mgO}_{\mathrm{mgX}}{ }^{-1} \cdot \mathrm{d}^{-1}\right)$ para Fase III deste estudo, calculado conforme a Equação 3.5.3 da seção 3.9.4 do capítulo 3. Onde $\left(\mathrm{X}_{\mathrm{a}}\right)$ representa a massa de lodo ativo determinado através da respirometria.

Tabela 4.10.2: Constantes cinéticas referentes à TCO, por miligrama de sólidos ativos por dia, com substratos solúvel, particulado e Fase endógena.

\begin{tabular}{|c|c|c|c|c|}
\hline \multicolumn{5}{|c|}{ Taxa equivalente de consumo de oxigênio $\left(\mathrm{mgO}_{\mathrm{eq}} \cdot \mathrm{mgX}_{\mathrm{a}} \cdot \mathrm{d}^{-1}\right)$} \\
\hline$X_{a}=929 \mathrm{mg}$ & $\mathrm{C}_{\mathrm{a}} \cdot \mathrm{L}^{-1}$ & & & O (respiração) \\
\hline Oxidante & Solúvel & Particulado & Esgoto sanitário & Endógena \\
\hline Oxigênio & 0,90 & 0,41 & 0,95 & 0,20 \\
\hline Oxigênio/Nitrato & 0,83 & 0,23 & 0,39 & - \\
\hline $\mathrm{TCO}_{\mathrm{eq}} / \mathrm{TCO}$ & 0,92 & 0,56 & 0,41 & - \\
\hline
\end{tabular}

\subsubsection{Comparação da capacidade de nitrificação e desnitrificação}

Segundo VAN HAANDEL e MARAIS a capacidade de desnitrificação é igual à massa de nitrogênio removida dividida pela vazão afluente. Na Tabela 4.10.3, podem-se observar os resultados da capacidade de desnitrificação $\left(\mathrm{D}_{\mathrm{C}}\right)$ e de nitrificação $\left(\mathrm{N}_{\mathrm{C}}\right)$ observada durante as Fases I, II e III do estudo em (mgN.L $\left.{ }^{-1}\right)$ de afluente. Quando se comparam os resultados, nota-se que a capacidade de desnitrificação foi muito próxima a de nitrificação nas Fases I e III, sendo: 99,8\% na Fase I, de 79,2\% na Fase II e de 93,1\% na Fase III, indicando que é possível produzir um efluente com uma concentração muito baixa de nitrato em um ambiente com baixa concentração de OD.

Tabela 4.10.3: Valores médios da capacidade de desnitrificação e nitrificação observada no sistema de lodo ativado.

\begin{tabular}{ccc|cc|rc}
\hline \multicolumn{7}{c}{ Capacidade de nitrificação e desnitrificação observada (mg.N.L. ${ }^{-1}$ ) } \\
\hline \multicolumn{2}{c}{ Fase I } & \multicolumn{2}{c}{ Fase II } & \multicolumn{2}{c}{ Fase III } \\
\hline Variável & $\mathrm{N}_{\mathrm{C}}$ & $\mathrm{D}_{\mathrm{C}}$ & $\mathrm{N}_{\mathrm{C}}$ & $\mathrm{D}_{\mathrm{C}}$ & $\mathrm{N}_{\mathrm{C}}$ & $\mathrm{D}_{\mathrm{C}}$ \\
\hline média & 59,0 & 58,6 & 58,6 & 46,4 & 39,4 & 36,7 \\
\hline máximo & 80,2 & 76,1 & 70,0 & 54,1 & 57,8 & 50,9 \\
\hline mínimo & 38,9 & 41,6 & 43,3 & 34,9 & 22,8 & 23,1 \\
\hline DP & 11,5 & 9,1 & 8,0 & 6,2 & 9,9 & 6,7 \\
\hline CV $(\%)$ & 19,6 & 20,0 & 13,6 & 10,0 & 25,1 & 20,0 \\
\hline AT & 41,2 & 34,5 & 26,8 & 19,1 & 39,0 & 27,8 \\
\hline
\end{tabular}




\section{CAPÍtUlO 5}

\section{CONCLUSÕES E RECOMENDAÇÕES}

O desenvolvimento deste estudo experimental resultou em importantes conclusões de aplicabilidade prática, relativas ao desempenho e operação do sistema de lodo ativado com aeração prolongada e fluxo contínuo de esgoto desenvolvendo o processo de nitrificação e desnitrificação simultânea. Ao analisar os resultados da investigação experimental obtidos com idades do lodo de 40, 30 e 20 dias e sob as mesmas condições de aeração, conclui-se que:

$\checkmark$ O processo de tratamento permaneceu estável durante todo o período de observação. Os resultados experimentais demonstram que é possível manter uma baixa concentração de OD no tanque de aeração em uma faixa relativamente estreita $\left(0,3-0,8 \mathrm{mg} \cdot \mathrm{L}^{-1}\right)$, por meio de um controle automatizado na aeração e, consequentemente desenvolver os processos de nitrificação e desnitrificação sob as mesmas condições (NDS) com alta eficiência e estabilidade, como se observou durantes as Fases I, II e III deste estudo.

$\checkmark$ Em termos de matéria orgânica, o tratamento resultou em alta eficiência na remoção de DQO e DBO, mesmo quando a idade do lodo é reduzida para 20 dias à eficiência foi acima de $90 \%$. Demonstrando que a baixa concentração de OD no tanque de aeração e as demais condições operacionais estabelecidas para o desenvolvimento do processo de NDS não foram limitantes na remoção do material orgânico.

$\checkmark$ Em relação à série de sólidos no efluente após o tratamento, a concentração manteve-se sempre baixa, demonstrando mais uma vez que a baixa concentração de OD no tanque de aeração e as demais condições operacionais da NDS não causaram danos significativos na floculação biológica. No licor misto se observou que a relação entre os SSV e SST foi maior que 0,80, provavelmente devido às características do afluente, resultando em um lodo excedente não tão estabilizado como o obtido em um sistema de lodo ativado com aeração prolongada convencional. Assim, recomenda-se uma melhor investigação na estabilização desse lodo. Ainda a partir dos resultados experimentais obtidos com o licor misto, se observou uma boa sedimentação e o desenvolvimento de uma rica comunidade microbiológica característica do processo de lodo ativado.

$\checkmark$ O processo de nitrificação ocorreu com alta eficiência durante todo o estudo, produzindo após o tratamento um efluente com baixas concentrações de nitrogênio amoniacal e orgânico, demonstrando que a influencia da baixa concentração de OD e a idade do lodo superior a 20 dias (idade considera limite para o sistema de lodo ativado 
com aeração prolongada) foram suficientes para o desenvolvimento estável e eficiente do processo de nitrificação.

$\checkmark$ Outro aspecto que fica claro a partir dos resultados experimentais é o desenvolvimento do processo de desnitrificação com alta eficiência durante todas as fases. A concentração de nitrato foi aumentada com a redução da idade do lodo para 20 dias, no entanto a concentração de nitrato no efluente após o tratamento ficou na faixa de 1 a 14 mgN.L $L^{-1}$, considerada baixa. Desse modo conclui-se que a concentração de OD estabelecida no tanque de aeração não afetou negativamente o processo de desnitrificação.

$\checkmark$ Em relação às variações da alcalinidade devido à amonificação, nitrificação e desnitrificação no sistema de lodo ativado, os resultados teóricos e observados foram compatíveis com a ocorrência simultânea dos processos de NDS. No entanto, dependendo da concentração de amônia e da alcalinidade no afluente, pode ser necessária a introdução de alcalinizante artificialmente, a fim de não ocorrer quaisquer limitações no processo de NDS.

Em relação às constantes cinéticas de nitrificação é possível afirmar que todas são adequadamente descritas pela equação de Monod, tendo-se como base dois substratos: amônia e oxigênio para as bactérias nitritantes e nitrito e oxigênio para as nitratantes. Especificamente em relação a cada constante cinética é possível afirmar que:

$\checkmark$ Os valores de crescimento específico máximo $\left(\mu_{\mathrm{m}}\right)$ das bactérias autotróficas nitritantes e nitratantes, obtidos durante as Fases I, II e III, resultaram muito próximas aos descritos na literatura, onde na Fase III com idade do lodo de 20 dias foi de $0,68 \mathrm{~d}^{-1}$ para as bactérias nitritantes e de $0,62 \mathrm{~d}^{-1}$ para as bactérias nitratantes que demonstram ótimo desempenho da nitrificação no sistema.

$\checkmark$ Os valores das taxas de utilização máxima de amônia $\left(r_{n \text { max }}\right)$, obtidos por meio da respirometria e testes analíticos foram maiores do que as obtidas com o nitrito. Durante os testes de diminuição de amônia não foi observado acúmulo de nitrito e, se observou que o acúmulo de nitrato devido à diminuição da amônia é mais rápido que por meio do nitrito. Desse modo, conclui-se que a nitrificação foi governada pelas bactérias autotróficas nitritantes.

$\checkmark$ Em relação às constantes cinéticas de desnitrificação, nota-se que para uma idade do lodo de 20 dias, a taxa de utilização de nitrato com esgoto sanitário é cerca de duas vezes menor que a taxa de utilização de amônia ou nitrito. No entanto, quando se comparam os resultados obtidos com os valores médios descritos na literatura, nota-se uma boa proximidade. Ainda, nos testes realizados, pode-se notar que a taxa de 
utilização de nitrato foi cerca de cinco vezes maior tendo como substrato material rapidamente biodegradável em relação ao material lentamente biodegradável e cerca de duas vezes quando o substrato era o próprio esgoto. Desse modo, se confirma que a disponibilidade de material carbonáceo tem papel fundamental nas taxas de desnitrificação no processo de NDS.

A utilização do modelo simplificado da teoria de lodo ativado, descrito por VAN HAANDEL e MARAIS (1999) para a determinação das constantes cinéticas da nitrificação e desnitrificação demonstrou ser bastante adequada, pois houve uma boa aproximação dos dados experimentais com os calculados segundo o modelo.

Quando se compram os resultados dos testes analíticos com os obtidos por meio da respirometria, nota-se uma boa proximidade. Desse modo, a respirometria demonstrou ser uma ferramenta confiável e prática para avaliar a atividade metabólica das bactérias heterotróficas e autotróficas presentes no lodo ativado.

Estudos em escala real devem ser conduzidos a fim de trazer um melhor entendimento desse fenômeno, pois no Brasil, muitas estações de tratamento de esgoto foram construídas ou estão sendo projetadas para operarem sob as condições da variante do processo de lodo ativado com aeração prolongada, reconhecidamente eficiente na remoção de matéria orgânica e na nitrificação do esgoto. Tais estações podem ser adaptadas para estas novas condições, de forma a se obter o benefício técnico da desnitrificação e o ganho econômico relativo à redução no consumo de energia elétrica para aeração. 


\section{CAPÍTULO 6}

\section{REFERÊNCIAS BIBLIOGRÁFICAS}

. Manual de saneamento. 3. Ed. rev. Brasília: FUNASA, 374p., 2006.

ANDREOTTOLA, G.; OLIVEIRA E.L.; FOLADORI P.;DALLAGO L.; PETERLINI R.;

CADONNA M. Método Respirométrico para o monitoramento de processos biológicos. Engenharia Sanitária e Ambiental. Artigo técnico, vol.10, Nº1,p.14-23, 2005.

APHA, 2005. Standard Methods for the Examination of Water and Wastewater, 21 ed. American Public Health Association/American Water Works Association/Water Environment Federation, Washington, DC, USA.

BENT HALLING-SORENSEN; SOREN NORS NIELSEN. A model of nitrogen removal from waste water in a fixed bed reactor using simultaneous nitrification and denitrification (SND). Elsevier Science - Ecological Modelling 87, p.131-141, 1996.

BRASIL, 1986. Resolução CONAMA N²0, de 18 de junho de 1986. Estabelece a classificação das águas doces, salobras e salinas. Diário Oficial [da] República Brasileira de Recursos Hídricos/Edusp;

BRASIL, 2005. Ministério do Desenvolvimento Urbano e Meio Ambiente - CONAMA. RESOLUÇÃO No 357 DE 17 DE MARÇO DE 2005. Disponível em: www.mma.gov.br/port/conama/res/res05/res35705.pdf;

CATUNDA, S. Y. C.; DEEP, G. S.; VAN HAANDEL, A. C.; FREIRE, R. C. S. Fast online measurement of the respiration rate in activated sludge systems. IEEE Instrumentation and measurement technology conference Bruxelas, Bélgica, Junho 4-6., 1996. 
COllovognARELl, C.; BERTANZA, G. Simultaneous Nitrification-Denitrification Processes in Activated Sludge Plants: Performance and Applicability. Water ScL TechnoL, 40 (4-5), 187-194, 1999.

COSTA, A.G.; FERREIRA, A.F.; VAN HAANDEL, A. C. Monitoramento da atividade bacteriana de um sistema de lodos ativados bardenpho por meio da respirometria. Engenharia Sanitária e Ambiental. Artigo técnico, vol.12, Nº1,p.17-23, 2007.

DOWNING, A.L. Selected subjects in waste treatment. 3 ed.: Delft, IHE., 1978.

FERREIRA, A. F. Uso da respirometria na avaliação da influência do pH na capacidade ativa das bactérias nitrificantes. Dissertação de Mestrado. 80 p. Campina Grande-PB: UFCG, 2002.

HELLINGA, C.; SCHELLEN, A. A. J. C; MULDER, J. W; van LOOSDRECHET, M. C. M; HEIJNEN, J. J. The SHARON process: an innovative method for nitrogen removal from ammonia-rich wastewater. Water Science and Technology, 37:135-142, 1998.

HELMER C, KUNST S. Simultaneous nitrification denitrification in an aerobic biofilm system. Water Sci Technol, 37(4-5), 183-187, 1998.

HONG W. ZHAO; DONALD S. MAVINIC; WILLIAM K. OLDHAM; FREDERIC A. KOCH. Controlling factors for simultaneous nitrification and denitrification in a TWO-STAGE intermittent aeration process treating domestic sewage. Water Reasearch, v.33 No 4, p. 961-970, 1998.

JORDAO, E. P.; PESSOA, C. A. Tratamento de Esgotos Sanitários. 4. ed. Belo Horizonte: Segrac Editora, vol. 1. p.906, 2005. 
KUENEN J.G. AND ROBERTSON L. A. Aerobic and anaerobic nitrification/denitrification processes. In: Water Quality International 94, Proc. IAWQ $17^{\text {th }}$ Biennial Conf., July 19-24, 1994, Budapest, Hungary, 91-99, 1997.

M.C. WENTZEL, A. MBEWE AND G.A. EKAMA. Batch test for measurement of readily biodegradable COD and active organism concentrations in municipal waste waters. Water SA, vol. 21, $\mathrm{N}^{\mathrm{o}} 2$, p.117-124, 1995.

MARAIS, G. v. R.; EKAMA, G. A. The Activated Sludge Process Part I: Steady State Behaviour. Water SA, v. 2, n. 4, p. 164-200, 1976.

MATSCHE. The elimination of nitrogen in the treatment planto $f$ Vienna-Blumenthal. Water Reasearch, v.6, p. 485-486, 1972.

METCALF e EDDY, Inc. Wastewater Engineering: Treatment and Reuse. McGraw Hill, 4th edition, p.1819, 2003.

MUINCH, E.; LANT, P.; KELLER, J. Simultaneous Nitrification and Denitrification in BenchScale Sequencing Batch Reactors. Water Res.,30 (2). 277-284, 1996.

MULDER, A. et al. Anaerobic ammonium oxidation discovered in a denitrifying fluidized bed reactor. FEMS Microbiology letters, v. 16, p.177-184, 1995.

NIELSEN, M.; et al. Kinetics, diffusional limitation and microscale distribution of chemistry and organisms in a CANON reactor. F.E.M.S. Microbiology Ecology. Vol. 51, p.247-256, 2005.

POCHANA K, KELLER J, LANT P. Model development for simultaneous nitrification and denitrification. Water Sci Technol, vol. 39(1): 235-243, 1999. 
POTH M., FOCHT D. D. N. kinetic analysis $\mathrm{N}_{2} \mathrm{O}$ production by Nirosomonas europaea an examination of nitrifier denitrification. Appl Environ Microbiol, vol.49(5): 1134-1141, 1985.

PROSAB - Programa de Pesquisas em Saneamento Básico: Nutrientes de esgoto sanitário: utilização e remoção - Edital 5 - Livro 2, Rio de Janeiro: Editora ABES, 428p., 2009.

RAYMOND J. ZENG; ROMAIN LEMAIRE; ZHIGUO YUAN; JURG KELLER. Simultaneous Nitrification, Denitrification, and Phosphorus Removal in a Lab-Scale Sequencing Batch Reactor. Wiley InterScience, vol.84, No², 2003.

RITTMANN B E, LANGELAND W E. Simultaneous denitrification with nitrification in singlechannel oxidation ditches. Journal WPCF, vol.57(4): 300-308, 1985.

ROBERTSON L. A. AND KUENEN J. G. Aerobic denitrification: a controversy revived. Arch. Microbiol. vol.139, 351-354, 1984.

SANTOS, E. V. M. Desnitrificação em sistemas de lodo ativado. 114p. Dissertação (Mestrado) - Universidade Federal de Campina Grande (UFCG), Campina Grande, 2009.

SATOH, H.; NAKAMURA, Y.; ONO, H.; OKABE, S. Effect of Oxygen Concentration on Nitrification and Denitrification in Single Activated Sludge Floes. BiotechnoL Bioeng., vol.83 (5), 604-607, 2003.

SCHMIDT, I, SLIEKERS, O, SCHMID, M, BOCK, E, FUERST, J, KUENE, J. G, JETTEN, M. S. M, STROUS, M. New concepts of microbial treatment processes for the nitrogen removal in wastewater. FEMS Microbiol. Rev. 772: 1-12, 2003. 
SEN. P.: DENTEL. S. K. Simultaneous Nitrification-Denitrification in a Fluidized Bed Reactor. Wvter ScL Technol., 38 (1), 247-254, 1998.

SEUNG H. BAEK, KRISHNA R. PAGILLA. Simultaneous nitrification and denitrification of municipal wastewater in aerobic membrane bioreactors. Water Reasearch, v.80 - N ${ }^{\circ} 2$, p.109117, 2008.

SILVA FILHO, H. A. Nitrificação em Sistemas de Lodo Ativado. 134 f. Dissertação (Mestrado) - Universidade Federal de Campina Grande, Campina Grande, 2009.

TCHOBANOGLOUS, G. \& SCHROEDER, E. D. Water Quality: Characteristics Modeling and Modification. New York: Addison-Wesley Publishing, 1985.

THAURÉ D, LEMOINE C, DANIEL O, MOATAMRI N, CHABROL J. Optimisation of aeration for activated sludge treatment with simultaneous nitrification denitrification. Water Sci Technol, vol.58(3), 639-645, 2008.

TURK. O.; MAVINIC, D. Maintaining Nitrite Building in a System Acclimated to Free Ammonia. Water Res., vol.23 (11), 1385-1388, 1989.

VAN HAANDEL, A. C. e CATUNDA, P. F. C. Determinação da taxa de consumo de oxigênio. Revista Engenharia Sanitária 21,4, PP 481-488, 1982.

VAN HAANDEL, A. C. e VAN DER LUBBE, J. Handbook Biological Wastewater Treatment - design and optimization of activate sludge systems, 2007. 
VAN HAANDEL, A. C. Nitrification and Denitrification Kinetics in the Activated Sludge Process. Cape Town: Departamento de Engenharia Civil da University of Cape Town, 1981. 650 p. (Tese, Doutorado em Engenharia Civil).

VAN HAANDEL, A. C., MARAIS, G. v. R. O Comportamento do Sistema de Lodo Ativado: Teoria e Aplicações para Projetos e Operações. Campina Grande: epgraf, 472 p., 1999.

VAN LOOSDRECHT, M. C. M. e JETTEN, M. S. M. Microbiological Conversions in Nitrogen Removal. Water Science and technology, v.38, n.1, p1-7,1998.

VAN VELDHUIZEN H.; VAN LOOSDRECHT M. C. M. Nitrogen removal at low BOD/N ratio - Nitrogen removal over nitrite in the main process stream of activated sludge processes, Stowa report no. 97-34, 1997.

VERSTRAETE W. Heterotrophic nitrification in soil and aqueous media - a review. Bull. Acad. Sci. USSR Biol. Ser., 4, 515-530, 1975.

VERSTRAETE, W. e PHILIPS, S. Nitrification-denitrification processes and technologies in new contexts. Environmental Pollution, v.102, p.717-26, 1998.

VILLAVERDE, S.; GARCIA, P.; LACALLE, M. L. et al. Nitrification-denitrification of UASB effluents highly loaded with nitrogen in an activated sludge reactor operated with short cycled aeration. Water Science and Technology, London, v.44, n.4, p.279-286, 2001.

VON SPERLING, M. Princípios do Tratamento Biológico de Águas Residuárias. Vol. 4 Lodos Ativados. 2.ed. Belo Horizonte: DESA-UFMG, v.1. P.428, 2002 
WANG JIANLONG; PENG YONGZHEN; WANG SHUYING; GAO YOUNGQING. Nitrogen Removal by Simultaneous Nitrification and Denitrification via Nitrite in Sequence Hybrid Biological Reactor. Chinese Journal of Chemical Engineering, vol.16 (5), p.778-784, 2008.

WANG, B.; HE, S.; WANG, L.; SHUO, L. Simultaneous nitrification and de-nitrification in MBR. Water Science and Technology, Londres, v. 52, n. 10, p. 435 - 442, 2005.

X. CHEN; T. FUJIWARA; K. OHTOSHI; S. INAMORI; K. NAKAMACHI; H. TSUNO. Evaluation of a novel oxidation ditch system for biological nitrogen and phosphorus removal from domestic sewage. IWA- Water Science \& Technology, v.62.8 - N², 2010.

Y.J. CHANG AND S.K. TSENG. A novel double-membrane system for simultaneous nitrification and denitrification in a single tank. Letters in Applied Microbiology, v.28, p.453456, 1999.

YING-CHIH CHIU; LI-LING LEE; CHENG-NAN CHANG; ALLEN C. CHAO. Control of carbon and ammonium ratio for simultaneous nitrification and denitrification in a sequencing batch bioreactor. Elsevier Science - International Biodeterioration \& Biodegradation 59, p.1-7, 2006.

YOO K, AHN K H, LEE H J, LEE K H, KWAK Y J, SONG K G. Nitrogen removal from synthetic wastewater by simultaneous nitrification and denitrification (SND) via nitrite in an intermittently-aerated reactor. Water Res, v.33(1): 145-154, 1999.

ZENG, R. J.; LEMAIRE; R.; YUAN, Z.; KELLER, Y. J. Simultaneous Nitrification, Denitrification, and Phosphorus Removal in a Lab-Scale Sequencing Batch Reactor. Biotechnol. Bioeng., 84 (2), 170-178, 2003. 
ZHANG P, ZHOU QI, SONG L P, GU G W. Study progress on simultaneous nitrification and denitrification. Chongqing Environmental Sciences, v.23(6): 20-24, 2001.

ZHANG P, ZHOU QI. Simultaneous nitrification and denitrification in activated sludge system under low oxygen concentration. Front. Environmental Sciences Eng. China, 2007, 2(1): 1-4

ZHAO H W, MAVINIC D S, OLDHAM W K, KOCH F A. Controlling factors for simultaneous nitrification and denitrification in a two-stage intermittent aeration process treating domestic sewage. Water Res, v.33(4): 961-970, 1999. 


\section{APÊNDICE - A}

\section{Valores pontuais das determinações da série de sólidos}

Tabela 1: Concentrações de sólidos totais e suas frações no esgoto sanitário afluente

\begin{tabular}{|c|c|c|c|c|c|c|c|c|c|c|c|}
\hline \multicolumn{12}{|c|}{ Sólidos Totais - Afluente (mg.L $\left.\mathrm{L}^{-1}\right)$} \\
\hline \multicolumn{4}{|c|}{ Fase I } & \multicolumn{5}{|c|}{ Fase II } & \multicolumn{3}{|c|}{ Fase III } \\
\hline Data & Total & Fixo & Volátil & Data & Total & Fixo & Volátil & Data & Total & Fixo & Volátil \\
\hline $19 / 8 / 10$ & 490 & 200 & 290 & $19 / 10 / 10$ & 560 & 310 & 250 & $10 / 1 / 11$ & 250 & 120 & 130 \\
\hline $21 / 8 / 10$ & 430 & 250 & 180 & $25 / 10 / 10$ & 410 & 200 & 210 & $13 / 1 / 11$ & 300 & 170 & 130 \\
\hline $23 / 8 / 10$ & 460 & 230 & 230 & $27 / 10 / 10$ & 470 & 240 & 230 & $18 / 1 / 11$ & 520 & 230 & 290 \\
\hline $25 / 8 / 10$ & 470 & 230 & 240 & $3 / 11 / 10$ & 590 & 260 & 330 & $20 / 1 / 11$ & 490 & 240 & 250 \\
\hline $27 / 8 / 10$ & 550 & 270 & 280 & $5 / 11 / 10$ & 460 & 240 & 220 & $26 / 1 / 11$ & 400 & 220 & 180 \\
\hline $30 / 8 / 10$ & 440 & 220 & 220 & $9 / 11 / 10$ & 440 & 220 & 220 & $28 / 1 / 11$ & 440 & 240 & 200 \\
\hline $1 / 9 / 10$ & 420 & 220 & 200 & $11 / 11 / 10$ & 430 & 240 & 190 & $1 / 2 / 11$ & 380 & 130 & 250 \\
\hline $3 / 9 / 10$ & 420 & 220 & 200 & $16 / 11 / 10$ & 450 & 230 & 220 & $3 / 2 / 11$ & 410 & 280 & 130 \\
\hline $8 / 9 / 10$ & 480 & 260 & 220 & $19 / 11 / 10$ & 460 & 220 & 240 & $8 / 2 / 11$ & 400 & 220 & 180 \\
\hline $11 / 9 / 10$ & 360 & 160 & 200 & $23 / 11 / 10$ & 390 & 190 & 200 & $10 / 2 / 11$ & 430 & 210 & 220 \\
\hline $14 / 9 / 10$ & 480 & 230 & 250 & $25 / 11 / 10$ & 441 & 260 & 181 & $15 / 2 / 11$ & 441 & 250 & 191 \\
\hline $16 / 9 / 10$ & 400 & 120 & 280 & $29 / 11 / 10$ & 480 & 200 & 280 & $17 / 2 / 11$ & 480 & 230 & 250 \\
\hline $20 / 9 / 10$ & 470 & 240 & 230 & $2 / 12 / 10$ & 460 & 280 & 180 & $1 / 3 / 11$ & 440 & 250 & 190 \\
\hline $22 / 9 / 10$ & 850 & 330 & 520 & $6 / 12 / 10$ & 600 & 350 & 250 & $15 / 3 / 11$ & 460 & 290 & 170 \\
\hline $24 / 9 / 10$ & 470 & 220 & 250 & $8 / 12 / 10$ & 420 & 200 & 220 & $17 / 3 / 11$ & 450 & 220 & 230 \\
\hline $27 / 9 / 10$ & 380 & 260 & 120 & $10 / 12 / 10$ & 440 & 190 & 250 & $22 / 3 / 11$ & 480 & 260 & 220 \\
\hline $29 / 9 / 10$ & 380 & 160 & 200 & $13 / 12 / 10$ & 460 & 210 & 250 & $24 / 3 / 11$ & 440 & 230 & 210 \\
\hline $1 / 10 / 10$ & 510 & 250 & 260 & - & - & - & - & $29 / 3 / 11$ & 460 & 240 & 220 \\
\hline $5 / 10 / 10$ & 460 & 230 & 230 & - & - & - & - & $31 / 3 / 11$ & 480 & 250 & 230 \\
\hline- & - & - & - & - & - & - & - & $5 / 4 / 11$ & 500 & 270 & 230 \\
\hline- & - & - & - & - & - & - & - & $7 / 4 / 11$ & 530 & 280 & 250 \\
\hline- & - & - & - & - & - & - & - & $12 / 4 / 11$ & 550 & 260 & 290 \\
\hline- & - & - & - & - & - & - & - & $18 / 4 / 11$ & 570 & 270 & 300 \\
\hline
\end{tabular}

Tabela 2: Concentrações de sólidos em suspensão e suas frações no esgoto sanitário afluente

\begin{tabular}{|c|c|c|c|c|c|c|c|c|c|c|c|}
\hline \multicolumn{12}{|c|}{ Sólidos em Suspensão - Afluente (mg.L-1) } \\
\hline \multicolumn{4}{|c|}{ Fase I } & \multicolumn{5}{|c|}{ Fase II } & \multicolumn{3}{|c|}{ Fase III } \\
\hline Data & Total & Fixo & Volátil & Data & Total & Fixo & Volátil & Data & Total & Fixo & Volátil \\
\hline $19 / 8 / 10$ & 22 & 3 & 19 & $19 / 10 / 10$ & 150 & 80 & 70 & $10 / 1 / 11$ & 55 & 5 & 50 \\
\hline $21 / 8 / 10$ & 81 & 6 & 75 & $25 / 10 / 10$ & 90 & 20 & 70 & $13 / 1 / 11$ & 62 & 10 & 52 \\
\hline $23 / 8 / 10$ & 95 & 9 & 86 & $27 / 10 / 10$ & 116 & 8 & 108 & $18 / 1 / 11$ & 190 & 32 & 158 \\
\hline $25 / 8 / 10$ & 113 & 7 & 106 & $3 / 11 / 10$ & 222 & 32 & 190 & $20 / 1 / 11$ & 118 & 16 & 102 \\
\hline $27 / 8 / 10$ & 206 & 22 & 184 & $5 / 11 / 10$ & 128 & 16 & 112 & $26 / 1 / 11$ & 120 & 15 & 105 \\
\hline $30 / 8 / 10$ & 104 & 2 & 102 & $9 / 11 / 10$ & 112 & 24 & 88 & $28 / 1 / 11$ & 110 & 10 & 100 \\
\hline $1 / 9 / 10$ & 96 & 2 & 94 & $11 / 11 / 10$ & 120 & 12 & 108 & $1 / 2 / 11$ & 100 & 12 & 88 \\
\hline $3 / 9 / 10$ & 112 & 20 & 92 & $16 / 11 / 10$ & 115 & 10 & 105 & $3 / 2 / 11$ & 126 & 16 & 110 \\
\hline $8 / 9 / 10$ & 84 & 42 & 42 & $19 / 11 / 10$ & 134 & 10 & 124 & $8 / 2 / 11$ & 80 & 10 & 70 \\
\hline $11 / 9 / 10$ & 80 & 28 & 52 & $23 / 11 / 10$ & 70 & 8 & 62 & $10 / 2 / 11$ & 74 & 8 & 66 \\
\hline $14 / 9 / 10$ & 92 & 18 & 74 & $25 / 11 / 10$ & 160 & 8 & 152 & $15 / 2 / 11$ & 65 & 10 & 55 \\
\hline $16 / 9 / 10$ & 76 & 50 & 26 & $29 / 11 / 10$ & 120 & 6 & 114 & $17 / 2 / 11$ & 50 & 15 & 35 \\
\hline $20 / 9 / 10$ & 86 & 2 & 84 & $2 / 12 / 10$ & 88 & 4 & 84 & $1 / 3 / 11$ & 70 & 10 & 60 \\
\hline $22 / 9 / 10$ & 276 & 12 & 264 & $6 / 12 / 10$ & 90 & 8 & 82 & $15 / 3 / 11$ & 150 & 20 & 130 \\
\hline $24 / 9 / 10$ & 90 & 10 & 80 & $8 / 12 / 10$ & 100 & 10 & 90 & $17 / 3 / 11$ & 80 & 15 & 65 \\
\hline $27 / 9 / 10$ & 102 & 2 & 100 & $10 / 12 / 10$ & 80 & 6 & 74 & $22 / 3 / 11$ & 78 & 8 & 70 \\
\hline $29 / 9 / 10$ & 98 & 2 & 96 & $13 / 12 / 10$ & 90 & 8 & 82 & $24 / 3 / 11$ & 100 & 12 & 88 \\
\hline $1 / 10 / 10$ & 124 & 16 & 108 & - & - & - & - & $29 / 3 / 11$ & 60 & 6 & 54 \\
\hline $5 / 10 / 10$ & 96 & 12 & 84 & - & - & - & - & $31 / 3 / 11$ & 70 & 12 & 58 \\
\hline- & - & - & - & - & - & - & - & $5 / 4 / 11$ & 80 & 10 & 70 \\
\hline- & - & - & - & - & - & - & - & $7 / 4 / 11$ & 90 & 8 & 82 \\
\hline- & - & - & - & - & - & - & - & $12 / 4 / 11$ & 108 & 12 & 96 \\
\hline- & - & - & - & - & - & - & - & $18 / 4 / 11$ & 120 & 16 & 104 \\
\hline
\end{tabular}


Tabela 3: Concentrações de sólidos totais e suas frações no efluente final

\begin{tabular}{|c|c|c|c|c|c|c|c|c|c|c|c|}
\hline \multicolumn{12}{|c|}{ Sólidos Totais - Efluente Final (mg.L-1) } \\
\hline \multicolumn{4}{|c|}{ Fase I } & \multicolumn{5}{|c|}{ Fase II } & \multicolumn{3}{|c|}{ Fase III } \\
\hline Data & Total & Fixo & Volátil & Data & Total & Fixo & Volátil & Data & Total & Fixo & Volátil \\
\hline $19 / 8 / 10$ & 370 & 290 & 80 & $19 / 10 / 10$ & 300 & 240 & 60 & $10 / 1 / 11$ & 350 & 220 & 130 \\
\hline $21 / 8 / 10$ & 320 & 260 & 60 & $25 / 10 / 10$ & 310 & 230 & 80 & $13 / 1 / 11$ & 370 & 270 & 100 \\
\hline $23 / 8 / 10$ & 370 & 300 & 70 & $27 / 10 / 10$ & 310 & 250 & 60 & $18 / 1 / 11$ & 370 & 250 & 120 \\
\hline $25 / 8 / 10$ & 310 & 240 & 70 & $3 / 11 / 10$ & 390 & 270 & 120 & $20 / 1 / 11$ & 550 & 450 & 100 \\
\hline $27 / 8 / 10$ & 320 & 260 & 60 & $5 / 11 / 10$ & 310 & 240 & 70 & $26 / 1 / 11$ & 510 & 320 & 190 \\
\hline $30 / 8 / 10$ & 340 & 270 & 70 & $9 / 11 / 10$ & 290 & 200 & 90 & $28 / 1 / 11$ & 500 & 300 & 200 \\
\hline $1 / 9 / 10$ & 320 & 250 & 70 & $11 / 11 / 10$ & 280 & 180 & 100 & $1 / 2 / 11$ & 580 & 350 & 230 \\
\hline $3 / 9 / 10$ & 300 & 220 & 80 & $16 / 11 / 10$ & 310 & 250 & 60 & $3 / 2 / 11$ & 550 & 270 & 280 \\
\hline $8 / 9 / 10$ & 330 & 270 & 60 & $19 / 11 / 10$ & 360 & 280 & 80 & $8 / 2 / 11$ & 530 & 240 & 290 \\
\hline $11 / 9 / 10$ & 320 & 250 & 70 & $23 / 11 / 10$ & 340 & 210 & 130 & $10 / 2 / 11$ & 500 & 350 & 150 \\
\hline $14 / 9 / 10$ & 380 & 240 & 140 & $25 / 11 / 10$ & 260 & 210 & 50 & $15 / 2 / 11$ & 580 & 220 & 360 \\
\hline $16 / 9 / 10$ & 300 & 220 & 80 & $29 / 11 / 10$ & 280 & 200 & 80 & $17 / 2 / 11$ & 500 & 290 & 210 \\
\hline $20 / 9 / 10$ & 370 & 240 & 130 & $2 / 12 / 10$ & 300 & 230 & 70 & $1 / 3 / 11$ & 450 & 240 & 210 \\
\hline $22 / 9 / 10$ & 370 & 260 & 110 & $6 / 12 / 10$ & 260 & 180 & 80 & $15 / 3 / 11$ & 400 & 210 & 190 \\
\hline $24 / 9 / 10$ & 400 & 280 & 120 & $8 / 12 / 10$ & 250 & 160 & 90 & $17 / 3 / 11$ & 420 & 210 & 210 \\
\hline $27 / 9 / 10$ & 320 & 250 & 70 & $10 / 12 / 10$ & 280 & 240 & 40 & $22 / 3 / 11$ & 380 & 230 & 150 \\
\hline $29 / 9 / 10$ & 370 & 290 & 80 & $13 / 12 / 10$ & 260 & 150 & 110 & $24 / 3 / 11$ & 340 & 190 & 150 \\
\hline $1 / 10 / 10$ & 330 & 220 & 110 & - & - & - & - & $29 / 3 / 11$ & 360 & 200 & 160 \\
\hline $5 / 10 / 10$ & 280 & 220 & 60 & - & - & - & - & $31 / 3 / 11$ & 290 & 180 & 110 \\
\hline- & - & - & - & - & - & - & - & $5 / 4 / 11$ & 310 & 200 & 110 \\
\hline- & - & - & - & - & - & - & - & $7 / 4 / 11$ & 300 & 190 & 110 \\
\hline- & - & - & - & - & - & - & - & $12 / 4 / 11$ & 330 & 210 & 120 \\
\hline- & - & - & - & - & - & - & - & $18 / 4 / 11$ & 290 & 200 & 90 \\
\hline
\end{tabular}

Tabela 4: Concentrações de sólidos em suspensão e suas frações no efluente final

\begin{tabular}{|c|c|c|c|c|c|c|c|c|c|c|c|}
\hline \multicolumn{12}{|c|}{ Sólidos em Suspensão - Efluente Final (mg.L-1) } \\
\hline \multicolumn{4}{|c|}{ Fase I } & \multicolumn{5}{|c|}{ Fase II } & \multicolumn{3}{|c|}{ Fase III } \\
\hline Data & Total & Fixo & Volátil & Data & Total & Fixo & Volátil & Data & Total & Fixo & Volátil \\
\hline $19 / 8 / 10$ & 9 & 3 & 6 & $19 / 10 / 10$ & 13 & 4 & 9 & $10 / 1 / 11$ & 10 & 2 & 8 \\
\hline $21 / 8 / 10$ & 11 & 2 & 9 & $25 / 10 / 10$ & 5 & 0 & 5 & $13 / 1 / 11$ & 12 & 2 & 10 \\
\hline $23 / 8 / 10$ & 10 & 0 & 10 & $27 / 10 / 10$ & 12 & 0 & 12 & $18 / 1 / 11$ & 16 & 2 & 14 \\
\hline $25 / 8 / 10$ & 8 & 0 & 8 & $3 / 11 / 10$ & 12 & 5 & 7 & $20 / 1 / 11$ & 6 & 2 & 4 \\
\hline $27 / 8 / 10$ & 7 & 0 & 7 & $5 / 11 / 10$ & 18 & 2 & 16 & $26 / 1 / 11$ & 10 & 4 & 6 \\
\hline $30 / 8 / 10$ & 5 & 0 & 5 & $9 / 11 / 10$ & 17 & 0 & 17 & $28 / 1 / 11$ & 8 & 3 & 5 \\
\hline $1 / 9 / 10$ & 4 & 0 & 4 & $11 / 11 / 10$ & 0 & 0 & 0 & $1 / 2 / 11$ & 5 & 2 & 3 \\
\hline $3 / 9 / 10$ & 18 & 8 & 10 & $16 / 11 / 10$ & 0 & 0 & 0 & $3 / 2 / 11$ & 8 & 4 & 4 \\
\hline $8 / 9 / 10$ & 1 & 0 & 1 & $19 / 11 / 10$ & 24 & 0 & 24 & $8 / 2 / 11$ & 10 & 4 & 6 \\
\hline $11 / 9 / 10$ & 2 & 0 & 2 & $23 / 11 / 10$ & 13 & 4 & 9 & $10 / 2 / 11$ & 2 & 0 & 2 \\
\hline $14 / 9 / 10$ & 11 & 6 & 5 & $25 / 11 / 10$ & 18 & 0 & 18 & $15 / 2 / 11$ & 6 & 3 & 3 \\
\hline $16 / 9 / 10$ & 4 & 2 & 2 & $29 / 11 / 10$ & 0 & 0 & 0 & $17 / 2 / 11$ & 12 & 4 & 8 \\
\hline $20 / 9 / 10$ & 9 & 0 & 9 & $2 / 12 / 10$ & 7 & 0 & 7 & $1 / 3 / 11$ & 15 & 5 & 10 \\
\hline $22 / 9 / 10$ & 19 & 6 & 13 & $6 / 12 / 10$ & 5 & 0 & 5 & $15 / 3 / 11$ & 5 & 0 & 5 \\
\hline $24 / 9 / 10$ & 32 & 7 & 25 & $8 / 12 / 10$ & 8 & 2 & 6 & $17 / 3 / 11$ & 15 & 5 & 10 \\
\hline $27 / 9 / 10$ & 28 & 16 & 12 & $10 / 12 / 10$ & 4 & 0 & 4 & $22 / 3 / 11$ & 5 & 0 & 5 \\
\hline $29 / 9 / 10$ & 32 & 13 & 19 & $13 / 12 / 10$ & 6 & 0 & 6 & $24 / 3 / 11$ & 10 & 2 & 8 \\
\hline $1 / 10 / 10$ & 16 & 5 & 11 & - & - & - & - & $29 / 3 / 11$ & 8 & 2 & 6 \\
\hline $5 / 10 / 10$ & 12 & 7 & 5 & - & - & - & - & $31 / 3 / 11$ & 6 & 3 & 3 \\
\hline- & - & - & - & - & - & - & - & $5 / 4 / 11$ & 4 & 0 & 4 \\
\hline- & - & - & - & - & - & - & - & $7 / 4 / 11$ & 6 & 2 & 4 \\
\hline- & - & - & - & - & - & - & - & $12 / 4 / 11$ & 2 & 0 & 2 \\
\hline- & - & - & - & - & - & - & - & $18 / 4 / 11$ & 5 & 0 & 5 \\
\hline
\end{tabular}


Tabela 5: Concentrações de sólidos totais e suas frações no licor misto

\begin{tabular}{|c|c|c|c|c|c|c|c|c|c|c|c|}
\hline \multicolumn{12}{|c|}{ Sólidos Totais - Licor Misto (mg.L-1) } \\
\hline \multicolumn{4}{|c|}{ Fase I } & \multicolumn{5}{|c|}{ Fase II } & \multicolumn{3}{|c|}{ Fase III } \\
\hline Data & Total & Fixo & Volátil & Data & Total & Fixo & Volátil & Data & Total & Fixo & Volátil \\
\hline $19 / 8 / 10$ & 5310 & 810 & 4500 & $19 / 10 / 10$ & 4190 & 630 & 3560 & $10 / 1 / 11$ & 3200 & 700 & 2500 \\
\hline $21 / 8 / 10$ & 5030 & 780 & 4250 & $25 / 10 / 10$ & 4390 & 610 & 3780 & $13 / 1 / 11$ & 3010 & 600 & 2410 \\
\hline $23 / 8 / 10$ & 4960 & 820 & 4140 & $27 / 10 / 10$ & 4510 & 750 & 3760 & $18 / 1 / 11$ & 3450 & 580 & 2870 \\
\hline $25 / 8 / 10$ & 5210 & 770 & 4440 & $3 / 11 / 10$ & 4590 & 840 & 3750 & $20 / 1 / 11$ & 3700 & 790 & 2910 \\
\hline $27 / 8 / 10$ & 5130 & 800 & 4330 & $5 / 11 / 10$ & 4500 & 600 & 3900 & $26 / 1 / 11$ & 3500 & 640 & 2860 \\
\hline $30 / 8 / 10$ & 5300 & 840 & 4460 & $9 / 11 / 10$ & 4150 & 650 & 3500 & $28 / 1 / 11$ & 3750 & 800 & 2950 \\
\hline $1 / 9 / 10$ & 5260 & 860 & 4400 & $11 / 11 / 10$ & 4200 & 700 & 3500 & $1 / 2 / 11$ & 3700 & 700 & 3000 \\
\hline $3 / 9 / 10$ & 4880 & 840 & 4040 & $16 / 11 / 10$ & 4250 & 630 & 3620 & $3 / 2 / 11$ & 3800 & 860 & 2940 \\
\hline $8 / 9 / 10$ & 4450 & 830 & 3620 & $19 / 11 / 10$ & 4100 & 600 & 3500 & $8 / 2 / 11$ & 4100 & 610 & 3490 \\
\hline $11 / 9 / 10$ & 4600 & 870 & 3730 & $23 / 11 / 10$ & 4250 & 830 & 3420 & $10 / 2 / 11$ & 4500 & 480 & 4020 \\
\hline $14 / 9 / 10$ & 4520 & 780 & 3740 & $25 / 11 / 10$ & 4300 & 610 & 3690 & $15 / 2 / 11$ & 4300 & 650 & 3650 \\
\hline $16 / 9 / 10$ & 4500 & 650 & 3850 & $29 / 11 / 10$ & 4330 & 740 & 3590 & $17 / 2 / 11$ & 4000 & 580 & 3420 \\
\hline $20 / 9 / 10$ & 4140 & 690 & 3450 & $2 / 12 / 10$ & 4210 & 680 & 3530 & $1 / 3 / 11$ & 2750 & 640 & 2110 \\
\hline $22 / 9 / 10$ & 4040 & 690 & 3350 & $6 / 12 / 10$ & 4330 & 630 & 3700 & $15 / 3 / 11$ & 3500 & 620 & 2880 \\
\hline $24 / 9 / 10$ & 3920 & 680 & 3240 & $8 / 12 / 10$ & 4250 & 610 & 3640 & $17 / 3 / 11$ & 3790 & 660 & 3130 \\
\hline $27 / 9 / 10$ & 3800 & 550 & 3250 & $10 / 12 / 10$ & 4350 & 740 & 3610 & $22 / 3 / 11$ & 3800 & 630 & 3170 \\
\hline $29 / 9 / 10$ & 3970 & 470 & 3500 & $13 / 12 / 10$ & 4400 & 630 & 3770 & $24 / 3 / 11$ & 3850 & 660 & 3190 \\
\hline $1 / 10 / 10$ & 3700 & 650 & 3050 & & & & & $29 / 3 / 11$ & 3860 & 600 & 3260 \\
\hline \multirow[t]{5}{*}{$5 / 10 / 10$} & 3760 & 650 & 3110 & & & & & $31 / 3 / 11$ & 3990 & 620 & 3370 \\
\hline & & & & & & & & $5 / 4 / 11$ & 4200 & 760 & 3440 \\
\hline & & & & & & & & $7 / 4 / 11$ & 4400 & 800 & 3600 \\
\hline & & & & & & & & $12 / 4 / 11$ & 4660 & 820 & 3840 \\
\hline & & & & & & & & $18 / 4 / 11$ & 4330 & 800 & 3530 \\
\hline
\end{tabular}

Tabela 6: Concentrações de sólidos em suspensão e suas frações no licor misto

\begin{tabular}{|c|c|c|c|c|c|c|c|c|c|c|c|}
\hline \multicolumn{12}{|c|}{ Sólidos em Suspensão - Licor Misto (mg.L-1) } \\
\hline \multicolumn{4}{|c|}{ Fase I } & \multicolumn{5}{|c|}{ Fase II } & \multicolumn{3}{|c|}{ Fase III } \\
\hline Data & Total & Fixo & Volátil & Data & Total & Fixo & Volátil & Data & Total & Fixo & Volátil \\
\hline $19 / 8 / 10$ & 4545 & 570 & 3975 & $19 / 10 / 10$ & 4005 & 520 & 3485 & $10 / 1 / 11$ & 2800 & 480 & 2320 \\
\hline $21 / 8 / 10$ & 4255 & 415 & 3840 & $25 / 10 / 10$ & 4405 & 625 & 3780 & $13 / 1 / 11$ & 2915 & 525 & 2390 \\
\hline $23 / 8 / 10$ & 4405 & 545 & 3860 & $27 / 10 / 10$ & 4205 & 615 & 3590 & $18 / 1 / 11$ & 3360 & 555 & 2805 \\
\hline $25 / 8 / 10$ & 4410 & 555 & 3855 & $3 / 11 / 10$ & 4335 & 665 & 3670 & $20 / 1 / 11$ & 3410 & 585 & 2825 \\
\hline $27 / 8 / 10$ & 4335 & 460 & 3875 & $5 / 11 / 10$ & 4465 & 665 & 3800 & $26 / 1 / 11$ & 3350 & 540 & 2810 \\
\hline $30 / 8 / 10$ & 4360 & 565 & 3795 & $9 / 11 / 10$ & 3800 & 550 & 3250 & $28 / 1 / 11$ & 3450 & 550 & 2900 \\
\hline $1 / 9 / 10$ & 4730 & 760 & 3970 & $11 / 11 / 10$ & 3950 & 550 & 3400 & $1 / 2 / 11$ & 3250 & 520 & 2730 \\
\hline $3 / 9 / 10$ & 4510 & 785 & 3725 & $16 / 11 / 10$ & 4050 & 800 & 3250 & $3 / 2 / 11$ & 3045 & 625 & 2420 \\
\hline $8 / 9 / 10$ & 4125 & 595 & 3530 & $19 / 11 / 10$ & 4000 & 675 & 3325 & $8 / 2 / 11$ & 3800 & 500 & 3300 \\
\hline $11 / 9 / 10$ & 4335 & 630 & 3705 & $23 / 11 / 10$ & 4060 & 665 & 3395 & $10 / 2 / 11$ & 4200 & 550 & 3980 \\
\hline $14 / 9 / 10$ & 4120 & 655 & 3465 & $25 / 11 / 10$ & 4100 & 810 & 3290 & $15 / 2 / 11$ & 4250 & 620 & 3630 \\
\hline $16 / 9 / 10$ & 4475 & 770 & 3705 & $29 / 11 / 10$ & 3800 & 550 & 3250 & $17 / 2 / 11$ & 4000 & 600 & 3400 \\
\hline $20 / 9 / 10$ & 3885 & 625 & 3260 & $2 / 12 / 10$ & 3725 & 480 & 3245 & $1 / 3 / 11$ & 2500 & 500 & 2000 \\
\hline $22 / 9 / 10$ & 3770 & 535 & 3235 & $6 / 12 / 10$ & 3950 & 700 & 3250 & $15 / 3 / 11$ & 3215 & 540 & 2675 \\
\hline $24 / 9 / 10$ & 3570 & 495 & 3075 & $8 / 12 / 10$ & 4000 & 650 & 3350 & $17 / 3 / 11$ & 3540 & 600 & 2940 \\
\hline $27 / 9 / 10$ & 3605 & 480 & 3125 & $10 / 12 / 10$ & 4100 & 650 & 3450 & $22 / 3 / 11$ & 3560 & 620 & 2940 \\
\hline $29 / 9 / 10$ & 3625 & 525 & 3100 & $13 / 12 / 10$ & 4200 & 600 & 3600 & $24 / 3 / 11$ & 3960 & 640 & 3320 \\
\hline $1 / 10 / 10$ & 3690 & 530 & 3160 & & & & & $29 / 3 / 11$ & 3850 & 645 & 3205 \\
\hline \multirow[t]{5}{*}{$5 / 10 / 10$} & 3770 & 740 & 3030 & & & & & $31 / 3 / 11$ & 3960 & 635 & 3325 \\
\hline & & & & & & & & $5 / 4 / 11$ & 3950 & 590 & 3360 \\
\hline & & & & & & & & $7 / 4 / 11$ & 3800 & 600 & 3200 \\
\hline & & & & & & & & $12 / 4 / 11$ & 3910 & 580 & 3330 \\
\hline & & & & & & & & $18 / 4 / 11$ & 3960 & 610 & 3350 \\
\hline
\end{tabular}


Tabela 7: Concentrações de sólidos totais e suas frações no retorno de lodo

\begin{tabular}{|c|c|c|c|c|c|c|c|c|c|c|c|}
\hline \multicolumn{12}{|c|}{ Sólidos Totais - Retorno de Lodo (mg.L-1) } \\
\hline \multicolumn{4}{|c|}{ Fase I } & \multicolumn{5}{|c|}{ Fase II } & \multicolumn{3}{|c|}{ Fase III } \\
\hline Data & Total & Fixo & Volátil & Data & Total & Fixo & Volátil & Data & Total & Fixo & Volátil \\
\hline $19 / 8 / 10$ & 5880 & 850 & 5030 & $19 / 10 / 10$ & 4380 & 600 & 3780 & $10 / 1 / 11$ & 3500 & 650 & 2850 \\
\hline $21 / 8 / 10$ & 5960 & 820 & 5140 & $25 / 10 / 10$ & 4850 & 700 & 4150 & $13 / 1 / 11$ & 3210 & 720 & 2490 \\
\hline $23 / 8 / 10$ & 5490 & 850 & 4640 & $27 / 10 / 10$ & 4740 & 780 & 3960 & $18 / 1 / 11$ & 3460 & 710 & 2750 \\
\hline $25 / 8 / 10$ & 6090 & 890 & 5200 & $3 / 11 / 10$ & 4620 & 730 & 3890 & $20 / 1 / 11$ & 3920 & 640 & 3280 \\
\hline $27 / 8 / 10$ & 5630 & 850 & 4780 & $5 / 11 / 10$ & 4690 & 790 & 3900 & $26 / 1 / 11$ & 4000 & 600 & 3400 \\
\hline $30 / 8 / 10$ & 5850 & 930 & 4920 & $9 / 11 / 10$ & 4700 & 650 & 4050 & $28 / 1 / 11$ & 3990 & 350 & 3640 \\
\hline $1 / 9 / 10$ & 5870 & 920 & 4950 & $11 / 11 / 10$ & 4650 & 700 & 3950 & $1 / 2 / 11$ & 3900 & 720 & 3180 \\
\hline $3 / 9 / 10$ & 5400 & 900 & 4500 & $16 / 11 / 10$ & 4600 & 680 & 3920 & $3 / 2 / 11$ & 4200 & 850 & 3350 \\
\hline $8 / 9 / 10$ & 4790 & 890 & 3900 & $19 / 11 / 10$ & 4500 & 860 & 3640 & $8 / 2 / 11$ & 4400 & 700 & 3700 \\
\hline $11 / 9 / 10$ & 5200 & 950 & 4250 & $23 / 11 / 10$ & 4450 & 730 & 3720 & $10 / 2 / 11$ & 4800 & 600 & 4200 \\
\hline $14 / 9 / 10$ & 4910 & 830 & 4080 & $25 / 11 / 10$ & 4730 & 870 & 3860 & $15 / 2 / 11$ & 4550 & 800 & 3750 \\
\hline $16 / 9 / 10$ & 4800 & 800 & 4000 & $29 / 11 / 10$ & 4650 & 750 & 3900 & $17 / 2 / 11$ & 4500 & 740 & 3760 \\
\hline $20 / 9 / 10$ & 4530 & 730 & 3800 & $2 / 12 / 10$ & 4600 & 700 & 3900 & $1 / 3 / 11$ & 3100 & 680 & 2420 \\
\hline $22 / 9 / 10$ & 4380 & 730 & 3650 & $6 / 12 / 10$ & 4500 & 650 & 3850 & $15 / 3 / 11$ & 3900 & 820 & 3080 \\
\hline $24 / 9 / 10$ & 3980 & 690 & 3290 & $8 / 12 / 10$ & 4600 & 640 & 3960 & $17 / 3 / 11$ & 3890 & 760 & 3130 \\
\hline $27 / 9 / 10$ & 4100 & 860 & 3240 & $10 / 12 / 10$ & 4650 & 680 & 3970 & $22 / 3 / 11$ & 4200 & 800 & 3400 \\
\hline $29 / 9 / 10$ & 4330 & 700 & 3630 & $13 / 12 / 10$ & 4700 & 600 & 4100 & $24 / 3 / 11$ & 4250 & 760 & 3490 \\
\hline $1 / 10 / 10$ & 4120 & 700 & 3420 & - & - & - & - & $29 / 3 / 11$ & 4025 & 690 & 3335 \\
\hline $5 / 10 / 10$ & 3870 & 570 & 3300 & - & - & - & - & $31 / 3 / 11$ & 4150 & 700 & 3450 \\
\hline- & - & - & - & - & - & - & - & $5 / 4 / 11$ & 4550 & 810 & 3740 \\
\hline- & - & - & - & - & - & - & - & $7 / 4 / 11$ & 4650 & 650 & 4000 \\
\hline- & - & - & - & - & - & - & - & $12 / 4 / 11$ & 5040 & 675 & 4365 \\
\hline- & - & - & - & - & - & - & - & $18 / 4 / 11$ & 4610 & 620 & 3990 \\
\hline
\end{tabular}

Tabela 8: Concentrações de sólidos em suspensão e suas frações no retorno de lodo

\begin{tabular}{|c|c|c|c|c|c|c|c|c|c|c|c|}
\hline \multicolumn{12}{|c|}{ Sólidos em Suspensão - Retorno de Lodo (mg.L-1) } \\
\hline \multicolumn{4}{|c|}{ Fase I } & \multicolumn{5}{|c|}{ Fase II } & \multicolumn{3}{|c|}{ Fase III } \\
\hline Data & Total & Fixo & Volátil & Data & Total & Fixo & Volátil & Data & Total & Fixo & Volátil \\
\hline $19 / 8 / 10$ & 5080 & 615 & 4465 & $19 / 10 / 10$ & 4405 & 680 & 3725 & $10 / 1 / 11$ & 3100 & 540 & 2560 \\
\hline $21 / 8 / 10$ & 4980 & 470 & 4510 & $25 / 10 / 10$ & 4795 & 690 & 4105 & $13 / 1 / 11$ & 3065 & 535 & 2530 \\
\hline $23 / 8 / 10$ & 4770 & 550 & 4220 & $27 / 10 / 10$ & 4505 & 670 & 3835 & $18 / 1 / 11$ & 3280 & 550 & 2730 \\
\hline $25 / 8 / 10$ & 5510 & 690 & 4820 & $3 / 11 / 10$ & 4535 & 705 & 3830 & $20 / 1 / 11$ & 3575 & 620 & 2955 \\
\hline $27 / 8 / 10$ & 4865 & 550 & 4315 & $5 / 11 / 10$ & 4560 & 700 & 3860 & $26 / 1 / 11$ & 3650 & 600 & 3050 \\
\hline $30 / 8 / 10$ & 4860 & 650 & 4210 & $9 / 11 / 10$ & 4395 & 710 & 3685 & $28 / 1 / 11$ & 3520 & 580 & 2940 \\
\hline $1 / 9 / 10$ & 5160 & 845 & 4315 & $11 / 11 / 10$ & 4400 & 700 & 3700 & $1 / 2 / 11$ & 3450 & 560 & 2890 \\
\hline $3 / 9 / 10$ & 5300 & 835 & 4465 & $16 / 11 / 10$ & 4210 & 650 & 3560 & $3 / 2 / 11$ & 3320 & 690 & 2630 \\
\hline $8 / 9 / 10$ & 4635 & 680 & 3955 & $19 / 11 / 10$ & 4400 & 780 & 3620 & $8 / 2 / 11$ & 3900 & 640 & 3260 \\
\hline $11 / 9 / 10$ & 4810 & 755 & 4055 & $23 / 11 / 10$ & 4350 & 705 & 3645 & $10 / 2 / 11$ & 4350 & 575 & 3775 \\
\hline $14 / 9 / 10$ & 4660 & 735 & 3925 & $25 / 11 / 10$ & 4595 & 740 & 3855 & $15 / 2 / 11$ & 4300 & 520 & 3780 \\
\hline $16 / 9 / 10$ & 4590 & 645 & 3945 & $29 / 11 / 10$ & 4035 & 635 & 3400 & $17 / 2 / 11$ & 4250 & 510 & 3740 \\
\hline $20 / 9 / 10$ & 4430 & 595 & 3835 & $2 / 12 / 10$ & 4100 & 680 & 3420 & $1 / 3 / 11$ & 2800 & 580 & 2220 \\
\hline $22 / 9 / 10$ & 4235 & 600 & 3635 & $6 / 12 / 10$ & 4250 & 710 & 3540 & $15 / 3 / 11$ & 3650 & 600 & 3050 \\
\hline $24 / 9 / 10$ & 3805 & 535 & 3270 & $8 / 12 / 10$ & 4300 & 720 & 3580 & $17 / 3 / 11$ & 3800 & 620 & 3180 \\
\hline $27 / 9 / 10$ & 3900 & 535 & 3365 & $10 / 12 / 10$ & 4450 & 680 & 3770 & $22 / 3 / 11$ & 3620 & 580 & 3040 \\
\hline $29 / 9 / 10$ & 4085 & 525 & 3560 & $13 / 12 / 10$ & 4420 & 710 & 3710 & $24 / 3 / 11$ & 3970 & 530 & 3440 \\
\hline $1 / 10 / 10$ & 4105 & 570 & 3535 & - & - & - & - & $29 / 3 / 11$ & 3900 & 520 & 3380 \\
\hline $5 / 10 / 10$ & 3855 & 310 & 3545 & - & - & - & - & $31 / 3 / 11$ & 3980 & 580 & 3400 \\
\hline- & - & - & - & - & - & - & - & $5 / 4 / 11$ & 4200 & 510 & 3690 \\
\hline- & - & - & - & - & - & - & - & $7 / 4 / 11$ & 3990 & 520 & 3470 \\
\hline- & - & - & - & - & - & - & - & $12 / 4 / 11$ & 4570 & 680 & 3890 \\
\hline- & - & - & - & - & - & - & - & $18 / 4 / 11$ & 3985 & 600 & 3385 \\
\hline
\end{tabular}




\section{APÊNDICE - B}

\section{Valores pontuais das determinações de DQO e DBO}

Tabela 1: Concentrações de DQO e DBO total e solúvel no esgoto sanitário

\begin{tabular}{|c|c|c|c|c|c|c|c|c|c|c|c|c|c|c|}
\hline \multicolumn{15}{|c|}{ DQO e DBO - Afluente (mg.L $\left.{ }^{-1}\right)$} \\
\hline \multirow{3}{*}{ Data } & \multicolumn{4}{|c|}{ FASE I } & \multicolumn{6}{|c|}{ FASE II } & \multicolumn{4}{|c|}{ FASE III } \\
\hline & \multicolumn{2}{|c|}{ DQO } & \multicolumn{2}{|c|}{ DBO } & \multirow{2}{*}{ Data } & \multicolumn{2}{|c|}{ DQO } & \multicolumn{2}{|c|}{ DBO } & \multirow{2}{*}{ Data } & \multicolumn{2}{|c|}{ DQO } & \multicolumn{2}{|c|}{ DBO } \\
\hline & total & Solúvel & total & Solúvel & & total & Solúvel & total & Solúvel & & total & Solúvel & total & Solúvel \\
\hline $19 / 8 / 10$ & 472 & 288 & 236 & 141 & $19 / 10 / 10$ & 576 & 184 & 288 & 90 & $10 / 1 / 11$ & 280 & 60 & 140 & 80 \\
\hline $21 / 8 / 10$ & 520 & 280 & 249 & 134 & $25 / 10 / 10$ & 464 & 216 & 232 & 106 & $13 / 1 / 11$ & 256 & 56 & 128 & 60 \\
\hline $23 / 8 / 10$ & 480 & 288 & 230 & 138 & $27 / 10 / 10$ & 504 & 400 & 252 & 195 & $18 / 1 / 11$ & 488 & 160 & 244 & 78 \\
\hline $25 / 8 / 10$ & 590 & 280 & 283 & 134 & $3 / 11 / 10$ & 664 & 320 & 332 & 156 & $20 / 1 / 11$ & 480 & 240 & 240 & 117 \\
\hline $27 / 8 / 10$ & 544 & 216 & 261 & 107 & $5 / 11 / 10$ & 528 & 240 & 264 & 117 & $26 / 1 / 11$ & 520 & 250 & 280 & 120 \\
\hline $30 / 8 / 10$ & 424 & 216 & 203 & 104 & $9 / 11 / 10$ & 440 & 280 & 220 & 137 & $28 / 1 / 11$ & 540 & 280 & 260 & 140 \\
\hline $1 / 9 / 10$ & 408 & 192 & 196 & 92 & $11 / 11 / 10$ & 504 & 320 & 252 & 156 & $1 / 2 / 11$ & 580 & 310 & 290 & 120 \\
\hline $3 / 9 / 10$ & 523 & 119 & 250 & 57 & $16 / 11 / 10$ & 488 & 280 & 244 & 137 & $3 / 2 / 11$ & 592 & 240 & 296 & 117 \\
\hline $8 / 9 / 10$ & 736 & 224 & 353 & 107 & $19 / 11 / 10$ & 536 & 280 & 268 & 140 & $8 / 2 / 11$ & 680 & 320 & 350 & 140 \\
\hline $11 / 9 / 10$ & 552 & 184 & 265 & 88 & $23 / 11 / 10$ & 480 & 240 & 240 & 117 & $10 / 2 / 11$ & 880 & 340 & 440 & 176 \\
\hline $14 / 9 / 10$ & 408 & 176 & 196 & 84 & $25 / 11 / 10$ & 520 & 280 & 260 & 137 & $15 / 2 / 11$ & 640 & 310 & 480 & 190 \\
\hline $16 / 9 / 10$ & 412 & 179 & 197 & 86 & $29 / 11 / 10$ & 600 & 296 & 300 & 145 & $17 / 2 / 11$ & 580 & 250 & 320 & 150 \\
\hline $20 / 9 / 10$ & 568 & 264 & 272 & 127 & $2 / 12 / 10$ & 640 & 312 & 320 & 152 & $1 / 3 / 11$ & 620 & 380 & 403 & 247 \\
\hline $22 / 9 / 10$ & 576 & 184 & 276 & 88 & $6 / 12 / 10$ & 550 & 285 & 280 & 142 & $15 / 3 / 11$ & 550 & 260 & 358 & 169 \\
\hline $24 / 9 / 10$ & 400 & 232 & 192 & 111 & $8 / 12 / 10$ & 500 & 270 & 263 & 150 & $17 / 3 / 11$ & 480 & 240 & 312 & 156 \\
\hline $27 / 9 / 10$ & 520 & 320 & 249 & 153 & $10 / 12 / 10$ & 530 & 250 & 244 & 124 & $22 / 3 / 11$ & 820 & 320 & 533 & 208 \\
\hline $29 / 9 / 10$ & 480 & 280 & 230 & 134 & $13 / 12 / 10$ & 600 & 310 & 312 & 160 & $24 / 3 / 11$ & 450 & 260 & 293 & 169 \\
\hline $1 / 10 / 10$ & 624 & 360 & 299 & 173 & - & - & - & - & - & $29 / 3 / 11$ & 530 & 280 & 345 & 182 \\
\hline $5 / 10 / 10$ & 471 & 235 & 225 & 113 & - & - & - & - & - & $31 / 3 / 11$ & 560 & 168 & 364 & 109 \\
\hline- & - & - & - & - & - & - & - & - & - & $5 / 4 / 11$ & 1040 & 680 & 676 & 442 \\
\hline- & - & - & - & - & - & - & - & - & - & $7 / 4 / 11$ & 680 & 310 & 442 & 202 \\
\hline- & - & - & - & - & - & - & - & - & - & $12 / 4 / 11$ & 696 & 384 & 452 & 250 \\
\hline- & - & - & - & - & - & - & - & - & - & $18 / 4 / 11$ & 552 & 384 & 359 & 250 \\
\hline
\end{tabular}

Tabela 2: Concentrações de DQO e DBO total e solúvel no efluente final após tratamento

\begin{tabular}{|c|c|c|c|c|c|c|c|c|c|c|c|c|c|c|}
\hline \multicolumn{15}{|c|}{ DQO e DBO - Efluente (mg.L $\left.{ }^{-1}\right)$} \\
\hline \multirow{3}{*}{ Data } & \multicolumn{4}{|c|}{ FASE I } & \multicolumn{6}{|c|}{ FASE II } & \multicolumn{4}{|c|}{ FASE III } \\
\hline & \multicolumn{2}{|c|}{ DQO } & \multicolumn{2}{|c|}{ DBO } & \multirow{2}{*}{ Data } & \multicolumn{2}{|c|}{ DQO } & \multicolumn{2}{|c|}{ DBO } & \multirow{2}{*}{ Data } & \multicolumn{2}{|c|}{ DQO } & \multicolumn{2}{|c|}{ DBO } \\
\hline & total & Solúvel & total & Solúvel & & total & Solúvel & total & Solúvel & & total & Solúvel & total & Solúvel \\
\hline $19 / 8 / 10$ & 72 & 48 & 38 & 23 & $19 / 10 / 10$ & 20 & 8 & 11 & 4 & $10 / 1 / 11$ & 4 & 2 & 2 & 2 \\
\hline $21 / 8 / 10$ & 80 & 60 & 38 & 29 & $25 / 10 / 10$ & 20 & 12 & 11 & 6 & $13 / 1 / 11$ & 4 & 2 & 2 & 2 \\
\hline $23 / 8 / 10$ & 96 & 80 & 46 & 38 & $27 / 10 / 10$ & 72 & 12 & 38 & 6 & $18 / 1 / 11$ & 4 & 2 & 2 & 2 \\
\hline $25 / 8 / 10$ & 54 & 35 & 26 & 17 & $3 / 11 / 10$ & 116 & 44 & 61 & 21 & $20 / 1 / 11$ & 4 & 2 & 2 & 2 \\
\hline $27 / 8 / 10$ & 40 & 28 & 19 & 13 & $5 / 11 / 10$ & 40 & 28 & 21 & 13 & $26 / 1 / 11$ & 10 & 6 & 4 & 2 \\
\hline $30 / 8 / 10$ & 44 & 28 & 21 & 13 & $9 / 11 / 10$ & 32 & 24 & 17 & 11 & $28 / 1 / 11$ & 15 & 8 & 7 & 4 \\
\hline $1 / 9 / 10$ & 23 & 24 & 23 & 12 & $11 / 11 / 10$ & 32 & 32 & 17 & 15 & $1 / 2 / 11$ & 20 & 10 & 10 & 4 \\
\hline $3 / 9 / 10$ & 11 & 20 & 11 & 9 & $16 / 11 / 10$ & 28 & 20 & 15 & 10 & $3 / 2 / 11$ & 100 & 40 & 53 & 19 \\
\hline $8 / 9 / 10$ & 12 & 8 & 6 & 4 & $19 / 11 / 10$ & 92 & 40 & 48 & 19 & $8 / 2 / 11$ & 50 & 20 & 20 & 10 \\
\hline $11 / 9 / 10$ & 40 & 16 & 19 & 8 & $23 / 11 / 10$ & 16 & 4 & 8 & 5 & $10 / 2 / 11$ & 20 & 4 & 11 & 5 \\
\hline $14 / 9 / 10$ & 8 & 4 & 4 & 2 & $25 / 11 / 10$ & 20 & 8 & 11 & 4 & $15 / 2 / 11$ & 10 & 4 & 4 & 2 \\
\hline $16 / 9 / 10$ & 12 & 4 & 6 & 2 & $29 / 11 / 10$ & 20 & 8 & 12 & 6 & $17 / 2 / 11$ & 4 & 2 & 2 & 6 \\
\hline $20 / 9 / 10$ & 52 & 36 & 25 & 17 & $2 / 12 / 10$ & 8 & 4 & 4 & 4 & $1 / 3 / 11$ & 10 & 5 & 7 & 3 \\
\hline $22 / 9 / 10$ & 36 & 20 & 17 & 10 & $6 / 12 / 10$ & 10 & 10 & 15 & 8 & $15 / 3 / 11$ & 20 & 10 & 13 & 7 \\
\hline $24 / 9 / 10$ & 76 & 20 & 36 & 10 & $8 / 12 / 10$ & 15 & 8 & 25 & 5 & $17 / 3 / 11$ & 15 & 8 & 10 & 5 \\
\hline $27 / 9 / 10$ & 60 & 20 & 29 & 10 & $10 / 12 / 10$ & 20 & 5 & 10 & 7 & $22 / 3 / 11$ & 40 & 20 & 26 & 13 \\
\hline $29 / 9 / 10$ & 64 & 28 & 31 & 13 & $13 / 12 / 10$ & 35 & 15 & 16 & 12 & $24 / 3 / 11$ & 60 & 30 & 39 & 20 \\
\hline $1 / 10 / 10$ & 40 & 32 & 19 & 15 & - & - & - & - & - & $29 / 3 / 11$ & 40 & 20 & 26 & 13 \\
\hline $5 / 10 / 10$ & 63 & 20 & 30 & 9 & - & - & - & - & - & $31 / 3 / 11$ & 80 & 40 & 52 & 26 \\
\hline- & - & - & - & - & - & - & - & - & - & $5 / 4 / 11$ & 72 & 40 & 47 & 26 \\
\hline- & - & - & - & - & - & - & - & - & - & $7 / 4 / 11$ & 40 & 10 & 26 & 7 \\
\hline- & - & - & - & - & - & - & - & - & - & $12 / 4 / 11$ & 32 & 4 & 21 & 3 \\
\hline- & - & - & - & - & - & - & - & - & - & $18 / 4 / 11$ & 16 & 4 & 10 & 3 \\
\hline
\end{tabular}




\section{APÊNDICE - C}

\section{Valores pontuais das determinações de nitrogênio}

Tabela 1: Concentrações de NKT, N-orgânico e amoniacal no esgoto sanitário

\begin{tabular}{|c|c|c|c|c|c|c|c|c|c|c|c|}
\hline \multicolumn{12}{|c|}{ Afluente (mgN.L ${ }^{-1}$ ) } \\
\hline \multicolumn{4}{|c|}{ Fase I } & \multicolumn{5}{|c|}{ Fase II } & \multicolumn{3}{|c|}{ Fase III } \\
\hline $19 / 08 / 10$ & 95,2 & 19,6 & 75,6 & $19 / 10 / 10$ & 81,2 & 5,6 & 75,6 & $10 / 01 / 11$ & 43,7 & 4,5 & 39,2 \\
\hline $23 / 08 / 10$ & 81,2 & 16,8 & 64,4 & $27 / 10 / 10$ & 81,2 & 7,3 & 73,9 & $18 / 01 / 11$ & 72,8 & 21,8 & 51,0 \\
\hline $25 / 08 / 10$ & 100,8 & 21,3 & 79,5 & $03 / 11 / 10$ & 84,0 & 19,6 & 64,4 & $20 / 01 / 11$ & 67,2 & 15,1 & 52,1 \\
\hline $27 / 08 / 10$ & 86,8 & 16,8 & 70,0 & $05 / 11 / 10$ & 85,1 & 21,8 & 63,3 & $26 / 01 / 11$ & 70,0 & 16,8 & 53,2 \\
\hline $01 / 09 / 10$ & 84,0 & 10,1 & 73,9 & $11 / 11 / 10$ & 81,2 & 16,8 & 64,4 & $01 / 02 / 11$ & 62,7 & 10,6 & 52,1 \\
\hline $03 / 09 / 10$ & 53,8 & 1,7 & 52,1 & $16 / 11 / 10$ & 84,0 & 16,8 & 67,2 & $03 / 02 / 11$ & 56,0 & 8,4 & 47,6 \\
\hline $08 / 09 / 10$ & 57,7 & 5,0 & 52,6 & $19 / 11 / 10$ & 72,8 & 5,6 & 67,2 & $08 / 02 / 11$ & 64,4 & 11,8 & 52,6 \\
\hline $11 / 09 / 10$ & 66,6 & 3,9 & 62,7 & $23 / 11 / 10$ & 75,6 & 14,0 & 61,6 & $10 / 02 / 11$ & 61,6 & 11,2 & 50,4 \\
\hline $14 / 09 / 10$ & 72,8 & 15,7 & 57,1 & $25 / 11 / 10$ & 78,4 & 14,0 & 64,4 & $15 / 02 / 11$ & 58,8 & 8,4 & 50,4 \\
\hline $16 / 09 / 10$ & 78,4 & 12,9 & 65,5 & $29 / 11 / 10$ & 64,4 & 5,6 & 58,8 & $17 / 02 / 11$ & 67,2 & 14,0 & 53,2 \\
\hline $27 / 09 / 10$ & 72,8 & 19,6 & 53,2 & $10 / 12 / 10$ & 67,2 & 5,6 & 61,6 & $22 / 03 / 11$ & 60,0 & 7,0 & 53,0 \\
\hline $29 / 09 / 10$ & 67,2 & 16,8 & 50,4 & $13 / 12 / 10$ & 58,8 & 2,8 & 56,0 & $24 / 03 / 11$ & 72,0 & 17,0 & 55,0 \\
\hline $01 / 10 / 10$ & 89,6 & 37,5 & 52,1 & - & - & - & - & $29 / 03 / 11$ & 60,0 & 5,0 & 55,0 \\
\hline $05 / 10 / 10$ & 78,4 & 22,4 & 56,0 & - & - & - & - & $31 / 03 / 11$ & 61,6 & 7,3 & 54,3 \\
\hline- & - & - & - & - & - & - & - & $05 / 04 / 11$ & 58,8 & 6,7 & 52,1 \\
\hline- & - & - & - & - & - & - & - & $07 / 04 / 11$ & 55,0 & 4,0 & 51,0 \\
\hline- & - & - & - & - & - & - & - & $12 / 04 / 11$ & 56,0 & 2,8 & 53,2 \\
\hline- & - & - & - & - & - & - & - & $18 / 04 / 11$ & 52,0 & 2,0 & 50,0 \\
\hline
\end{tabular}

Tabela 2: Concentrações de NKT, N-orgânico e amoniacal no efluente final após o tratamento

\begin{tabular}{|c|c|c|c|c|c|c|c|c|c|c|c|}
\hline \multicolumn{12}{|c|}{ Efluente (mgN.L $\left.{ }^{-1}\right)$} \\
\hline \multicolumn{4}{|c|}{ Fase I } & \multicolumn{5}{|c|}{ Fase II } & \multicolumn{3}{|c|}{ Fase III } \\
\hline DATA & NKT & N org. & $\mathbf{N H}_{3}$ & DATA & NKT & N org. & $\mathbf{N H}_{3}$ & DATA & NKT & N org. & $\mathrm{NH}_{3}$ \\
\hline $19 / 08 / 10$ & 7,5 & 1,9 & 5,6 & $19 / 10 / 10$ & 9,5 & 3,9 & 5,6 & $10 / 01 / 11$ & 6,7 & 2,2 & 4,5 \\
\hline $21 / 08 / 10$ & 8,0 & 2,4 & 5,6 & $25 / 10 / 10$ & 7,3 & 4,5 & 2,8 & $13 / 01 / 11$ & 11,2 & 5,6 & 5,6 \\
\hline $23 / 08 / 10$ & 9,0 & 1,2 & 7,8 & $27 / 10 / 10$ & 7,3 & 3,9 & 3,4 & 18/01/11 & 2,8 & 2,8 & 0,0 \\
\hline $25 / 08 / 10$ & 6,5 & 0,9 & 5,6 & 03/11/10 & 4,5 & 2,2 & 2,2 & $20 / 01 / 11$ & 3,4 & 3,4 & 0,0 \\
\hline $27 / 08 / 10$ & 7,3 & 3,4 & 3,9 & $05 / 11 / 10$ & 3,4 & 1,7 & 1,7 & $26 / 01 / 11$ & 5,6 & 2,2 & 3,4 \\
\hline $30 / 08 / 10$ & 9,5 & 3,9 & 5,6 & $09 / 11 / 10$ & 3,9 & 2,2 & 1,7 & $28 / 01 / 11$ & 5,0 & 2,2 & 2,8 \\
\hline $01 / 09 / 10$ & 5,6 & 2,8 & 2,8 & $11 / 11 / 10$ & 4,5 & 1,7 & 2,8 & $01 / 02 / 11$ & 3,4 & 1,1 & 2,2 \\
\hline $03 / 09 / 10$ & 1,1 & 0,6 & 0,6 & $16 / 11 / 10$ & 5,0 & 1,7 & 3,4 & $03 / 02 / 11$ & 5,6 & 2,8 & 2,8 \\
\hline $08 / 09 / 10$ & 1,1 & 1,1 & 0,0 & $19 / 11 / 10$ & 3,4 & 1,1 & 2,2 & $08 / 02 / 11$ & 8,4 & 6,7 & 1,7 \\
\hline $11 / 09 / 10$ & 1,7 & 1,7 & 0,0 & $23 / 11 / 10$ & 5,6 & 1,7 & 3,9 & $10 / 02 / 11$ & 6,2 & 3,9 & 2,2 \\
\hline $14 / 09 / 10$ & 2,8 & 2,2 & 0,6 & $25 / 11 / 10$ & 4,5 & 1,7 & 2,8 & $15 / 02 / 11$ & 5,6 & 3,9 & 1,7 \\
\hline $16 / 09 / 10$ & 1,1 & 1,1 & 0,0 & $29 / 11 / 10$ & 2,8 & 2,2 & 0,6 & $17 / 02 / 11$ & 6,7 & 3,9 & 2,8 \\
\hline $20 / 09 / 10$ & 7,8 & 6,7 & 1,1 & $02 / 12 / 10$ & 2,8 & 2,8 & 0,0 & $01 / 03 / 11$ & 3,0 & 1,5 & 1,5 \\
\hline $22 / 09 / 10$ & 5,6 & 5,6 & 0,0 & $06 / 12 / 10$ & 3,4 & 1,7 & 1,7 & $15 / 03 / 11$ & 7,5 & 3,0 & 4,5 \\
\hline $24 / 09 / 10$ & 8,0 & 6,3 & 1,7 & $08 / 12 / 10$ & 2,2 & 1,1 & 1,1 & $17 / 03 / 11$ & 4,0 & 2,7 & 1,3 \\
\hline $27 / 09 / 10$ & 8,4 & 6,2 & 2,2 & $10 / 12 / 10$ & 2,2 & 1,7 & 0,6 & $22 / 03 / 11$ & 3,0 & 2,0 & 1,0 \\
\hline $29 / 09 / 10$ & 5,6 & 2,8 & 2,8 & $13 / 12 / 10$ & 1,7 & 0,6 & 1,1 & $24 / 03 / 11$ & 2,5 & 2,0 & 0,5 \\
\hline $01 / 10 / 10$ & 9,0 & 3,4 & 5,6 & - & - & - & - & $29 / 03 / 11$ & 4,0 & 3,5 & 0,5 \\
\hline $05 / 10 / 10$ & 6,7 & 3,4 & 3,4 & - & - & - & - & $31 / 03 / 11$ & 4,5 & 1,7 & 2,8 \\
\hline- & - & - & - & - & - & - & - & $05 / 04 / 11$ & 2,2 & 2,2 & 0,0 \\
\hline- & - & - & - & - & - & - & - & $07 / 04 / 11$ & 1,5 & 1,3 & 0,2 \\
\hline- & - & - & - & - & - & - & - & $12 / 04 / 11$ & 1,3 & 1,3 & 0,0 \\
\hline- & - & - & - & - & - & - & - & $18 / 04 / 11$ & 1,0 & 0,8 & 0,2 \\
\hline
\end{tabular}


Tabela 3: Concentrações de nitrito e nitrato no efluente final após tratamento

\begin{tabular}{|c|c|c|c|c|c|c|c|c|}
\hline \multicolumn{9}{|c|}{ Efluente (mgN.L $\left.{ }^{-1}\right)$} \\
\hline \multicolumn{3}{|c|}{ Fase I } & \multicolumn{3}{|c|}{ Fase II } & \multicolumn{3}{|c|}{ Fase III } \\
\hline DATA & $\mathrm{NO}_{2}^{-}$ & $\mathrm{NO}_{3}^{-}$ & DATA & $\mathrm{NO}_{2}^{-}$ & $\mathrm{NO}_{3}^{-}$ & DATA & $\mathrm{NO}_{2}^{-}$ & $\mathrm{NO}_{3}$ \\
\hline $19 / 08 / 10$ & 0,07 & 0,00 & $19 / 10 / 10$ & 0,67 & 5,00 & $10 / 01 / 11$ & 0,0 & 5,5 \\
\hline $23 / 08 / 10$ & 0,18 & 0,05 & $27 / 10 / 10$ & 0,04 & 6,80 & $18 / 01 / 11$ & 0,0 & 8,5 \\
\hline $25 / 08 / 10$ & 0,16 & 0,08 & $03 / 11 / 10$ & 0,07 & 5,50 & $20 / 01 / 11$ & 0,0 & 10,0 \\
\hline $01 / 09 / 10$ & 0,39 & 0,10 & $11 / 11 / 10$ & 0,25 & 4,80 & $01 / 02 / 11$ & 0,0 & 14,0 \\
\hline $03 / 09 / 10$ & 0,43 & 1,25 & $16 / 11 / 10$ & 0,14 & 6,80 & $03 / 02 / 11$ & 0,0 & 11,8 \\
\hline $08 / 09 / 10$ & 0,11 & 1,72 & $19 / 11 / 10$ & 0,30 & 5,00 & $08 / 02 / 11$ & 0,0 & 10,2 \\
\hline $11 / 09 / 10$ & 0,15 & 1,69 & $23 / 11 / 10$ & 0,17 & 4,77 & $10 / 02 / 11$ & 0,0 & 8,5 \\
\hline $14 / 09 / 10$ & 0,14 & 1,60 & $25 / 11 / 10$ & 0,20 & 5,82 & $15 / 02 / 11$ & 0,0 & 6,8 \\
\hline $27 / 09 / 10$ & 0,19 & 0,83 & $10 / 12 / 10$ & 0,21 & 6,34 & $22 / 03 / 11$ & 0,0 & 1,3 \\
\hline $29 / 09 / 10$ & 0,12 & 0,66 & $13 / 12 / 10$ & 0,19 & 7,77 & $24 / 03 / 11$ & 0,0 & 1,0 \\
\hline $01 / 10 / 10$ & 0,01 & 0,59 & - & - & - & $29 / 03 / 11$ & 0,0 & 5,2 \\
\hline $05 / 10 / 10$ & 0,04 & 0,78 & - & - & - & $31 / 03 / 11$ & 0,0 & 5,8 \\
\hline- & - & - & - & - & - & $05 / 04 / 11$ & 0,0 & 5,5 \\
\hline- & - & - & - & - & - & $07 / 04 / 11$ & 0,0 & 6,0 \\
\hline- & - & - & - & - & - & $12 / 04 / 11$ & 0,0 & 5,2 \\
\hline- & - & - & - & - & - & $18 / 04 / 11$ & 0,0 & 5,3 \\
\hline
\end{tabular}




\section{APÊNDICE - D}

\section{Valores pontuais das determinações de alcalinidade}

Tabela 1: Concentrações de alcalinidade no afluente e efluente durante as Fases I, II e III.

\begin{tabular}{|c|c|c|c|c|c|c|c|c|}
\hline \multicolumn{9}{|c|}{ Alcalinidade total Afluente e Efluente - $\left(\mathrm{mgCaCO}_{3} \cdot \mathrm{L}^{-1}\right)$} \\
\hline & Fase I & & & Fase II & & & Fase III & \\
\hline DATA & Afluente & Efluente & DATA & Afluente & Efluente & DATA & Afluente & Efluente \\
\hline $19 / 08 / 2010$ & 200 & 40 & $19 / 10 / 2010$ & 240 & 50 & $10 / 01 / 2011$ & 180 & 100 \\
\hline $21 / 08 / 2010$ & 220 & 35 & $25 / 10 / 2010$ & 230 & 15 & $13 / 01 / 2011$ & 190 & 130 \\
\hline $23 / 08 / 2010$ & 240 & 25 & $27 / 10 / 2010$ & 245 & 45 & $18 / 01 / 2011$ & 230 & 100 \\
\hline $25 / 08 / 2010$ & 235 & 38 & $03 / 11 / 2010$ & 250 & 50 & $20 / 01 / 2011$ & 220 & 180 \\
\hline $27 / 08 / 2010$ & 210 & 20 & $05 / 11 / 2010$ & 220 & 60 & $26 / 01 / 2011$ & 225 & 100 \\
\hline $30 / 08 / 2010$ & 215 & 15 & $09 / 11 / 2010$ & 230 & 50 & $28 / 01 / 2011$ & 180 & 90 \\
\hline $01 / 09 / 2010$ & 220 & 20 & $11 / 11 / 2010$ & 240 & 45 & $01 / 02 / 2011$ & 185 & 85 \\
\hline $03 / 09 / 2010$ & 225 & 18 & $16 / 11 / 2010$ & 225 & 40 & $03 / 02 / 2011$ & 175 & 80 \\
\hline $08 / 09 / 2010$ & 240 & 15 & $19 / 11 / 2010$ & 250 & 50 & $08 / 02 / 2011$ & 180 & 110 \\
\hline $11 / 09 / 2010$ & 243 & 20 & $23 / 11 / 2010$ & 236 & 60 & $10 / 02 / 2011$ & 180 & 120 \\
\hline $14 / 09 / 2010$ & 200 & 15 & $25 / 11 / 2010$ & 240 & 70 & $15 / 02 / 2011$ & 200 & 100 \\
\hline $16 / 09 / 2010$ & 218 & 20 & $29 / 11 / 2010$ & 245 & 45 & $17 / 02 / 2011$ & 210 & 80 \\
\hline $20 / 09 / 2010$ & 230 & 28 & $02 / 12 / 2010$ & 250 & 60 & $01 / 03 / 2011$ & 210 & 70 \\
\hline $22 / 09 / 2010$ & 192 & 30 & $06 / 12 / 2010$ & 210 & 55 & $15 / 03 / 2011$ & 270 & 110 \\
\hline $24 / 09 / 2010$ & 190 & 55 & $08 / 12 / 2010$ & 220 & 60 & $17 / 03 / 2011$ & 230 & 80 \\
\hline $27 / 09 / 2010$ & 185 & 60 & $10 / 12 / 2010$ & 200 & 55 & $22 / 03 / 2011$ & 200 & 55 \\
\hline $29 / 09 / 2010$ & 190 & 75 & $13 / 12 / 2010$ & 215 & 40 & $24 / 03 / 2011$ & 210 & 60 \\
\hline $01 / 10 / 2010$ & 200 & 70 & - & - & - & $29 / 03 / 2011$ & 190 & 70 \\
\hline $05 / 10 / 2001$ & 275 & 60 & - & - & - & $31 / 03 / 2011$ & 195 & 60 \\
\hline- & - & - & - & - & - & $05 / 04 / 2011$ & 170 & 60 \\
\hline- & - & - & - & - & - & $07 / 04 / 2011$ & 205 & 70 \\
\hline- & - & - & - & - & - & $12 / 04 / 2011$ & 210 & 80 \\
\hline- & - & - & - & - & - & $18 / 04 / 2011$ & 220 & 95 \\
\hline
\end{tabular}




\section{APÊNDICE - E}

Valores das médias diárias do monitoramento online do lodo

Tabela 1: Valores das médias diárias das determinações online de pH, OD, REDOX e temperatura durante as Fases I, II e III

\begin{tabular}{|c|c|c|c|c|c|c|c|c|c|c|c|c|c|c|}
\hline \multicolumn{15}{|c|}{ Medições online - Licor misto } \\
\hline \multicolumn{5}{|c|}{ Fase I } & \multicolumn{5}{|c|}{ Fase II } & \multicolumn{5}{|c|}{ Fase III } \\
\hline DATA & OD & REDOX & $\mathbf{T}\left({ }^{0} \mathbf{C}\right)$ & $\mathbf{p H}$ & DATA & OD & REDOX & $\mathbf{T}\left({ }^{\circ} \mathbf{C}\right)$ & $\mathbf{p H}$ & DATA & OD & REDOX & $\mathbf{T}\left({ }^{\circ} \mathbf{C}\right)$ & pH \\
\hline $21 / 08 / 10$ & 0,44 & 82 & 22,0 & 6,8 & $19 / 10 / 10$ & 0,58 & 148 & 20,1 & 6,7 & $13 / 01 / 11$ & 0,45 & 114 & 22,5 & 6,7 \\
\hline $22 / 08 / 10$ & 0,46 & 112 & 20,3 & 6,8 & $20 / 10 / 10$ & 0,70 & 147 & 21,1 & 6,8 & $14 / 01 / 11$ & 0,36 & 113 & 23,8 & 6,9 \\
\hline $23 / 08 / 10$ & 0,43 & 123 & 21,4 & 6,8 & $21 / 10 / 10$ & 0,65 & 146 & 21,8 & 6,8 & $15 / 01 / 11$ & 0,42 & 109 & 22,9 & 6,9 \\
\hline $24 / 08 / 10$ & 0,40 & 124 & 19,9 & 6,8 & $22 / 10 / 10$ & 0,73 & 144 & 22,2 & 6,8 & $16 / 01 / 11$ & 0,38 & 109 & 22,3 & 6,9 \\
\hline $25 / 08 / 10$ & 0,41 & 123 & 24,1 & 6,8 & $23 / 10 / 10$ & 0,72 & 147 & 21,3 & 6,8 & $17 / 01 / 11$ & 0,34 & 112 & 26,9 & 6,7 \\
\hline $26 / 08 / 10$ & 0,37 & 126 & 23,6 & 6,9 & $24 / 10 / 10$ & 0,61 & 148 & 23,0 & 6,8 & $18 / 01 / 11$ & 0,31 & 108 & 25,5 & 7,0 \\
\hline $27 / 08 / 10$ & 0,59 & 123 & 23,2 & 6,9 & $25 / 10 / 10$ & 0,52 & 147 & 20,5 & 6,8 & $19 / 01 / 11$ & 0,28 & 104 & 26,2 & 7,0 \\
\hline $28 / 08 / 10$ & 0,39 & 123 & 23,2 & 6,9 & $26 / 10 / 10$ & 0,50 & 146 & 21,3 & 6,8 & $20 / 01 / 11$ & 0,22 & 102 & 26,5 & 7,0 \\
\hline $29 / 08 / 10$ & 0,62 & 122 & 24,7 & 6,9 & $27 / 10 / 10$ & 0,52 & 144 & 17,8 & 6,8 & $21 / 01 / 11$ & 0,26 & 100 & 25,4 & 6,7 \\
\hline $30 / 08 / 10$ & 0,37 & 124 & 21,0 & 6,9 & $28 / 10 / 10$ & 0,51 & 144 & 23,6 & 6,8 & $22 / 01 / 11$ & 0,28 & 93 & 25,0 & 6,5 \\
\hline $31 / 08 / 10$ & 0,41 & 124 & 21,9 & 6,9 & $29 / 10 / 10$ & 0,52 & 145 & 20,5 & 6,8 & $23 / 01 / 11$ & 0,25 & 88 & 26,0 & 6,7 \\
\hline $01 / 09 / 10$ & 0,44 & 125 & 23,0 & 6,9 & $30 / 10 / 10$ & 0,53 & 147 & 21,3 & 6,8 & $24 / 01 / 11$ & 0,24 & 91 & 25,5 & 6,5 \\
\hline $02 / 09 / 10$ & 0,39 & 121 & 24,5 & 6,9 & $31 / 10 / 10$ & 0,53 & 144 & 22,5 & 6,8 & $25 / 01 / 11$ & 0,27 & 98 & 23,6 & 6,6 \\
\hline $03 / 09 / 10$ & 0,38 & 124 & 20,2 & 6,9 & $01 / 11 / 10$ & 0,51 & 129 & 21,8 & 6,8 & $26 / 01 / 11$ & 0,25 & 93 & 23,9 & 6,6 \\
\hline $04 / 09 / 10$ & 0,37 & 125 & 22,4 & 6,9 & $02 / 11 / 10$ & 0,51 & 136 & 22,3 & 6,7 & $27 / 01 / 11$ & 0,25 & 88 & 24,1 & 6,7 \\
\hline $05 / 09 / 10$ & 0,43 & 123 & 18,6 & 6,9 & $03 / 11 / 10$ & 0,51 & 136 & 23,0 & 6,7 & $28 / 01 / 11$ & 0,26 & 85 & 21,5 & 7,0 \\
\hline $06 / 09 / 10$ & 0,47 & 124 & 17,3 & 6,8 & $04 / 11 / 10$ & 0,49 & 136 & 23,5 & 6,8 & $29 / 01 / 11$ & 0,34 & 46 & 24,9 & 6,9 \\
\hline $07 / 09 / 10$ & 0,48 & 124 & 18,1 & 6,8 & $05 / 11 / 10$ & 0,46 & 145 & 24,9 & 6,8 & $30 / 01 / 11$ & 0,37 & 69 & 25,2 & 7,0 \\
\hline $08 / 09 / 10$ & 0,46 & 125 & 18,4 & 6,8 & $06 / 11 / 10$ & 0,48 & 148 & 21,0 & 6,8 & $31 / 01 / 11$ & 0,35 & 75 & 24,7 & 7,0 \\
\hline $09 / 09 / 10$ & 0,41 & 125 & 17,2 & 6,8 & $07 / 11 / 10$ & 0,50 & 135 & 22,0 & 6,8 & $01 / 02 / 11$ & 0,35 & 80 & 24,9 & 6,9 \\
\hline $10 / 09 / 10$ & 0,41 & 124 & 20,0 & 6,8 & $08 / 11 / 10$ & 0,52 & 136 & 21,5 & 6,7 & $02 / 02 / 11$ & 0,36 & 84 & 25,6 & 6,9 \\
\hline $11 / 09 / 10$ & 0,42 & 123 & 17,1 & 6,8 & $09 / 11 / 10$ & 0,51 & 128 & 20,5 & 6,7 & $03 / 02 / 11$ & 0,44 & 84 & 23,7 & 6,9 \\
\hline $12 / 09 / 10$ & 0,50 & 123 & 24,7 & 6,7 & $10 / 11 / 10$ & 0,50 & 129 & 22,0 & 6,8 & $04 / 02 / 11$ & 0,63 & 74 & 22,2 & 7,1 \\
\hline $13 / 09 / 10$ & 0,45 & 124 & 24,5 & 6,7 & $11 / 11 / 10$ & 0,48 & 132 & 21,0 & 6,8 & $05 / 02 / 11$ & 0,43 & 109 & 23,3 & 6,9 \\
\hline $14 / 09 / 10$ & 0,41 & 124 & 24,0 & 6,7 & $12 / 11 / 10$ & 0,49 & 135 & 20,5 & 6,9 & $06 / 02 / 11$ & 0,38 & 109 & 22,3 & 6,9 \\
\hline $15 / 09 / 10$ & 0,42 & 125 & 20,9 & 6,7 & $13 / 11 / 10$ & 0,52 & 125 & 20,0 & 6,9 & $07 / 02 / 11$ & 0,34 & 112 & 26,9 & 6,7 \\
\hline $16 / 09 / 10$ & 0,45 & 132 & 20,0 & 6,7 & $14 / 11 / 10$ & 0,50 & 124 & 21,0 & 6,8 & $08 / 02 / 11$ & 0,31 & 108 & 25,5 & 7,0 \\
\hline $17 / 09 / 10$ & 0,42 & 131 & 22,3 & 6,7 & $15 / 11 / 10$ & 0,48 & 120 & 20,5 & 6,8 & $09 / 02 / 11$ & 0,28 & 104 & 26,2 & 7,0 \\
\hline $18 / 09 / 10$ & 0,46 & 134 & 18,2 & 6,7 & $16 / 11 / 10$ & 0,52 & 137 & 20,3 & 6,7 & $10 / 02 / 11$ & 0,22 & 102 & 26,5 & 7,0 \\
\hline $19 / 09 / 10$ & 0,47 & 131 & 19,5 & 6,7 & $17 / 11 / 10$ & 0,52 & 135 & 21,7 & 6,7 & $11 / 02 / 11$ & 0,27 & 100 & 26,0 & 6,6 \\
\hline $20 / 09 / 10$ & 0,50 & 133 & 19,5 & 6,7 & $18 / 11 / 10$ & 0,49 & 128 & 22,9 & 6,9 & $12 / 02 / 11$ & 0,28 & 93 & 25,0 & 6,5 \\
\hline $21 / 09 / 10$ & 0,45 & 132 & 21,1 & 6,7 & $19 / 11 / 10$ & 0,52 & 100 & 20,0 & 6,9 & $13 / 02 / 11$ & 0,25 & 88 & 26,0 & 6,7 \\
\hline $22 / 09 / 10$ & 0,42 & 133 & 22,1 & 6,7 & $20 / 11 / 10$ & 0,54 & 94 & 18,4 & 6,9 & $14 / 02 / 11$ & 0,24 & 91 & 25,5 & 6,5 \\
\hline $23 / 09 / 10$ & 0,39 & 134 & 22,8 & 6,8 & $21 / 11 / 10$ & 0,48 & 120 & 26,9 & 6,8 & $15 / 02 / 11$ & 0,27 & 98 & 23,6 & 6,6 \\
\hline $24 / 09 / 10$ & 0,37 & 132 & 20,2 & 6,8 & $22 / 11 / 10$ & 0,49 & 120 & 23,4 & 6,6 & $16 / 02 / 11$ & 0,25 & 93 & 23,9 & 6,6 \\
\hline $25 / 09 / 10$ & 0,45 & 134 & 21,0 & 6,8 & $23 / 11 / 10$ & 0,47 & 123 & 22,4 & 6,5 & $17 / 02 / 11$ & 0,25 & 88 & 24,1 & 6,7 \\
\hline $26 / 09 / 10$ & 0,40 & 132 & 20,8 & 6,8 & $24 / 11 / 10$ & 0,46 & 124 & 23,1 & 6,5 & $18 / 02 / 11$ & 0,26 & 85 & 21,5 & 7,0 \\
\hline $27 / 09 / 10$ & 0,50 & 132 & 20,6 & 6,8 & $25 / 11 / 10$ & 0,41 & 117 & 23,7 & 6,5 & $19 / 02 / 11$ & 0,40 & 90 & 22,5 & 7,0 \\
\hline $28 / 09 / 10$ & 0,58 & 136 & 19,5 & 6,8 & $26 / 11 / 10$ & 0,39 & 114 & 22,7 & 6,6 & $20 / 02 / 11$ & 0,50 & 75 & 25,0 & 7,0 \\
\hline $29 / 09 / 10$ & 0,46 & 131 & 21,2 & 6,8 & $27 / 11 / 10$ & 0,35 & 112 & 23,9 & 6,6 & $21 / 02 / 11$ & 0,34 & 46 & 24,9 & 6,9 \\
\hline $30 / 09 / 10$ & 0,43 & 133 & 22,1 & 6,8 & $28 / 11 / 10$ & 0,34 & 115 & 24,9 & 6,5 & $22 / 02 / 11$ & 0,37 & 69 & 25,2 & 7,0 \\
\hline $01 / 10 / 10$ & 0,41 & 132 & 21,3 & 6,8 & $29 / 11 / 10$ & 0,26 & 103 & 25,0 & 6,5 & $23 / 02 / 11$ & 0,35 & 75 & 24,7 & 7,0 \\
\hline $02 / 10 / 10$ & 0,43 & 133 & 19,9 & 6,8 & $30 / 11 / 10$ & 0,35 & 114 & 23,8 & 6,6 & $24 / 02 / 11$ & 0,35 & 80 & 24,9 & 6,9 \\
\hline $03 / 10 / 10$ & 0,50 & 130 & 17,2 & 6,7 & $01 / 12 / 10$ & 0,39 & 113 & 24,2 & 6,8 & $25 / 02 / 11$ & 0,36 & 84 & 25,6 & 6,9 \\
\hline $04 / 10 / 10$ & 0,53 & 131 & 18,4 & 6,7 & $02 / 12 / 10$ & 0,38 & 112 & 25,3 & 6,9 & $26 / 02 / 11$ & 0,44 & 84 & 23,7 & 6,9 \\
\hline $05 / 10 / 10$ & 0,50 & 129 & 19,8 & 6,7 & $03 / 12 / 10$ & 0,32 & 127 & 25,5 & 6,9 & $27 / 02 / 11$ & 0,50 & 110 & 24,0 & 7,0 \\
\hline $06 / 10 / 10$ & 0,48 & 133 & 21,2 & 6,7 & $04 / 12 / 10$ & 0,50 & 111 & 25,1 & 7,1 & $28 / 02 / 11$ & 0,45 & 80 & 24,0 & 7,0 \\
\hline $07 / 10 / 10$ & 0,48 & 131 & 20,0 & 6,7 & $05 / 12 / 10$ & 0,45 & 125 & 24,9 & 6,8 & $01 / 03 / 11$ & 0,50 & 90 & 22,5 & 7,0 \\
\hline $08 / 10 / 10$ & 0,42 & 133 & 22,1 & 6,7 & $06 / 12 / 10$ & 0,58 & 80 & 24,8 & 7,2 & $02 / 03 / 11$ & 0,42 & 50 & 20,4 & 7,1 \\
\hline $09 / 10 / 10$ & 0,48 & 129 & 20,0 & 6,7 & $07 / 12 / 10$ & 0,60 & 95 & 22,5 & 7,2 & $03 / 03 / 11$ & 0,42 & 48 & 20,2 & 7,1 \\
\hline $10 / 10 / 10$ & 0,80 & 134 & 21,1 & 6,8 & $08 / 12 / 10$ & 0,42 & 107 & 26,6 & 6,6 & $04 / 03 / 11$ & 0,22 & 76 & 21,0 & 7,1 \\
\hline $11 / 10 / 10$ & 0,49 & 133 & 17,2 & 6,7 & $09 / 12 / 10$ & 0,41 & 112 & 26,2 & 6,9 & $05 / 03 / 11$ & 0,73 & 100 & 20,9 & 7,0 \\
\hline $12 / 10 / 10$ & 0,50 & 135 & 15,6 & 6,7 & $10 / 12 / 10$ & 0,42 & 104 & 22,4 & 7,2 & $06 / 03 / 11$ & 0,48 & 90 & 21,5 & 7,0 \\
\hline $13 / 10 / 10$ & 0,52 & 134 & 14,7 & 6,7 & $11 / 12 / 10$ & 0,44 & 98 & 22,8 & 7,0 & $07 / 03 / 11$ & 0,40 & 70 & 21,1 & 7,0 \\
\hline $14 / 10 / 10$ & 0,30 & 131 & 22,7 & 6,7 & $12 / 12 / 10$ & 0,47 & 104 & 22,9 & 6,9 & $08 / 03 / 11$ & 0,40 & 70 & 21,6 & 7,0 \\
\hline
\end{tabular}


Tabela 1 (continuação): Valores das médias diárias das determinações online de pH, OD, REDOX e temperatura durante as Fases I, II e III

\begin{tabular}{|c|c|c|c|c|c|c|c|c|c|c|c|c|c|c|}
\hline \multicolumn{15}{|c|}{ Medições online - Licor misto } \\
\hline \multicolumn{5}{|c|}{ Fase I } & \multicolumn{5}{|c|}{ Fase II } & \multicolumn{5}{|c|}{ Fase III } \\
\hline DATA & OD & REDOX & $\mathbf{T}\left({ }^{\circ} \mathbf{C}\right)$ & $\mathbf{p H}$ & DATA & OD & REDOX & $\mathbf{T}\left({ }^{\circ} \mathbf{C}\right)$ & $\mathbf{p H}$ & DATA & OD & REDOX & $\mathbf{T}\left({ }^{\circ} \mathbf{C}\right)$ & $\mathbf{p H}$ \\
\hline $15 / 10 / 10$ & 0,35 & 133 & 20,7 & 6,7 & $13 / 12 / 10$ & 0,36 & 69 & 28,1 & 6,7 & $09 / 03 / 11$ & 0,42 & 79 & 23,0 & 7,1 \\
\hline $16 / 10 / 10$ & 0,55 & 146 & 24,2 & 6,7 & $14 / 12 / 10$ & 0,47 & 115 & 24,3 & 6,7 & $10 / 03 / 11$ & 0,49 & 90 & 23,8 & 7,1 \\
\hline $17 / 10 / 10$ & 0,70 & 144 & 20,1 & 6,7 & $15 / 12 / 10$ & 0,48 & 121 & 24,4 & 6,6 & $11 / 03 / 11$ & 0,16 & 80 & 24,5 & 7,2 \\
\hline $18 / 10 / 10$ & 0,80 & 147 & 19,9 & 6,7 & $16 / 12 / 10$ & 0,50 & 123 & 22,7 & 6,0 & $12 / 03 / 11$ & 0,36 & 105 & 22,8 & 7,2 \\
\hline- & - & - & - & - & $17 / 12 / 10$ & 0,50 & 69 & 23,0 & 6,7 & $13 / 03 / 11$ & 0,57 & 82 & 23,6 & 7,2 \\
\hline- & - & - & - & - & $18 / 12 / 10$ & 0,64 & 113 & 24,2 & 6,2 & $14 / 03 / 11$ & 0,43 & 89 & 23,4 & 7,2 \\
\hline- & - & - & - & - & $19 / 12 / 10$ & 0,71 & 126 & 22,8 & 6,1 & $15 / 03 / 11$ & 0,44 & 127 & 22,9 & 7,2 \\
\hline- & - & - & - & - & $20 / 12 / 10$ & 0,44 & 100 & 24,3 & 7,1 & $16 / 03 / 11$ & 0,49 & 137 & 21,0 & 7,1 \\
\hline- & - & - & - & - & $21 / 12 / 10$ & 0,44 & 110 & 23,4 & 6,9 & $17 / 03 / 11$ & 0,56 & 124 & 22,9 & 7,2 \\
\hline- & - & - & - & - & $22 / 12 / 10$ & 0,46 & 95 & 24,7 & 6,6 & $18 / 03 / 11$ & 0,48 & 141 & 23,9 & 7,2 \\
\hline- & - & - & - & - & $23 / 12 / 10$ & 0,22 & 113 & 25,0 & 6,9 & $19 / 03 / 11$ & 0,43 & 110 & 21,3 & 7,2 \\
\hline- & - & - & - & - & $24 / 12 / 10$ & 0,73 & 70 & 22,6 & 7,4 & $20 / 03 / 11$ & 0,51 & 118 & 21,0 & 7,1 \\
\hline- & - & - & - & - & $25 / 12 / 10$ & 0,44 & 63 & 24,0 & 7,1 & $21 / 03 / 11$ & 0,49 & 120 & 22,3 & 7,2 \\
\hline- & - & - & - & - & $26 / 12 / 10$ & 0,42 & 92 & 24,5 & 6,8 & $22 / 03 / 11$ & 0,38 & 121 & 22,9 & 7,2 \\
\hline- & - & - & - & - & $27 / 12 / 10$ & 0,45 & 97 & 23,4 & 6,7 & $23 / 03 / 11$ & 0,30 & 109 & 23,5 & 7,2 \\
\hline- & - & - & - & - & $28 / 12 / 10$ & 0,54 & 102 & 24,4 & 6,8 & $24 / 03 / 11$ & 0,44 & 130 & 24,2 & 7,1 \\
\hline- & - & - & - & - & $29 / 12 / 10$ & 0,34 & 50 & 24,5 & 6,9 & $25 / 03 / 11$ & 0,21 & 130 & 24,1 & 7,2 \\
\hline- & - & - & - & - & $30 / 12 / 10$ & 0,48 & 87 & 24,8 & 6,9 & $26 / 03 / 11$ & 0,18 & 123 & 24,8 & 7,2 \\
\hline- & - & - & - & - & $31 / 12 / 10$ & 0,41 & 106 & 24,2 & 7,0 & $27 / 03 / 11$ & 0,40 & 132 & 24,7 & 7,2 \\
\hline- & - & - & - & - & $01 / 01 / 11$ & 0,37 & 114 & 24,0 & 7,1 & $28 / 03 / 11$ & 0,38 & 141 & 24,8 & 7,0 \\
\hline- & - & - & - & - & $02 / 01 / 11$ & 0,80 & 89 & 23,0 & 7,2 & $29 / 03 / 11$ & 0,27 & 145 & 23,1 & 7,0 \\
\hline- & - & - & - & - & $03 / 01 / 11$ & 0,50 & 24 & 24,5 & 7,0 & $30 / 03 / 11$ & 0,39 & 161 & 21,7 & 6,8 \\
\hline- & - & - & - & - & $04 / 01 / 11$ & 0,35 & 24 & 24,0 & 7,0 & $31 / 03 / 11$ & 0,39 & 160 & 22,5 & 6,8 \\
\hline- & - & - & - & - & $05 / 01 / 11$ & 0,55 & 89 & 25,0 & 6,8 & $01 / 04 / 11$ & 0,41 & 157 & 23,6 & 7,0 \\
\hline- & - & - & - & - & $06 / 01 / 11$ & 0,36 & 134 & 24,3 & 6,4 & $02 / 04 / 11$ & 0,72 & 84 & 23,8 & 7,1 \\
\hline- & - & - & - & - & $07 / 01 / 11$ & 0,40 & 137 & 24,6 & 6,7 & $03 / 04 / 11$ & 0,13 & 141 & 21,1 & 7,0 \\
\hline- & - & - & - & - & $08 / 01 / 11$ & 0,48 & 135 & 26,1 & 7,0 & $04 / 04 / 11$ & 0,45 & 144 & 20,9 & 6,8 \\
\hline- & - & - & - & - & $09 / 01 / 11$ & 0,45 & 123 & 25,9 & 7,0 & $05 / 04 / 11$ & 0,80 & 48 & 22,9 & 6,9 \\
\hline- & - & - & - & - & $10 / 01 / 11$ & 0,49 & 118 & 25,9 & 7,0 & $06 / 04 / 11$ & 0,41 & 46 & 21,9 & 7,0 \\
\hline- & - & - & - & - & $11 / 01 / 11$ & 0,47 & 119 & 26,0 & 7,0 & $07 / 04 / 11$ & 0,22 & 125 & 22,5 & 7,1 \\
\hline- & - & - & - & - & $12 / 01 / 11$ & 0,42 & 117 & 24,9 & 6,9 & $08 / 04 / 11$ & 0,26 & 131 & 22,0 & 6,9 \\
\hline- & - & - & - & - & - & - & - & - & - & $09 / 04 / 11$ & 0,19 & 134 & 21,3 & 6,9 \\
\hline- & - & - & - & - & - & - & - & - & - & $10 / 04 / 11$ & 0,71 & 136 & 20,9 & 6,9 \\
\hline- & - & - & - & - & - & - & - & - & - & $11 / 04 / 11$ & 0,34 & 150 & 18,6 & 6,9 \\
\hline- & - & - & - & - & - & - & - & - & - & $12 / 04 / 11$ & 0,50 & 120 & 23,0 & 7,0 \\
\hline- & - & - & - & - & - & - & - & - & - & $13 / 04 / 11$ & 0,49 & 89 & 22,6 & 7,0 \\
\hline- & - & - & - & - & - & - & - & - & - & $14 / 04 / 11$ & 0,54 & 143 & 23,8 & 6,9 \\
\hline- & - & - & - & - & - & - & - & - & - & $15 / 04 / 11$ & 0,53 & 140 & 24,8 & 7,0 \\
\hline- & - & - & - & - & - & - & - & - & - & $16 / 04 / 11$ & 0,42 & 135 & 25,7 & 7,0 \\
\hline- & - & - & - & - & - & - & - & - & - & $17 / 04 / 11$ & 0,43 & 127 & 24,8 & 7,0 \\
\hline- & - & - & - & - & - & - & - & - & - & $18 / 04 / 11$ & 0,41 & 138 & 22,8 & 7,0 \\
\hline
\end{tabular}

